\title{
(UwU \\ The effect of the adoption of International Financial Reporting Standards on foreign portfolio investment in Africa
}

\section{MO Omotoso \\ iD orcid.org/0000-0002-0423-4643}

Thesis accepted in fulfilment of the requirements for the degree Doctor of Philosophy in Accountancy at the North-West University

Promoter: $\quad$ Prof DP Schutte

Graduation: July 2020

Student number: 29332583 


\section{DEDICATION}

This thesis is dedicated to the Almighty God the Father, Jesus Christ the Son, and the Holy Spirit for His precious lovingkindness to achieve this monumental academic feat, regardless of all odds. Father God, I say thank You for Your unconditional, unfailing, and steadfast love. 


\section{DECLARATION}

I, Matthew Olubayo Omotoso (Student number 29332583), hereby declare that the thesis titled "The effect of the adoption of International Financial Reporting Standards on foreign portfolio investment in Africa" is my original research work and that all the relevant sources used or cited have been reported and acknowledged by way of references, and that this thesis has not been previously in its entirety or submitted by me or any other person for the degree purposes at this, or any other University. I understand that all the copies of this thesis submitted for examination purposes will remain the property of the North-West University.

Declared at

on this day

Signature 


\begin{abstract}
The goal of achieving a uniform high-quality international accounting standards for financial reporting started in the second half of the 20th Century. This idea became a reality in the year 2001, when the International Accounting Standards Board (IASB) developed the International Financial Reporting Standards (IFRS) as a financial reporting framework for all the listed companies globally. The decision to have a single set of high-quality global accounting standards was accelerated due to the development in the world economy, especially at the end of the Second World War. Besides, the rapid expansion in the globalisation of financial markets and the internationalisation of economic trade across the world demand for unified international accounting standards.
\end{abstract}

Previously, each country made use of its national accounting standards framework for the preparation of financial statements. This development caused much diversity in accounting rules and practices across the nations. It affected the quality, credibility, reliability, and transparency of financial statements, which in turn affected the inflow of foreign investments and hindered economic growth. Consequently, the proponents of IFRS suggest that the adoption of IFRS will improve transparency and enhance the comparability of financial statements in the adopting countries. Hence, foreign investors will be able to compare the financial statements prepared in one IFRS jurisdiction with similar listed companies in other countries to aid the investment decision process. This scenario is assumed to enhance the efficient allocation of resources substantially and diversification of foreign capital, especially in the adopting countries.

Given this background and reflecting on the needs of developing countries' eagerness for foreign capital for economic sustainability, it is believed that adoption of IFRS will influence more inflows of foreign portfolio investment into the adopting countries as suggested by the proponents of IFRS. The European Union took the lead in 2005 when it made it mandatory for all the listed companies in the Union to start using IFRS as an accounting framework for the preparation and presentation of financial statements. Given this, many other developed and developing countries embraced the adoption of IFRS, including certain African countries with the assumption that the adoption of IFRS would enhance more inflows of foreign capital in the adopting countries.

This thesis set out to either confirm or refute the initial assumption that IFRS adoption would improve the foreign investment inflow for economic growth purposes in adopting countries. Thus, it examines the effect of the adoption of IFRS on foreign portfolio investment (FPI) in Africa. Annual data from the Balance of Payments and International Investment Positions (BOP/IIP) from 
1994 to 2015 on total foreign portfolio investments in liabilities (equity and debt) were collected. Panel data regression analysis incorporating pooled regression, fixed-effects, and random-effects models was estimated. Also, the generalised method of moment estimator was employed to address the problem of endogeneity, usually associated with panel data analysis and as a robustness check for the model. The logit regression model was used to examine the determinant factors of IFRS adoption.

Various statistical tests were estimated, such as the diagnostic test, using the histogram and JarqueBera statistics, difference-in-difference (DID) test, the unit root test, and the cross-sectional dependence test. The Hausman's chi-square was estimated to determine the best alternative technique between the fixed-effects and random-effects models. Also the Arellano-Bond estimator autocorrelation $A R\langle 1\rangle$ and $A R\langle 2\rangle$ was used to evaluate the validity of the variable instruments in the model. Besides, the average marginal effect (AME) was estimated for the effect of each covariate on the result. Certain covariates were estimated as control variables in the model.

The statistical results show a significant and positive effect of the adoption of IFRS on FPI inflows after the adoption and implementation of IFRS in adopting countries. Equally, the finding further indicates a significant difference in the volume of FPI inflows after the adoption of IFRS than before the adoption, in adopting countries. The statistical estimates also reveal a positive and significant effect of IFRS adoption on FPI in adopting countries, compare with non-adopting IFRS countries where it shows a negative and non-significant relationship. It shows that countries that adopted IFRS experience more inflows in FPI compare with the non-adopting countries in Africa. Furthermore, the logit regression results show that culture, the legal system, political system, investor protection, market capitalisation, and tax were found to be positively significant with the probability of adopting IFRS in the logistic model.

This thesis, therefore, suggests that the adoption of IFRS is justified in the selected countries in Africa since the results indicated a positive and significant effect of IFRS adoption on FPI in these countries. Hence, substantiated the assumption of IFRS proponents that adoption will enhance the flow of FPI in adopting countries for economic development. Policies measure to monitor the activities of listed firms and to enforce compliance with IFRS rules and regulations are warranted. These policies would further enable IFRS adopting countries to enhance more flow of FPI.

Keywords: IASB, IFRS, Accounting quality, FPI, National Accounting Standards, Financial statement, Comparability, Panel data, SGMM, European Union, Covariates, DID 


\section{ACKNOWLEDGEMENTS}

I want to express my sincere and deep appreciation to those who have made suggestions, contributions, and assistance in making this thesis a great success and to achieve the mission of earning a doctoral degree in accountancy at the North-West University (NWU), Potchefstroom Campus, South Africa. The list is endless. Nevertheless, the following people and the institution need to receive due recognition.

First, I wish to duly acknowledge the immeasurable guidance, tremendous encouragement, and the unparalleled advice of my study leader, Professor D.P. Schutte, School of Accounting Sciences. The timely completion and success of this thesis revolved around his cooperation. Sincerely, your positive and strict drive for academic excellence demonstrated during this research is highly commendable. For that, I am exceedingly grateful.

I am also indebted to all the members of staff of the Faculty of Economic and Management Sciences and the School of Accounting Sciences at the North-West University (NWU), Potchefstroom Campus. They offered valuable, constructive critique, suggestions, and comments during and after the presentation of my proposal at the colloquium, especially Professor Nico Van der Merwe. I appreciate you all.

I thank the Management of the NWU for the tuition-free programme for all the qualifying postgraduate students. If not for this singular financial support, my mission of attaining a postgraduate degree in the field of accountancy would have remained a dream. The Management of the Faculty of Economic and Management Sciences added its financial support as well, and I am grateful for this.

I received valuable assistance from the library staff of the Ferdinand Postma Library (NWU). I so appreciated their friendliness and their eagerness to assist.

I am thankful for the help Professor Faans Steyn, Statistical Consultant, NWU, gave on relevant and appropriate statistical techniques for the data analysis.

I thank Osun State Polytechnic, Iree (Nigeria), for study leave to pursue this $\mathrm{PhD}$ programme in South Africa. I am grateful to my colleagues at the Faculty of Financial Studies (Osun State Polytechnic, Nigeria) for their support, encouragement, and prayers. 
Besides, I would like to recognise the academic motivation from Professor Lere Amusan (NWU, Mafikeng Campus, South Africa), Professor Gbade Fakeye (University of Ibadan, Nigeria), and Dr Adeleke Omolade (Federal University, Oye-Ekiti, Nigeria).

I would also like to express my profound gratitude to all my family members, particularly my brothers and sisters, parents-in-law, and brothers- and sisters-in-law, who contributed to my success. I also appreciate the prayers and encouragement of individual and corporate friends. May God bless you all.

My late parents, Joseph and Emily Omotoso, were taken from me at a very tender age. Nevertheless, they left me with the lesson that I can achieve my goals in life if I show dedication, perseverance, hard work, and a fear of God. How wonderful it would have been if they were alive to rejoice with me. I hope that they continue to rest in the bosom of their Saviour until we meet to part no more.

Above all, I am grateful to my wife, Beatrice, for her prayers, patience, and understanding during my absence from home. I can add to this my lovely children who sacrificed time that we were supposed to spend together. I cannot but mention our granddaughter, Bright, and son-in-law, Sanmi. I appreciate your understanding and support while away. You are all dear to me. God bless you all.

Finally, I have to thank my heavenly Father and my Saviour, who has been my source of wisdom, knowledge, and understanding since I was born. I got to where I am not in my power, but by His grace. God Almighty, I say You are too kind. 
LIST OF ABBREVIATIONS

\begin{tabular}{|c|c|}
\hline ABBREVIATION & DESCRIPTION \\
\hline AAA & American Accounting Association \\
\hline $\mathrm{AEO}$ & African Economic Outlook \\
\hline AfDB & African Development Bank \\
\hline AICPA & American Institute of Certified Public Accountants \\
\hline AISG & Accounting International Study Group \\
\hline ASEA & African Securities Exchanges Association \\
\hline ASOBAT & A Statement of Basic Accounting Theory \\
\hline BCBS & Basel Committee on Banking Supervision \\
\hline BD3 & Benchmark Definition, Third Edition \\
\hline $\mathrm{BoP}$ & Balance of Payments \\
\hline BPM5 & Balance of Payments Manual, Fifth Edition \\
\hline BRICS & Brazil, Russia, India, China, and South Africa \\
\hline $\mathrm{CF}$ & Conceptual Framework \\
\hline CITR & Company Income Tax Rates \\
\hline $\mathrm{CV}$ & Coefficient of Variation \\
\hline EPZ & Export Processing Zones \\
\hline EU & European Union \\
\hline FASB & Financial Accounting Standards Board \\
\hline FDI & Foreign Direct Investment \\
\hline FEM & Fixed-effects Model \\
\hline FPI & Foreign Portfolio Investment \\
\hline GAAP & Generally Accepted Accounting Principles \\
\hline GMM & Generalised Method Of Moments \\
\hline IASB & International Accounting Standards Board \\
\hline IASC & International Accounting Standards Committee \\
\hline IASCF & International Accounting Standards Committee Foundation \\
\hline IFRIC & International Financial Reporting Interpretations Committee \\
\hline IFRS & International Financial Reporting Standards \\
\hline IIP & International Investment Position \\
\hline IMF & International Monetary Fund \\
\hline IOSC & International Organisation of Securities Commissions \\
\hline IRD & Interest Rate Differential \\
\hline JB & Jarque Bera \\
\hline LAC & Latin America and the Caribbean \\
\hline
\end{tabular}




\begin{tabular}{|c|c|}
\hline MoU & Memorandum of Understanding \\
\hline OECD & Organisation for Economic Co-operation and Development \\
\hline POLS & Pooled Ordinary Least Square \\
\hline PwC & PricewaterhouseCoopers \\
\hline REM & Random -effects Model \\
\hline SAC & Standards Advisory Council \\
\hline SEC & Securities Exchange Commission \\
\hline SGMM & System Generalised Methods of Moment \\
\hline SSRN & Social Science Research Network \\
\hline TICPI & Transparency International Corruption Perception Index \\
\hline UN & United Nations \\
\hline UNCTAD & United States of America \\
\hline USA & World Bank \\
\hline WB & World Development Indicator \\
\hline WDI & World Governance Indicators \\
\hline WGI & Wilcoxon Signed-Rank Test \\
\hline WSRT & World Trade Organization \\
\hline WTO & Worldwide Tax Summaries \\
\hline WTS & \\
\hline
\end{tabular}




\section{TABLE OF CONTENTS}

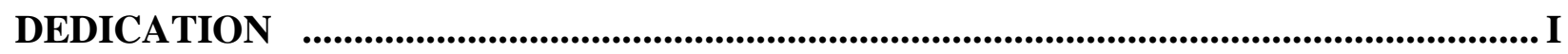

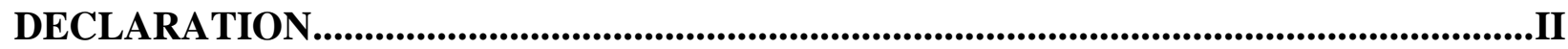

ABSTRACT _................................................................................................................................ III

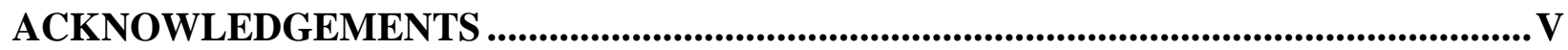

LIST OF ABBREVIATIONS .......................................................................................... VII

CHAPTER ONE: INTRODUCTION .........................................................................1

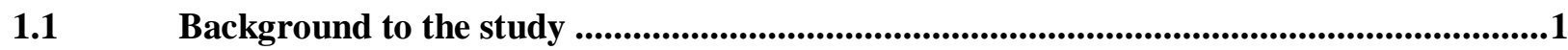

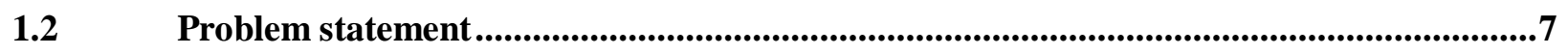

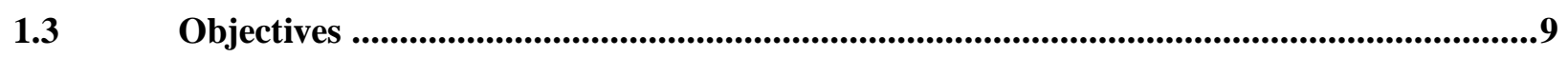

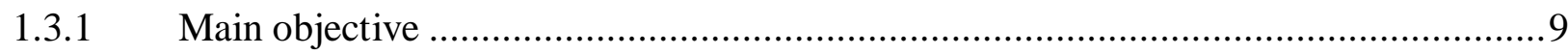

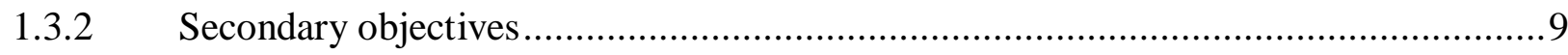

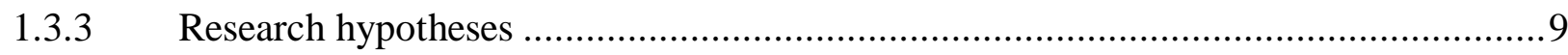

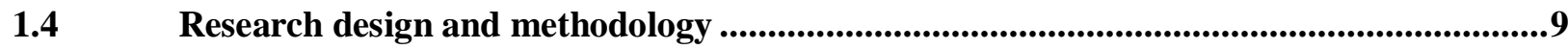

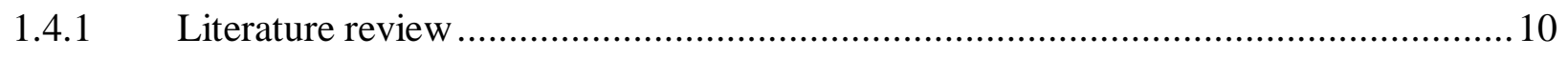

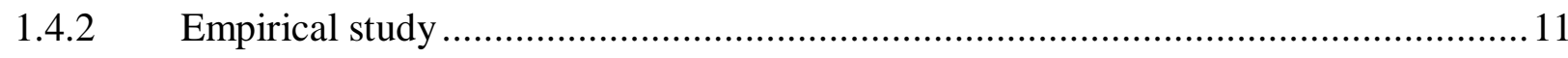

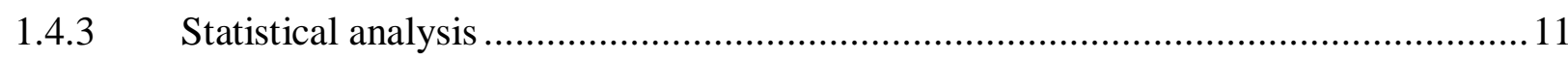

1.4.4 Paradigmatic assumptions and perspectives .................................................... 12

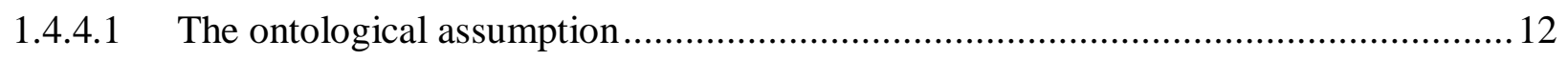

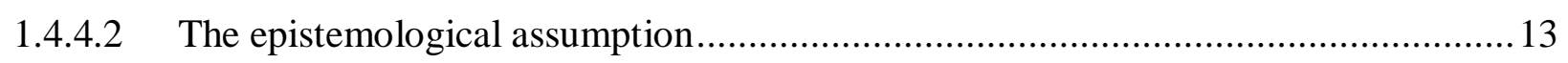

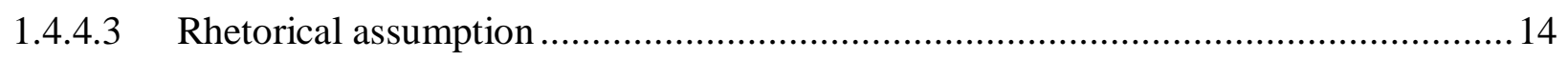

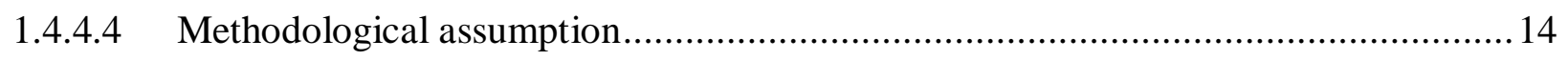


Target population, selection, and data collection approach ........................................15

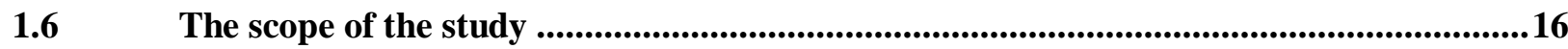

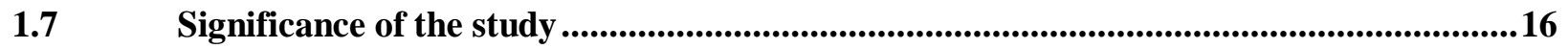

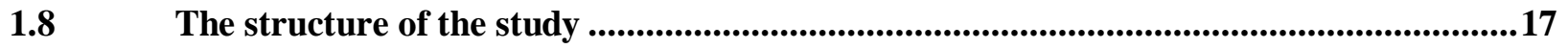

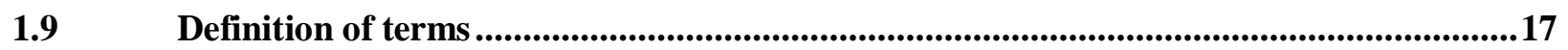

CHAPTER TWO: $\quad$ LITERATURE REVIEW ON FOREIGN PORTFOLIO

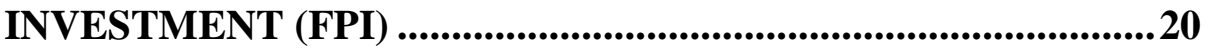

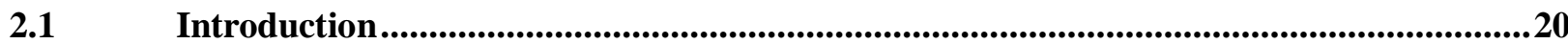

2.2 Conceptualising foreign investments ...................................................................................21

2.2.1 Foreign direct investment explained ........................................................ 21

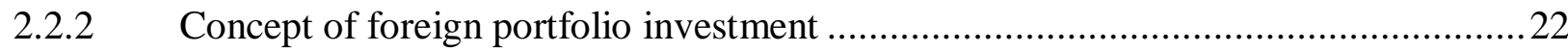

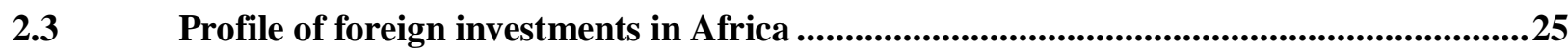

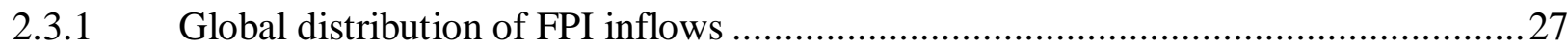

2.3.2 Trends of FPI, equity and debt in Africa (1994-2015)...........................................30

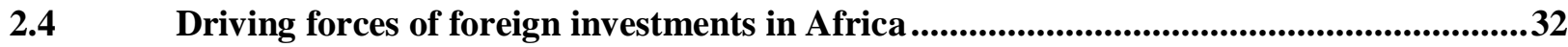

$2.5 \quad$ The theoretical framework for FPI .....................................................................................37

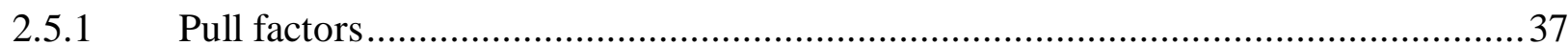

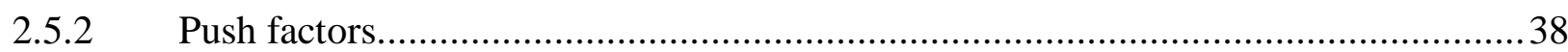

2.6 Overview of the literature on the determinants of FPI .................................................39

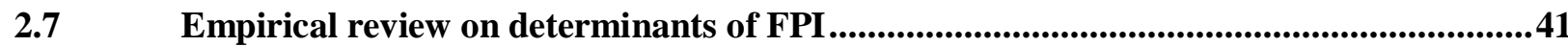

2.8 Potential determinant factors of foreign investments in Africa ....................................45

2.8.1 International Financial Reporting Standards (IFRS) …...................................46 


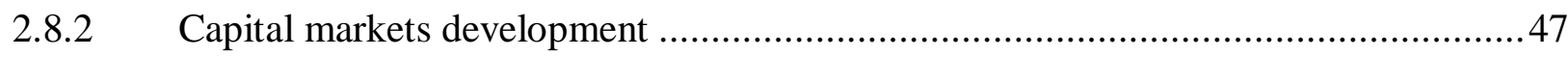

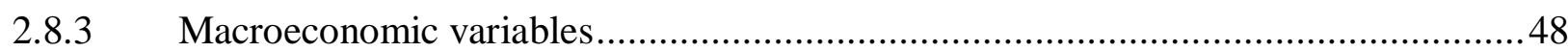

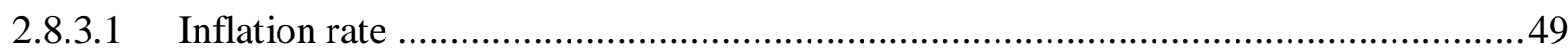

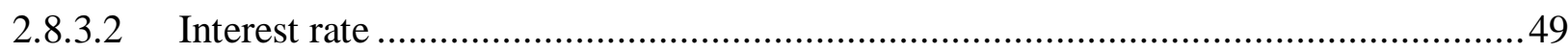

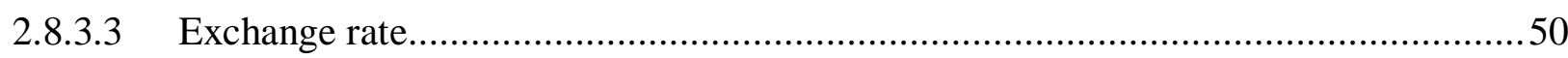

2.8.3.4 Economic growth ....................................................................................... 51

2.8.3.5 Market openness or foreign operations ..................................................... 52

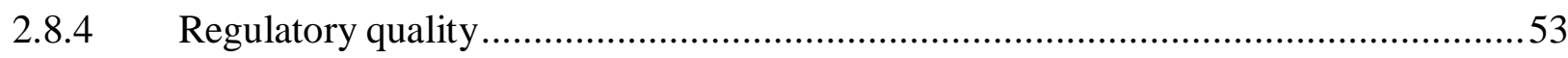

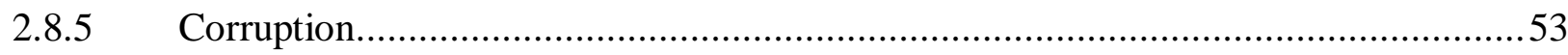

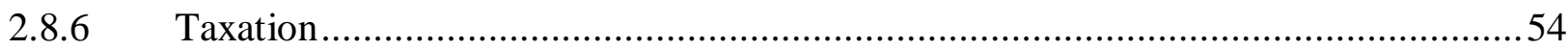

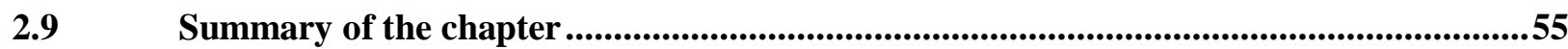

CHAPTER THREE: LITERATURE REVIEW: INTERNATIONAL FINANCIAL REPORTING STANDARDS (IFRS) ......................................57

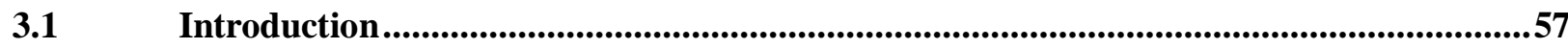

H.2 Historical background of international accounting standards..................................58

Conceptualising financial reporting and financial statements ....................................63

3.4 The IASB framework for the preparation and presentation of financial statements ......65

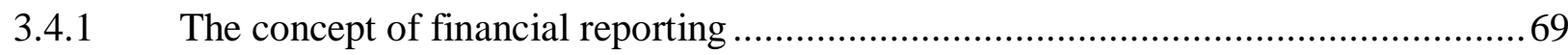

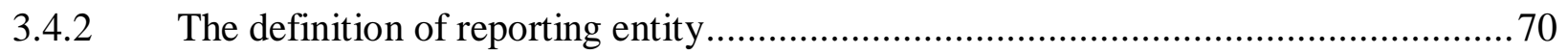

3.4.3 The definition of the users of accounting information and their information

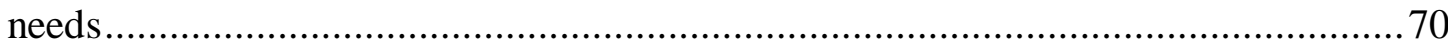

3.4.4 Underlying assumptions of accounting standards ...................................... 71 


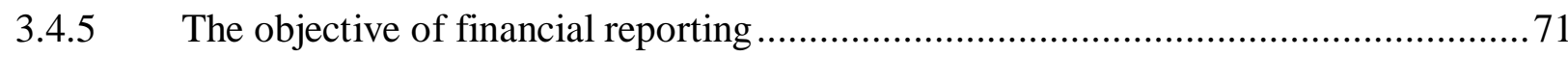

3.4.6 Qualitative characteristics of financial reporting ............................................. 72

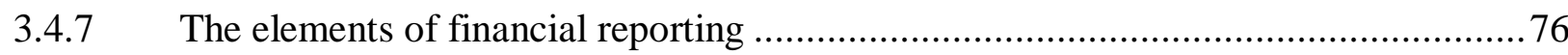

3.4.8 Recognition of the elements of financial statements ........................................ 78

3.4.9 Measurement of financial statement elements ................................................. 79

IFRS worldwide jurisdiction and the status of adoption in Africa ...................................80

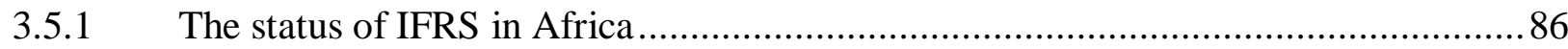

S.6 Some relevant theories relating to accounting information ............................................90

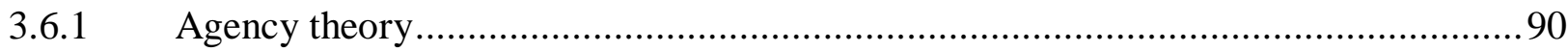

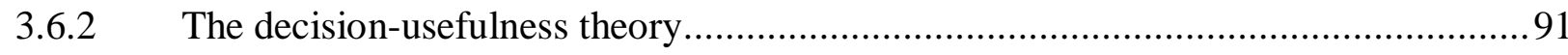

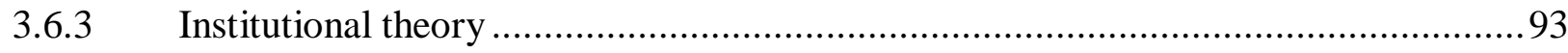

3.6.4 The information asymmetry theory .......................................................... 95

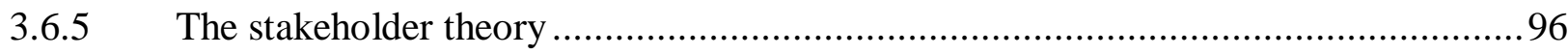

3.6.6 The relevant theoretical underpinning ..................................................... 98

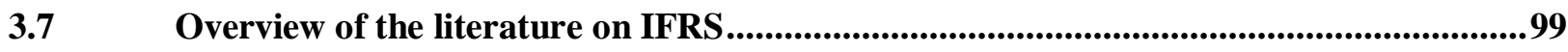

3.8 The empirical relationship between IFRS and FPI .............................................................104

F.9 Factors influencing the adoption of IFRS in Africa ......................................................107

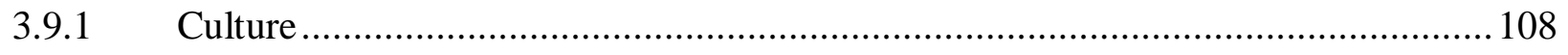

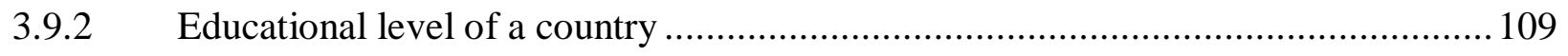

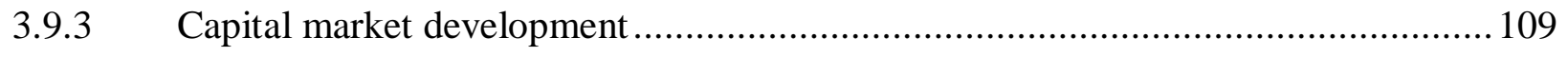

F.9.4 Foreign operations or trade openness .................................................... 110

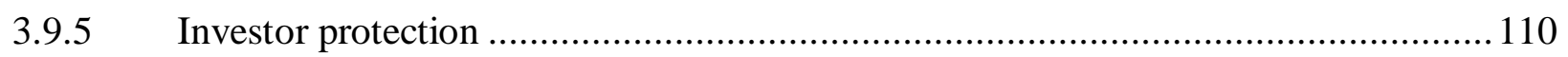


3.9.6 Economic growth.

3.9.7 Taxation

3.9.8 The legal system and the rule of law.

3.9.9 Political system

3.9.10 External pressure

3.10 Summary of the chapter. 114

CHAPTER FOUR: $\quad$ RESEARCH DESIGN AND METHODOLOGY 115

4.1 Introduction 115

4.2 Research problem and research questions......................................................................117

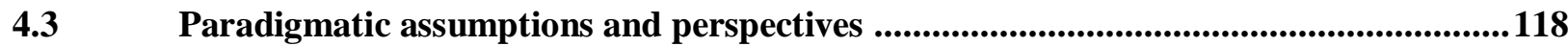

4.3.1 Philosophy: ontological (the nature of reality) and axiological (role of values) assumptions

4.3.2 Positivism

4.3.3 Realism

4.3.4 Interpretivism.

4.3.5 Pragmatism

4.3.6 The appropriate philosophy adopted for this research

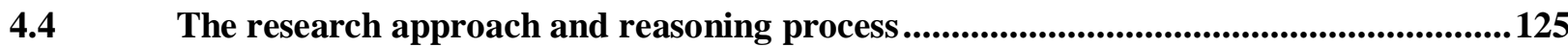

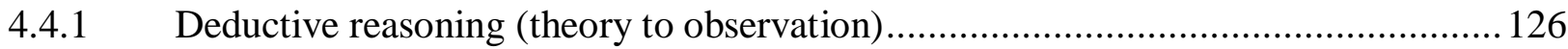

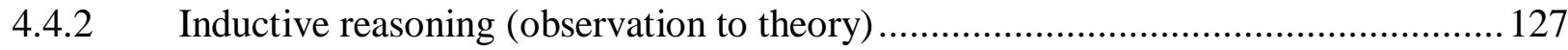

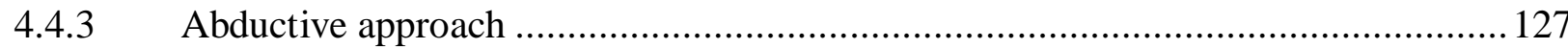

4.4.4 Research reasoning process adopted in this study ......................................... 127 
4.4.5 Quantitative research method ................................................................. 128

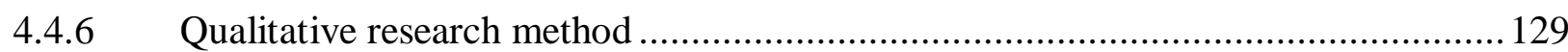

4.4.7 Methodological choice adopted in this study ............................................ 129

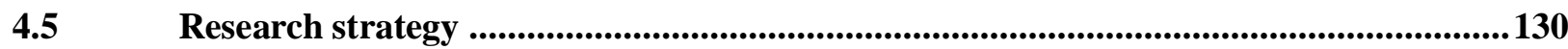

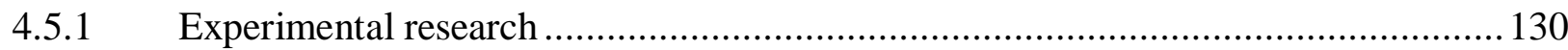

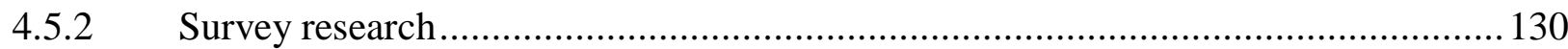

4.5.3 Research strategy utilises for this study ..................................................... 131

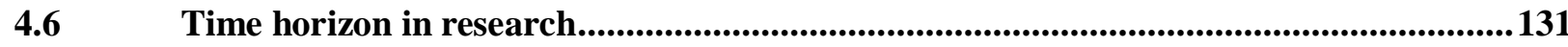

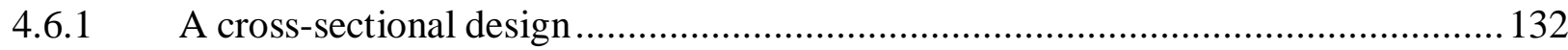

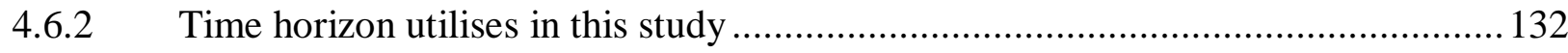

4.7 Research technique and procedures .................................................................................132

4.7.1 The Conceptual framework for the study ..................................................... 133

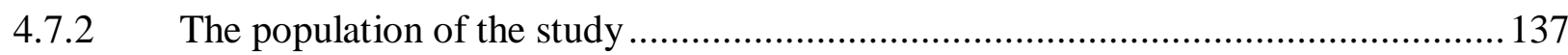

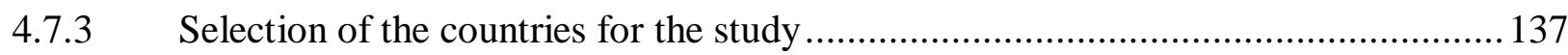

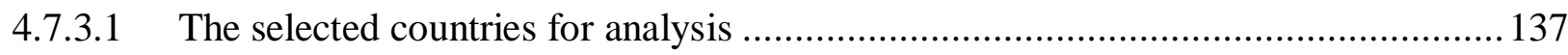

4.7.4 Data collection method and its appropriateness to the thesis ............................... 141

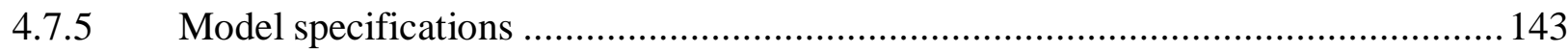

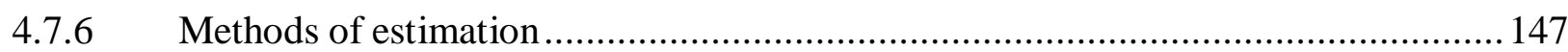

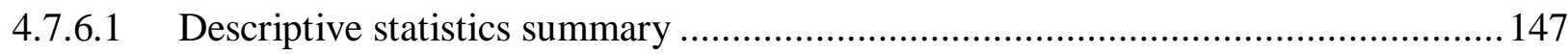

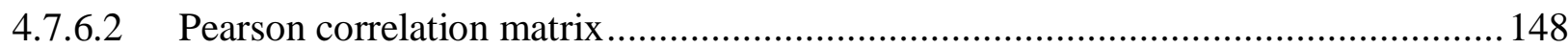

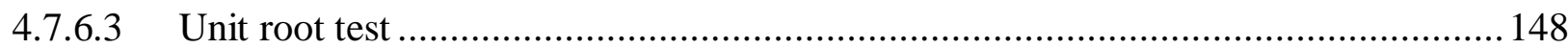

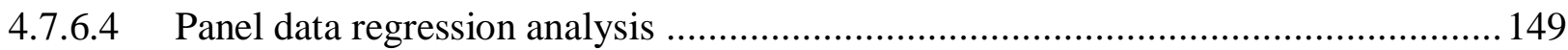


4.7.6.5 Pooled ordinary least squares regression model (POLS)

4.7.6.6 Fixed-effects regression model estimation.................................................... 153

4.7.6.7 Random-effects regression model estimation ............................................ 154

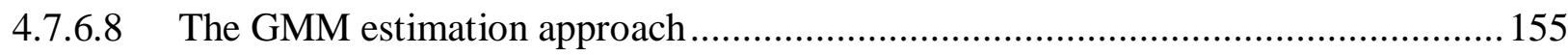

4.7.7 Variables descriptions and measurements for the panel data regression model........ 158

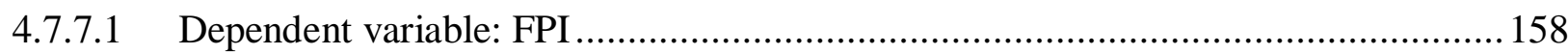

4.7.7.2 The main explanatory variable: IFRS adoption........................................... 159

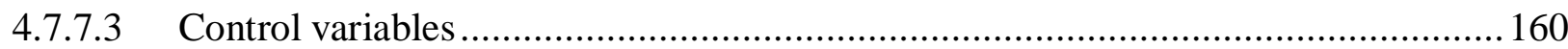

4.7.8 Logit regression model: determinant factors of IFRS adoption ........................... 162

4.7.8.1 Logistic regression model specification ....................................................... 163

4.7.8.2 Variable description and measurement for the logit regression model.................... 165

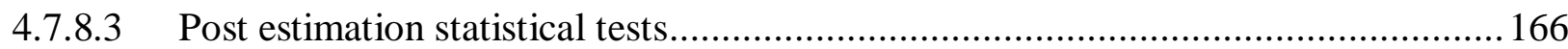

4.8 The particular paradigm and approaches employed for the thesis...............................167

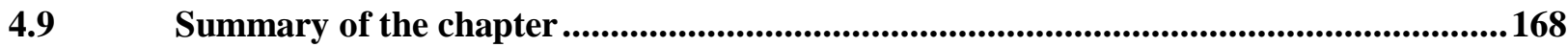

CHAPTER FIVE: DATA ANALYSIS AND INTERPRETATION OF

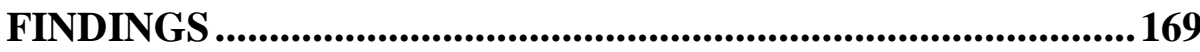

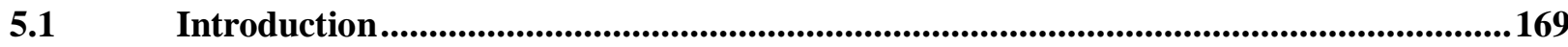

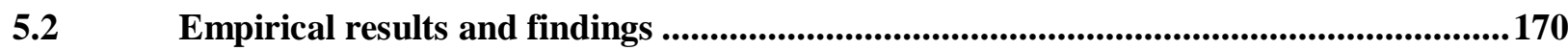

5.2.1 Diagnostic: Normality test for objective 1 dataset.......................................... 170

5.3 Descriptive statistics before the adoption of IFRS (1994-2004): adopting countries .....171

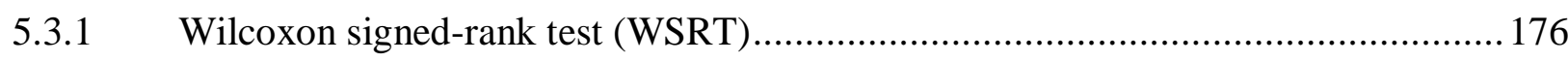


5.3.2 Trend analysis of the effect of the adoption of IFRS on FPI (1994-2015),

adopting countries

$5.4 \quad$ Correlation analysis - IFRS adopting countries (1994-2015)....................................177

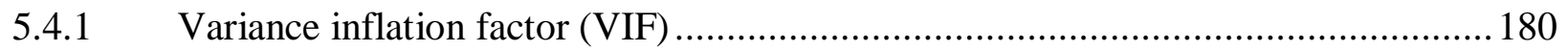

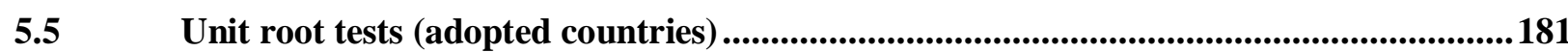

5.6 Panel data regression estimating the benchmark variables before IFRS adoption .......182

5.6.1 Regression results of benchmark variables before IFRS adoption (REM option) .... 182

5.6.2 Panel data regression coefficients (standard error) of the effect of post-IFRS adoption on FPI: adopting countries

5.6.3 REM regression results comparing the pre-and post-effect of IFRS adoption on FPI: adopting countries

5.6.4 SGMM results of the effect of IFRS adoption on FPI

5.6.5 Hypothesis testing, before and after effect of IFRS adoption on FPI

5.6.6 Discussion of the findings of the effect of IFRS adoption on FPI before and after the adoption

5.7 The effect of IFRS adoption on FPI, adopting and non-adopting countries (Objective 2)

5.7.1 Diagnostic test: Normality test for objective 2 dataset 194

5.7.2 Descriptive statistics for adopting and non-adopting countries (2005-2015)

5.7.3 The correlation matrix of the effect of IFRS adoption on FPI when comparing the adopting and non-adopting countries 196

5.7.4 Variance inflation factor (VIF) 199

5.7.5 Unit root test for the adopting and non-adopting countries 200 
5.7.6 SGMM regression results of the effect of IFRS adoption on FPI among the adopting and non-adopting countries

5.7.7 Difference-in-difference (DID) test of FPI inflows (adopting and non-adopting countries)

5.7.8 Hypothesis testing of the effect of IFRS adoption on FPI among the adopting and non-adopting countries

5.7.9 Discussion of the results of the effect of IFRS on FPI inflow among the adopting and non-adopting countries

5.8 Analysis of the determinant factors that influence the probability of IFRS adoption: a lpgistic regression approach (Objective 3) .206

5.8.1 Diagnostic test: Normality test for objective three dataset..............................207

5.8.2 The correlation matrix of the determinants of IFRS adoption.............................207

5.8.3 Logit regression model: determinant factors of IFRS adoption ...........................210

5.8.4 Post-estimation test, average marginal effect (AME) ....................................... 214

5.8.5 Hypothesis testing: IFRS determinant factors ......................................... 217

5.8.6 Discussion of the findings: IFRS determinant factors ..................................... 218

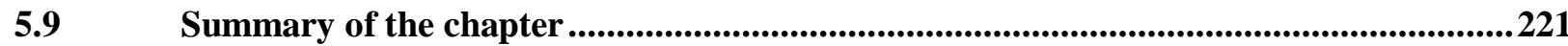

CHAPTER SIX: $\quad$ CONCLUSION AND RECOMMENDATIONS .........................224

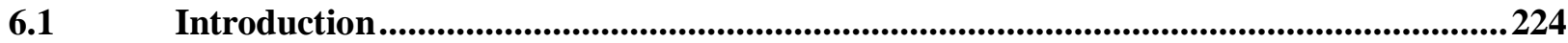

6.1.1 The purpose of the study: revisiting the research questions and objectives ............225

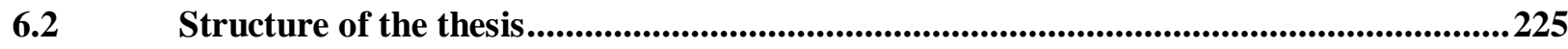

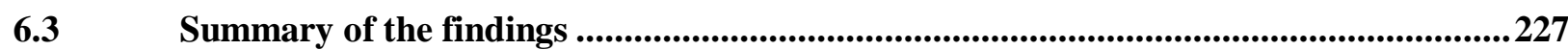

6.3.1 Positioning the findings against the background of the appropriate theory .............228 
6.4 Research contributions

6.5 Policy recommendations 230

6.6 Limitations 230

6.7 Suggestions for future research.

6.8 General conclusion

APPENDIX A: TREND ANALYSIS OF FPI INFLOW BEFORE AND AFTER THE ADOPTION OF IFRS

APPENDIX B: POOLED OLS REGRESSION RESULTS BEFORE IFRS ADOPTION

APPENDIX C: CROSS SECTIONAL DEPENDENCE TEST BEFORE IFRS ADOPTION

APPENDIX D: FIXED-EFFECTS REGRESSION RESULTS BEFORE IFRS ADOPTION

APPENDIX E: THE HAUSMAN TEST BEFORE IFRS ADOPTION 266

APPENDIX F: RANDOM-EFFECTS REGRESSION RESULTS BEFORE IFRS

ADOPTION

APPENDIX G: SGMM REGRESSION RESULTS BEFORE IFRS ADOPTION. 267

APPENDIX H: SERIAL CORRELATION TEST BEFORE IFRS ADOPTION ..............268

APPENDIX I: POLS REGRESSION RESULTS AFTER IFRS ADOPTION .................268

APPENDIX J: CROSS SECTIONAL DEPENDENCE TEST AFTER IFRS

ADOPTION

APPENDIX K: FIXED-EFFECTS REGRESSION RESULTS AFTER IFRS

ADOPTION

APPENDIX L: RANDOM-EFFECTS REGRESSION RESULTS AFTERIFRS

ADOPTION

APPENDIX M: THE HAUSMAN TEST RESULTS AFTER IFRS ADOPTION. 270

APPENDIX N: SGMM REGRESSION RESULTS AFTER IFRS ADOPTION 271 
APPENDIX O: SERIAL CORRELATION TEST AFTER IFRS ADOPTION

APPENDIX P: SGMM REGRESSION RESULTS, IFRS ADOPTING AND NON-

ADOPTING COUNTRIES

APPENDIX Q: SERIAL CORRELATION TEST ADOPTING AND NON-ADOPTING

COUNTRIES

.273

APPENDIX R: DIFFERENCE-IN-DIFFERENCE (DID) TEST, ADOPTED AND NON-

ADOPTED COUNTRIES RESULTS, 273

APPENDIX S: LOGIT REGRESSION RESULTS FOR IFRS DETERMINANTS (LOGARITHMIC ODDS OF IFRS ADOPTION)

APPENDIX T: LOGIT REGRESSION RESULTS (ODDS RATIOS) 275

APPENDIX U: LOGIT REGRESSION RESULTS (AVERAGE MARGINAL

EFFECTS) 276

APPENDIX V: REGISTRATION OF TITLE 277

APPENDIX W: CERTIFICATE OF PRESENTATION AT AREF CONFERENCE ......278

APPENDIX X: LANGUAGE EDITOR'S DECLARATION ..............................................279

APPENDIX Y: STATISTICIAN LETTER OF CONFIRMATION 280 


\section{LIST OF TABLES}

Table 2.1: $\quad$ The global annual average of FPI inflows (US\$ millions) ..........................28

Table 2.2: $\quad$ Minority investor protection index in the region.........................................35

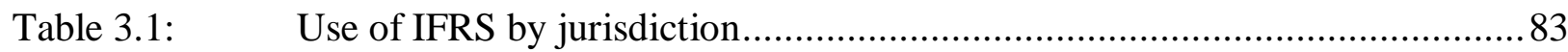

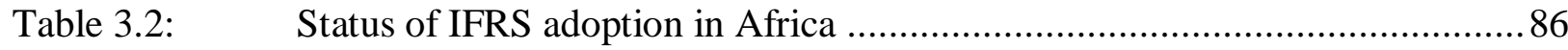

Table 4.1: $\quad$ IFRS status classifications in Africa with the relevant year of adoption....... 138

Table 4.2: $\quad$ Summary of subpopulations selected for the study ................................ 140

Table 5.1: $\quad$ Descriptive statistics before IFRS adoption (adopted countries) (19942004)

Table 5.2: $\quad$ Descriptive statistics after IFRS adoption (adopted countries) (20052015) 1744

Table 5.2a: $\quad$ Wilcoxon signed-rank test comparing FPI volume before and after IFRS adoption: adopting countries 1766

Tables 5.2b: Wilcoxon signed-rank test showing a significant level of FPI (before and after). 1766

Table 5.3: $\quad$ Correlation analysis, IFRS adopted countries 1994-2015 17979

Table 5.3a: $\quad$ Estimation of variance inflation factor (VIF) ......................................... 1800

Table 5.4: $\quad$ Unit root test results (adopted countries) 1994-2015 1811

Table 5.5: $\quad$ Regression coefficients (standard error) of factors assumed to influence FPI before IFRS adoption: adopting countries (1994-2004) REM option... 1833

Table 5.6: Cross-sectional dependence test), pre-IFRS adoption 1844

Table 5.7: Panel data regression coefficients (standard error) with IFRS adoption variable and covariates (1994-2015) 
Table 5.8: $\quad$ Cross-sectional dependence test, post-IFRS adoption 1888

Table 5.9: Descriptive statistics for IFRS adopting and non-adopting countries (2005-2015) 1966

Table 5.10: $\quad$ Correlation matrix for IFRS adopting and non-adopting countries including covariates 2005-2015 1988

Table 5.10a: Measure of the degree of multicollinearity using the variance inflation factor (VIF) 19999

Table 5.11: Unit root test results for the adopting and non-adopting countries 2000

Table 5.12: $\quad$ SGMM regression results for the effect of IFRS adoption on FPI in adopting and non-adopting countries 2005-2015 2022

Table 5.13: $\quad$ Difference-in-differences test of pre-and-post FPI inflows in adopting and non-adopting IFRS countries 2044

Table 5.14: $\quad$ Correlation matrix for the determinants of IFRS adoption 2099

Table 5.15: Logit regression model results on determinant factors of IFRS 2100

Table 5.16: $\quad$ Post-estimation test results, using the average marginal effect (AME)......2 2177 


\section{LIST OF FIGURES}

Figure 2.1: $\quad$ FPI flows into developing countries (US\$ millions) 29

Figure 2.2: $\quad$ FPI flows into the world, advanced and developing countries, 1994-2015 (US\$ millions). 30

Figure 2.3: $\quad$ Total of FPI inflow in Africa, 1994-2015 (US\$ millions) 31

Figure 2.4: $\quad$ Total of FPI, equity, and debt flow into African countries 1994-2015 (US\$ millions) 32

Figure 3.1: Components of a conceptual framework based on the IASC/IASB 69

Figure 3.2: $\quad$ Relationships of the qualitative characteristics of financial information.........76

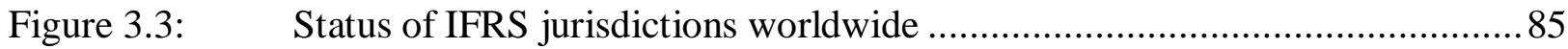

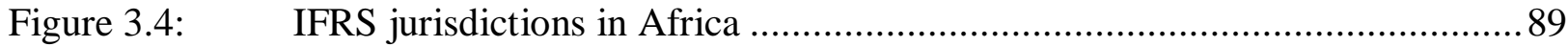

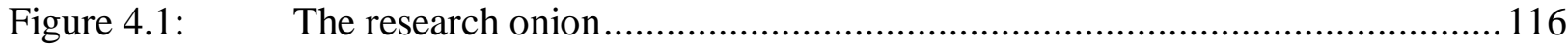

Figure 4.2: $\quad$ The research paradigm illustrating the conceptual framework for the study..... 136

Figure 4.3: $\quad$ The explicit philosophical perception and approaches adopted for the thesis 167

Figure 5.1: $\quad$ Normality test for pre-and-post-effect of IFRS adoption on FPI 1711

Figure 5.2: $\quad$ Normality test for adopting and non-adopting IFRS countries 1944

Figure 5.3 Normality test for determinant factors dataset (logistic model) .207 


\section{CHAPTER ONE: INTRODUCTION}

\subsection{Background to the study}

The effective flow of foreign portfolio investment requires a high-quality financial statement that is transparent, reliable, and comparable with similar listed companies worldwide (Judge et al., 2010). The authors explained further that before the emergence of the International Financial Reporting Standards (IFRS) as a unified global financial reporting standard, each country developed, pursued, and maintained its national accounting standards. Walton and Aerts (2007:17) report that as a result of the consolidation of global financial markets, accounting information prepared following national accounting standards no longer met the needs of participants in international capital markets. As a result, many countries embraced the adoption of IFRS as an international accounting standards framework for all the listed companies (Ball, 2016).

Additionally, the growth in the number of international transactions and the increase in foreign investments over the last few decades have broadened the dimension and scope of financial reporting. Deegan (2010:21) opines that financial reporting has become an essential and relevant tool for communication with various users of accounting information, especially foreign investors. Consequently, there is a need for a more transparent financial reporting since there are many discrepancies and variations in financial reports prepared according to the different national accounting standards worldwide (Madawaki, 2012).

The previous use of a wide variety of different accounting practices caused accounting diversity and rendered the financial statements unclear and incomparable (Walton \& Aerts, 2007:17). Similarly, this problem of accounting diversity deterred investors from getting reliable and transparent financial statements for strategic investment decisions (Vidal-Garcia \& Vidal, 2016). The issue of accounting diversity, among other things, called for unified international accounting standards since the lack of clarity in financial statements, negatively affected the flow of foreign investments.

The move towards the adoption of a single set of high-quality accounting standards worldwide has been long in the making, but it was not until 2001 that it became a reality, when the International Accounting Standards Board (IASB) set out to achieve a single set of high-quality global accounting standards with the development of IFRS (Ball, 2016). Prockazka (2012) emphasises that unified accounting standards were expected to enhance the quality of financial information and improve the flow of foreign investments. Furthermore, the expectation was that adopting a 
uniform accounting standard would stimulate the credibility and quality of financial statements. Moreover, literature reported that capital market investors, in particular, required a more transparent and high-quality financial report that would make the comparability of financial statement possible (Amiram, 2012; Matthew, 2009; Schutte \& Buys, 2011; Shima \& Yang, 2012). According to Ball (2016), IFRS was developed to enhance the transparency of financial reporting in order to provide users with complete and accurate information concerning the firm's financial position. This hoped-for advantage encouraged many countries, including certain countries in Africa, to lend support for the adoption of IFRS, in exchange for national standards.

Zeghal and Mhedhbi (2006) emphasise that the complexity and increase in the number of international capital markets make the accounting information prepared and audited using national accounting and auditing systems irrelevant. According to them, this practice does not meet the requirements of the accounting information needed by global equity investors. In the same vein, Amiram (2012), Palea (2013), and Riahi-Belkaoui (2012:191) report that financial statements prepared with national accounting standards are not transparent enough and at the same time show a high degree of information asymmetry. Thus, making foreign investment decisions extremely difficult and eventually reducing the flow of foreign investments. These issues, among others, plagued the international accounting environment before the introduction of IFRS (Nobes, 2011). Given this, the assumption was that using a single set of high-quality accounting standards worldwide would improve the transparency and comparability of financial statement and reduce the cost of financial statement preparation, in turn influencing the flow of foreign investments (HassabElnaby, 2003).

The International Accounting Standards (IAS) Regulator (Regulation No. 1606/2002) made an effort to formulate a single unified set of international accounting standards. They stated that the objective of harmonising the financial statements presented by listed companies is to enhance transparency and cross-country comparability of financial statement. Hence strengthen the functioning of the international and national capital markets. A single set of global accounting standards could encourage foreign investors to compare the financial statements prepared in one IFRS jurisdiction with the similar listed companies across the globe. The Regulator further stated that the adoption of IFRS would trigger efficient allocation of foreign capital diversification and improve the foreign investments inflow for economic development in the adopting countries.

The adoption of IFRS has been on the increase after the European Union (EU) mandated all listed companies in the Union to adopt IFRS from 2005 onwards This development in the EU prompted 
the adoption of IFRS by many countries worldwide (Gordon et al., 2012). Currently, nearly 166 countries worldwide have adopted IFRS as a single set of accounting standards (IFRS, 2018). Aharony et al. (2010), Amiram (2012), Armstrong et al. (2010), Chen et al. (2014), Ding et al. (2007), and Shima and Gordon (2011) believe that the adoption of IFRS will have economic consequences in the adopting countries, especially in improving the inflow of foreign investments.

Amiram (2012) and Ding et al. (2007) predict that a unified international accounting standard will reduce accounting distance, influence the comparability of accounting information worldwide, give a solid foundation to and improve capital market activities, and the confidence of foreign investors. Additionally, it would enable the capital market participants to depend on the financial statements prepared using IFRS as accurate, reliable, and efficient accounting information for investment decisions (Amiram, 2012). Similarly, the proponents of IFRS justify the idea of a collective adoption of a single set of international accounting standards. They emphasise that it will ensure a high degree of financial statement transparency and comparability (Bruggemann, 2011:1-2). Also, it would trigger the effective functioning of capital markets in the adopting countries because the barrier to the inflow of FPI caused by the use of different national accounting standards will be removed when IFRS is adopted and implemented.

In another vein, accounting literature emphasises that the accounting system is one of the components of the total institutional system that can influence FPI flows, similar to other institutional governance structures such as regulatory framework and corruption (Ball, 2001; Efobi et al., 2014). Similarly, Nnadi and Soobaroyen (2015) report that the accounting standard is a significant part of a country's institutional governance structures because of its apparent advantages. Coincidentally, little research has focussed on the consequences of accounting standards in influencing foreign investments (Dunning, 2006; Ramasamy \& Yeung, 2010; Sandler \& Younas, 2014). Ben-Othman and Kossentini (2015) emphasise that accounting information prepared according to the global accounting standard framework becomes part of a country's institutional structure. Hence IFRS is seen as a variable that may enhance foreign investments, especially in developing countries. Unfortunately, little attention has been given to the relationship between accounting standards and foreign investments in the literature (Gordon et al., 2012).

However, as earlier explained, the Regulator aims of IFRS adoption focus on certain assumptions. They assumed that with the adoption of IFRS, the financial statement would be more transparent and reliable to enhance comparability of financial statement globally. Also, there will be a positive economic effect on the economy of adopting countries. These propositions were subject to the 
argument in the literature. For example, Ball (2006) emphasises that financial reporting practices are majorly determined by the firm's reporting incentives which may be affected if the incentives remain unchanged. This may negate the assumption of IFRS Regulator.

Similarly, Ball (2010) reports that the direction of the economic consequence of IFRS adoption is uncertain. Additionally, Benish et al. (2015) and Bruggemann (2011:12-13) report that the assumption that IFRS adoption will make the financial statement to be more comparable globally to trigger FPI is uncertain. There is another assumption by the IASB that IFRS is principle base, in the sense that it provides the accountant (the preparer of the financial statement) to use discretion in recording any transactions and not rule base. Bruggemann (2011: 11-12) explains whether IFRS provides the accountant with more or less discretion than any national accounting standards. Nobes and Stadler (2015) corroborate this view, by reporting that accounting standards framework (national or international) requires the accountant to exercise non-discretionary reporting and made a subjective judgement. Thus, the possibility of an accountant in using the discretion on any accounting transaction is still uncertain. This implies that the different opinion of the researchers on the stated assumptions of the IASB in developing IFRS was not consensus supported in the literature. Hence, this thesis may further highlight why empirical evidence on the relationship between IFRS adoption is inconclusive.

Foreign investments in the forms of FDI and FPI are the most important economic policies that are attracting foreign capital. It has become a significant policy formulation and implementation in many countries as the engine of economic development and growth. Many empirical studies that have examined the association between IFRS adoption and foreign investments in developing countries focussed mainly on foreign direct investment (Adetula et al., 2014; Efobi et al., 2014; Efobi, 2017; Emeni, 2014; Kwarbai et al., 2016; 2012; Nnadi \& Sooboroyen, 2015; Owolabi \& Iyoha, 2012). While empirical studies on IFRS and FPI in developing countries are limited BenOthman and Kossentini (2015), this shows that, despite the importance of financial reporting information to existing and potential investors in FPI (e.g. equity and debt investors) to take the decision, FPI has received less attention in the literature.

Foreign investments are commonly in the forms of foreign direct investment (FDI) and foreign portfolio investment (FPI) (UNCTAD, 1999). FDI involves investments mostly in real assets, such as ownership of a direct business or a controlling interest in a foreign company to secure lasting interest while FPI includes the activities of buying and selling securities in the financial markets (Amiram \& Frank, 2015 \& UNCTAD, 1999). FDI and FPI are relatively related in the definition 
because the source of them originate from investors in another country of the world. However, there is a primary difference between them in terms of management control. FDI investors exercise more control over the activities of the firm, while FPI investors do not involve in the economic activities of the firm. Aziz et al. (2015) and ThankGod (2014) report that FPI is an international financial activity that consists of buying and selling shares, bonds, or money market instruments in the global capital market. FPI has been a significant factor that influences the mobilisation of long-term capital and promotes economic growth globally (Easterly et al., 2001). Unfortunately, the search for a general theoretical framework that may influence the inflows of foreign investments is yet to be fruitful (Gordon et al., 2012). Due to the benefits of IFRS adoption in an economy, it is assumed that it may be a significant factor that can influence FPI. Ironically, the empirical findings in the literature on the nexus between IFRS adoption and FPI are scanty, especially in the context of African countries.

Foreign investment capital mobilisation is a concern for all the economies in the world, especially the policymakers and researchers. Bakre (2008) points out that African countries have remained underdeveloped economically for many decades due to the dearth of resources. Thereby results in poor performance in various sectors of the economy. Because of this, many countries have shifted their focus in recent times to different approaches to attracting foreign capital. The global adoption of IFRS is one of these strategies. Hence, it will be more appropriate for any government to identify factors that can influence foreign investment inflows, such as the adoption of IFRS. Jaiblai and Shenai (2019) illustrate that the quest to attract foreign capital entails the investigation of its determinants that would influence the flow of foreign capital.

The pronouncement of the Regulator of accounting standards on the positive relationship between IFRS adoption and foreign investments, coupled with the role accounting standards, can play in attracting foreign investments, motivates this research. Nyor (2012) believes that if African countries can adopt IFRS, there would be enormous economic benefits in terms of foreign investments. Since financial statements will be more transparent and comparable globally, there would be a better inflow of FPI. The study is also encouraged by the shortage of capital for economic development in African countries. It is assumed that with the adoption of IFRS, there will be a better flow of foreign investments for economic growth. Given this, DeFond et al. (2011:241) note that research on the effect of IFRS on foreign investments, particularly on FPI, is essential since it would show the actual effect and significance of the usefulness of accounting information in FPI decision-making processes and in attracting foreign investors. Foreign investors 
in equity and debt securities are more interested in a capital market that discloses high-quality accounting information. Importantly, that can give them access to investment opportunities at a minimal cost. Unfortunately, this area of research, to some extent, is rare in the literature, since IFRS is rarely mentioned in the literature as a driver of FPI (Gordon et al., 2012).

As aforementioned, the flow of FPI (including equity capital flows and debt capital flows) can trigger the economic growth and development in developing countries, such as Africa. It is assumed that it can make available adequate and necessary capital flow for economic development and sustainability. However, it has been stated in the literature that the efficacy of FPI in influencing economic development is uncertain because of its characteristics as the most mobile categories of foreign capital inflows (Gumus et al., 2013). It is characterised as a very liquid and highly volatile investment (hot money) that can move freely across the national boundaries by the investors for high returns, at the first sign of economic adversity. This implies that FPI is based on the economic conditions of a country to attract its inflows.

Importantly, comapred to other categories of foreign investments (i.e. FDI) the focus is not on long-term profitability expectattion, but rather driven by the short-term speculative forces coupled with volitile macroeconomic differentials in each economy (Vo, et al., 2017). This short-time period causes much concern to the destination countries. Besides, policies that will assure stability and efficiency in the capital market should be enhanced. For this reason, IFRS was developed to cater to the needs of capital market participants in FPI (equity and debt markets). These category of foreign investors will need efficient and accurate accounting information and reliable financial reporting for investment decision that will enable them to diversify their investments for economic development (Ben-Othman \& Kossentini 2015).

The proponents of IFRS claim that a country that adopts IFRS is expected to experience more inflow in foreign investments for economic growth than non-adopting countries (McCreevy, 2005; Tweedie, 2006). Based on this premise, various empirical studies have examined whether this objective has been achieved (Amiram, 2012; Beneish et al., 2015; Chen et al., 2010; Efobi 2017) However, they reported different findings on the relationship between IFRS adoption and FPI. For example, Beneish et al. (2015) and Chen et al. (2010) empirical studies reveal a positive and significant relationship between IFRS and FPI. While Amiram (2012) and Efobi (2017) report a negative link between IFRS and FPI. This thesis contributes to the existing literature by examining the effect of IFRS adoption on FPI inflow in Africa. The evidence from the empirical findings from this research will enable the thesis to evaluate, establish, confirm, or refute the suggested 
assumptions of IFRS proponents. This thesis postulates that countries that required all their listed companies to adopt IFRS will show a more significant inflow of FPI than the non-adopting countries.

\subsection{Problem statement}

The primary purpose of the adoption of IFRS as a single set of high-quality international accounting standards is to increase the transparency and enhance the comparability of financial statements globally, which assumes to strengthen the equity and debt markets in the adopting countries (Amiram, 2012; Chen et al., 2014; McCreevy, 2005; Tweedie, 2006). Developing countries, including African countries, are capital scarce and one of the efforts assumed to increase the inflow of foreign investments for capital growth and development is the adoption of international accounting standards, i.e., IFRS. Bakre (2008) and Manyara (2013) emphasise that a universal unified accounting standard is assumed to contribute to the enhancement of FPI.

Many countries have adopted IFRS, including certain African countries, but the extent of the usefulness of IFRS in influencing foreign investments, such as FPI, has not been studied in the African context extensively. Ball (2016) mentions that a few existing studies have examined the relationship between IFRS and foreign investments. The author explained further that it remains uncertain whether IFRS adoption facilitates an increase in the volume of foreign capital in the adopting countries. Amiram (2012) explains that there is little information on how the uniform accounting information affects FPI decisions.

Furthermore, financial statements prepared with globally accepted accounting standards, such as IFRS, are assumed to influence the quality of accounting information positively and further enhance the efficiency of capital markets for the optimum allocation of capital for investment purposes (Shima \& Yang, 2012). However, the empirical findings of scholars (e.g., Ben-Othman and Kossentini 2015; Boolaky 2012; Bova and Perira 2012; Daske et al. 2008; Efobi 2017) on this matter are inconsistent and mismatched, so the effect of IFRS on FPI remains unclear. The inconsistent and mismatched in the literature indicate the different and unequal outcome of the empirical studies, hence the demand for further empirical research.

According to Amiram (2012), Chen et al. (2014), Emeni (2014), and Louis and Urcan (2014), only a few studies have focussed on the effect of IFRS on FPI in Africa. Most studies emphasised the effect of IFRS on different contextual issues, such as foreign direct investment (i.e., Adetula et al., 2014; Efobi, 2017; Gordon et al., 2012; Kwarbai et al., 2016; Jinadu et al., 2016; Nnadi \& 
Soobaroyen, 2015). What is more, many of these studies that examined the effect of IFRS on foreign investments were carried out in more advanced economies, and mostly at the firm level, with few at a country level (Beneish et al., 2015; Chen et al., 2010; Hong et al., 2014). Most of these studies did not specifically focus on African countries; it is, therefore, assumed that their findings might not reflect the real situation in African countries in particular. This evidence further suggests that the empirical effect of IFRS adoption on FPI at a country level is still scant in the existing literature in Africa.

Importantly, a considerable body of research, especially in advanced economies as previously mentioned, investigated the motivations behind the adoption of IFRS, particularly in influencing the flow of foreign investments in adopting countries as suggested by the proponents of IFRS. Hence the findings from this research intends to link it to the validity of the opinion of the proponents. They suggested that the adoption tends to trigger the flow of foreign investments in adopting counties. Thus making Africa be considered important as a case study in this research to determine how effective the adoption has increased the FPI inflows.

Additionally, evidence from the literature suggests that although IFRS has gained full acceptance internationally, there are still large areas, specifically in Africa, where many countries still make use of national accounting standards framework for listed companies (Ball, 2016; IFRS, 2018). This practice is assumed to hinder the flow of foreign investments. Hence there is the need to examine why there is heterogeneity in African counties decisions to embrace IFRS adoption despite its benefits in attracting foreign investments for economic development.

Following on the above, the investigation of these problems raises fundamental research questions. These include the following:

(i) What is the significant difference in FPI inflows between before and after the adoption of IFRS among adopting IFRS countries in Africa?

(ii) To what extent is the magnitude of the significant difference in FPI inflows among countries that adopted IFRS and countries that did not adopt IFRS in Africa?

(iii) What factors predict the probability of adoption of IFRS in Africa? 


\subsection{Objectives}

\subsubsection{Main objective}

The primary objective of this study is to empirically examine the effect of the adoption of IFRS on FPI in Africa.

\subsubsection{Secondary objectives}

The secondary objectives as they flow from the main objective are to:

(i) examine the significant difference in FPI inflows in IFRS adopting countries in Africa by comparing the situation before and after the adoption;

(ii) investigate the significant difference in FPI inflows among IFRS adopting countries and nonadopting IFRS countries in Africa;

(iii) examine the factors that predict the probability of adoption of IFRS in Africa.

\subsubsection{Research hypotheses}

The following hypotheses are tested in null form and analysed in the study:

(i) There is no significant difference before and after IFRS adoption in FPI inflows in adopting IFRS countries in Africa.

(ii) There is no significant difference in the FPI inflows of countries that adopted IFRS compared to countries that did not adopt IFRS in Africa.

(iii) There is/are no factor(s) that predict the probability of adoption of IFRS in African countries.

\subsection{Research design and methodology}

Leedy and Omrod (2012:3) explain that a research design is a plan for a study that gives the overall framework to indicate how the relevant data relating to each variable will be collected and tested empirically. It is a strategic plan, according to which the researcher aims to achieve his goals. In other words, it is the blueprint for making the research objectives and finding answers to the research questions (Cooper \& Schindler, 2014:82). 
Bless et al. (2006:66) explain that a research design is a procedure for determining the nature of the relationship between variables. It is a framework for the collection and analysis of data, and it expresses underlying links among the variables (Bryman \& Bell, 2011:49). The research design is the pillar that sustains the explanatory quality of research. It creates a link between the research questions and the completion of the research plan, while the research methodology focuses on how to process an inquiry. It explains the kinds of problems that are worth investigating, i.e., what constitutes the research problem, testing of hypotheses, how data will be collected and the process (Denzin \& Lincoln, 2011:14). The research design employed in this study explained the strategy of inquiry into the effect of the adoption of IFRS on FPI. Thus, it puts the paradigm in motion to the empirical world by connecting the researcher to specific methods of collecting and analysing empirical materials.

For this study, the research design that was employed for this study was based on the research onion suggested by Saunders et al. (2012:128). An ex post facto quantitative research method was utilised as a method for collecting different data on all the variables. The research design and methodology for this study contain some elements, as discussed below.

\subsubsection{Literature review}

The study emphasises the effect of IFRS adoption on FPI in Africa. The relevant existing literature is reviewed as a starting point. A literature review refers to a collection of scholarly writings on a topic under study. The review is necessary for providing a theoretical underpinning for the thesis and to the scientific justification for the study (Mafuwane, 2012). A literature review informs the researcher on the current state of knowledge in the chosen field (Walliman, 2017:52). Also, it helps researchers create continuity by interacting with the existing literature. Guthrie (2010:28) explains that a literature review is an analysis of current and relevant studies to set the context and define the research. Studies have been conducted on the relationship between the adoption of IFRS and foreign investments since the emergence of IFRS. The various studies focused on different viewpoints and were held in diverse global environments. It is pertinent that these studies be considered in terms of the objectives of the study, the definitions, and the methodology that were adopted. The findings of the studies as they relate to this empirical study, are also significant. In doing this, the thesis can use the existing studies to examine the effect of IFRS adoption on FPI in Africa. 
Consequently, secondary sources such as scholarly journal articles, text books, thesis, dissertations are exclusively used for the review of the literature in this research as found in the databases accessible from the North-West University library. All these sources of information serve as a basis for collecting data on dependent and independent variables for this thesis.

\subsubsection{Empirical study}

A quantitative approach was employed to achieve the aim of this study. Quantitative research methods assist in exploring, presenting, describing, and examining the associations and trends among the variables that are tested (Saunders et al., 2012:472). It uses different objective measurements to gather data to address the research questions and to test various hypotheses (Ary et al., 2018:17). Thus, the use of a quantitative approach gives the advantage of gaining an understanding of the perception of the study and forming the hypotheses to be tested. Manyara (2013) emphasises that the quantitative method is suitable where the research involves the investigation of variables that can influence the outcome of the findings of the study or predict the outcome. As this thesis examined the effect of IFRS adoption on FPI, this method was suitable to achieve the objectives of this study.

\subsubsection{Statistical analysis}

Data analysis involves the use of descriptive statistics to summarise data and regression techniques. Descriptive statistics include the mean, maximum value, minimum value, and standard deviation. Also, the coefficient of variation (CV) is computed to compare FPI before and after the adoption of IFRS. The CV has been used in the literature to compare the measurements of the dispersion of two distributions to cut the effects of factors such as inflation (Bajpai, 2009:129; Taylor, 2007:53). The Pearson correlation matrix was employed to determine if there is any collinearity or multicollinearity among two or more independent variables. The unit root tests were computed to determine the stationarity of the variables in the model.

In the case of regression techniques, panel data were used for the analysis due to the nature of the data collected. Brooks (2014:647) emphasises that panel data evolve in a situation where observations exist in a cross-sectional and time-series dimension. For example, in this thesis, quantitative data were collected on FPI, and control variables in 15 countries (adopting countries) for 22 years (11 years before 1994-2004, and 11 years after 2005-2015 adopting IFRS), and 20 non-adopting IFRS countries for 11 years (2005-2015). Because of this, a panel data regression technique comprising the Pooled Ordinary Least Square (POLS), Fixed-effects Model (FEM), and 
Random-effects Model (REM) was employed for the statistical estimation of the variables. Furthermore, the commonly used Hausman test is used to determine the best alternative between FEM and REM. Besides, the System Generalised Methods of Moment (SGMM) is employed as a control for the endogeneity among the variables and as a check of robustness.

Also, data analysis included the diagnostic test using a histogram and the Jarque Bera (JB) test, the Wald chi-square test to evaluate the validity of the panel data estimate, and the cross-sectional dependence test for the suitability of POLS for analysis. The Hausman chi-square test was used to determine the best alternative between REM and FEM, and the Arellano-Bond test was computed to test for the autocorrelation $A R\langle 1\rangle$ and $A R\langle 2\rangle$ in the model. Furthermore, the logit regression model was used to estimate the factors that influence the adoption of IFRS in adopting countries. This model was employed by Kolsi \& Zehri (2013), Zeglar \& Mhedhbi (2006), as well as Zehri \& Chouaibi (2013).

\subsubsection{Paradigmatic assumptions and perspectives}

Rocco et al. (2003) define a paradigm as a "worldview." Creswell and Poth (2017:19-20) emphasise that a "paradigm is a set of beliefs or assumptions that guide a researcher's inquiry." Every researcher brings a particular set of connecting philosophical assumptions and positions to his research. Which includes ontological (positivism, realism, interpretivism, and pragmatism), epistemological (deductive, inductive and abductive), rhetorical and methodological assumptions (Rocco et al., 2003). However, the literature emphasises that no specific or single research approach would solve all research problems (Tuli, 2011). Thus, the choice of a particular methodology will depend on the paradigm that guides the research activity. The paradigm involved ontology, epistemology, and methodology. These paradigms are briefly discussed below.

\subsubsection{The ontological assumption}

Ontology relates to the nature of reality (Saunders et al., 2012). It is concerned with the theory of being (Collis \& Hussey, 2013:46-47). The ontological assumption of reality distinguishes between four philosophical assumptions, namely pragmatism, positivism, realism, and interpretivism (Saunders et al., 2012:140). It emphasises the researcher's view of the nature of reality. The pragmatist view of reality holds that there are many approaches to interpreting the world. Also, they assume that no single opinion can elucidate the total picture. These various assumptions are discussed in Chapter 4. On the other hand, the positivist views reality as external and objective, in 
other words, independent from the researcher (Saunders et al., 2012:140). Thus, the positivist assumption is relevant to this thesis.

Bisman (2010) explains that the ontological principle is founded on the assumption that the reality of accounting statements can be revealed since accounting statements are objective. Also, accounting hypotheses can be developed, tested, and verified to arrive at a general universal law. This thesis, therefore, made use of secondary data, which is quantitative, to collect information on variables to be tested based on the existing theory and to formulate and test the hypotheses. In the same vein, quantitative data on IFRS, FPI, and covariates are pre-existing, therefore external and independent of this thesis. These variables are measured and analysed to estimate the causal relationships between them to address the research questions and achieve the objectives of the thesis.

\subsubsection{The epistemological assumption}

Collis and Hussey (2013:46-47) opine that epistemological assumption is concerned with what is regarded as valid knowledge. It is the theory of knowledge that informs the research (Tuli, 2011). It involves the investigation of the association between the researcher and what is being researched. It describes how a researcher is concerned with the adequate and valid knowledge of the matter being investigated. It asks how we know what we know. The positivist researchers, for example, focus on facts instead of the impression and belief that it is through observations of an event that reliable data can be generated (Saunders et al., 2012:140). Positivism observes individual behaviour to discover and validate causal relationships for the prediction of general forms of individual activity in the future (Tuli, 2011). This thesis reports on data on various estimated variables from selected counties that have adopted and IFRS and countries that have not to observe each country's specific characteristics over some time.

Furthermore, deductive, inductive, and abductive reasoning can be used in developing a theory (Tuli, 2011). For deductive reasoning, theory in accounting can be developed from general to specific through logical deduction, which would enable some predictions that could be tested against empirical data (Riahi-Belkaoui, 2004:330-331). In this case, this thesis tested IFRS adoption as a reality that influences the FPI. Deductive reasoning is related to the positivist paradigm and quantitative research, which is natural science-oriented. It is, therefore, more appropriate for this study to use deductive reasoning. It shows that the relevant underpinning theory of accounting information would be tested in this thesis. Inductive reasoning is associated 
more with qualitative reasoning, while the abductive logic utilises both quantitative and qualitative research approaches in developing a theory.

\subsection{Relevant theory of accounting information}

Beiske (2007:1) suggests that deductive reasoning research examines specific underpinning theories to find out if they are appropriate under the premise under which they are being tested. It means that deductive logic is theory-driven. The theory guides the researcher on how to understand and plan the research. However, there are many theories relating to accounting information, but there are no specific accepted theories for the process, according to which accounting theories can be developed universally (Deegan, 2010:7).

Nevertheless, some relevant accounting theories are derived from agency theory (Alchian \& Demsetz, 1972; Jensen \& Meckling, 1976), institutional theory (Hawley, 1981, DiMaggio \& Powell, 2000), positive accounting theory (Watts \& Zimmerman, 1978), and the decisionusefulness theory (AAA 1966; Chambers, 1955). The thesis identifies decision-usefulness as the relevant underpinning theory since the significant purpose of IFRS adoption is to make financial statements communicate more useful information to the stakeholders to create economic and investment decisions about the firm. These matters are discussed under the research design and methodology in detail in Chapter 4.

\subsubsection{Rhetorical assumption}

Rhetorical assumptions have to do with the language of research that the researcher adopts, which may be active or passive. In positivist research, it is recommended to write in a formal style by employing the passive voice (Collis \& Hussey, 2013:48). In essence, since this research is adopting the positivist assumption inclined to objectivism, passive voice is more appropriate. The passive voice will make sure that the thesis is objective and personal opinions or values are not allowed to influence the findings.

\subsubsection{Methodological assumption}

The research methodology is the technique that transforms the ontological and epistemological assumptions into a framework that explains how the researcher will research following the principles, concepts, procedures and related practices that control the research (Sarantakos, 2005:28). The method of data collection will go a long way to determine the particular research 
approach to adopt. For example, positivist research, which is underpinned by an objectivist epistemology, is related to quantitative research methodologies that focus on collecting secondary data, measuring variables, and testing hypotheses. Qualitative methods are underpinned by interpretivist epistemologies that fully involve the researcher in the research activities, such as interviewing the relevant people to gain more knowledge in the investigation.

Collis and Hussey (2013:48) opine that the methodological assumption is related to the techniques of the research. A positivist paradigm frames this study due to the nature of the data collected. Positivism emphasises scientific research, which is still relevant in social sciences research. Knowledge is derived from positive information, and it can be scientifically verified. This thesis is quantitative, and positivism is connected with quantitative methods of analysis by using statistical analyses of data. The 'research onion' framework formulated by Saunders et al. (2012:128) was employed as the research methodology analysis procedures. It emphasises how data are collected and in what manner the research questions of this thesis are addressed.

\subsection{Target population, selection, and data collection approach}

Collis and Hussey (2013:197-198) define a population as a collection of items under review for statistical analysis. The total number of countries in Africa served as the entire population of this study. From this, countries that had fully adopted IFRS and non-adopting countries were selected for the study. Secondary data were collected from 35 selected African countries. The relevant data for the time frame of the study was available for the selected countries. The period of the study was divided into two for the adopted countries, namely, before the adoption of IFRS and after the adoption of IFRS.

Similarly, data for countries that have not adopted IFRS were collected and compared with those that have adopted according to the inflows of their FPI. These periods of data collection are essential because the number of years of adoption of IFRS affects the extent of the impact felt by the adopting countries (Ball, 2016). Likewise, the periods made the outcome more significant, considering the length of time for which the data were collected. All countries considered as sovereign African countries, according to the United Nations scheme of geographic regions, were included in the population. 


\subsection{The scope of the study}

The study focused on the effectiveness of a unified international accounting standard in African countries. The research questions examine the efficacy and significance of IFRS adoption as a single set of international accounting standards for the inflow of FPI in IFRS adopting countries in Africa. The period of the study was divided into pre-adoption of IFRS (1994-2004) and postadoption (2005-2015) for the adopting countries for data collection. Similarly, data were collected for all the variables to be tested from countries that have adopted IFRS and non-adopters in Africa where data were available. The data will enable the study to examine the flow of FPI in countries that have fully adopted IFRS and in non-adopting countries from 2005-2015. However, since a small number of African countries have adopted IFRS, the study further employed panel data as well to investigate the factors that influence the adoption of IFRS in the adopting countries.

\subsection{Significance of the study}

This study could be of importance for the government and other bodies that are responsible for setting accounting standards. They can evaluate the consequence of the adoption of IFRS on FPI in Africa. It could also be relevant to those countries that have not adopted IFRS and help them decide whether to adopt IFRS, given the influence of IFRS on FPI flow from countries that have adopted it. Also, the results could assist the IASB in its efforts to drive worldwide adoption of IFRS. The findings could also have implications for policymakers who are interested in accounting, international business, and economic development since it emphasises the relationship between the adoption of IFRS and FPI flows in African countries.

Scholars in accounting fields could also benefit from the outcome of the study. The study contributes to the existing knowledge by examining the effect of IFRS adoption on FPI in Africa, having controlled for other covariates that influence foreign portfolio investments. This study is different from the previous studies on foreign investments since it looks at data for 22 years (11 years before and 11 years after IFRS adoption) for the analysis to avoid the problem of short-term measurement instability and to remove any bias. Likewise, it adopts FPI as the dependent variable rather than common other contextual issues, such as FDI. Similarly, a panel data analysis using pooled ordinary least squares, a fixed-effects model, a random-effects model, and a systemgeneralised method of moment was employed rather than only ordinary least squares approach (Gordon et al., 2012; Ng, 2015). 


\subsection{The structure of the study}

Chapter 1 discusses the need for this research as an introduction to the study. The problem statement, research questions, primary and secondary objectives, and hypotheses were addressed. Additionally, the research design and methodology of the study were briefly explained. The chapter sets out the purpose of the whole thesis and how it will be accomplished. Chapter 2 provides a literature overview of FPI by discussing the concept, the driving forces and the factors that can influence FPI in Africa. Chapter 3 continues the literature review by looking at international accounting standards. It gives historical perspectives of international accounting standards worldwide and discusses the concepts of financial reporting and financial statements. The chapter also discusses the IASB conceptual framework for financial reporting and IFRS jurisdictions worldwide and the African status of IFRS. The factors that can influence the adoption of IFRS were also reviewed.

Chapter 4 focuses on the research design and methodology and provides reasons for the research strategy adopted. The chapter also discusses the philosophical assumptions and identifies the underlying premise of the study. Besides, the conceptual framework that examines the relationships between the variables is presented in a diagrammatic representation. It shows the links between dependent and independent variables to provide consistency for an empirical thesis of this nature.

Chapter 5 presents an analysis of the data and an interpretation of the results, while Chapter 6 concludes by giving a summary of the research, the significant findings of the thesis, conclusions, recommendations, the contribution to existing knowledge and suggestions for further studies.

\subsection{Definition of terms}

The following terms are central to this study:

Accounting standards: It is a set of principles and procedures that agreed upon as a framework for companies to prepare financial reporting to enhance its transparency and comparability.

Harmonisation: The harmonisation is a process of creating unified accounting standards. It increases the comparability of accounting practices and set boundaries for their degree of variation. 
Financial report: It refers to formal financial documents prepared by an entity with acceptable international accounting standards to record both economic and non-economic transactions for some time.

Africa: This is the second-largest continent in the world after Asia and forms the target population for this study.

Cross-border investment: It represents the flow of investment from one country to another to acquire a lasting management interest in an entity.

International financial reporting standard (IFRS): It is a set of accounting standards developed by the IASB, an independent not-for-profit organisation, to provide a global accounting standard framework for public companies to prepare financial statements for the usefulness of stakeholders. IFRS is required for a domestic public company, or it may be permitted, but not required.

Investment decision: This is the act of determining a geographical place, time, and amount that investors would like to invest to postpone their current consumption to make a profit on the amount invested shortly. The geographical location may be in another country or the country of the investor.

Equity investment: An equity investment refers to buying shares of stock of an entity for regular income in terms of dividends and with the expectation of capital appreciation.

Financial accounting: This is a measurement and communication system that provides economic and social information about an identifiable entity to permit users to make informed judgements and decisions, leading to optimum allocation of resources and the accomplishment of organisational objectives.

The usefulness of accounting information: It is the relevance of accounting information in the capital market allocation process.

Conceptual framework of accounting: This is referred to as a constitution, a coherent system of interrelated objectives and fundamentals that can lead to a consistent standard that provides guidelines for identifying the boundaries of financial reporting. 
Global financial reporting standard adoption: This means that national rules are set aside and replaced by a requirement or permission to use IFRS directly. It would be compulsory for all listed companies in countries that adopted IFRS. 


\section{CHAPTER TWO: LITERATURE REVIEW ON FOREIGN PORTFOLIO INVESTMENT (FPI)}

\subsection{Introduction}

Chapter 1 introduced the study and provided the background to the study, the problem statement, the research questions, the objectives, and the hypotheses. Furthermore, the chapter discussed the research design and methodology approach and the paradigmatic assumptions and perspectives related to the study.

This chapter offers a review of existing literature on research about FPI in Africa to highlight gaps in the literature relevant to FPI. Hence, the chapter focuses on relevant and recent literature on FPI inflows. It examines the concepts of foreign investments, the influence of accounting standards on FPI and the history and trend of FPI. Additionally, the driving force of foreign investments and the theoretical and empirical framework of FPI were equally examined. Besides, factors that determine the inflows of foreign investments to a particular country were discussed, and lastly, the summary of the chapter.

Creswell (2014:27-28) mentions that a literature review serves many purposes, one being to share with the reader findings and conclusions of other studies that are relevant to the present study. It also provides a framework for establishing the importance of the research and the basis to compare the outcome with other findings. Also, Walliman (2011:52) emphasises that a literature review is an evaluation conducted by the researcher of existing literature relevant to the title of the current research, and it confirms the necessity for conducting further research.

Zikmund et al. (2013:63) state that a literature review is a search of published works of scholars that explain and present empirical results that are relevant to the current study. Also, Collis and Hussey (2014:76) clarify that a literature review identifies an existing body of knowledge that is relevant to the present research. A literature review aims to enable the researchers to acquaint themselves with the existing body of knowledge so that they understand the links between existing research and the current study (Neuman, 2014:126).

For this study, secondary sources of data were used. Therefore, the review of the literature for this study involved academic journals in financial accounting and economics and some recent textbooks relevant to the study. Also, internet databases such as the Social Science Research 
Network (SSRN), ProQuest theses and dissertations, Emerald academic journals in accounting, finance, and economics in North-West University online library were used for internet searches.

\subsection{Conceptualising foreign investments}

To understand the issues and concepts related to foreign investment flow, one should identify the source of these flows, which is the financial account in the balance of payments (BoP). The financial account in the BoP emphasises the components of investment flow (Amaya \& Rowland, 2003). The IMF (2009) categorises the financial account into five: (i) foreign direct investment (FDI); (ii) FPI; (iii) financial derivatives; (iv) other investments; and (v) reserve assets domiciled with the central bank. Although this study focuses on FPI, the other concepts are also briefly explained.

Researchers still disagree on what constitutes the definition of FPI. Essentially, there is no clear definition of FPI and FDI. They are typically juxtaposed (Makoni \& Marozva, 2018). For this kind of research, a clear definition of what constitutes FPI is vital for investors in global capital markets. According to the BoP components, direct investment and portfolio investment are components of a country's national financial accounts. The portfolio investment is further classified into equity and debt, which is the focus of this study. Many countries in the world invest in other economies, through FPI and FDI. The definition of these two concepts is examined below.

\subsubsection{Foreign direct investment explained}

The primary definition of FDI is contained in the BPM5 of the IMF (1993) and the BD3 (OECD, 1996). The BPM5 states that "FDI refers to an investment made to acquire a lasting interest in enterprises operating outside of the economy of the investor. Further, in cases of FDI, the investor's purpose is to gain an effective voice in the management of the enterprise. Since the main future of FDI is taken to be the lasting interest of direct investors in an enterprise, only capital that is provided by the direct investor either directly or through other enterprises related to the investor should be classified as FDI'. The forms of investment for FDI are classified as equity capital, the reinvestment of earnings and the provision of long-term and short-term intra-company loans.

Furthermore, the OECD defines FDI as "a direct investment enterprise is an incorporated or unincorporated enterprise in which a single foreign investor either owns 10 per cent or more of the ordinary shares or voting power of an enterprise or owns less than 10 per cent of the ordinary 
shares or voting power of the enterprise, yet still, maintain an effective voice in management. An effective voice in management only implies that direct investors can influence the management of an enterprise and does not imply that they have absolute control." FDI is the category of foreign investment where a resident entity in a particular country obtains a lasting interest in an enterprise in another country. A lasting interest means that the investor intends to have a long-term relationship and a certain degree of control in the management of the entire enterprise. The investor has to have $10 \%$ or more of the voting power (UNCTAD, 1999).

FDI can take the form of investment, like establishing business operations or acquiring business assets, greenfield investment, or mergers and acquisitions in other countries. It involves establishing a direct business interest in a foreign country such as buying or building a manufacturing company. FDI is a real investment in the assets of the company in which the investor has invested; it is non-debt-creating, and it is not volatile. Furthermore, the UNCTAD (2011:30) states that FDI is an investment to establish lasting economic relations that offer the opportunity of implementing effective control of the management.

The World Bank (2011) defines FDI as: "Foreign direct investment are the net inflows of investment to acquire a lasting management interest (10 per cent or more of voting stock) in an enterprise operating in an economy other than that of the investor. It is the sum of equity capital, reinvestment of earnings, other long-term capital, and short-term capital, as shown in the balance of payments." Thus, the influence of control in management differentiates FDI from FPI.

Studies on foreign investment flow focus extensively on FDI (Dunning, 2006). The research on FDI flows into developing countries is discussed in depth in the literature, while FPI is discussed less (Bevan \& Estrin, 2004; Carstensen \& Toubal, 2004; Humanicki et al., 2013). Understanding the importance of FPI inflows is necessary, especially when the focus is on the association between IFRS adoption and FPI since IFRS was mainly developed to cater to the needs of capital market participants. The next section discusses the concept of FPI.

\subsubsection{Concept of foreign portfolio investment}

UNCTAD (1999) defines FPI as investment involving the transfer of financial assets by the resident individuals, enterprises and institutions in the country of the investor to an investee country. This transfer of financial assets may be directly or indirectly in the assets of the firm. Also, it entails involvement in the activities of the financial market, that is, buying and selling of securities. Investors aim to benefit from capital appreciation through diversification of 
investments. On the other hand, the OECD (2013:29) defines FPI as the type of foreign investment that involves investment in equity and debt securities, which does not include instruments classified as direct investment or reserves.

Also, the IMF defines FPI narrowly as an investment in equity and debt securities that do not form part of direct investments. They state that investment worth less than ten per cent is classified as FPI, and higher than ten per cent will be an investment in FDI. The IMF's (2017:2-3) Coordinated Portfolio Investment Survey emphasises the attribute of investments classified as portfolio investments as traded or tradable securities. The further explain that equity securities claim the residual of the assets after all other claims have been met after liquidation. Debt securities (bonds and notes, money market instrument holders, debenture holders) are creditors to the firm, and their claim will take pre-eminence in case of liquidation. IMF further defines FPI as cross-border transactions and positions involving equity or debt securities other than those included in direct investment or reserve assets.

However, researchers on FPI have also used different definitions. Thankgod (2014) defines FPI to be an international capital flow consisting of the movement of financial assets across the international frontier for the main objective of gaining profit. The study further explains that it is the transfer of accumulated assets from less productive to the most productive economy across the globe. Aziz et al. (2015) state that FPI is an international financial activity that consists purchasing of shares, bonds, or money market instruments with a short-term maturity period. This activity is to enable investors to seize the opportunity of favourable interest rates to obtain higher returns in foreign secondary capital markets. They further explained that FPI would increase the liquidity position of investee countries. It includes investments by a resident entity in one economy in equity and debt securities of an enterprise resident in another economy to obtain again, which does not necessarily mean having a lasting controlling interest.

The BoP also classifies FPI into equity and debt as forms of portfolio investments. Equity refers to the part of the firm's capital raised in exchange for shares of ownership in the company. Also, debt security is raised through borrowing from a source outside the company. PwC (2016:3-5) gives the characteristics of equity and debt as follows: equity is associated with the corporate rights, ownership, and control through voting rights, the uncertain return of investment, return dependent on business results, business risk, and subordinated in payment. Debt has the following characteristics: obligation to the repayment of the principal sum, a predetermined and fixed return related to the principal amount, credit risks, and preference in payment. 
Thus, FPI is a type of investment that is characterised as financial. The investors remain passive in the management of the firm. Their primary concern is the future appreciation of the capital invested and regular returns from the investment, irrespective of any time frame of the relationship and control of the company. Unlike FDI, FPI does not enhance any form of technology transfer or skill transfer by being involved in the training of host workers.

These various definitions and characteristics of FPI in literature imply that its attractiveness in developing countries is a function of many factors. These characteristics include the level of development of the accounting environment that will assist the investors in making investment decisions and institutional infrastructure. The investors aim to get profit quickly from shares and interest from debt, otherwise known as hot money. It is a short form of investment and highly volatile. Invariably a negative shock in the economy will enable the quick reversal of investment. Given this, the host countries must be conscious of these and prevent any sudden withdrawal of investment, which may cause an economic crisis.

Furthermore, apart from FDI and FPI, the balance of payments further categorises some investments under financial account as follows: (i) Financial derivatives that cover financial instruments, indicators or commodities. (ii) Other investments are grouped as short and long-term trade credits, loans, currency and deposits, and other account receivables and payables. Lastly (iii) reserve assets consist of monetary gold, special drawing rights, the reserve position in the IMF, foreign exchange and others (Amaya \& Rowland, 2004; Kumar, 2018).

This thesis relies on the definition of the IMF for FPI. It emphasises the components of FPI as an investment in equity and debt securities that were considered volatile. It refers to investment made by residents of a particular country in financial assets (i.e. equity and debt) of another country. These sets of foreign investors can make more use of global accounting information, IFRS, for their investment decisions than any other foreign investors (Amiram, 2012). This type of investor will rely more on accounting information published by the listed companies using global accounting standards, e.g., IFRS, than information published by other foreign investors (Beneish et al., 2015). This study focuses on total FPI inflows in countries in Africa.

The next sections offer a historical overview of foreign investments in Africa. The inflow of FPI is more important for capital formation and economic development, which can be influenced by the development of various institutional infrastructures such as IFRS adoption and sound macroeconomic variables. 


\subsection{Profile of foreign investments in Africa}

Most African countries gained independence in the 1960s, and they were in doubt about free international trade and foreign investment (Dupasquier \& Osakwe, 2006). During the 1970s and 1980s, most African countries showed very little or no increase in foreign investments (Ghosh et al., 2017). The West saw Africa as a continent of recurring problems such as economic instability, weak governance, declining economic growth, social conflict, leading to a marginal share of foreign investment between 1980 and 2000. The West finds it difficult to extend much foreign capital to the continent of Africa. The period of the 1970s and 1980's also witnessed fundamental economic policies that were mostly inward-looking economic strategies to encourage economic growth and development. These policies ranged from the protection of domestic industries, foreign exchange reserves, nationalisation of foreign companies to import substitutions, among others (Dupasquier \& Osakwe, 2006).

The study of Asfaw (2015) emphasises that these inward-looking strategies for economic growth and development in Africa had a negative effect and also affected the living standard of the people. Dupasquier and Osakwe (2006) further report that the poor economic performance caused by internal economic strategies did not conform with the globalisation activities worldwide. Therefore, it led to a change from inward-looking policies to more outward developing strategies to attract more foreign investors. Because of this, many African countries have tried over the years to reverse the economic downturn and decline in foreign investment and have embarked on policies that would improve the trend of foreign investments. Among them is the adoption of IFRS, which is expected to invigorate the capital markets and enhance foreign capital flows. Thomsen (2005) explains that the desire to attract foreign investors has provided a healthy initiative for African governments to reform policies and practices.

Capital flows as a source of investment, in terms of FDI and FPI, in developing economies increased significantly at the beginning of the 1990s after a period of stagnation (Amaya \& Rowland, 2004). The increase in capital flows to developing countries worldwide since the end of the $20^{\text {th }}$ century is attributed to change in different economic fundamental and country-specific conditions (Ahmad \& Zlate, 2014). Khayat (2016) explains that the flow was induced by the removal of various restrictions placed on foreign investments by numerous developing countries. The author further mentioned that developing countries introduced different economic policies, such as trade liberalisation and privatisation. These policies aimed to influence more flows of foreign investments. 
AEO (2017:18-34) reports that Africa recorded its lowest FPI inflows in 2016 because of the reaction of investors to the global economic shock, resulting in buying fewer assets of developing countries. Khayat (2016) explains that FPI is known to be extremely volatile, and any shock or disequilibrium in the world economy that brings a global economic crisis will affect developing economy because a large number of developing countries receive foreign investments. Thus, foreign investment trends are central to economic development since they act as both driver and outcome of economic performance. Therefore, understanding the trend of foreign investment, especially FPI, is vital for policymakers. Foreign investment flows constitute an important part of the BoP, and policymakers must understand their behaviour and trends (Amaya \& Rowland, 2004).

FPI is classified by International Investment Position (IIP) as equity and debt securities and similarly described as cross-border investments. UNCTAD (1999) states that FPI involves a transfer of financial assets by way of investment by resident individuals, enterprises, and institutions of one country in securities of another country, either directly in the assets of the companies or indirectly through financial markets. Furthermore, Haider et al. (2016) explain that FPI is the capital inflow into the country through foreign investment. It is in the form of stocks and shares securities or debt securities in the host country. FPI becomes a widespread phenomenon because it is a short-term investment as compared to FDI. The foreign investors speculate on the boom in the market and invest by keeping sight of the economic variables. Haider et al. (2016) point out that the trends related to FPI worldwide, especially in the developing economies, have changed in the last century.

Daly and Vo (2013) state that the trend of foreign investors investing in a foreign country in the last decade is encouraging. Smimou (2014) explains that foreign investment is one of the significant factors that affect the economic development of any nation. Thus, it causes many governments of the world to devise plans and policies that will influence flows of foreign capital. Among them is the recently introduced IFRS. The existence of investment barriers in less developed countries, such as lack of information, differences in capital controls and accounting standards, political instability, and taxation policies, are some of the factors that hinder the flows of FPI. Thus, the main focus of FPI is the contribution of capital for investment purposes. Therefore, all efforts must be made to reduce any hindrances to the flow of foreign capital, especially in developing countries. One such barrier to FPI flow is inconsistent accounting practices (Frost et al., 2009). 
According to Gordon et al. (2012), variables that are assumed to determine the inflows of foreign investments are the country's gross domestic product and the average labour wage rate. Others are growth rate, openness to imports and exports, infrastructure, exchange rate, and long-term interest rate, voice, stability, government, regulation, law, and corruption. They stated that the general theory of the determinants of foreign investment had not been achieved. The link between accounting standards, IFRS, and foreign investment has not received much attention in the literature. It is therefore pertinent to examine the influence of IFRS on FPI before adoption, after adoption, and in the case of non-adoption in African countries.

The next section discusses the FPI inflows worldwide and in particular Africa from 1994-2004, the period before the existence of IFRS. Also from 2005-2015 after the introduction of IFRS. The ultimate goal is to determine the magnitude of changes in FPI inflows before and after the adoption of IFRS for countries in Africa that have adopted IFRS.

\subsubsection{Global distribution of FPI inflows}

The global FPI inflow has shown tremendous growth according to the data extracted from IMF BoP and the IIP from 1994 to 2015. The data are presented in Table 2.1. The data show that the world FPI inflow amounted to US\$47 billion from 1994-1999, a period of six years. From 20002004 it amounted to US\$83 billion. Between 2005 and 2010, the FPI figure shows US\$228 billion and an amount of US\$259 billion from 2011 to 2015.

The total amount of FPI inflows to industrialised economies from 1994-1999 amounted to US\$46 billion. Between 2000 and 2004, it increased to US\$81 billion, and from 2005 to 2010, the figure grew tremendously to US $\$ 216$ billion. While the period between 2011 and 2015 revealed a total of US\$241 billion. Comparing these figures with total world FPI for the same periods reveals that the developed economy shared 99\%; 98\%; 99\% and 93\% respectively during the same periods, while the remaining insignificant figures went to less developed economies worldwide. Between 1994 and 2004, the percentage increase of inflows of FPI to developed countries was 475\%. Also, there was an $87 \%$ increase between 2005 and 2015 . These percentages are close to the total world FPI percentages within the periods aforementioned.

Consequently, FPI is a phenomenon that primarily concerns developed economies, and the available data reveal that they still attract a higher share of worldwide FPI than developing countries. The figure shows that a larger percentage of total FPI went to industrialised countries. This view is confirmed by the table below. Between 1994 to 2015, a significant share of the FPI 
inflows was received by the United States of America and the United Kingdom. Out of the total FPI inflows of US $\$ 620$ billion to advanced economies, the United States of America had a 30\% share while the United Kingdom came second with a share of $1 \%$.

Table 2.1 further explains that the total FPI for all developing countries from 1994 to 2015 amounted to US\$35 billion, which represents 9\% of the entire world FPI. Latin America and the Caribbean had a significant share of the total FPI of developing countries, with a total of US\$14 billion amounting to $40 \%$ of the full share of the developing countries. In contrast, Asia had a total of US\$12 billion, representing 34\% of the entire percentage of FPI in developing countries. Both regions experienced economic crises that led to the reduced inflow of the FPI in the early ' 90 s and late '90s. During these periods, 1994-1999, according to Table 2.1, the total amount of FPI inflows for the two regions amounted to US\$.956billion for six years. The Mexican crisis of 1994 and 1995 and the Asian crisis of 1997 to 1998 led to a significant reduction in the inflow of FPI. The table shows that after the crisis, the FPI resumed its increase in the two regions. The African continent has not received significant capital inflows in the form of FPI over the years, especially from 1994 to 2015 . Table 2.1 reveals that overall, the performance was abysmal compared to other continents. In total, the FPI inflows into Africa amounted to US\$2.956 billion.

Table 2.1: The global annual average of FPI inflows (US\$ millions)

\begin{tabular}{|c|c|c|c|c|c|}
\hline Region & $\mathbf{1 9 9 4 - 1 9 9 9}$ & $\mathbf{2 0 0 0 - 2 0 0 4}$ & $\mathbf{2 0 0 5 - 2 0 1 0}$ & $\mathbf{2 0 1 1 - 2 0 1 5}$ & Total \\
\hline World & $47,888,961$ & $83,565,164$ & $228,949,327$ & $259,599,533$ & $620,002,985$ \\
\hline Developed Countries & $46,577,059$ & $81,000,266$ & $216,231,641$ & $241,458,391$ & $585,267,357$ \\
\hline Developing Countries & $1,454,737$ & $3,829,360$ & $12,745,321$ & $16,965,192$ & $34,994,610$ \\
\hline Latin America and Caribbean & 691,946 & $1,735,413$ & $5,017,379$ & $6,349,065$ & $13,793,803$ \\
\hline Asian Countries & 269,369 & $1,127,970$ & $4,325,824$ & $5,901,507$ & $11,624,670$ \\
\hline African Countries & 184,424 & 230,651 & $1,016,100$ & $1,564,928$ & $2,996,103$ \\
\hline
\end{tabular}

Source: Extracted from IMF Balance of Payments and International Investment Position 1994-2015

The analysis, as mentioned above in Table 2.1, is confirmed by the two graphic representations below that depict FPI inflows in the world into both advanced and developing countries. 


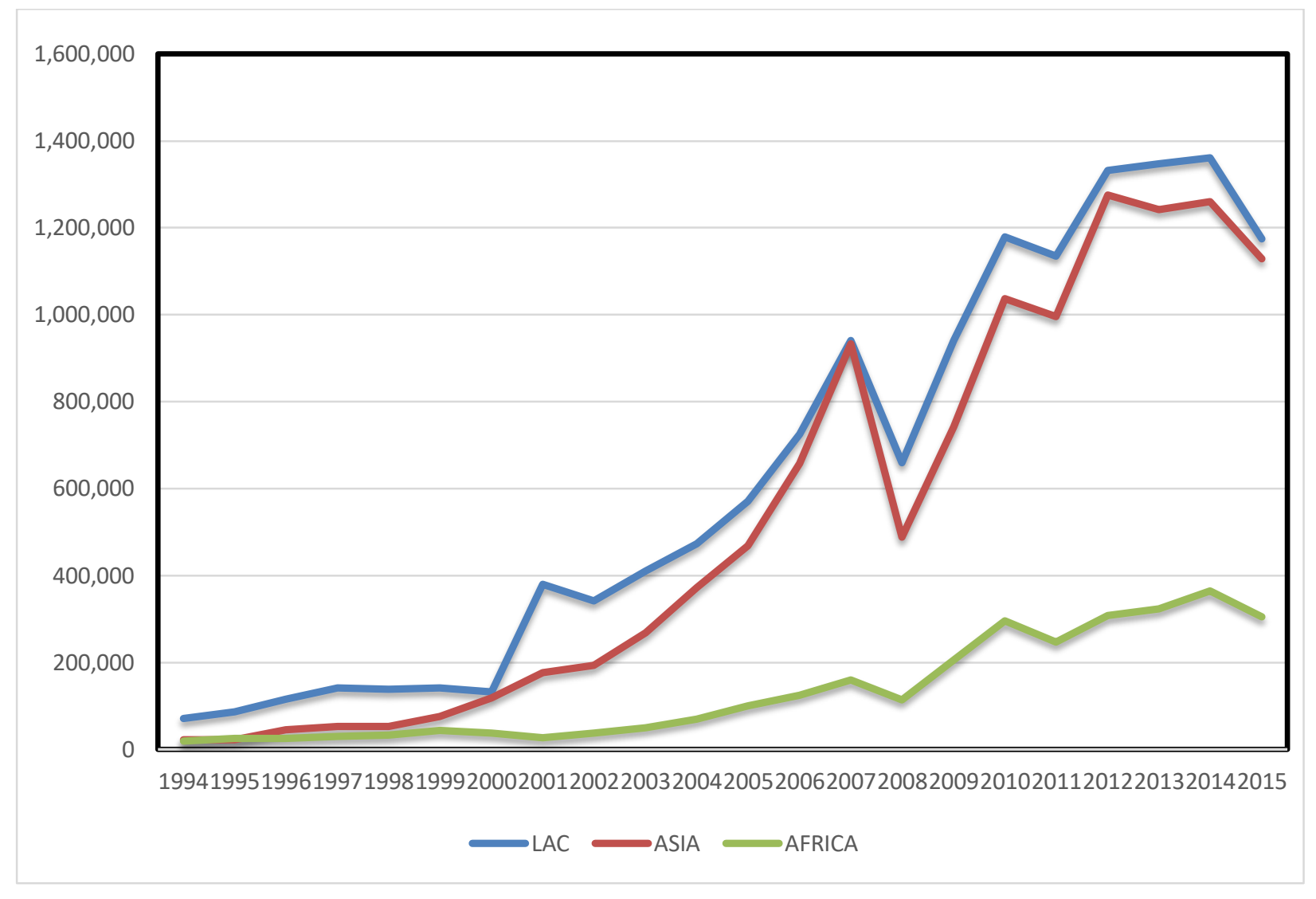

Figure 2.1: FPI flows into developing countries (US\$ millions)

Source: IMF: Balance of Payments and International Investment Position 1994-2015

Figure 2.1 reveals that there was a relative growth in the FPI inflows into Latin and Caribbean America (LAC) and Asia, but LAC experienced more inflows of FPI than Asia. In the case of Africa, there was a wider gap in the trends than on the other two continents. The wider gap means that the inflow of FPI into African countries is low compared to different continents of the world. The figure further shows that there was a high degree of volatility in developing countries' markets, which eventually affected the inflows of FPI. The economic crisis between 2007 and 2008 also had a significant impact on portfolio investments across the world. Hence, causing a sharp drop in the inflows of FPI during this period of crisis. Furthermore, starting in 2012, there has been a downward slope in the trend of portfolio inflows.

The figure further shows that the African continent is far behind other continents in the performance of FPI inflow mobilisation. The poor performance calls for efforts of the respective governments to devise means of improving the inflow of FPI to enhance economic growth. It is assumed that with the adoption of IFRS, the continent of Africa may experience more inflow of FPI. 


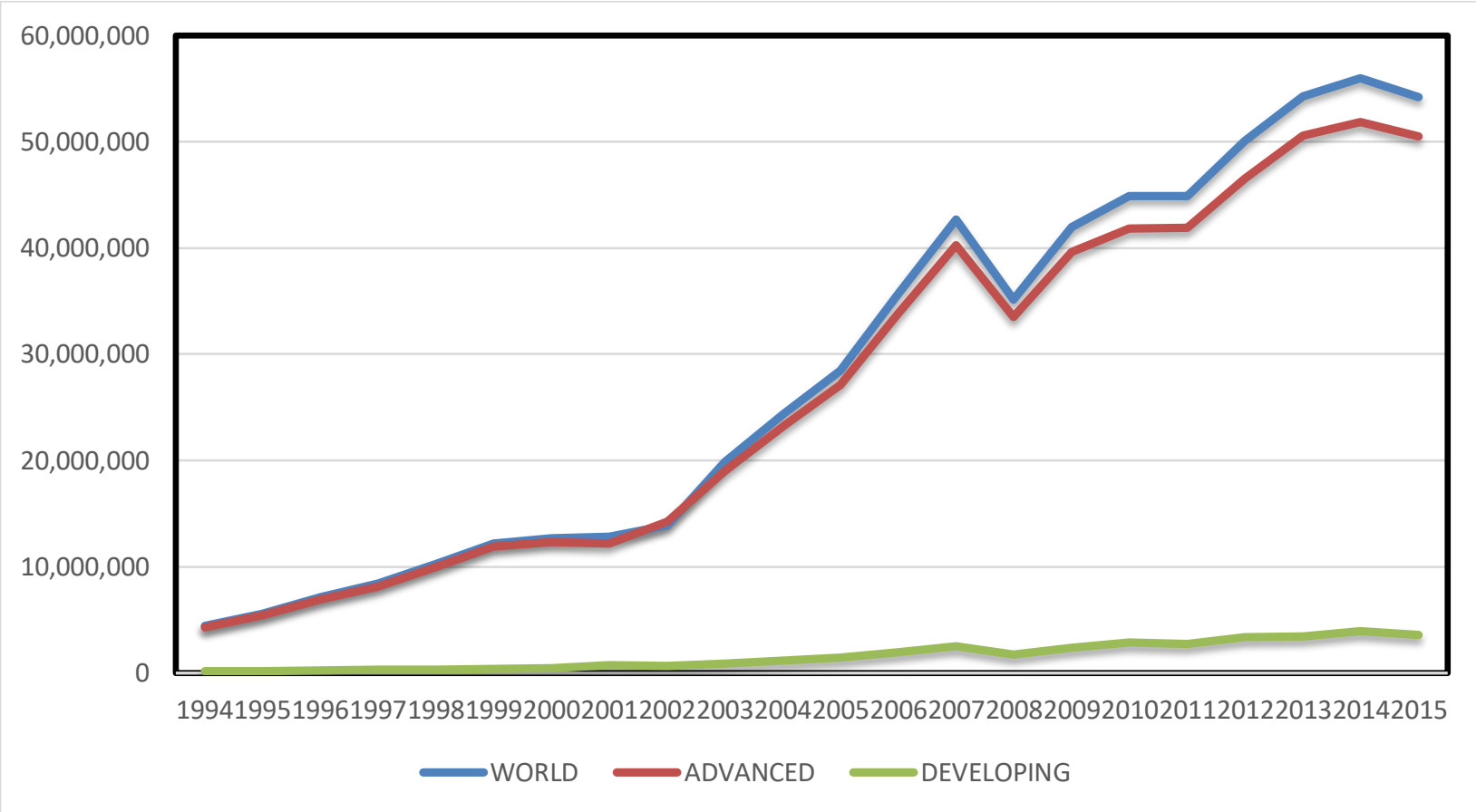

Figure 2.2: FPI flows into the world, advanced and developing countries, 1994-2015 (US\$ millions).

Source: IMF: Balance of Payments and International Investment Position 1994-2015

As illustrated in Figure 2.2, the portfolio investment flows to advanced, and world markets have been relatively stable, but at a low rate of growth. The figure further shows that the FPI flows to these markets started rising and became volatile from the year 2000 till 2007/2008 when the markets experienced a drastic fall due to the financial crisis. Figure 2.2 shows that, after the period of crisis, there was a rise in FPI inflows before it dropped again in 2012. However, the general trends in FPI inflows into these markets have been steady despite the shock in the world economy. The situation is quite different in developing countries. Figure 2.1 shows that Africa was isolated from these trends due to insignificant growth in FPI, especially from 1994 to 2004, while the developing markets also started experiencing a relative and volatile growth in FPI inflows from 2005. The volatility may be due to the introduction of unified global accounting standards, which has the objective of attracting foreign investment capital.

\subsubsection{Trends of FPI, equity and debt in Africa (1994-2015)}

Developing countries, including Africa, have made efforts in the past to attract foreign capital flows as it would provide opportunities to attract capital markets development and improve the trends of FPI inflow (Obstfeld, 2009). Available data from IMF BoP and the IIP, 1994-2015 on 
FPI (equity and debt securities) inflows are examined to look into the behaviour of FPI trends in Africa.

Figure 2.3 explains the trend of FPI inflows in Africa from 1994-2015.

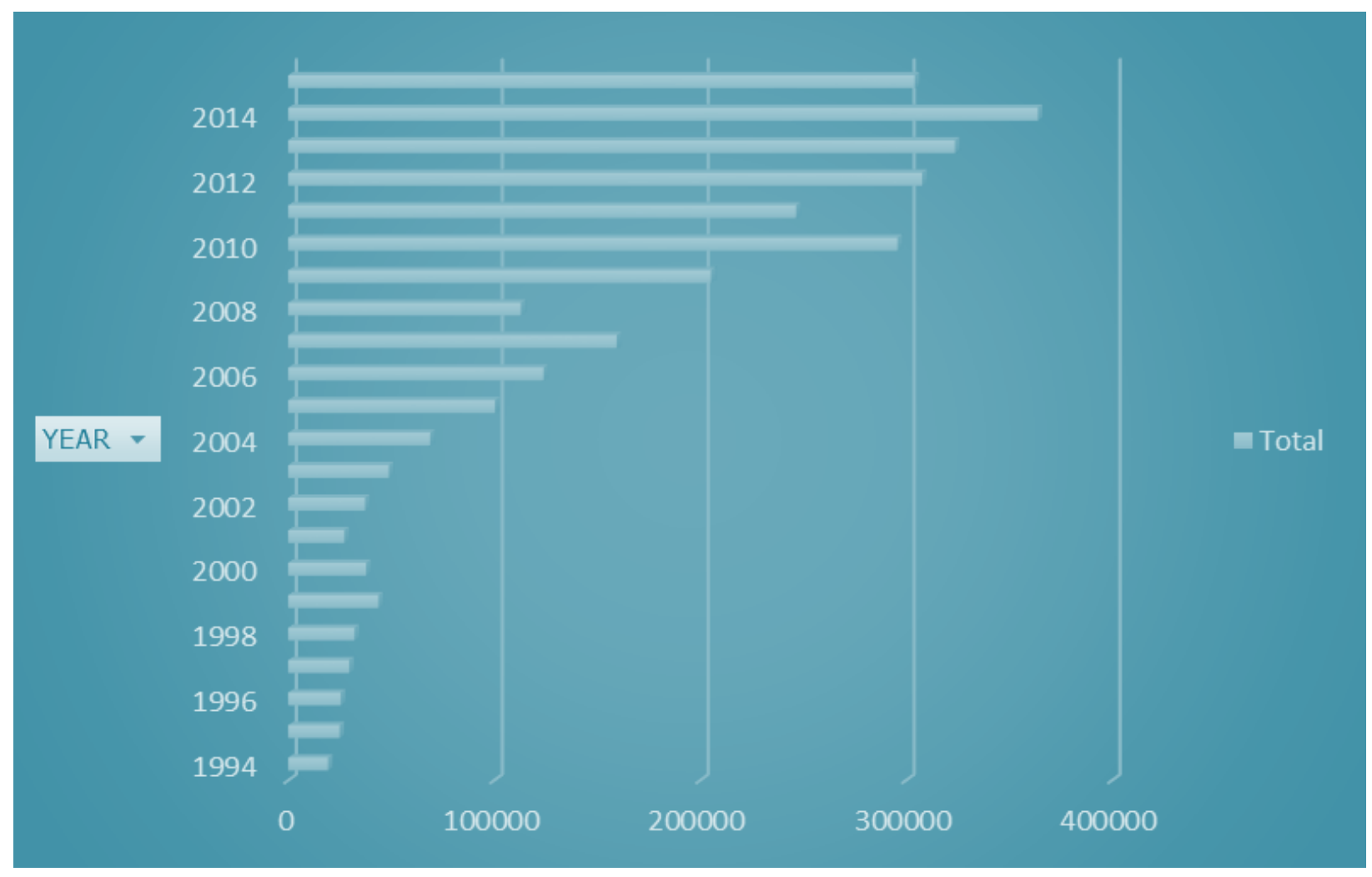

Figure 2.3: Total of FPI inflow in Africa, 1994-2015 (US\$ millions)

Source: IMF, Balance of Payments and International Investment Position, 1994-2015

Figure 2.3 shows that there was a relative change in the trend of FPI inflows into Africa from 1994-2015. Hence indicates an improvement in the inflow of total FPI from 2005 to 2015. This improvement was more pronounced probably due to the introduction of IFRS in 2005.

Similarly, Figure 2.4 shows the total FPI, equity, and debt securities in Africa from 1994-2015. The figure shows an improvement in the trends of FPI from 2005-2015. According to the figure, the trend of equity investment was relatively stable and low between the years 1994-2004. The table shows that from 2005 to 2015 the trend turned upward and became highly volatile. 


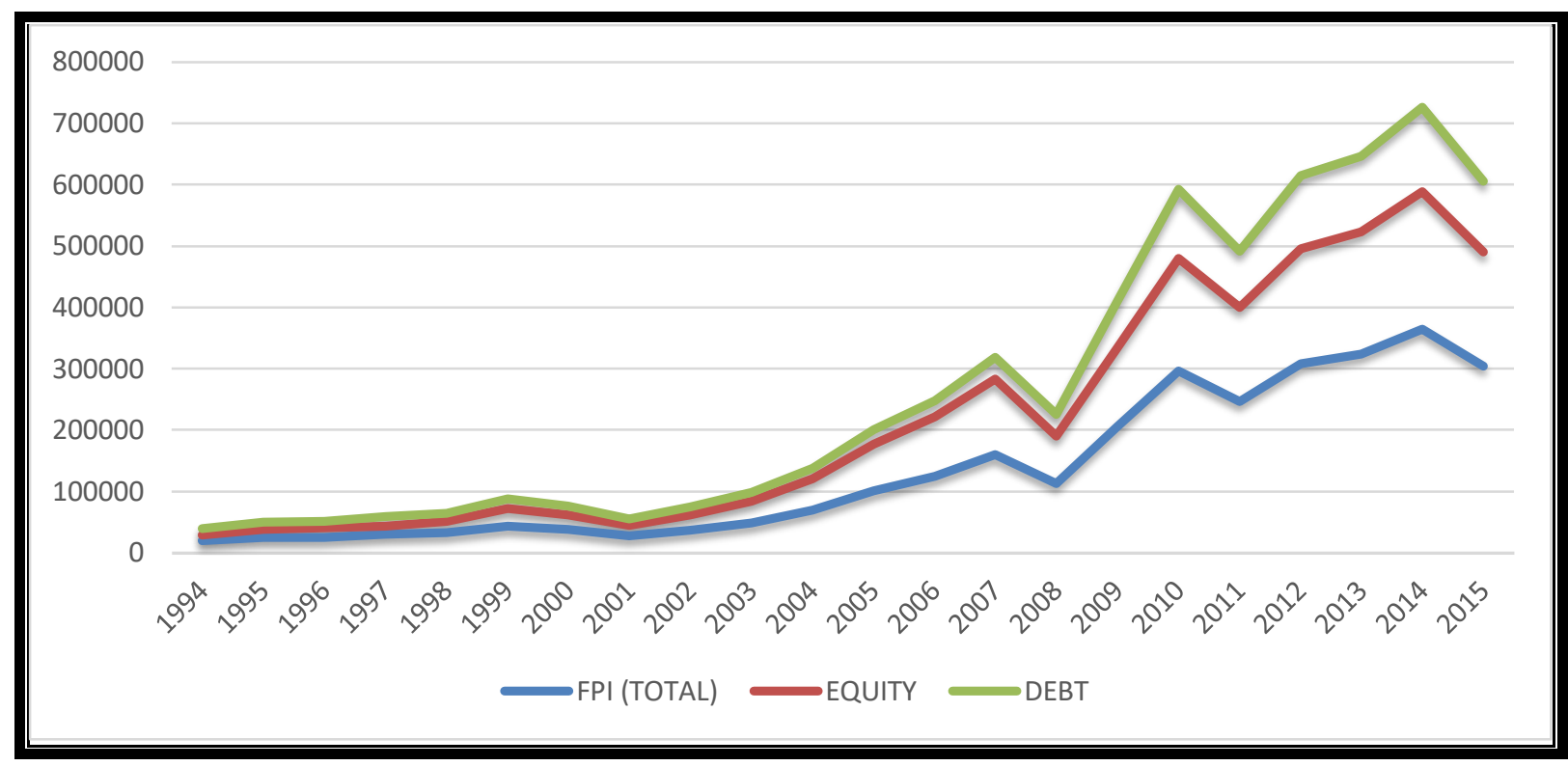

Figure 2.4: Total of FPI, equity, and debt flow into African countries 1994-2015 (US\$ millions)

Source: IMF, Balance of Payments and International Investment Position, 1994-2015

\subsection{Driving forces of foreign investments in Africa}

UNCTAD (2016) reports that investment and technology are two primary variables of structural transformation, but investment rates in Africa are currently low relative to the investment requirements. Also, comparing investment rates with other regions in developing countries revealed that the rate of investments in Africa, compared to what is observed in other developing regions is incomparable (see Table 2.1). Boosting foreign investments is, therefore, of strategic importance in achieving the African developmental goal agenda. Turnovsky (2011) explains that capital accumulation is regarded as a vital determinant of an economy's long-run growth.

The concern about the attractiveness of foreign investment is not the responsibility of African countries or investee countries alone, but instead of other countries of the world that have any trade or investment relations with Africa. Schneidman and Signe (2019) report the support of initiatives of the United States of America (USA) in the area of market development in African countries. The report states that the USA will assist Africa to expand economic opportunities and to create stronger cooperation to increase technical assistance to foster education, to protect food security, advance peaceful conflict resolution and improve the quality of life. Implementation of these programmes will create an enabling investment environment and attract more foreign investors. 
Over the years, many African countries have introduced different policy measures that may attract foreign investment flows (Wall et al., 2019). These measures, according to the body, ranging from new investment policy, investment laws, international investment agreements, and dispute settlements. In 2017, UNCTAD published a report examining the role of the stock exchange in promoting economic growth and sustainable development. In the same year, BRICS came out with an outline of investment facilitation in priority areas. The policy envisaged promoting investment facilities, enhancing transparency and improving efficiency. The G.20, in their efforts to create a policy investment, drive endorsed cross-border investment guidelines that would guide the government in devising cross-border investments in 2016. Also, they provided general guidance for investment policymaking to foster an open, transparent and conducive global policy environment for investments. Furthermore, Mozambique and Brazil signed an agreement on an institutional framework, a thematic agenda for investment cooperation and facilitation in 2015.

Considering the importance of investment policies, 46 countries and economies, including African countries, initiated 96 different policy measures on investment liberalisation and facilitation of investments (UNCTAD, 2016). According to the report, African countries are among the most dynamic economies that liberalise and facilitate foreign investments. For example, the report explains that Zimbabwe allows foreign investors to own up to $49 \%$ of the shares of companies listed on the Zimbabwe stock exchange. On the other hand, Egypt amended her investment law through out-of-court settlement and more incentives for investing in a specific sector.

Similarly, Guinea introduced a new code of tax exemption and investment protection. In the case of Rwanda, a new investment code was enacted that includes additional tax incentives and protection in case of expropriation. South Africa adopted the Promotion and Protection of Investment Act. The Act confirms commitments to national treatment security of investments and transfer of funds that will create an enabling environment for foreign investments. Moreover, on the issue of business licensing procedures, the UNCTAD further explains that Angola enacted new legislation to reduce the administrative bottlenecks surrounding the adoption of legitimate investment. At the same time, Djibouti and Kenya established free trade zones to attract more foreign investments. In the same vein, China established Export Processing Zones (EPZ) in Zambia, Mauritius, and Egypt. These zones were set up to encourage the inflow of foreign investments in Africa.

All this can be achieved by investing more in public investments, which primarily consist of public infrastructures. Poor performance and inadequate public and institutional infrastructures reduce 
the incentives to attract foreign investors. Many African countries are taking care of these issues (Buys et al., 2010; Naude, 2009). Some African countries have adopted IFRS, which assume to serve as a driving force to foreign investments inflow, especially FPI.

In the same vein, the development of capital markets in Africa will also be a driving force in influencing foreign investments. Currently, the continent has 23 security exchanges, most of which are small due to a low level of market capitalisation and number of listed stocks. As of 2015, the African Securities Exchanges Association Annual Report reports that African countries have a total number of 26 stock exchanges that represent 1500 listed companies with an aggregate market of capitalisation of USD 1trillion. With this small African capital market, there are ongoing efforts to enhance the capital markets in Africa to enable more foreign equity investors.

Given this, the African Development Bank (AfDB) and ASEA signed a five-year memorandum of understanding $(\mathrm{MoU})$. The $\mathrm{MoU}$ is to enable the promotion of foreign capital inflow for economic growth in Africa. The focus of the MoU, in particular, is to influence more foreign investments in equity of listed companies. According to the reports, the partnership will facilitate various projects such as (i) financial markets infrastructure development; (ii) the introduction of new products in the market; (iii) improving market liquidity and market participation; (iv) information-sharing and capacity-building. The MoU is also essential to deliver the Bank's high five priorities: light up and power Africa; feed Africa; industrialise Africa; integrate Africa and improve the quality of life of Africans. All these efforts are aimed at achieving the Sustainable Development Goals (SDGs) for 2030 and to drive more foreign investments, to ensure the development of capital markets, and to attract more foreign investments, especially FPI (AfDB/ASEA, 2016). It is assumed that the improvement in the capital markets will facilitate the adoption of IFRS since it was developed for the needs of capital market participants.

Furthermore, in West Africa, the Bourse Regionale des Valeurs Mobilieres, the Ghana Stock Exchange, the Nigerian Stock Exchange, and the Sierra Leone Stock Exchange have initiated a move to harmonise rules and create a common platform (e.g., common currency) to enlarge the capital markets (Agyapong, 2014). These efforts of harmonisation of international accounting standards may encourage more companies to be listed on the stock exchanges. It serves as a driver to influence foreign investments in Africa. A functional capital market will support high-quality financial statements, which catalyses the adoption of IFRS (Ben-Othman \& Kossentini, 2015).

Several African countries have tried to overcome the perception of Africa being a hazardous 
location for foreign investments by addressing their regulatory policies framework that has adverse effects on foreign investment inflow, such as investor protection policies (UNCTAD, 2013:9293). For example, some countries' rating based on the protection of foreign investors in Africa, was below the average with the value of 0-10 compared to other regions in the world. Combined efforts related to investor protection and the quality of accounting standards (IFRS) may attract more foreign investors because of the assurance of their legal protection. Table 2.2 below explains this:

Table 2.2: Minority investor protection index in the region

\begin{tabular}{|c|c|}
\hline Region & Minority investor protection index (0-10) \\
\hline Sub-Saharan Africa & 4.3 \\
\hline South Asia & 5.3 \\
\hline OECD high income & 6.5 \\
\hline The Middle East \& North Africa & 4.5 \\
\hline Latin American \& Caribbean & 4.8 \\
\hline Europe \& Central Asia & 6.4 \\
\hline East Asia \&Pacific & 5.2 \\
\hline
\end{tabular}

Source: The World Bank Doing Business, June 2016

The OECD high-income region has the highest protection rate of investors with 6.5, while SubSaharan Africa has the least investor protection with 4.3. Likewise, the Middle East and North Africa, with a rate of 4.5, are also below average. Because of this, many foreign investors will shift their capital to where there is the most significant protection. Given this shows that more efforts are needed to influence foreign investments in Africa. Because of this, many African countries have decided to reduce various types of regulatory barriers that are relevant to foreign investment flows. Kenya, Nigeria, Tanzania, Uganda, Zambia, and Ghana, for example, expanded the scope of foreign investments by reducing some of the sectors that were barred to foreign investors. Similarly, they overhauled laws governing their sensitive sectors that are attractive to foreign investors to allow more foreign investments (UNCTAD, 2016:92-94).

The primary objective of the investment is to receive regular payments of interest or dividend and capital appreciation. The issue of controlling the capital invested, dividend, and interest policy have been a severe challenge to foreign investment flows. Therefore, different strategies have been put in place to allow the repatriation of profits and capital. Ndikumana and Boyce (2011) emphasise that African countries have shown the minimum restrictions on capital control on the 
repatriation of dividends and capital. This effort attracts more flow of foreign capital since investors are assured of getting their capital and returns without any restriction.

Recently, some African countries have been reviewing their policies to attract foreign investment of all kinds. East African countries such as Ethiopia have promoted the development of industrial systems on textiles, leather, agro-processing, and pharmaceuticals to attract foreign investments (AfDB/OECD/UNDP, 2017:44-68). Kenya is also taking the lead on investors' radar due to signing new business laws, e.g., the Companies Act, the Business Registration Service Act, the Insolvency Act, the Finance Act 2015, and the Special Economic Zones Act (AfDB/OBECD/UNDP, 2017:44:68). These policies intend to provide a series of incentives for foreign investors.

In West African countries, such as Ghana and Nigeria, Greenfield projects in oil, coal, and natural gas are also encouraged, and such investments have improved the economy tremendously. Also, Ghana witnessed more considerable investments in financial and business services (AfDB/OECD/UNDP, 2017:44-68). The various kinds of driven policies put into place by some African countries have resulted in improving the capital flow to Africa.

African countries have taken significant steps to make foreign investments more attractive, primarily by granting generous fiscal concessions to foreign investors. Such as tax holidays and tax rebates to international firms, income tax exemptions, investment allowance and exemptions from customs duty, and exemptions from duty and value-added tax. It was reported that Guinea, Kenya, Cote d'Ivoire, Senegal, Lesotho, Zambia, and Mozambique had used generous tax incentives to attract foreign investments. Besides, nearly all African countries had adopted the strategy of using various tax concessions and tax incentives to influence foreign investments because the approach is relevant to the promotion of foreign investment flow. For example, South African reports show that secured property rights and low domestic risk have influenced foreign capital flow (Forbes \& Warnock, 2010). Based on these discussions, it is assumed that if all the policies concerning the improvement in the flow of foreign investments are adequately implemented there is a tendency that it will invigorate the capital markets and enhance more flow of foreign investments. The next section will highlight the relevant theory of foreign portfolio investment. 


\subsection{The theoretical framework for FPI}

An extensive literature has identified two significant categories of the theory that underlying the surge in FPI inflows as a pull factor and push factor (Agenor, 1998; Calvo et al., 1996; Chuhan et al., 1998; Fernandez-Arias, 1996; Forbes \& Warnock, 2012; Fratzscher, 2012; Fuertes et al., 2016; Taylor \& Sarno, 1997). These theories investigate the effect of national (pull) and international (push) factors contributing to the variation of foreign capital inflow in Africa (Gossel \& Biekpe, 2017). Hasan (2004) elucidates that the motive of influencing the flow of foreign capital by any country will necessitate the essence of investigating factors that can enhance the flow of foreign investments. Pull-push theory aimed to provide the overarching determinants attracting foreign investments flow.

Consequently, the literature emphasises that any forms of foreign investments (i.e. FDI and FPI) attracting by either pull or push factors or both may be harmful to the host economy because of its impact on fiscal and monetary policy variables in influencing the real sector (Gossel \& Biekpe, 2017). Nevertheless, the major concerns of the researchers in international business and economics are the determinant factors of foreign investment flows, which is the focus of these theories (pull and push theories) that explained the direction of foreign investments flow. These theories are explained below.

\subsubsection{Pull factors}

The quest to attract foreign capital entails the investigation of its determinants (pull and push) that would influence the flow of foreign capital (Hasan, 2004). The pull factors reflect the local economic pressures that can influence the flow of capital into a country (Sarno et al., 2016). Pull factors refer to development in the national economy's prospects notably related to stabilisation in macroeconomic variables and structural reform credibility. The most important of these factors are market size, economic growth, trade openness, and macroeconomic variables, such as effective inflation stabilisation strategy. Thus, pull factors are internal to the host country, and they are internal to the economy, while push factors are external to the economies that receive the flow of foreign investments (Sarno et al., 2016; Tasdemir \& Ozmen, 2018). Researchers have identified the importance of pull factors in influencing FPI in developing economies (Garg \& Dua, 2014; Sarno et al., 2016). They emphasise that liberalisation such as privatisation of public enterprise and subsequent improvement in macroeconomic variables have improved the creditworthiness of developing economies in attracting flows of foreign investments. 
Basu and Srinivasan (2002:10-13) report that well-structured economic reform and stability in the political environment have contributed to the flows of foreign investments. Also, a country's level of education, level of corruption, taxation, bank efficiency, and government regulating quality are essential for foreign investments (Amiram, 2012; Gordon et al., 2012; Nnadi \& Soobaroyen, 2015). Pull factors are the internal economic forces that can influence the inflows of foreign capital into a country. These are fiscal policies (Kahn et al. 1993), trade openness (Bonga-Bonga \& Kinfack, 2019), creditworthiness (Bekaert, 1995), institutional quality (Kant, 2018; RodriguezPose \& Cols, 2017), market size, and macroeconomic variables. Other factors are the country's level of education, level of corruption, taxation, bank efficiency, and government regulatory quality (Nnadi \& Soobaroyen, 2015).

\subsubsection{Push factors}

The various studies on the determinants of foreign investment flow focused on the effect emanating from the push and pull factors (Gossel \& Biekpe, 2017). Push factors relate to external factors apart from other significant economic factors at the domestic level that can influence flows of foreign investments. Push factors refer to those factors that are exogenous to the investee country from the country that supplies the capital, mostly the advanced economy (Amaya \& Rowland, 2004). International economic pressures enable capital to be pushed to another economy (Sarno et al., 2016). These factors may be attributed to rising wealth in a particular country, a global policy that may influence flows of foreign capital and which may have an economic effect on all countries, new technology and improvement in means of communication, cyclical reduction in interest rates, international portfolio diversification, and stock market performance (Sarno et al., 2016). Besides, it refers to external shocks including specific regulatory changes in the world economy, e.g. the development of IFRS as a framework for the listed companies to prepare and present their financial statement, Similarly, advancements in the creditworthiness of an indebted nation may also play a significant role in capital flows (Calvo et al., 1996). Also, they argued that pull factors were relevant in the flow of foreign investments, most notably in 1990, but the major determinants are push factors.

Push factors dominate the pull factors because they explained more than eighty per cent variation of FPI flows (Sarno et al., 2016). This phenomenon holds for the majority of countries worldwide. Forces that have a bearing on foreign and economic globalisation are the primary determinants of FPI. Thus, countries' exposures to international issues appear to be more significant than domestic risks in influencing FPI flows. According to the IMF (2012), foreign forces are the primary 
determinants of FPI rather than local economic effects. Albuquerque et al. (2002) report that internal (pull) factors are not significantly relevant in influencing foreign investment flow.

\subsubsection{The push-pull factors dichotomy}

The push-pull dichotomy explicitly explained the significant drivers of capital flows. However, it has particular limitation such as contagion effects that is related to foreign investors behaviour which is difficult to distinguish, either pull or push or both in nature (Koepke, 2019). In another vein, the push-pull framework has been challenged by the researchers. They argued that it is inappropriate and misguided to investigate the developing and advanced economy growth separately. That the focus should be on differences between developing economy and advanced economy variables (i.e. interest rate differentials and growth differentials) because the economic effect of developing and advanced economy on foreign capital flows may differ significantly in magnitude (Ahmed \& Zlate, 2014; Herrmann \& Mihaljek, 2013). However, despite these limitations, the pull and push framework is still the foremost FPI theory that offers a comprehensive and analytical background in determining the inflow of foreign capital flow (Koepke, 2019). Thus, it means that they are the major key drivers of FPI.

\subsection{Overview of the literature on the determinants of FPI}

Before the discussion of the empirical evidence on the determinants of FPI, this sub-section reviews some literature on foreign capital flows. The economies across the globe have different economic and political policies, among others, that can influence the inflows of foreign investments, such as macroeconomic stabilisation and structural adjustments programme for economic sustainability. Given this, various determining factors that assumed to influence foreign investments have attracted a lot of recognition and attention in the literature.

Khayat (2016) explains that the Heckscher Ohlin model, which gives credit to foreign investments as part of international capital flows, includes it as an essential topic in the literature of economics. The author further explained that the study of the determining factors of foreign investments had been given serious attention due to its importance for the development of capital formation in the economy. Previous studies have examined the influence of many variables on foreign investment flows, such as economic growth rate, market size, government institutions, financial development, trade expenses, natural resources, human capital, exchange rate, inflation rate, infrastructure, corruption, education, etcetera (Khayat, 2016). Similarly, Calvo et al. (1996) explain that some of the pull factors also include creditworthiness of a country and improvement in fiscal and monetary 
policies. On the other hand, Asiedu (2002) opines that weak policy formulation and implementation, coupled with the policy on restrictions in the trade may hinder the flow of foreign investments.

Lo-Duca (2012) believes that foreign investment inflow and outflow are significant to economic development. The study further emphasised that capital inflows depend on the cost of transactions, information asymmetry, the size of the capital markets, and the growth rate of the gross domestic products (GDP). Governments will embrace any policy that will reduce the cost of investments and information asymmetry. Ahmad et al. (2016) explain that GDP growth rate, market size, market efficiency, and higher expected returns influence the movement of FPI. They add that if all variables, as mentioned above, are stable over the years, there is a tendency for stability in the economy, and foreign investment inflows may be increased.

Waqas et al. (2015) report that macroeconomic variables of the investee country mainly influence FPI inflows. They further explained that macroeconomic variables affect volatility in FPI and that a country with stable macroeconomic variables will likely witness more foreign investments, especially FPI. AyodeleFolorunso et al. (2019) explain that developing counties, including African countries, would need more flows of FPI to bridge the gap between savings and foreign exchange and to solve the prevailing insufficiency of foreign capital in Africa that hinders the progress of economic development. In recent times, primarily, due to advancement in technology, FPI has been one of the most important foreign investment types in many countries (Haider et al., 2016). Aziz et al. (2015) report that FPI is useful in obtaining higher investment returns and a reasonable decrease in investment risk because of its dynamic nature of international investment diversification. Ahmad et al. (2015) report that economic growth sustainability will influence FPI and aid international investment diversification.

Furthermore, different studies also explain that push factors reflect the international economic forces that push capital flow from one country to another country. For example, Calvo et al. (1996) and Fernandez-Aries (1996) explain that changes in international interest rates and economic growth are push factors that can influence foreign investments. Also, Sarno et al. (2016) emphasise that low-interest rates, low potential growth, weak global risk aversion, and international portfolio diversification constitute push factors. Koepke (2019) explain that push factors are more relevant to FPI (debt and equity) because the increase in international risk aversion adversely affects FPI investors which necessitate the movement of capital from one economy to another. 
Gossel and Biekpe (2015) opine that push factors influence foreign investment in the short-run and long-run rather than domestic factors. Sarno et al. (2016) emphasise that each of the factors of pull and push that influence the direction of FPI inflows seems to vary among the countries. Thus, the debate on the relevance importance of these theories as determinant factors that influence FPI is still on among the international business and economists' researchers. It believes that the introduction of mandatory global accounting standards can be seen as one of the global economic forces that push foreign investments from one country to adopting IFRS countries.

Generally, this thesis is highly related to a more recent global policy on accounting standards introduced in 2005, when the IASB developed IFRS as accounting standards framework for all the listed firms globally in preparing their financial statements. The view is to make the financial statement more transparent and comparable internationally to influence foreign investments. However, reflecting on the pull and push factors, aforementioned, it was discovered that no attention has gone to the accounting standards as one of the significant factors that can additionally influence inflows of foreign investments especially, FPI inflows in African countries (Gordon et al., 2012; Nnadi \& Soobaroyen, 2015).

It shows that previous studies that examined factors that can influence foreign investments failed to include accounting standards in their formulated models, especially before the development of IFRS. Consequently, to add to the existing literature on the identified traditional determining factors of foreign investments, the feasibility of accounting standards (i.e. IFRS) is one of the factors that are supplemented by the current conventional factors (pull and push) for this thesis. Hence, it would show how significance is IFRS adoption in influencing FPI.

\subsection{Empirical review on determinants of FPI}

This section reviews empirical evidence on the determinant factors of foreign investments. Empirical evidence on foreign investments evaluates the effects of the determinant factors (pull and push) on capital flow. The importance of internal and external factors as determinant of foreign capital flows has been a significant discussion among the researchers in international business and economics. Large numbers of studies have empirically examined the nexus between foreign investments and their possible determinants. The empirical findings from these studies were inconsistent and mismatch, which might due to different emphasis by the researchers, the methodology adopted, and the environment where the research was carried out. 
However, most of the empirical evidence on the determinants of foreign investment focus on FDI. According to the literature, they employed the Dunning eclectic paradigm that appears to be the most comprehensive background that highlights FDI determinants factors of foreign direct investment in terms of ownership, location, and internationalisation (OLI-paradigm) Ramasamy \& Yeung 2010). This paradigm was developed from the research work of Dunning $(1980 ; 2001 \&$ 2006). Based on the work of Dunning, the types of FDI have been categorised into four components: market-seeking, resource-seeking, efficiency-seeking, and strategic reasons (Ramasamy \& Yeung, 2010).

Consequently, many researchers were guided in their empirical studies by these stimuli to describe the determinant factors that influence FDI in Africa (Anyanwu \& Erhijakpor, 2004; Asiedu, 2006; Asiamah et al., 2019; Bissoon, 2011; Jaiblai \& Shenai, 2019; Kahai, 2004; Okafor, 2012; Udah \& Ayara, 2012). Their empirical findings showed that variables that depict these motivations factors, such as, inflation, gross domestic product (GDP), exchange rates, openness, infrastructure, market size, and human capital are the foremost or classical factors that determine FDI. Furthermore, Sichel and Kinyondo (2012) examine factors that influence flows of FDI among 45 African countries between 1980 and 2009. The findings indicate that macroeconomic variables such as GDP growth, trade openness, and natural resources are factors that determine the flow of FDI in these countries. Also, Mijiyawa (2015) investigates the determinant factors of FDI in 53 African countries between 1970 and 2009, employing GMM model estimator. The findings show that trade openness, political stability, infrastructure, market size, and per capital GDP are factors that positively determine the flow of FDI in these countries.

Most recently, Milner (2019) examines the determinant factors of FDI into Sub-Saharan African countries before and after the global financial crisis employed the multiple linear regression analysis to determine the relationship between FDI, trade openness, institutional quality, and infrastructure investment. The findings reveal that trade openness was a determinant factor of FDI before and after the global financial crisis, and institutional quality determines the flow of FDI after the crisis. At the same time, low infrastructure investment was a determinant factor in both periods. In another study, Dondashe and Phiri (2018) examine the macroeconomic determinants of FDI for the South African economy using data collected between 1994 and 2016 on per capita GDP, the inflation rate, government size, real interest rate, and terms of trade. The ARDL model for cointegration was used for the statistical estimation. The findings reveal that all the estimated 
variables, apart from the rate of inflation, are positively and significantly determine the flow of FDI in the South African economy.

Nearly all the existing work on the determinant factors that influence the flow of foreign investments in emerging and developing countries mainly focuses on FDI, while the determinant factors of FPI were given a less concern (Humanicki et al., 2013). The literature reveals that some researches focussed on pull factors, while others emphasise push factors and in some cases, both pull and push factors were given as consideration for the determinants of FPI. For instance, Dua and Garg (2013) investigate the determinants of FPI flows to the emerging economy, using India as a case study, between 1995-2011 employing autoregressive-distributed lag (ARDL). The results suggested that strong economic growth, lower exchange rate volatility, and making the domestic financial market less vulnerable to shocks are the major determinants factors of FPI inflows to an emerging economy.

In another empirical study, Ahmed and Zlate (2014) examine capital flows to emerging market economics: a brave new world between 2002-2013 in 12-country, using static panel data by means of fixed effect. The findings show that growth and interest rate differential between emerging economies and advanced economies are statistically and economically important determinants of the flow of foreign capital. Similarly, Ramírez and González (2017) investigate the empirical analysis of the drivers of international capital flows to emerging economies in the post-crisis period using the pull versus push framework in 15 emerging economies employing a panel data analysis. The results indicate that external factors remain the main determinant of capital flows. Belke and Volz (2019) investigate the empirical significance of push and pull factors of different types of capital flows (FDI, FPI, and loan) in 32 emerging markets and developing economies from 20092017, employing time-series panel dataset. The findings show that global liquidity, economic policy uncertainty, and yield spread are the most identifying significant drivers of FPI flows; they are also relevant to other categories of capital inflows.

Furthermore, in the study of Agarwal (1997), foreign portfolio investment in some developing countries: a study of determinants and macroeconomic impact, in 6-country between 1986-1993, examines the impact of some determinants variables, such as inflation rate, real exchange rate, index of economic activity, and domestic capital market using multiple regression analysis. Findings indicate that inflation has a significant negative impact and real exchange rate, index of economic freedom, domestic capital market are having a significant positive impact on foreign capital flows. 
Singhania and Saini (2018) investigate the determinants of FPI in developed and developing counties with a sample of 19 developed and developing countries for a period of 10-year (20042013) using fixed and random effects as well as generalised method of moments. The results found out that interest rate differential, trade openness, host country stock market performance, and US stock market returns are significant factors that influence flows of FPI in developed and in developing counties. In addition to these variables, it was discovered that the freedom index variable also influences FPI in developing countries.

Arias-Rodríguez et al. (2016) estimate a model for gross capital flows taking samples from developing economies and assess their long-term determinants by using a panel co-integration technique. Results show that there is a co-integration link between significant push and pull factors and gross capital flows. For example, the results indicate a positive link between FDI and GDP growth and a negative association with public debt. In the case of FPI, it has a positive association with international financial market volatility. This emphasises the mobility nature of FPI. In the study of Rodríguez-Pose and Cols (2017) on the role of institutional governance as a determinant of foreign investments in 22 sub-Saharan Africa using a panel data regression model. The findings show that factors such as a lower level of corruption, government effectiveness, voice and accountability, and the rule of law are more relevant to influence foreign investments in subSaharan Africa.

Aziz et al. (2015) examine the impact of the determinants of FPI in Pakistan between 2005 and 2014 using OLS regression model to determine among the estimated variables (foreign exchange rate, trade degree of openness, inflation rate, the growth rate of real GDP, and market capitalisation. The results indicate that trade degree of openness, the growth rate of real GDP, and market capitalisation are the major significant factors the drive FPI inflows. In another study, Ekeocha et al. (2012) modelling the long-run determinants of FPI by considering the market capitalisation, real exchange rate, real interest rate, real gross domestic product, and trade openness between 1981-2010 in Nigeria, using time series analysis particularly the finite distributed lag model. The findings show a positive long-run association between FPI and market capitalisation and trade openness.

Nielsen and Bjornskov (2012) examine determinant factors of FPI inflows in 29 sub-Saharan African countries between 1996-2010 employing the panel data regression analysis. The findings reveal that the regulatory quality, control of corruption, financial market openness, size of the market, and infrastructure are the primary positive and significant factors that drive FPI into the 
sub-Saharan African region. In another vein, Funke et al. (2005) examine the factors in support of capital inflows in developing economies comprising of 12 Asian countries, 42 African countries, 20 countries in the Western Hemisphere, and 7 other countries, making a total of 81 countries between 1975-2002. GMM regression estimator was applied as a statistical analysis technique. The results show that higher economic growth rates and better institutions are positively related to FPI inflows in these counties. Alderighi et al. (2018) investigate the determinants of cross-border portfolio equity flows in emerging markets between 2006 and 2018. The study examines whether push and pull factors, as well as explicit and implicit barriers to investment, corporate governance standards, and market structure features influence cross-border equity inflows. The findings show that pull factors have more influence than push factor in determining cross-border equity flows in an emerging market.

The existing empirical literature examined above, on the possible factors that determine the inflows of foreign investments, has failed to reach a consensus concerning the specific factors that can influence the flow of foreign capital. It means that a satisfactory and consistent framework for the determinant of foreign capital flow has not been identified in the literature. This evidence supports the view of Ajayi (2006) and Asiedu (2006) that there is no particular factor that may influence foreign investments in a country because of the fundamental inequalities that characterise each country or region. However, the adoption of IFRS is considered to be a significant contributor of foreign investments worldwide since the aims of IFRS are presumed to be similar across the globe (Gordon et al., 2012; Ng, 2015; Nnadi \& Soobaroyen, 2015). In any way, despite the substantial empirical evidence on the determinant factors of foreign capital, the most robust gap relates to accounting standards (i.e. IFRS) as a factor that can drive foreign investments, especially, FPI. Hence, this thesis intends to empirically fill this gap in the literature by examining the nexus between IFRS adoption and FPI in Africa. The next section discusses some of these factors.

\subsection{Potential determinant factors of foreign investments in Africa}

Based on the aforementioned, this section discusses a set of variables that are assumed to be the most possible determinants of foreign portfolio investment flows in Africa, as identified in the literature review and empirical study. These variables are defined and discussed in the following section. 


\subsubsection{International Financial Reporting Standards (IFRS)}

Vo et al. (2017) opine that capital flows are not specifically motivated by the receiving countries pull factors only, but also by other international factors. Thus, according to Taylor and Sarno (1997), both domestic and global factors drive capital flows to other economies, particularly the equity and debt capital flows. Importantly, based on the usefulness of financial reporting to FPI investors, this research emphasises that FPI flows are driven by the global push factors, such as IFRS.

IFRS is assumed to be an international pressure that affects all countries by improving financial statement to encourage flows of FPI. Adopting the IFRS means that financial statement prepared following the unified global accounting standard framework will be more reliable to make it more transparent and comparable globally. Thus, bringing more capital inflows into adopting IFRS countries (McCreevy, 2005; Tweedie, 2006). Because of this, IFRS seems to be a global policy that is common to many countries, and that it will be a form of push factor.

Additionally, the adoption of IFRS is seen as a crucial effort driving foreign investments, especially FPI (Gordon et al., 2012). They further emphasised that a robust accounting regulatory framework will be essential for economic development. Deegan (2010:21) reports that highquality accounting reports will be useful to influence international investment, such as equity investors and lenders, among others. In another study, Tarca (2012:1-17) reports that IFRS adoption will enhance cross-border investments in Africa. These views seem to be possible since the objectives of the adoption of IFRS are similar across the globe.

Nevertheless, only 17 African countries, out of 54 sovereign's nation of Africa have permitted their listed companies to use IFRS as a standard accounting framework to prepare their financial statements (Ball, 2016). Obviously, due to the benefits of IFRS adoption in terms of making the financial statements comparable, transparent, reducing the degree of asymmetry, and the cost of capital, it is assumed that it will attract foreign investments (Nnadi \& Soobaroyen, 2015). It can be argued that most of the factors embraced in the pull-push framework as the determinant of FPI inflows concentrated more on macroeconomic variables, institutional factors, infrastructure efficiency, among others. However, the adoption of IFRS, which is assumed to influence inflow of FPI, significantly has received less research attention in the literature. Consequently, the inconsistencies in the theoretical and empirical findings on pull and push factors necessitate the shift in the literature to focus on the contextual globalisation issue, such as the adoption of IFRS 
as a determinant of foreign capital. This gap in the literature, therefore, calls for investigation of the effect of IFRS adoption on FPI to determine the explanatory power of accounting standards in influencing foreign investments.

\subsubsection{Capital markets development}

Schellhase and Woodsome (2017) explain that the financial system in any country serves as a significant pillar for viable economic development, and capital markets are a central component of efficient financial markets. The literature has reported a positive relationship between the financial sector and economic growth. Ruiz (2018) explains that there is a positive, first-order relationship between financial development and economic growth. According to Adebowale and Lawson (2018) and Zhuang et al. (2009), there is a consensus that capital market development plays a positive and significant role in facilitating foreign capital for economic growth. Shandu et al. (2013) emphasise that capital markets are essential for the provision of long-term capital and in driving a country's economic growth.

African countries lack adequate access to capital, suggesting that more attention should be given to various policies to improve the capital markets so that it can attract more FPI (World Bank, 2014). The market capitalisation of listed companies in Africa has grown over the last few decades but has not outgrown the other regions of the world. The World Bank explains that from \$295bn in 2003, the total market capitalisation has reached a reasonable figure of $\$ 732$ billion in 2013. Furthermore, South Africa's Johannesburg Stock Exchange (JSE) accounted for a significant percentage of total market capitalisation, followed by the Nigerian Stock Exchange and the Nairobi Securities Exchange with \$123, \$56b and \$15 billion respectively. In the case of Latin America, the report shows that capital markets grew from $\$ 450$ billion in 2003 to $\$ 2,217$ billion in 2012, which is far more. In another developing economy, South East Asia, the market capitalisation of listed companies grew from 2003 to 2012 from $\$ 597$ billion to $\$ 1967$ billion. The report emphasised that African countries are far behind other regions with a high level of market capitalisation, which might be due to insufficient inflows of foreign investments into the region.

Despite the low level of market capitalisation, Africa's equity market is recognised among the indices used by investors and portfolio managers to measure performance (Schellhase \& Woodsome, 2017). Ezeaku et al. (2018) emphasise that equity investors are interested in capital markets that are performing. They postulate that a well-developed capital market has high volumes of trade and higher market capitalisation to assist investors in making decisions as to the liquidity 
and size of the market. Thus, it can be argued that countries that allow their listed companies to use the IFRS framework in preparing financial statements are assumed to experience more development in the capital market and be more attractive to foreign investors.

Kimeli (2017) reports that IFRS adoption will make financial statements more transparent and comparable with other financial statements worldwide and will encourage more participation in the capital markets. The existence of the virile capital market is essential in attracting foreign investments. Opare et al. (2019) also emphasise that with the adoption of IFRS, financial statements will be more transparent and comparable with high-quality accounting disclosure. All these attributes are essential in increasing global capital markets and influencing foreign investment flows. Furthermore, the adoption of IFRS will improve capital market liquidity (Kimeli, 2012). These situations will create more confidence for foreign investors in the capital markets. The existence of virile capital will improve foreign investments and have a positive effect on FPI. Bruggemann (2011:45-82) confirms that IFRS adoption encourages equity investments from foreign investors. Market capitalisation is used in this study to measure the presence of the capital market in each African country.

\subsubsection{Macroeconomic variables}

It is a common belief that foreign investment inflows play a crucial role in the economic development of any nation, particularly in less developed countries that have a dearth of capital for developmental purposes (Pala \& Orgun, 2015). Adequate inflows of foreign capital can help regulate the balance of payments and international trade deficit if the macroeconomic variables are highly efficient. Because of this, many countries worldwide liberalise their domestic economies to attract more inflows of foreign investment. UNCTAD (2013) explains that most countries adopted policies on investments that focus on foreign investment promotion and financial liberalisation.

Many countries experienced a rise in foreign capital flows in terms of financial integration before the financial crisis of 2008. This crisis led to a decline in FPI due to the weakness of macroeconomic variables (Pala \& Orgun, 2015). Unstable macroeconomic variables with a high incidence of currency crashes, high rates of inflation, and budget deficits keep African countries from attracting FPI (James et al., 2014). Lower foreign capital flows are related to weak macroeconomic and financial conditions in many economies. Garg et al. (2014) report a positive relationship between domestic output growth, the exchange rate, and portfolio investment. Kinda 
(2013) explains that there is a positive and significant relationship between inflation, interest rates, financial structure and development, and FPI. Gumus et al. (2013) explain that many macroeconomic variables can attract FPI to financial markets, such as interest rates, exchange rates, inflation rates, economic growth rate, tax rates, country risk, trade openness, and transaction costs. Governments worldwide focus on these and other factors to maintain stability in the economy. For this study, the rate of inflation, interest rates, exchange rates, and the economic growth rate are used as a proxy for macroeconomic variables.

\subsubsection{Inflation rate}

Inflation in an economy causes a persistent rise in the cost of production (capital, for example), and this is a threat to foreign investors because of the adverse effects it will have on their returns from the investment (Gumus et al., 2013). A higher rate of inflation means that there is economic instability in such a country (Nnadi \& Soobaroyen, 2014). Investors may be discouraged in investing in an economy where the interest rates are high. Amaya and Rowland (2003) emphasise that a stable macroeconomic condition in a country shows that such a country will have a low and stable inflation rate, and this will encourage foreign investors to invest in such an economy. Onyeiwu and Shrestha (2004) emphasise that most African countries with high rates of inflation will attract less foreign investments. Therefore, a high percentage of inflation will have a negative impact on FPI. Kimeli (2017) as well as Li and Shroff (2010) state that with the adoption of IFRS, the cost of capital will be reduced due to more transparency in the financial reporting and improved capital efficiency, which will attract more foreign investors. Consequently, it is assumed that capital reduction can only be achieved in an economy that has a stable inflation rate.

\subsubsection{Interest rate}

Obansa et al. (2013) affirm that the interest rate is the return or yield on investment, especially investment with an accounting rate of return, or opportunity cost of postponed present consumption. Jhingan (2003) defines interest rate as the price equivalent to the supply of credit, in addition to the net increase in the amount of money at the particular time of the demand for investment, plus net hoarding in the period. However, interest rates are charged as compensation for the exposure to inflation because inflation gives the current amount less purchasing power shortly (Jelilov, 2016). The interest rate plays a crucial role in the allocation of scarce economic resources, which in turn influences the growth and economic development of a country. It serves as a motivation for deposit mobilisation and credit creation for economic development. 
The interest rate differential (IRD) between the host and the source country can also determine the magnitude of the inflow of FPI (Garg \& Dua, 2014). Investors invest their capital in an economy after adjustments have been made for the risk, and the returns are reasonably high. According to Gumus et al. (2013) and Sur et al. (2019), FPI inflows are sensitive to the interest rates differential. Capital flows to a country with a high-interest rate because of the differences between the real interest rate (based on inflation) differential in the international markets. IRD is a differential measuring the gap in interest rates between two similar interest-bearing assets. Onuorah and Nnenna (2013) and Pala and Orgun (2015) report that the interest rate has a positive impact on foreign investments. Thus, the interest rate is one of the variables that can attract FPI in Africa due to the real interest rate differential in international markets. A high real rate of interest will attract more FPI, especially portfolio investors (Culha, 2006; Gupta \& Gordon, 2003; Waqas et al., 2015).

Portfolio investors will also take into consideration the host country's exchange rate and the interest rate because if the host country's exchange rate is devalued, it will be more profitable for foreign investors to invest in such an economy (Bleaney \& Greenaway, 2001). The volatility in the real exchange rate will have a direct correlation with foreign investment. Moreover, Hymer (1976) explains that international portfolio investors will be attracted by the high real interest rate in the sense that it will reduce the borrowing costs. They continue to invest until the actual rate of interest is equal throughout the world after considering the embedded investment risks. Thus, a high real rate of interest will attract more flows of FPI. In this study, interest rate proxied with the real rate of interest differential.

\subsubsection{Exchange rate}

Exchange rate instability is another factor determining flow of foreign capital flows. Highly effective exchange rate policies send a strong positive signal to foreign investors considering investment decisions, especially when it comes to how the policy will affect the repatriation of their returns and capital (Rodriguez-Pose \& Cols, 2017). Sudden and unexpected volatility or fluctuations in the exchange rate will affect foreign investors because it is an important indicator to consider in terms of predicting the profitability of their investment capital (Gumus et al., 2013). Thus, it shows that instability in the rate of an exchange over time will cause disequilibrium in the market, and it will affect economic growth and cause an obstacle to foreign investors.

Brink and Viviers (2003:225) state that due to the fluctuation, the allocation of resources will be affected because the volatility will influence foreign investment capital. The exchange rate reflects 
a significant relationship with FPI because when it appreciates, it shows a speculative opportunity for investors, and they like to invest and diversify their investment in the form of FPI (Ahmad et al., 2015). In another study, exchange rate fluctuation is mentioned as an essential risk factor that will affect the portfolio investor's investment decisions and cause uncertainty in their returns (Ncube et al., 2012:22). Furthermore, if the investors observe that the risk of volatility of the exchange rate is high, they will expect a higher rate of return to compensate them for the high rate of risk (Gumus et al., 2013).

There are different opinions concerning the implications of the exchange rate for capital flows. The study of Kyereboah-Coleman and Agyire-Tettey (2008) state that the exchange rate will have a negative effect on foreign capital flows. In another opinion, Jeon and Rhee (2008) emphasise that there is a positive effect on international capital flows, while Brahmasrene and Jiranyakul (2001:13) find that there is no evidence for a positive or negative impact on foreign capital flows, only real income plays an important role. Suliman (2005) explains that the depreciation of the real exchange rate attracts foreign investment to African countries, while real exchange rate volatility causes greater instability in foreign investment in a country. They also emphasised that the real exchange rate influences foreign investment inflow. Thus, the exchange rate is one of the factors examined in the literature as a determinant factor for foreign capital flow. It also formed part of the control variables considered in this study, but the different opinions about its effect on FPI may limit the findings of this thesis.

\subsubsection{Economic growth}

Economic growth is one of the primary pull factors influencing FPI into a particular country (Sarno et al., 2016). Economic growth causes significant changes in portfolio investment. Countries that have a sustained growth rate and a low level of inflation should attract more flows than other economies since portfolio investors will have more confidence in such a market (Amaya \& Rowland, 2003). A rapid growth in rates indicates that the economy is expanding, and portfolio investors will earn higher returns on the capital invested.

The African Economic Outlook (2017:44-68) reports that the African growth rate in 2016 was less than in 2015. It was down from 3.4\% in 2015 to 2.6\% in 2016. Since 2013 the trend has significantly decreased. In 2013 it was $3.9 \%$, and it fell to $2.2 \%$ in 2016 . It is a wrong signal to foreign investors and creates a lack of confidence in the African economic system. The reasons for this deterioration was the slow rate of growth of the dominant partner, lousy weather and 
drought in some African countries, a fall in the commodity prices and sluggish and fragile economic recovery in advanced economies. Despite this poor performance over the years, there is an expectation that the growth will improve due to more effective policies on macroeconomic governance (African Economic Outlook, 2017:44-68).

Waqas et al. (2015) say that FPI mainly depends on the macroeconomic variables of the host countries, and if these factors are stable in a country (especially the growth rate), there is a tendency that they will expect more flows of FPI. Stability in the economic policies of a government will attract more foreign capital, improve the economic prosperity and better the economic conditions of the people.

\subsubsection{Market openness or foreign operations}

Rodriguez-Pose and Cols (2017) explain that market openness will facilitate trade with the other parts of the world, especially when an investor is seeking to export their products to or invest their capital in another country. Market openness considers the relation between host countries and other parts of the world. It is the belief that open economies will attract more FPI inflows than a country that is more protected (Amaya \& Rowland, 2004). Another study explains that it would be convenient for the investors to move capital in and out of a country with market openness (Chakrabaiti, 2000:91-92). Thus, a country with stringent control of capital and restrictive trade policies will not encourage inflows of foreign capital.

Most of the African countries have recently liberalised their domestic economy by removing the stringent conditions that may hinder the free flow of foreign capital (UNCTAD, 2016). Gumus et al. (2013) emphasise that it may be challenging to invest in some capital markets around the world because the barriers placed in the entry may be more complicated due to government policies. This situation may drive away foreign investors who are looking for a friendlier investment environment to invest their money. Bartels et al. (2014) and Buckley et al. (2013) explain that an open-door policy to foreign investors will influence foreign investments in the host country. Countries with less stringent international policies concerning economic transactions will experience more flows of foreign investments. Thus, it is measured by deflating the total of imports and export with the value of GDP. 


\subsubsection{Regulatory quality}

Kaufman et al. (2008) emphasise that regulatory quality is one of the indicators used to measure good governance in a particular country. It measures the ability and capacity of the government to formulate and implement sustainable policies that will facilitate and enhance the development of the private sector in a country (Rodriguez-Pose \& Cols, 2017). It serves as an excellent signal for foreign investors to believe that their investments are well protected. Frequent changes in the policies of the government in a country will discourage foreign investors. The indicator is measured in units from -2.5 to 2.5 points. The higher values indicate that the government is consistently formulating and implementing sound policies that will promote private sector development and enhance a friendly investment environment.

\subsubsection{Corruption}

The significance of institutional structure is assessed by looking at the interaction of control of corruption with the primary explanatory variable. Efobi et al. (2014) and Chen et al. (2014) explain that a country would benefit more from IFRS adoption if the institutional framework is developed. Dunning (2005) posits that institutional structure should be an essential variable in foreign investment research because it determines the investment environment of a country. Control of corruption is another indicator for measuring good governance. Countries that have better systems to fight corruption can influence FPI (Rodriguez-Pose \& Cols, 2017). The perception of investors is that the level of corruption in a country will remain stable, and once there is any significant negative variation in the level, the investor will consider the country too risky to invest their money. Control of corruption indicates the extent to which the public sector is used for private ends. A high level of corruption will be a deterrent to inflows of FPI (Dupasquier \& Osakwe, 2006).

Bardham (1997) explains that corruption has existed for a long time in different forms, to varying extents, and with different consequences. Corruption is a very complicated situation with diverse causes and effects depending on how different disciplines perceive it. Sociologists, legal scientists, and political scientists have different opinions about the issue of corruption, but in general, they believe that it is a situation where the government is not transparent, there is a lack of independence and abuse of public power for personal gain. Economists view corruption as weak and nontransparent economic institutions and the abuse of public power for personal gains. Friedman et al. (2000: 462) "characterise corruption as any illegal activities that represent costs imposed on 
business by bureaucrats from which the government obtains no revenue and which do not generate any positive benefits for the society." This definition emphasises the misuse of office by public or private officers.

Azam and Ahamd (2013) explain that corruption is seen as an institutional factor that does not influence the excellent implementation of macroeconomic variables. Because of this, corruption will have a very significant impact on a country's financial markets and have an adverse effect on FPI (Jain et al., 2017). They explain further that asymmetric information and investor uncertainty are likely to be influenced by the degree of corruption, because increased information about gain from corruption will be hidden from the public markets and not disclosed, and this will discourage the investors and have a negative effect on FPI. Asymmetric information occurs where some market participants have undue information over other participants concerning returns and risk of the securities.

Esley and O'Hara (2004) reveal that public and private information affects returns from the securities, and investors will demand higher yields to hold stocks due to private information. Therefore, the high level of corruption in a country will increase the cost of transactions and reduces the inflow of foreign investment. Investors will move their capital to an economy where the level of corruption is minimal, with a low level of the transaction cost. Stenzel and Wagner (2014) report that opacity (that may be caused by corruption) existing in financial markets will lead to higher trading costs and decreased portfolio investment.

The CPI (2015) rates countries on the level of corruption of their public officers to promote accountability, transparency, and integrity. Presently, Transparency International ranks more than 100 countries globally. They rank countries from ' 0 ' to ' 10 ', where larger values indicate a less corrupt country. CPI 2015 shows that 40 countries out of 46 that were covered in a survey in 2015 had high levels of corruption, indicating that that $87 \%$ of African countries covered by CPI in 2015 had a high rate of corruption. The high degree of corruption in Africa may deter the inflow of foreign investments and can lead to a reduction of FPI. Due to the importance of corruption, it was estimated in the model as one of the covariates.

\subsubsection{Taxation}

Bartram and Dufey (2001) say that taxes can be both an advantage and a disadvantage to portfolio investors. Tax rules and policies are not within the control of investors coming to a host country to invest since each country promulgates its laws relating to taxes. Individual countries determine 
the tax rates be paid on income derived from various investments, e.g., withholding tax rates on unearned income. This kind of tax may be interest from fixed investment, dividends from shares, capital gains, and royalties.

UNCTAD (2014) stresses that taxes have been powerful tools to attract FPI in developing countries through various tax strategies involving tax exemptions or a lower rate of tax relevant to the promotion of foreign investment. The nature of the tax policies of a country will influence foreign investors because tax plays a significant role in attracting portfolio investment, and investors will base their returns on after-tax investment returns (Gumus et al., 2013).

PwC Worldwide Tax Summaries report that is withholding tax on dividend, interest, and royalties ranging from $10 \%$ to $20 \%$ for investors non-resident in Africa. Mauritius and Madagascar charge $0 \%$ withholding tax on dividends, while Botswana charges $7.5 \%$. The report further shows that company income tax rates (CITR) range from $22 \%$ to $37 \%$ in Africa, while Mauritius charges only 7.5\%. The different rates charged by each country are bound to affect FPI inflows. Those who charge a higher rate should expect a lower inflow of portfolio investment. CITR was used as a variable to measure tax in this study.

Many studies (such as Anyanwu and Erhijakpor, 2004; Bissoon, 2011; Jaiblai and Shenai, 2019) have empirically examined some of these benchmarks factors, as mentioned earlier, determining factors that assumed to influence foreign capital. The aim is to provide the overarching determinants attracting foreign investments, but the findings from the literature were mixed and ambiguous. Jaiblai and Shenai (2019) argue that studies were unable to identify specific determinants of the flow of foreign capital into Africa. Ajayi (2006) and Asiedu (2006) emphasise that there is no particular factor that may influence foreign capital investments in a country due to the fundamental inequalities that characterise each country or region — indicating that the best theory or the specific determinants factors of foreign capital is yet to be achieved. There are reasons to believe that, according to the background of this thesis, the adoption of IFRS may be an additional variable that may influence foreign investments (DeFond et al., 2011 \& Gordon et al., 2012). Unfortunately, few studies have focused on the relationship between IFRS and foreign investments in Africa, especially FPI (Nnadi \& Soobaroyen, 2015).

\subsection{Summary of the chapter}

This chapter reviewed the relevant literature on the concept, the trend, the theoretical and empirical framework, and some of the potential relevant benchmark factors that were assumed to influence 
FPI. The chapter evidenced that the pattern of FPI in Africa was shallow compared to other regions in the world. This poor performance was attributed to the inability of the various studies to identify the specific determinants of the flow of foreign capital into Africa. Given this, many African countries (as discussed in the chapter) have embarked on various investment policies that would attract more flow of foreign capital, especially the investors in equity and debt capital. To achieve this, AfDB and ASEA have signed a memorandum of understanding to improve the capital market development in attracting FPI. It is hoped that the improvement of the capital market will accelerate the adoption of IFRS in Africa. The next chapter focuses on a review of the relevant literature on IFRS.

The worldwide adoption of IFRS over a decade ago was a new development in financial reporting. The hope was that the adoption of global accounting standards would bring economic benefits to adopting countries in terms of efficient cross-border investment transactions, enhancement of accounting reporting information, greater comparability of financial reporting, and a reduction in information asymmetries between investors. The inclusion of IFRS as a variable that can influence the inflows of FPI and reduce the problem of a lack of capital for economic development in African countries is essential. The second part of the literature review focuses on the extent to which the adoption of IFRS would influence the inflows of FPI in Africa. The literature review on IFRS includes definitions of accounting standards, objectives, and the conceptual framework of IFRS, the relevant accounting information theory, the empirical relationship between IFRS and FPI, and determinant factors of IFRS in Africa. 


\section{CHAPTER THREE: LITERATURE REVIEW: INTERNATIONAL FINANCIAL REPORTING STANDARDS (IFRS)}

\subsection{Introduction}

Chapter 2 examined the existing literature on various issues relating to foreign portfolio investments and its determining factors in Africa. This chapter reviews the current research on the effect of IFRS on FPI in Africa. Thus, the key objective of this chapter is to provide the missing link between IFRS and FPI in Africa that will stimulate the empirical investigation included in the study.

Bughin and Chui (2013) observe that current trends in the global economy and advances in technology have led to a growth in international financial transactions. The authors further highlight that these developments require financial reporting information that is more transparent and comparable (i.e., IFRS) to ensure the efficient allocation of resources. Before the event of IFRS by the IASB in 2001, listed companies presented their financial reporting information following national accounting standards that varied from country to country (Cairns et al., 2011). This procedure increased accounting diversity in the financial reporting of listed companies due to international differences in accounting practices. It made comparable financial reporting difficult and hindered the flow of foreign portfolio investments, especially in developing economies (Nobes \& Parker, 2008:25).

The development of IFRS as high-quality international accounting standards was prompted by the rapid growth in economic globalisation and an increase in global financial transactions, which require transparent and comparable financial reporting (Nobes \& Parker, 2008:102). These global economic developments made financial information prepared using national accounting standards irrelevant to the investment decisions of foreign investors. Given this, there was an increase in the recognition of IFRS as a single set of international accounting standards that would be more relevant and reliable for investment decisions. This chapter explores the existing literature on IFRS.

The chapter is organised into ten eight sections. The first section is the introduction that details this chapter aim to accomplish. Section 2 provides historical background on international accounting standards. It traced the history of accounting standards from the 1950s to 2005 when IFRS emerged as a single set of international accounting standards. 
The third section examines the concept of financial reporting and financial statements, while Section 4 focuses on the IASB Conceptual Framework. This framework defines a reporting entity, the users of accounting information, the objective of financial statements, their underlying assumptions and qualitative characteristics, the elements of financial statements, and their recognition and measurement.

Section 5 examines the universal application of IFRS as well as the status of adoption in African countries. In this section, the total number of IFRS jurisdictions worldwide and in African countries is reported. Section 6 focuses on the relevant accounting theories, while Section 7 discusses the overview of the literature on IFRS. The empirical relationship between IFRS and FPI was discussed in Section 8. Furthermore, factors that can influence the adoption of IFRS in African countries formed the focus of Section 9. Finally, Section 10 summarises the chapter and explains the focus of the next chapter, which considers the philosophical assumptions and the methodological approach of the study.

\subsection{Historical background of international accounting standards}

The convergence of international accounting standards is not a recent phenomenon in accounting history (Ortega, 2017). The move towards the convergence of international accounting standards started in the late 1950s. This effort was in response to post-World War II economic integration and improvement, with the associated growth in globalisation, the internalisation of economic activities worldwide, the increase in international capital market participants, and technological development. Besides, the Asian crisis of 1998, the liquidation of many global companies, including international accounting firms, and the increase in the growth of multinational companies necessitated advancement with the convergence of international accounting standards. In another development, Ball (2016) and Land and Lang (2002) report that the US, the UK, and Canada made efforts to develop international accounting standards to reduce variation in accounting standards worldwide.

Deegan (2010:112-126) believes that the continuous increase in the activities of multinational companies and the globalisation of capital markets also called for uniformity in financial accounting and financial reporting practices. The differences in accounting practices among countries affect the credibility of financial reporting. It consequently affects the efficient allocation of financial resources. HassabElnaby et al. (2003) stress that all these difficulties that occurred due to specific inevitable trends in the global economy, as well as the legal and political environment 
and different economic models, affect the confidence of the users of financial statements. They, therefore, called for improvement in accounting standards.

The International Accounting Standards Committee (IASC), the International Organisation of Securities Commissions (IOSC), and the European Union (EU) played a significant role in the effort to establish uniform international accounting standards. They realised the influence of all these global developments on accounting practices and their effects on cross-border investments. As a result, they promoted a single set of international accounting standards worldwide (Chasteen et al., 1992:17). Their focus was to improve the credibility of financial statements worldwide, especially for the benefit of investors and other users of financial statements. The significant events in the evolution of international accounting standards worldwide are discussed below.

During the 1950s and early 1960s, countries all over the world expressed the need for international accounting and auditing standards after the end of World War II. After the end of the war, there was an increase in economic incorporation across the world. These developments brought expansions in international trade and foreign investments, hence the need for a uniform global accounting system. Therefore, the $8^{\text {th }}$ International Congress of Accountants was held in 1962 to call for uniform international accounting and auditing standards (FASB/IASB, 2013).

The congress focused principally on the relevance of accounting in the world economy in general. Participants agreed that steps should be taken to develop accounting and auditing standards. To achieve this, the American Institute of Certified Public Accountants (AICPA) established a Committee on International Relations to create a developmental programme that would assist the committee in reaching an agreement on unified accounting standards (FASB/IASB, 2013). The programme focused on the development of cooperation and the exchange of information and ideas among international accountants. The report of the committee was published in 1964 with the title, Professional Accounting in 25 Countries (Kohler, 1965).

In 1966, the AICPA (US), the United Kingdom, and Canada formed a study group, the Accounting International Study Group (AISG), to compare the significant differences between the accounting standards. The study group reported 20 areas of variations in the accounting standards being used on three continents. Thus, it was the first international step for the establishment of accounting convergence.

In 1973, AICPA and eight other countries decided to transform the existing AISG into the IASC as the first international accounting standard-setting body. The IASC later became an independent 
international accounting standard-setter, namely the International Accounting Standards Board (IASB). Likewise, in 1979, the FASB collaborated with representatives from the UK Accounting Standards Board, the Accounting Standards Board of Canada, and the IASC. They were included in the task force to revise its accounting standards on foreign currency and to make the first effort of the FASB to collaborate with its counterparts to develop accounting standards (FASB/IASB, 2013).

In 1987, the number of accounting standards for various accounting problems issued by the IASC totalled 25. These standards passed through the same process as existing standards being used around the world. The IASC allowed for alternative treatments for the same transaction among those who were using the standards. They also embarked on comparability and improvement projects to reduce the number of alternatives allowed. In 1988, the FASB became a member of the IASC consultative group and continued to provide input on technical and other issues and to coordinate the US activities.

In 1988, the FASB supported the internationalisation of standards to influence foreign investments. It also focused more on international accounting activities to have a unified accounting system worldwide that could facilitate foreign investments. In 1990, the FASB developed a strategic plan for global operations to purposely expand collaborations among countries' accounting standardsetters that were not using IAS. Also, the US Congress and the Securities Exchange Commission were involved in the internalisation of accounting standards. They supported the idea of having a single set of high-quality international accounting standards.

In 1993, the G4 was formed comprising the US, the United Kingdom, Canada, and Australia. The group was later joined by New Zealand to make it G4+1. The purpose of the group was to find solutions to standard accounting and reporting issues. In achieving the objectives, they published eleven research reports on various accounting standards. Consequently, these reports assisted them in removing any differences between their accounting standards. The FASB staff also compared the IASC and US GAAP. The results of their studies resulted in the publication of the "IASC-US Comparison project: A report on the similarities and differences between IASC standards and U.S. GAAP."

The year 1995 witnessed the involvement of the International Organisation of Securities Commission (IOSC) in recommending the endorsement of IASC standards for foreign investments and listing purposes in all capital markets. Besides, in 1996, the US Congress stated that 
"establishing a high-quality, comprehensive set of generally accepted international accounting standards in cross-border securities offerings would facilitate international financing activities." The Securities Exchange Commission (SEC) also considered the acceptance of the IASC standards as a basis for accounting reports. Apart from the US Congress and the SEC considering unified accounting standards worldwide, the financial crises in some parts of the world in 1998 also prompted more calls from international organisations, such as the World Bank and the International Monetary Fund (IMF), for the rapid completion and global adoption of high-quality international accounting standards. Consequently, the FASB published a book in 1999 titled International accounting standards setting: A vision for the future. The book emphasises that the concept was to have an international financial reporting system that would represent a single set of high-quality accounting standards.

The SEC issued a concept of international accounting standards in the year 2000. The idea explained the condition under which the SEC would accept foreign financial statements using IAS. The situation then required the elimination of the reconciliation of foreign financial statements to US GAAP. In 2001, the IASC was reconstituted into the IASB for improvements in the governance, funding, and independence of the IASC. Also, the IASB was to be overseen by the Trustees of the IASC Foundation (IASCF).

The International Accounting Standards Committee Foundation (IASCF) has the primary responsibility of supervising the IASB in developing an accounting standards framework and principles for international corporate entities. The purpose of the IASB under the IASCF is as follows (Roberts et al., 2005:17):

\footnotetext{
"...to develop in the public interest, a single set of high quality, understandable, enforceable, and globally accepted financial reporting standards based upon clearly articulated principles. The standards should require high quality, transparent and comparable information in financial statements, and other financial reporting to help investors and other users of financial information make economic decisions, promote the uses and vigorous application of the standards, take account of the needs of a range of sizes and types of entities in diverse economic settings, and promote and facilitate the adoption of IFRS through the convergence of national accounting standards and IFRS."
}

The authority of the IASCF lies with the trustees, which comprises nineteen members (individuals): six from North America, six from Europe, four from Asia/Pacific, and the remaining three from other regions. Each member must be knowledgeable in finance and be dedicated to the IASB as a high-quality international accounting standard-setter. The trustees are responsible for 
fundraising, and they appoint the members of the IASB, the International Financial Reporting Interpretations Committee (IFRIC) and the Standards Advisory Council (SAC). The IFRIC came into existence in 2002 as a new version of the Standing Interpretation Committee (SIC). Their duties are to interpret the application of standards according to the IASB framework for public comments and to take cognisance of practice issues that have no bearing on IFRS practices. Furthermore, the SAC serves as an adviser to the IASB on matters to be acted upon and those issues that are more pertinent to its work that need immediate attention.

In 2002, a remarkable achievement in the history of international accounting worldwide was recorded. The year 2002 was the year the European Union (EU) required all listed companies to prepare their consolidated financial statements using IFRS as of 2005. Hence making the EU the first significant capital market to require IFRS. A memorandum of association was signed by the FASB and the IASB towards the convergence of US GAAP and IFRS to develop high-quality accounting standards for the needs of investors and to eliminate any further reconciliation with US GAAP by foreign private issuers of financial statements.

The goal of achieving a single set of accounting standards became a reality in 2001 . The year the IASB finally developed IFRS as a unique set of accounting standards for all listed companies when preparing their financial statements. The introduction of unified accounting systems was supported and endorsed by prominent internationally recognised economic and political bodies. The World Bank, the International Monetary Fund (IMF), the G8, the G7 Finance Ministers and Central Bank Governors, the International Organization of Securities Commissions (IOSCO), the Basel Committee on Banking Supervision, the United Nations (UN) and the Organization for Economic Cooperation and Development (OECD), the World Trade Organization, multinational companies and international accounting firms have publicly recommended the adoption of a single set of global accounting standards (Saidi, 2013).

The popularity of IFRS in the last few years has grown tremendously and has become the global financial reporting benchmark for domestically listed companies in many countries (Nyor 2012). As of 29 January 2018, 97 countries worldwide required all their listed companies to use IFRS (Deloitte, 2018). Nevertheless, some large economies, such as China, India, Japan, and the US, have not allowed or permitted the use of IFRS for financial reporting by their locally listed companies (Ball, 2016). 
Since its creation in 1973 up to December 2000, the IASC has issued 41 standards. Roberts et al. (2005:24) classify the standards according to various accounting issues as follows: general aspects (IAS 1); specific aspects (IAS 7, 8, 14, 24, 33, 34); asset recognition and measurement (IAS 2, 16, 23, 25, 36, 38, 40); liability recognition and measurement (IAS 10, 12, 17, 19, 37); financial instruments, assets and liabilities (IAS 32, 39); recognition of economic activity (IAS 11, 18, 20); measurement of inflation (IAS 29); group accounting (IAS 3, 21, 27, 28, 31); and specialist industries (IAS 26, 30, 41).

Similarly, the IASB issued 17 IFRS starting from 2004 to 2017: IFRS 1 - First-time adoption of IFRS (2004); IFRS 2 - Share-based payments (2004); IFRS 3 - Business combinations (2008); IFRS 4 - Insurance contracts (2004 - will be superseded by IFRS 17 on 1 January 2021); IFR 5 Non-current assets held for sale and discontinued operations (2004); IFRS 6 - Exploration for and evaluation of mineral assets (2004); IFRS 7 - Financial instrument disclosures (2005); IFRS 8 Operating segments (2006); IFRS 9 - Financial instruments (2014); IFRS 10 - Consolidated financial statements (2011); IFRS 11 - Joint arrangements (2011); IFRS 12 - Disclosure of interests in other entities (2011); IFRS 13 - Fair value measurement (2011); IFRS 14 - Regulatory deferral accounts (2014); IFRS 15 - Revenue from contracts with customers (2014); IFRS 16 Leases (2016); and IFRS 17 - Insurance contracts (2017) (IFRS Foundation, 2017).

There is clear evidence that many countries have adopted IFRS, either partially or substantially, for the preparation of their financial statements. Consequently, considering the importance of financial reporting and financial statements in providing relevant financial information to various external users (investors, creditors, government regulatory agencies, and financial intermediaries), the next section discusses the importance of these two concepts.

\subsection{Conceptualising financial reporting and financial statements}

Financial reporting involves the financial disclosure of information to stakeholders regarding the financial performance of an entity over some time (IASB, 2010). The Board further explains that the primary aim of financial reporting is to provide high-quality financial reporting information concerning the performance of economic entities. The information provided could be useful for economic decision-making for existing and prospective investors, both local and foreign. Additionally, financial reporting is a set of financial documents prepared by the accountants of a company that will guide investors in making investment decisions. Staubus (2013:20) explains that the general objective of accounting is to provide financial information regarding an enterprise 
for use in making investment decisions. Similarly, Spiceland and Sepe (2007:7) report that financial reporting enhances financial and other information from other sources to facilitate effective performance and functioning of international capital markets for the allocation of capital.

The Committee on Technology of the American Institute of Certified Public Accountants originally defined accounting as "the art of recording, classifying, and summarising, in a significant manner and terms of money, transactions and events which are, in part at least, of a financial character, and interpreting the results thereof" (Riahi-Belkaoui 2012:98). Recently, accounting has been defined concerning the concept of information as a service activity that provides quantitative financial information about economic entities. The information provided is intended to be useful in making economic decisions and choices among courses of action (RiahiBelkaoui 2012:98). Thus, the changes in the world business environment have influenced the approach of recording economic transactions. In addition to the sophisticated nature of financial information, the needs of present users necessitated the redefinition of the role of accounting.

Glautier et al. (2011:303) stress that the decision-making concepts of financial reporting should reflect information that will assist investors to pre-determine their future capital appreciation and regular increase of income from their investments. Similarly, Gibson (2013:30-32) is of the view that financial reporting information should be comprehensive and understandable to communicate information regarding the business and economic activities of an enterprise to stakeholders to make economic decisions. The author further mentioned that financial reporting is used as a broad term to include the communication of any financial information to internal and external users. Information will consist of financial statements (which form an essential part of financial reporting) and other relevant financial reports, either in monetary or non-monetary terms. The financial statements and other reports of an entity are prepared for comparability with previous financial statements of the entity and the financial statements of other companies.

The financial statements should be useful decision-making documents for all the stakeholders since they will make the entity's business visible and enable the stakeholders to determine its performance. The stakeholders are equity shareholders, creditors, and government agencies. Others are employees and their unions, suppliers and prospective investors, which might be local or foreign investors (Staubus, 2013:14-25; Walton \& Aerts, 2006:1-8). All these categories of users of financial statements, including the prospective investors, are specifically interested in having the relevant economic and financial information relating to the performance of the firm. 
This information may include the ability to meet the expectations of all stakeholders, information concerning the viability of the non-current assets, and the net assets, etcetera.

Riahi-Belkaoui (2012:341) emphasises that financial statements could be a source of information to users in assessing management stewardship, determining the present and prospects of the company by the suppliers of capital, and assisting the government in fiscal policy implementations. Also, users will be more interested in financial statements if the accounting information relied upon in making investment decisions meets the outcome of their expectations.

Financial reports and financial statements are financial documents that disclose more useful accounting information about an entity's financial progress that will assist users in making economic decisions. Given this, these financial documents must possess qualitative attributes that are expected of financial information (Deegan, 2013:228). IFRS Conceptual Framework makes this possible by providing the structure and direction that underline the process of financial reporting. Additionally, the Framework identifies the qualitative attributes that financial information must possess before it can be useful for making economic decisions. Thus, the next section is devoted to the discussion of the conceptual framework for financial reporting.

\subsection{The IASB framework for the preparation and presentation of financial statements}

The efforts to develop a Conceptual Framework (CF) for financial reporting began in the United States (US) in 1920. These efforts took different dimensions in the form of academic publications by accounting researchers and through a series of conferences organised by professional accounting bodies advocating for the development of a conceptual framework for accounting standards setters (Zeff, 2018).

The work of the following researchers and the reports of committees focusing on the development of a conceptual framework is significant: Sanders et al. (1938:5-7); Moonitz, (1961); and of recent, Clarke et al. (2019) and Deb (2019). Some other relevant works that have a relationship with the development of a conceptual framework are Edwards and Bell (1965) and Chambers (1966).

Additionally, the Statement of Basic Accounting Theory (1966) and the Accounting Principles Board Statement No 4 (1970) also contributed to the move to have a conceptual framework for accounting. Similarly, in response to the urgent need to have a theoretical framework, the Board of Directors of the American Institute of Certified Public Accountants initiated two study groups in April 1971. The groups are the Wheat Committee and the Accounting Objectives Study Group, 
known as "the Trueblood Commission," which made efforts to ascertain the primary objectives of financial accounting (Langenderfer, 1986; Riahi-Belkaoui, 2004:167). The report of the Wheat Committee led to the establishment of the Financial Accounting Standards Board (FASB). These efforts show that the US played an earlier role in having a conceptual framework for financial reporting (Zeff, 1999).

Zeff (2018) reports that the conceptual framework for financial reporting was on the agenda of the FASB, whereas it was not in that of the IASC after 16 years of its existence. In the same vein, IAS 1 , issued in 1974, contains three bases that constitute the conceptual framework. These bases were identified as the application to publish financial statements, the focus on a wide range of users, and the decision-usefulness objectives of financial statements (Alexzander et al., 2013:4-5). The IASC used different existing national standards with different concepts and objectives of financial statements to formulate its conceptual framework.

The IASC initiated a steering committee on a conceptual framework project in 1982 and concurrently worked on "building block" projects involving the objectives and elements of financial statements. Similarly, Cairns (2001:5) reports that at an international conference on standard-setting, many speakers unanimously spoke in favour of the significance of having a conceptual framework for financial reporting for standard-setters. It can be deduced from this evolutionary trend of conceptual framework development that it was subject to the influence of professional accounting bodies and institutional pressures on the IASC to develop a conceptual framework (Canfferman \& Zeff, 2007).

Nevertheless, the IASC anticipated that the Board needed to have a guideline in terms of financial reporting conceptual frameworks. Because of this, in 1986, the IASC decided to develop a conceptual framework for financial reporting that would not form part of the standards. According to the Board, the framework would serve as standard-setting procedures and, at the same time, be of assistance to the preparers of financial statements as well as auditors and users of financial statements for interpreting the standards (IASB, 2010). After this plan, specifically in 1989, the first set of the IASC's conceptual framework was published. Deegan (2010:213) reports that the IASC Framework that was published in 1989 was later adopted by its successor, the IASB, in April 2001.

The adopted framework is known as the Conceptual Framework for Financial Reporting (the Framework) and was approved by the IASB. In 2002, the FASB and the IASB had a joint project 
on the conceptual framework. The goal of the project was to have a complete, comprehensive single document of the Conceptual Framework and to enable the use of the same theoretical basis. Unfortunately, the joint project was abandoned in 2010 after finalising the objectives of general purpose financial reporting and the qualitative characteristics of useful financial information. During the agenda consultation in 2011, participants urged the IASB to revisit its Framework due to the many issues confronting it since 1989. They observed that, since 1989, the IASB Conceptual Framework had not significantly changed. Because of this, the Framework was reviewed in March 2018 to accommodate a few shortcomings in the existing Framework (Deloitte, 2018).

Gerber (2016) argues that the goals of the Conceptual Framework for financial reporting can be viewed from three different theoretical perspectives, namely a classical perspective, decisionusefulness, and an information economics basis. The classical perspective stems from inductive and deductive approaches. In the case of an inductive approach, it starts from observations of the financial information of an entity to construct generalisation and principles of accounting from the observations. In contrast, a deductive approach initiates accounting principles and techniques from general to specific (Riahi-Belkaoui, 2012:111-112).

Under the classical approach, the Conceptual Framework describes the existing practice of an accountant, prescribes the future method, and gives the definitions of terms (Alexander et al., (2013:14-15). However, in developing a conceptual framework, there is a need to choose between the two alternatives. The decision-usefulness approach is the primary reason for preparing financial information to serve as a useful document for all users of financial statements.

Eventually, most researchers in accounting see this approach as focusing only on a segment of the users of accounting information. Macve (2010) observes that preparers of financial statements are supposed to be accountable to all users of financial settlements. Accordingly, the author explains that achieving these two objectives, namely decision-usefulness and accountability, may look unachievable. In the case of the third perspective, namely, the information economics basis, accounting information is seen to be similar to a commodity that should be competed for. Therefore, a conceptual framework should be developed in such a way that it would enable accounting information to be fought for as with a commodity.

The Conceptual Framework is a theory of accounting prepared by an accounting standard-setting body that enables practical problems to be tested and interpreted. Nobes and Parker (2008:118-12) explain that the Framework is used by the Board and auditors and users of financial statements in 
understanding the standards for a faithful presentation of financial statements. Nobes and Parker (2008:120) explain that the Conceptual Framework was developed to give a fair presentation or an accurate and fair view of the state of economic affairs and the performance of an entity, thus increasing the assurance of users and assisting them in making investment decisions. Additionally, Burton and Jermakowicz (2015:45) explain that the Framework enables the IASB (and the Interpretation Committee) to ascertain the various models it will employ when setting accounting standards.

In another related opinion, Pelger (2016) believes that the Framework serves as a guideline for standard-setters, while Lennard (2007) reports that the Framework provides a clear and coherent basis for financial reporting. He further specified that it embodies various concepts that influence the preparation and presentation of financial reporting. Deegan (2013:244-247) emphasises that the Conceptual Framework tends to highlight the decision-usefulness of financial reporting instead of concentrating on the issues that concern management stewardship.

Riahi-Belkaoui (2012:173) is of the view that the IASB's Framework can act as a constitution for the process of setting accounting standards by resolving disputes that may arise when a particular standard conforms or does not conform with the Conceptual Framework. The Conceptual Framework will enable the accounting standards to be developed based on agreed principles. Deegan (2010:212) emphasises that for financial reporting to be developed logically and consistently, there must be a consensus on some critical issues, for example, scope, objective, and the qualitative characteristics of financial statements. The agreement on these issues will make accounting standards consistent.

Figure 3.1 depicts the IASC/IASB's components of a conceptual framework. It sets out the concepts that underlie the preparation and presentation of financial reporting for external users. It deals with the definitions of financial reporting, the reporting entity, and the users of financial statements and their information needs. It also includes the objectives of financial statements, the underlying assumptions and the qualitative characteristics of useful financial information (relevance, reliability, comparability, timeliness, and understandability). Additionally, the concept comprises elements from which financial statements are constructed (assets, liabilities, equity, income, and expenses), the recognition criteria, and the measurement basis and techniques (Deegan, 2010: 213). These are discussed in the next sections. 


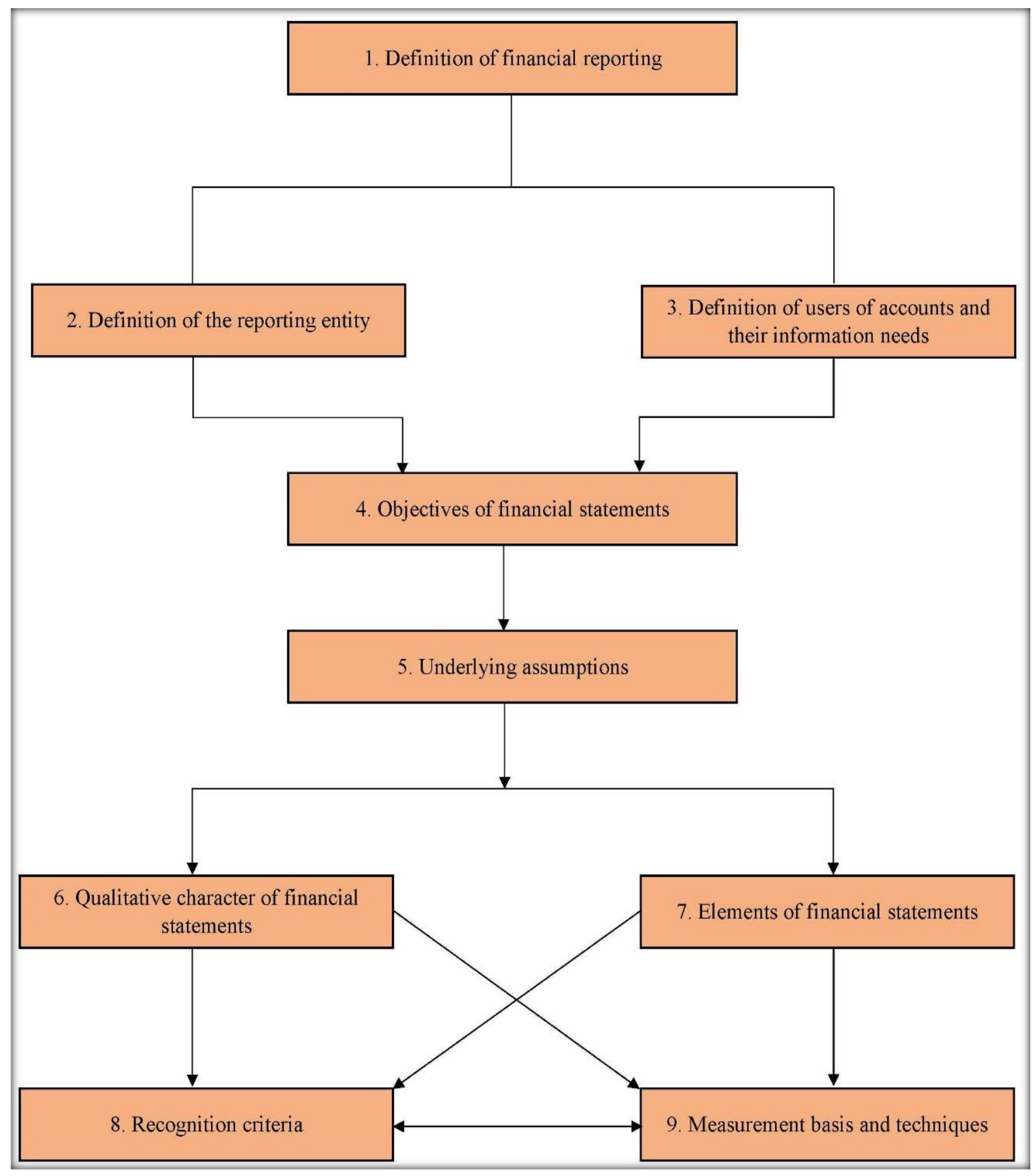

Figure 3.1: Components of a conceptual framework based on the IASC/IASB

Source: Deegan (2010)

\subsubsection{The concept of financial reporting}

The idea of financial reporting is discussed in paragraph 12 of the IASB's framework for the preparation and presentation of financial statements. According to the Framework, the financial report provides the financial position, financial performance and changes in the financial position 
of an entity, which is useful to a wide variety of users of financial information in assisting them in making economic decisions. Deegan (2010:214) thinks that the first issue to be discussed in developing the accounting framework is the concept of financial reporting. The author further mentions that it might be challenging to establish a framework for financial reporting if there is no agreement on the concept.

\subsubsection{The definition of reporting entity}

Deegan (2010:221) explains that reporting entities are saddled with the responsibility of preparing and presenting general purpose financial statements that comply with accounting standards and other generally accepted accounting principles to satisfy the information needs of individual users - both internal and external. Likewise, the IASC Framework, Paragraph 8, adopted by the IASB, reports that a reporting entity is an entity that prepares the financial statements that users exclusively depend upon for investment decisions. The framework also emphasises that the general purpose financial statements should be made by reporting entities in compliance with the Conceptual Framework and accounting standards.

An entity is believed to be a reporting entity when it makes available relevant information about its performance in the general purpose financial statements that are generally not accessible to users. Also, the framework applies to the financial statements of all commercial, industrial, and business reporting entities that are public or private companies. Thus, the available financial information forms the basis upon which users depend on making and appraising their economic decisions concerning the entity.

\subsubsection{The definition of the users of accounting information and their information needs}

The description of the users of accounting information based on 2010 IASB framework includes investors, (existing and potential) employees, lenders, suppliers, and other trade creditors, customers, governments and their agencies, and the public. Additionally, there are peculiar needs for each user. Walton and Aerts (2006:8) emphasise that investors will be concerned with the risks and returns from the capital invested. Kothari et al. (2010) explain that financial information is useful to investors for at least two reasons, namely, equity valuation and evaluation of the management performance. Walton and Aerts (2006:8) also explain that the employees and their union representatives will be interested in the profitability and stability of the firm to pay their salaries and retirement benefits. The authors further emphasise that lenders and other trade creditors require information about the entity's ability to meet the repayments of their loans. Also, 
governments and their agencies will be interested in how the resources are allocated. Furthermore, how they will regulate the activities of the entity for the payment of taxes. The availability of accounting information to various users will encourage the exchange of resources between the providers of information and their users, mostly foreign investors.

\subsubsection{Underlying assumptions of accounting standards}

Chasteen et al. (1992:41-43) and Spiceland and Sepe (2016:24-25) identify four assumptions underlying the accounting standards, namely accounting entity assumption, periodicity assumption, going concern assumption, and monetary hypothesis. The accounting entity assumption emphasises that all economic events should be related or correspond to a specific accounting entity. In the case of the periodicity assumption, financial information must be available periodically that will enable users to make decisions. The going concern assumption assumes that the entity will continue its operations in perpetuity, except in the case of liquidation. The monetary assumption indicates that all economic activities should be measured in monetary terms. Besides, the framework of financial reporting rests on these assumptions that the users of financial reporting anticipate when making use of the financial statements. Thus, understanding all these assumptions will give users confidence that the financial statements were prepared according to their expectations and the standards required by the authorities.

\subsubsection{The objective of financial reporting}

The IASB (2010) explains that the purpose of general-purpose financial reporting is to provide financial information about the reporting entity that is useful to exist and potential investors, lenders, and other creditors in making decisions about providing resources to the entity. The IASB (2010), Pelger (2015), and Riahi-Belkaoui (2012:182) emphasise that this objective forms the foundation of the Conceptual Framework of financial reporting. Also, the aim is to provide useful financial information about the reporting entity to existing and potential investors. This information will support their rational investment appraisal decisions regarding the efficient allocation of resources. They further explain that financial reporting provides information about the stewardship responsibility of management. Accordingly, to meet users' expectations, the financial information provided should be understandable. It must also assist investors in assessing the amount, timing, and uncertainty of their future cash flow in the form of dividends and interest, as well as the prospective inflows to the company (Spiceland \& Sepe, 2016:16-17). 
Despite the objectives of decision usefulness and stewardship responsibility, financial reporting is not an end in itself, but a means to specific purposes. The IASB (2010) framework states that: "to a large extent, financial reports are based on estimates, judgements, and models rather than exact depictions." Thus, users must also source affiliated financial information about a particular entity elsewhere.

\subsubsection{Qualitative characteristics of financial reporting}

To satisfy the needs of various users of financial information, specifically investors, financial statements prepared under generally accepted accounting principles must possess specific useful characteristics. Van Greuning et al. (2011:4) explain five crucial qualitative characteristics of financial information; namely, it must be relevant, reliable, timely, comparable and understandable. Nobes and Stadler (2015) explain that the qualitative components of financial information are vital for standard-setters and, in particular, for entities. Also, these characteristics assist them when they are confronted with the decision to choose accounting policies. The qualitative aspects also reduce the problems experienced by auditors when interpreting and applying the standards. Each of the qualitative characteristics is discussed below.

Van Greuning et al. (2011:5) explain that relevance concerns accounting information that can influence the economic decisions of users to evaluate past, present, and future events or to correct their past assessments about investments. Hence the relevance shows that accounting information is relevant and material if the omission or misstatement of certain information could influence the economic decisions of users taken based on the financial statements. Riahi-Belkaoui (2012:166) explains that relevance provides information that will aid investors in making economic decisions. The IASB (2010) Statement of Financial Accounting Concepts No. 2 Qualitative Characteristics of Accounting Information reports that relevant accounting information can make a difference in economic decision making as it enables users to predict the outcomes of future events or to confirm or correct prior expectations. Thus, it shows that accounting information has the capability of assisting the users in predicting future economic events and confirmation of their expectations. The supporting role will enable the users to determine the extent the entity has met their anticipations. Thus, accounting information serves a dual purpose by improving investors' capacities to predict the future outcome of events and providing feedback on earlier expectations.

The second characteristic of financial information is the reliability of the information provided. The IASB (2010) Statement of Financial Accounting Concepts No. 2 Qualitative Characteristics 
of Accounting Information explains that reliability is the quality of information presented in such a manner that the information is reasonably free from error and bias and faithfully represents what it purports to represent. Van Greuning et al. (2011:4) show that, for accounting information to be reliable, it must be free from material error and bias and can be depended upon by users to represent faithfully that which it purports to represent or could reasonably be expected to serve.

Van Greuning et al. (2011:4) further state that reliability can also be explained in terms of other concepts, namely faithful representation, completeness, being free from material errors, prudence, transparency, neutrality, and substance over form. According to the IFRS Framework for the Preparation and Presentation of Financial Statements: Transparency and Data Quality, transparency focuses on making available accounting information on existing conditions, decisions, and actions that are accessible, visible, and understandable to all market participants. Also, it is a prerequisite for accountability to investors and international financial institutions by reducing the tendency of markets to place undue emphasis on positive or negative reports that can reduce volatility in global financial markets (Van Greuning, 2011:8-9).

The IASB (2010) emphasises that relevance and reliability are the two primary qualities that make accounting information useful for decision-making. Subject to constraints imposed by cost and materiality, increased relevance and increased reliability are the characteristics that make information a more desirable commodity that is useful in making decisions. If either of those qualities is absent, the information will not be useful.

The next characteristic to be mentioned is timeliness. The IASB (2010) Conceptual Framework on the objective of general-purpose financial reporting, states that timeliness refers to the availability of relevant information for economic decision-making promptly to enhance investment decisions. Spiceland and Sepe (2016: 16-17) express that information is timely when it is available at the appropriate time or periodically for the investment decisions process by users. Generally, belated accounting information will be less useful and may hinder investors' ability to assess the riskiness of their investments promptly.

However, some information may continue to be timely long after the end of a reporting period, like when users are interested in assessing the trend of a particular transaction (QC29). Thus, for accounting information to be relevant, it must be presented at the appropriate time. It was also emphasised that early communication of accounting information to users, especially foreign investors, is vital to avoid any delays in making economic decisions based on the accounting 
reports (Riahi-Belkaoui, 2004:166). If information is not available when it is needed or becomes available long after the reported events, it will have no more value relevance for the prediction of future actions. Thus, it means that financial information lacks relevance and is of insufficient importance to rely upon for investment decisions. Although timeliness alone cannot make information relevant, a lack of timeliness in presenting accounting information can rob information of relevance it might otherwise have had. Consequently, it loses its value.

Nevertheless, another characteristic is comparability. The essence of the comparability of accounting statements is essential for the benefits of foreign investors and other users. The IASB (2010) expresses that investment decisions will involve comparing different alternatives and choosing between them. The Board further explains that the comparability of accounting information enables users to examine the common aspects among them and to determine the differences between them. As a result, investors will be able to form an opinion as to whether a firm is consistent in applying the accounting principles and methodology over a period of time for a particular item. The expectation of developing IFRS is to make the financial statements prepared in one IFRS jurisdiction comparable to similar listed companies globally (Houqe et al., 2012).

Similarly, a faithful representation of an item in the financial statements of an entity must also have a certain degree of resemblance in another entity when compared (IASB 2010). Fatima et al. (2018) opine that accounting information, over time, must be presented consistently between entities to enable existing and prospective investors a basis of comparing the information. Investors, regulators, and academics have recognised the importance of financial statement comparability. The Securities and Exchange Commission (2000), as a regulatory body, emphasised that when investors judge the outstanding merits and comparability of investments, there is a possibility that the allocation of resources will be more efficient, and investors' confidence will be enhanced. Comparability of financial statements also touches on consistency in measurement and displays the economic effects of similar transactions across the entities.

Furthermore, the accounting policies employed in the preparation of financial statements must be disclosed to enable the users to compare notes. Lang et al. (2010) emphasise that financial information comparability worldwide increased after IFRS adoption in many countries.

The final characteristic of financial information is the understandability of accounting information, which is considered crucial for standard-setters (Deegan, 2010:228). The IASB (2010) framework emphasises that financial information is considered to be understandable if users understand it 
despite any relevant complex information that has been disclosed. This characteristic will enable users to gain an understanding of the financial information against the background of their decisions. Fatima et al. (2018) accounting information should be easily understood by users who have basic knowledge of business and economic activities and who are willing to study the report; otherwise, a financial adviser must be sought. Understandable financial information will enable investors to understand the strength of a particular entity to avoid the perils of accounting ethnocentrism (claiming of superiority) (Nobes \& Parker, 2008:17). Figure 3.2 explains in summarised form the relationships between the qualitative characteristics of financial information. 


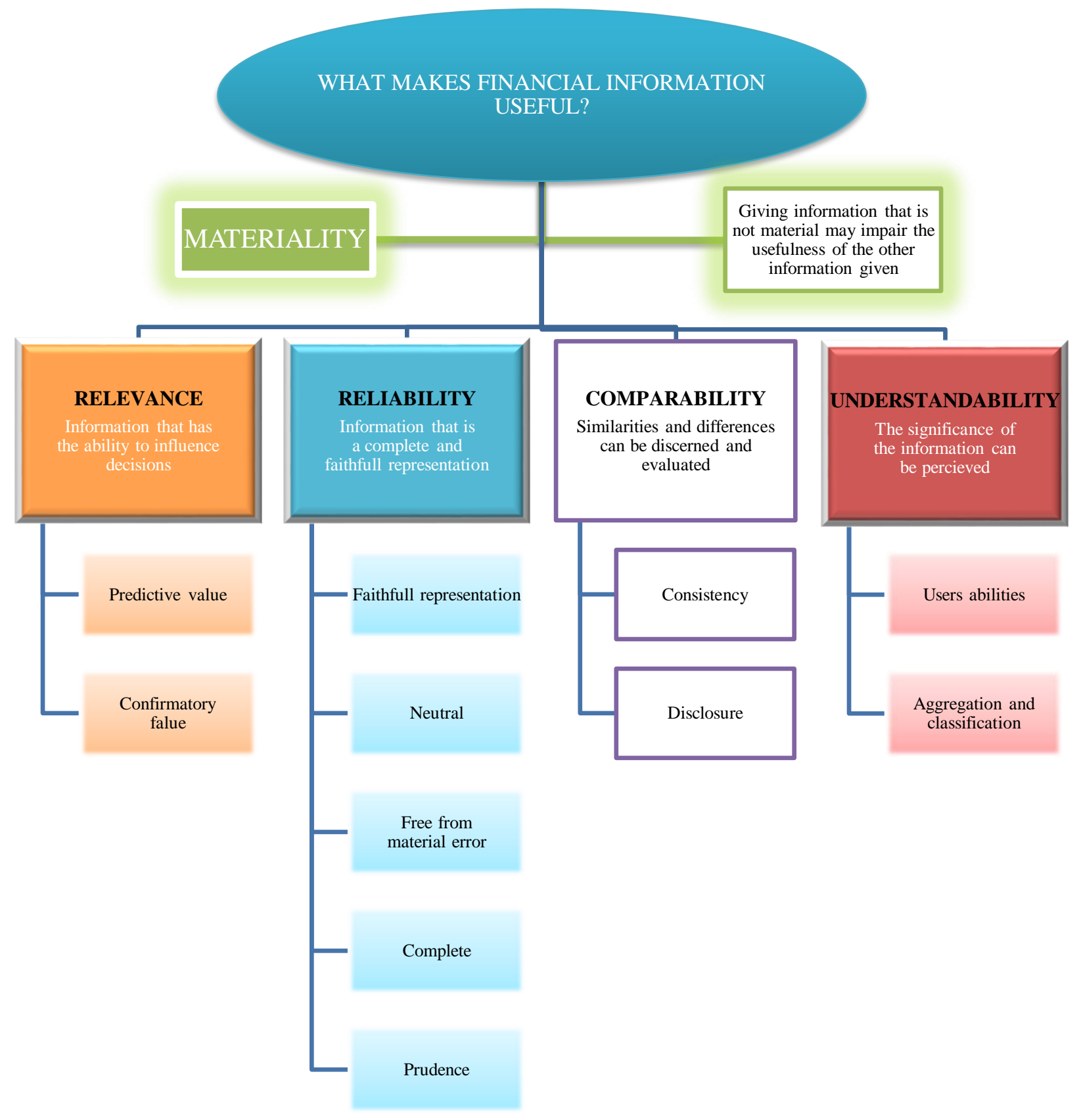

Figure 3.2: Relationships of the qualitative characteristics of financial information

Source: Weetman (2006:107) modified by the researcher

\subsubsection{The elements of financial reporting}

The IASB's (2010) Conceptual Framework reports that to show the effect of financial transactions and other financial events on the financial statements, operations, and other activities are usually organised into different classifications according to their economic attributes. These attributes are 
elements of financial statements: assets, liabilities, equity, revenues, and expenses. Walton and Aerts (2006: 87) categorise these elements into two groups according to their relativity and measurement. They explain that assets, liabilities, and equity are the elements used to appraise an entity's financial position in the statements of financial situation. At the same time, revenues and expenses measure the performance of an entity in the statements of profit or loss and other comprehensive income.

Riahi-Belkaoui (2012:188-189) explains that assets are the potential future economic benefits based on the consequences of past transactions. Likewise, Walton and Aerts (2006:88-90) emphasise that assets add value to the entity in terms of improving its future cash inflows. The reporting entity must have the capacity to control the resources that gave rise to the future benefits of the cash flows or to deny the access of others to such benefits (Deegan 2010:237-238). Another element of financial statements is liabilities. It represents the present obligation of an entity arising from past events, the settlement of which is anticipated to result in an outflow of the entity's resources representing economic benefits (IASB, 2010). Riahi-Belkaoui (2012:188-189) defines liabilities as "probable future sacrifices of economic benefits arising from the present obligations of a particular entity to transfer assets or provide services to other entities in the future as a result of past transactions or events."

Walton and Aerts (2006: 90) affirm that an entity's liabilities are a present obligation that emanates from previous events. They explain that the settlement of that obligation involves an outflow of economic benefits from the entity in the form of the payment of cash, the transfer of other assets, and the rendering of services. The existence of any liability in an entity will involve a loss of economic benefits.

Next is the equity of the entity. The IASB (2010) defines equity as the residual interest in the assets of the entity after deducting all its liabilities [Framework 4.4(c)]. Walton and Aerts (2006:91) report that equity is the pecuniary ownership interest in the business. Additionally, it is the residual interest that represents a claim or right to the entity's net assets after the demands for liabilities have been met in liquidation. The authors also explained that equity may be sub-classified into various types of capital and reserves, such as shareholders' capital and retained earnings in the statement of financial positions. This classification is relevant to the decision-making needs of users of financial statements when there is any legal constraint against the company regarding the distribution of its assets or how to apply its equity (Walton \& Aerts, 2006:91). 
The IASB (2010) states that income encompasses both revenue and gains. Revenue arises in the course of the ordinary activities of an entity and carries a variety of different names, including sales, fees, interest, dividends, royalties, and rent (Framework 4.29). Riahi-Belkaoui (2012: 188189) defines income as the change in the equity of an enterprise during a period. That is different from the change in equity that results from an owner's investment or payments made to owners. Gains represent other items that meet the definition of income and may or may not arise in the course of the ordinary activities of an entity. The author further explains that the definition of income includes any amount realised from the revaluation of marketable securities and increases in the carrying amount of long-term assets. Also, any gains realised during business are disclosed in the comprehensive income statement separately because knowledge is useful for making economic decisions.

The IASB (2010) defines expenses as encompassing losses as well as those expenses that arise in the course of the ordinary activities of an entity, which include the cost of sales, wages, and depreciation. According to the IASB Framework, expenses usually take the form of an outflow or reduction of assets such as cash and cash equivalents, inventory, property, and plant and equipment. Losses represent other items that meet the definition of expenses that may or may not arise in the course of the ordinary activities of the entity. Losses arising from the course of business represent decreases in economic benefits and are the same as other expenses. According to the Framework, these include those resulting from unforeseen calamities, for example, fire, flood, the disposal of non-current assets, and losses arising from an adverse rate of exchange if a transaction was carried out in another currency. Losses are disclosed separately in the comprehensive income statement since knowledge of them is useful for making economic decisions (Framework 33-35).

\subsubsection{Recognition of the elements of financial statements}

After identifying the elements of financial statements, the issue of recognising criteria of the elements is also paramount. Deegan (2010:242) states that the requirements of recognition should be adopted before an item can be incorporated as elements in any of the financial statements. These criteria include the definition, measurability, relevance, and reliability of an item before it can be classified as an element in the financial statements (Riahi-Belkaoui 2012:190). Because of this, any item can be recognised if it meets all the attributes of a particular element, and its value or cost can be reliably determined. Also, the flow of future economic benefits of such an item will accrue to the entity. Accordingly, the IASB (2010) states that the recognition of the elements of financial 
statements involves a given monetary value for a transaction to be included in the relevant financial statements.

\subsubsection{Measurement of financial statement elements}

Measurement is the process of determining the monetary value at which the elements of financial statements are recognised and carried in the statement of financial position and the comprehensive income statement (Framework 4.54). Thus it involves the selection of a particular basis of measurement. The IASB (2010) lists some different measurement bases that are employed to varying degrees and in varying combinations in the financial statements, namely historical cost, current replacement cost, the present value of future cash flows and current market value (Framework 4.55).

Similarly, fair value can also be used to measure the elements of financial statements. Fair value is the amount at which an asset could be exchanged between knowledgeable, willing parties at an arm's length transaction (Van Greuning, 2011: 110). It is the price received when an asset is sold or paid for in transferring the liability. However, the transaction of selling and transfer of the liability must be executed in a proper and orderly manner between the market participants.

Also, it is assumed that the transaction would take place in a most advantageous manner and without any bias that would maximise the sales proceeds and minimise the amount paid for the transfer of the liability (Glover et al., 2016). Fair value is used in IFRS to mean a current market exchange price between willing buyers and sellers (Nobes \& Parker, 2008: 346). Fair value can be regarded as an exit value, which means the amount at which an entity could dispose of the asset. A significant feature of IFRS is the extent to which the standards express a clear explanation of fair value or has a strong opinion on fair value accounting or mark-to-market accounting. IFRS requires, in certain circumstances, that assets, liabilities, and equity instruments should be measured at fair value. The most common standards that refer to fair value are IAS 16, IAS 36, IAS 38, IAS 39, IAS 40, IFRS 2, IFRS 3, and IFRS 13.

Mrsa et al. (2008) report that part one of the most critical aspects of financial information given in a financial report concerns the value of an entity, particularly the value of its assets, liabilities, and equity. They further explain that the concept of capital maintenance is related to how an entity defines the capital that it aims to maintain profit determination. The IASB (2010) Conceptual Framework mentions two concepts of capital, namely a financial concept of capital and physical theory of capital. An economic concept of capital, such as invested money, is one where capital is 
linked to the net assets or equity of an entity. Also, a physical theory of capital is when the capital is connected to the productive capacity of the entity according to the number of units it can produce. The choice of the relevant principles of capital by an entity should be based on the needs of the users, especially the shareholders, who will need the financial information to make decisions.

The development of the Conceptual Framework aims to achieve a true and faithful presentation of financial information according to internationally accepted accounting standards (i.e., IFRS). This is to enable the financial statements to be prepared in such a way that they will show a true and fair view of an entity's economic activities over a period of time (Efobi, 2017). In the opinion of Deegan (2010:231), the absence of a conceptual framework for internationally recognised accounting standards will make the general objectives of financial reporting unachievable since a comprehensive theoretical framework will serve as a guide or a constitution for the preparer of the financial statement and make it more transparent and comparable.

\subsection{IFRS worldwide jurisdiction and the status of adoption in Africa}

The IASB came into existence in 2001 for the main reason for developing IFRS. The efforts of the European Union (EU) in the adoption of IFRS are noteworthy, and emphasis this section emphasises how they are progressing with the adoption of IFRS.

Soderstrom and Sun (2007), in addition to Duarte et al. (2015) emphasise that the issue of accounting convergence in the EU progressed in the 1990s with the advancement of IAS harmonisation events. The advancement necessitated the adoption of a single currency with accompanied political rearrangements in the EU. According to these authors, the achievement of a single currency in the EU was seen as an initial step towards achieving unified international accounting standards. Additionally, Jindrichovska and Kubichkova (2016) explain that the harmonisation of accounting standards was also officially facilitated in Europe by two EU directives, namely the Fourth Directive on the annual accounts of companies (July 1978) and the Seventh Directive on consolidated reports (1983). These are the primary two documents employed by the EU to promote international accounting harmonisation.

Similarly, Soderstrom and Sun (2007) report that the purpose of these directives was to focus on the differences in national accounting standards in the EU that hinder the comparability of accounting data within the region. The directives of 1978 focused on the harmonisation of national laws on accounting regulations. The essence of these was to make it easier for investors and other 
users to rely on the accounts of entities in other member states and to promote fair competition, while the 1983 directive was concerned with the consolidation of accounting systems in member states (Roberts et al., 2005:354). These developments were designed to make financial statements comparable with other similar entities.

Marquez-Ramos (2011) remarks that these directives had a positive impact on financial statements since the quality of the financial statements of the member states has improved. However, the inclusion of diverse options that were open to different interpretations made it difficult for the directives to achieve their purpose. For example, companies seeking capital from international capital markets have to prepare a new set of accounts for that specific purpose. Because of this, the EU began to make moves to collaborate with the IASB to develop high-quality international accounting standards (i.e., IFRS) that would be acceptable and capable of achieving broad worldwide acceptance.

Eventually, IFRS was developed in 2001, and the EU adopted IFRS for use in preparing the consolidated financial statements of quoted companies. The introduction of IFRS for listed companies worldwide was one of the most critical changes in global accounting regulations (Gordon et al., 2012). This phenomenon has encouraged many countries to reform their accounting practices by adapting their national accounting practices to harmonise with IFRS (Saidi, 2013).

Barely a year after IFRS was developed, the (EU) member states demanded that all their quoted companies use IFRS commencing from 2005 (EC, 2002). Thus it shows that the EU was the first to require the use of IFRS for the preparation of financial statements of their domestic quoted companies. This development made it mandatory for all member states to adopt IFRS from January 2005. January 2005 marked a significant milestone in the efforts towards the acceptance of IFRS in the EU. This move by the EU formed the basis of harmonising financial statements in the place of the national accounting standards of different countries (Marquez-Ramos, 2011). Also, some African countries abandoned their various national accounting standards for the adoption of IFRS. Among them are South Africa (one of the first African countries to adopt IFRS), Botswana, Kenya, Ghana, Mauritius, and Lesotho (PwC, 2010).

Roberts et al. (2005: xii) explain that, apart from the EU, many countries have taken a series of steps to harmonise their accounting standards with IFRS. Because of this, some countries have adopted IFRS in full, some have reviewed their national standards to accommodate the main aspects of IFRS with some local variations, while others are still considering the options of 
harmonising their national accounting standards with IFRS. However, some of those countries that have adopted IFRS include large economies such as Australia, New Zealand, Hong Kong, Canada, South Africa, and Brazil.

The authors further explain that Australia, New Zealand, Hong Kong, the Philippines, and Singapore have international accounting standards and rules that are very close to IFRS. Likewise, Australia and New Zealand adopted local standards that are described as IFRS equivalents, but without any of the permitted options of the IASB and IFRS. In the case of Hong Kong and the Philippines, the report states that they have adopted national standards identical to IFRS, including all accounting options. Hong Kong also made it possible for companies that are domiciled in Hong Kong but incorporated in another country to issue IFRS financial statements rather than Hong Kong GAAP statements (Walton \& Aerts, 2006:25-27). Moreover, Singapore adopted IFRS with a few changes to recognition and measurement principles. In Japan, listed foreign companies can make use of IFRS, while domestic companies are not allowed.

China developed a representative set of local accounting standards that do not converge with IFRS. However, the country signed a memorandum with the IASB in November 2005, endorsing the convergence to its domestic Accounting Standards for Business Enterprises (ASBE). The memorandum was updated in November 2015. With this development, China is in IFRS jurisdiction (Ball, 2016). The story is different in the US since the SEC accepts IFRS as highquality accounting standards, but they are not allowed to be used for official listed local companies. The SEC permits only the US GAAP for listing. Ball (2016) explains that the possibility of the US adopting IFRS lies with the SEC, who is responsible for observing the accounting and auditing of companies who have securities quoted in US capital markets. Additionally, apart from the US, China, and Japan, who have the largest economies and are the most populous countries and have yet to adopt IFRS, two other populous countries that are, however, to choose IFRS are India and Indonesia. The table below gives a detailed summary of the use of IFRS worldwide by jurisdiction. 
Table 3.1: Use of IFRS by jurisdiction

\begin{tabular}{|c|c|c|c|c|}
\hline Jurisdiction & Jurisdiction & Jurisdiction & Jurisdiction & Jurisdiction \\
\hline Abu Dhabi* & Chile* & Hungary* & Mauritius* & Serbia* \\
\hline $\begin{array}{l}\text { Afghanistan* } \\
\text { (NSE) }\end{array}$ & China**** & Iceland* & Mexico** & Sierra Leone* \\
\hline Albania** (NSE) & $\begin{array}{c}\text { Cote } \\
\text { D'Ivoire**** }\end{array}$ & India*** & Moldova* & Singapore $* * * *$ \\
\hline $\begin{array}{l}\text { Algeria**** } \\
\text { (NSE) }\end{array}$ & Colombia**** & Indonesia $* * * *$ & Mongolia* & Slovenia* \\
\hline $\begin{array}{c}\text { American } \\
\text { Samoa***(NSE) }\end{array}$ & Costa Rica* & $\operatorname{Iran} * * * *$ & Montenegro* & $\begin{array}{l}\text { The Slovak } \\
\text { Republic* }\end{array}$ \\
\hline Angola** & Croatia* & Iraq* & Morocco** & South Africa* \\
\hline Anguilla* & Cuba**** & Ireland* & Mozambique*** & Spain* \\
\hline $\begin{array}{l}\text { Antigua and } \\
\text { Barbuda* }\end{array}$ & Cyprus* & Israel** & Myanmar*** & Sri Lanka* \\
\hline Argentina** & Czech R.* & Italy* & Namibia* & Suriname $* * *$ \\
\hline Armenia* & Denmark* & Jamaica* & Netherlands* & Swaziland*** \\
\hline Aruba*** & Dominica $^{* * *}$ & Japan*** & $\begin{array}{l}\text { Netherlands } \\
\text { Antilles*** }\end{array}$ & Sweden* \\
\hline Austria* & Dominican R.* & Jordan* & Nepal*** & Switzerland*** \\
\hline Australia* & Dubai* & Kazakhstan* & $\begin{array}{c}\text { New } \\
\text { Caledonia*** } \\
(\mathrm{NSE})\end{array}$ & Taiwan* \\
\hline Azerbaijan* & Ecuador* & Kenya* & New Zealand* & Tajikistan* \\
\hline The Bahamas* & Egypt $^{* * * *}$ & Korea South* & Nicaragua* $^{*}$ & Tanzania* \\
\hline Bahrain* & El Salvador*** & Kuwait* & Niger**** & Thailand $* * * *$ \\
\hline Bangladesh* & Eritrea** (NSE) & Kyrgyzstan* & Nigeria* & $\operatorname{Togo}_{0} * * *$ \\
\hline Barbados* & Estonia* & Laos*** & Norway* & $\begin{array}{l}\text { Trinidad and } \\
\text { Tobago* }\end{array}$ \\
\hline Belgium* & Fiji* & Latvia* & Oman* & Tunisia $* * * *$ \\
\hline Belarus** & Finland* & Lebanon** & Pakistan* & Turkey*** \\
\hline Belize** (NSE) & France* & Liberia** (NSE) & Panama* & $\begin{array}{c}\text { Turkmenistan } * * * \\
*\end{array}$ \\
\hline Benin $* * * *$ & Gambia* (NSE) & Liechtenstein* & Papua N. Guinea* & Uganda* \\
\hline Bermuda*** & Germany* & Lesotho*** & Paraguay*** & Ukraine** $^{* *}$ \\
\hline Bhutan**** & Georgia* & Lithuania* & Peru* & $\begin{array}{l}\text { The United } \\
\text { Kingdom* }\end{array}$ \\
\hline Bolivia*** & Ghana* & Luxembourg* & Philippines**** & $\begin{array}{l}\text { The United States } \\
\text { of America**** }\end{array}$ \\
\hline
\end{tabular}




\begin{tabular}{|c|c|c|c|c|}
\hline Jurisdiction & Jurisdiction & Jurisdiction & Jurisdiction & Jurisdiction \\
\hline $\begin{array}{c}\text { Bosnia and } \\
\text { Herzegovina* }\end{array}$ & Gibraltar*** & Libya** $^{* *}$ & Poland* & Uruguay $* * * *$ \\
\hline Botswana* & Grenada* & Macau*** (NSE) & Portugal* & Uzbekistan $* * * *$ \\
\hline Brazil**** & Greece* & Macedonia* & Qatar* & $\begin{array}{l}\text { Vanuatu*** } \\
\text { (NSE) }\end{array}$ \\
\hline $\begin{array}{l}\text { Brunei } \\
\text { Darussalam*** } \\
\text { (NSE) }\end{array}$ & $\begin{array}{l}\text { Greenland } * * * \\
\text { (NSE) }\end{array}$ & $\begin{array}{l}\text { Madagascar** } \\
\text { (NSE) }\end{array}$ & $\begin{array}{l}\text { Reunion*** } \\
\text { (NSE) }\end{array}$ & Venezuela**** \\
\hline Bulgaria* & Guam**** (NSE) & Malawi* & Romania* & Vietnam**** \\
\hline Burkina Faso ${ }^{* * * *}$ & Guatemala* & Malaysia* & Russia* & $\begin{array}{l}\text { Virgin Islands } \\
\text { (British)*** }\end{array}$ \\
\hline $\begin{array}{l}\text { Burundi***** } \\
\text { (NSE) }\end{array}$ & Guyana* & Maldives*** & Samoa*** (NSE) & $\begin{array}{l}\text { Virgin Island } \\
\text { (US)**** (NSE) }\end{array}$ \\
\hline Cambodia* & Haiti*** & Mali**** & $\begin{array}{l}\text { St Kitts and } \\
\text { Nevis* }\end{array}$ & West Bank /Gaza* \\
\hline Canada* & Honduras* & Malta* & Saudi Arabia* & Yemen $* * *(\mathrm{NSE})$ \\
\hline \multirow[t]{2}{*}{$\begin{array}{c}\text { Cayman } \\
\text { Islands*** }\end{array}$} & Hong Kong* & $\begin{array}{l}\text { Mauritania**** } \\
\text { (NSE) }\end{array}$ & Senegal $* * * *$ & Zambia* \\
\hline & & & & Zimbabwe* \\
\hline
\end{tabular}

Source: Ball (2016); IFRS (2017) and PwC (2016). (Notes: * = IFRS required for all domestic listed companies; **= IFRS require for some listed companies; $* * *=I F R S$ permitted by the country; ****=IFRS not permitted by the country; NSE = Countries with no Stock Exchange).

According to the IASB, IFRS is classified into four different categories. Firstly, IFRS is required for all domestic listed companies if a country has fully adopted IFRS as a national accounting standards framework for all locally listed companies. Secondly, IFRS is required for some listed companies, mostly financial and lending institutions. This category means that only a specific sector of the economy is allowed to use IFRS. Thirdly, IFRS is permitted by the country, meaning that companies have the option to use either IFRS framework or national accounting standards. Finally, IFRS is not permitted by the jurisdictions.

Table 3.1 shows a total of 176 IFRS jurisdictions worldwide. Most information was sourced from the website of IASPLUS, which is considered as the best and most reliable source of information on the status of IFRS worldwide (Ramanna \& Sletten, 2010). The webpage also provides details about an individual country's IFRS status. The table indicates the following: the total number of jurisdictions where IFRS is required for all domestic listed companies is 106. Where IFRS is required for some listed local companies amounts to 14 jurisdictions; where IFRS is permitted 
equals 31 ; and where IFRS is not permitted amounts to 25. The table further indicates that 22 IFRS jurisdictions have no stock exchange. The countries without a stock exchange are shown with the term "NSE" in the table. However, the total jurisdictions worldwide that permit or require IFRS for domestic listed companies equals 151 . The outcome of this finding is demonstrated in the figure below.

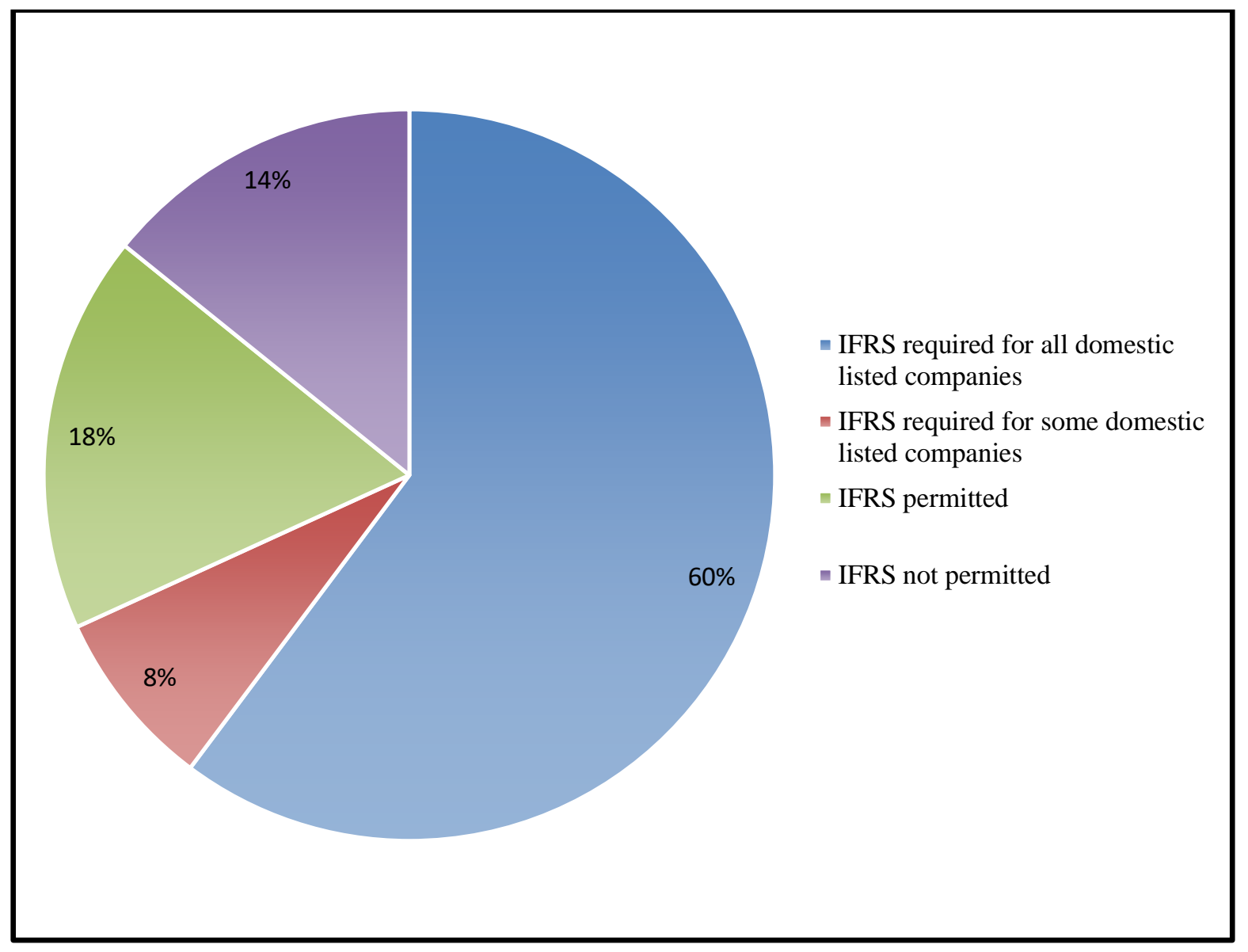

Figure 3.3: Status of IFRS jurisdictions worldwide

Source: Compiled from Table 3.1

The above figure indicates in percentages the global status of IFRS adoption. The chart shows where IFRS is required for all domestic listed companies, and this represents $60 \%$ of the total jurisdictions. Also, only $8 \%$ of domains require IFRS for some locally listed companies, while jurisdictions that permit IFRS amount to $18 \%$, and only $14 \%$ of the total jurisdictions do not permit the use of IFRS. Thus, after more than a decade after IFRS was introduced, many countries are yet to adopt it, most notably the large and most advanced economies. Moreover, after examining IFRS jurisdictions worldwide, it is also essential to investigate the status of IFRS in Africa. 


\subsubsection{The status of IFRS in Africa}

The globalisation of the economy, coupled with the internationalisation of business, advanced the establishment of a single set of international accounting standards (Chand \& White, 2007). Moreover, the UNCTD (2008) reports that developing countries, including African countries, should enjoy the benefits of the globalisation of business, which, in turn, facilitates the development of IFRS. Similarly, McCreevy (2005) and Tweedie (2006) state that developing and emerging economies will also benefit immensely from the adoption of a single set of high-quality international accounting standards. Hence enable them to achieve a stable and liquid capital market that will influence their economic growth. The authors also emphasise that unfamiliar standards (i.e., national standards) create a risk premium, which increases the cost of capital and, in turn, reduces foreign investment inflow.

Additionally, Tweedie (2006) expresses the common belief that a set of single international accounting standards will improve transparency, increase foreign investments, and reduce the cost of capital. Prior research has examined the desire of developing and emerging economies to adopt IFRS. Draz and Ahmad (2017) emphasise that developing nations lack the funds to earmark financial and technical resources to develop high-quality local accounting standards, which makes it all the more worthwhile to adopt international standards. Furthermore, the adoption of IFRS by developing countries will save time, cost and efforts instead of preparing their accounting standards. Table 3.2 below presents the status of IFRS adoption in African countries.

Table 3.2: $\quad$ Status of IFRS adoption in Africa

\begin{tabular}{|c|c|c|c|c|c|c|c|}
\hline Country & $\begin{array}{c}\text { IFRS } \\
\text { permitte } \\
\mathbf{d}\end{array}$ & $\begin{array}{c}\text { IFRS } \\
\text { not } \\
\text { permitte } \\
\mathbf{d}\end{array}$ & $\begin{array}{c}\text { IFRS } \\
\text { required } \\
\text { for some } \\
\text { listed } \\
\text { compani } \\
\text { es }\end{array}$ & $\begin{array}{c}\text { IFRS } \\
\text { required } \\
\text { for all } \\
\text { listed } \\
\text { compani } \\
\text { es }\end{array}$ & $\begin{array}{c}\text { The audit } \\
\text { report } \\
\text { states } \\
\text { complian } \\
\text { ce with } \\
\text { IFRS }\end{array}$ & $\begin{array}{c}\text { Use of } \\
\text { IFRS by } \\
\text { unlisted } \\
\text { compani } \\
\text { es }\end{array}$ & $\begin{array}{c}\text { Year of } \\
\text { adoptio } \\
\text { n }\end{array}$ \\
\hline Algeria & & $\mathrm{XX}$ & & & & & \\
\hline Angola & & $\mathrm{XX}$ & & & & & \\
\hline Benin & & $\mathrm{XX}$ & & & & & \\
\hline Botswana & & & $\mathrm{XX}$ & & & \\
\hline $\begin{array}{c}\text { Burkina } \\
\text { Faso }\end{array}$ & & $\mathrm{XX}$ & & & & & \\
\hline Burundi & & & & & & \\
\hline
\end{tabular}




\begin{tabular}{|c|c|c|c|c|c|c|c|}
\hline Country & $\begin{array}{c}\text { IFRS } \\
\underset{d}{\text { permitte }}\end{array}$ & $\begin{array}{c}\text { IFRS } \\
\text { not } \\
\text { permitte } \\
\text { d }\end{array}$ & $\begin{array}{c}\text { IFRS } \\
\text { required } \\
\text { for some } \\
\text { listed } \\
\text { compani } \\
\text { es }\end{array}$ & $\begin{array}{c}\text { IFRS } \\
\text { required } \\
\text { for all } \\
\text { listed } \\
\text { compani } \\
\text { es }\end{array}$ & $\begin{array}{l}\text { The audit } \\
\text { report } \\
\text { states } \\
\text { complian } \\
\text { ce with } \\
\text { IFRS }\end{array}$ & $\begin{array}{l}\text { Use of } \\
\text { IFRS by } \\
\text { unlisted } \\
\text { compani } \\
\text { es }\end{array}$ & $\begin{array}{c}\text { Year of } \\
\text { adoptio } \\
\text { n }\end{array}$ \\
\hline $\begin{array}{l}\text { Cape } \\
\text { Verde }\end{array}$ & & $\mathrm{XX}$ & & & & & \\
\hline Cameroon & & $\mathrm{XX}$ & & & & & \\
\hline $\begin{array}{l}\text { Central } \\
\text { Africa }\end{array}$ & & $\mathrm{XX}$ & & & & & \\
\hline Chad & & $X X$ & & & & & \\
\hline Comoros & & $\mathrm{XX}$ & & & & & \\
\hline $\begin{array}{c}\text { Cote } \\
\text { d'Ivoire }\end{array}$ & & $\mathrm{XX}$ & & & & & \\
\hline $\begin{array}{l}\text { D.R. } \\
\text { Congo }\end{array}$ & & $X X$ & & & & & \\
\hline Djibouti & & $\mathrm{XX}$ & & & & & \\
\hline Egypt & & $\mathrm{XX}$ & & & & & \\
\hline E. Guinea & & $\mathrm{XX}$ & & & & & \\
\hline Eritrea & & & $X X$ & & & & 2009 \\
\hline Ethiopia & & $\mathrm{XX}$ & & & & & \\
\hline Gabon & & $X X$ & & & & & \\
\hline $\begin{array}{c}\text { The } \\
\text { Gambia }\end{array}$ & & & & $\mathrm{XX}$ & & & 2007 \\
\hline Ghana & & & & $\mathrm{XX}$ & $\mathrm{XX}$ & $\mathrm{XX}$ & 2007 \\
\hline Guinea & & $\mathrm{XX}$ & & & & & \\
\hline G. Bissau & & $\mathrm{XX}$ & & & & & \\
\hline Kenya & & & & $X X$ & $\mathrm{XX}$ & $\mathrm{XX}$ & 2005 \\
\hline Lesotho & & & $X X$ & & $\mathrm{XX}$ & & 2009 \\
\hline Liberia & $\mathrm{XX}$ & & & & & & 2018 \\
\hline Libya & & & $\mathrm{XX}$ & & & & \\
\hline $\begin{array}{c}\text { Madagasca } \\
\mathrm{r}\end{array}$ & & & $\mathrm{XX}$ & & & & 2005 \\
\hline Malawi & & & & $\mathrm{XX}$ & $\mathrm{XX}$ & & 2001 \\
\hline Mali & & $\mathrm{XX}$ & & & & & \\
\hline Mauritania & & $\mathrm{XX}$ & & & & & \\
\hline Mauritius & & & & $\mathrm{XX}$ & & $\mathrm{XX}$ & 2005 \\
\hline Morocco & & & $X X$ & & & & 2008 \\
\hline
\end{tabular}




\begin{tabular}{|c|c|c|c|c|c|c|c|}
\hline Country & $\begin{array}{c}\text { IFRS } \\
\text { permitte } \\
d\end{array}$ & $\begin{array}{c}\text { IFRS } \\
\text { not } \\
\text { permitte } \\
\text { d }\end{array}$ & $\begin{array}{c}\text { IFRS } \\
\text { required } \\
\text { for some } \\
\text { listed } \\
\text { compani } \\
\text { es }\end{array}$ & $\begin{array}{c}\text { IFRS } \\
\text { required } \\
\text { for all } \\
\text { listed } \\
\text { compani } \\
\text { es }\end{array}$ & $\begin{array}{l}\text { The audit } \\
\text { report } \\
\text { states } \\
\text { complian } \\
\text { ce with } \\
\text { IFRS }\end{array}$ & $\begin{array}{c}\text { Use of } \\
\text { IFRS by } \\
\text { unlisted } \\
\text { compani } \\
\text { es }\end{array}$ & $\begin{array}{c}\text { Year of } \\
\text { adoptio } \\
\text { n }\end{array}$ \\
\hline $\begin{array}{l}\text { Mozambiq } \\
\text { ue }\end{array}$ & & & & $\mathrm{XX}$ & $\mathrm{XX}$ & $\mathrm{XX}$ & 2010 \\
\hline Namibia & & & & $X X$ & & $\mathrm{XX}$ & 2005 \\
\hline Niger & & $X X$ & & & & & \\
\hline Nigeria & & & & $\mathrm{XX}$ & & $\mathrm{XX}$ & 2012 \\
\hline $\begin{array}{l}\text { R. of } \\
\text { Congo }\end{array}$ & & $\mathrm{XX}$ & & & & & \\
\hline Rwanda & & & & $\mathrm{XX}$ & $\mathrm{XX}$ & $\mathrm{XX}$ & 2008 \\
\hline $\begin{array}{c}\text { Sao Tome } \\
\text { P }\end{array}$ & & $\mathrm{XX}$ & & & & & \\
\hline Seychelles & & $\mathrm{XX}$ & & & & & \\
\hline Senegal & & $\mathrm{XX}$ & & & & & \\
\hline $\begin{array}{l}\text { Sierra } \\
\text { Leone }\end{array}$ & & & & $\mathrm{XX}$ & $\mathrm{XX}$ & $X X$ & 2010 \\
\hline Somalia & & $\mathrm{XX}$ & & & & & \\
\hline $\begin{array}{l}\text { South } \\
\text { Africa }\end{array}$ & & & & $X X$ & $X X$ & $\mathrm{XX}$ & 2005 \\
\hline $\begin{array}{l}\text { South } \\
\text { Sudan }\end{array}$ & & $X X$ & & & & & \\
\hline Sudan & & $\mathrm{XX}$ & & & & & \\
\hline Swaziland & & & & $\mathrm{XX}$ & $\mathrm{XX}$ & $\mathrm{XX}$ & 2009 \\
\hline Tanzania & & & & $\mathrm{XX}$ & $\mathrm{XX}$ & $\mathrm{XX}$ & 2004 \\
\hline Togo & & $\mathrm{XX}$ & & & & & \\
\hline Tunisia & & $X X$ & & & & & \\
\hline Uganda & & & & $\mathrm{XX}$ & & $\mathrm{XX}$ & 1998 \\
\hline Zambia & & & & $\mathrm{XX}$ & & $X X$ & 2005 \\
\hline Zimbabwe & & & & $X X$ & $X X$ & & 1996 \\
\hline TOTAL & 1 & 30 & 6 & 17 & 12 & 14 & \\
\hline
\end{tabular}

Source: Ball (2016); IFRS (2017); Deloitte (2017), PwC (2016) 
Table 3.2 is divided into eight columns. The first column contains a list of all 54 African countries, which forms the total population for this study. The next column lists countries that have permitted the use of IFRS, but they have not yet commenced with its use. Only Liberia falls into this category. The date of commencement was slated for 2018 due to the problem of Ebola. The third column shows the total number of African countries yet to adopt IFRS, 30 in total. Six countries (6), (fourth column), require the use of IFRS for some listed companies. In comparison, 17 countries (fifth column) made the use of IFRS mandatory for all domestic companies listed on the various countries' stock exchanges. The column for audit reports (sixth column), indicates compliance of the individual country with IFRS. The next column reveals the number of countries that have permitted the use of IFRS for SMEs, while the last column shows the date of adoption of IFRS.

The following countries in Africa do not have stock exchanges: Angola, Cameroon, Central African Republic, Chad, Comoros, Democratic Republic of Congo, Equatorial Guinea, Gabon, Gambia, Guinea, Lesotho, Liberia and the Republic of Congo. The non-availability of the stock exchange may affect the timely adoption of IFRS. The total number of IFRS jurisdictions in Africa equals 24 that permit or require IFRS for domestic listed companies. The figure below elucidates the outcome of the findings.

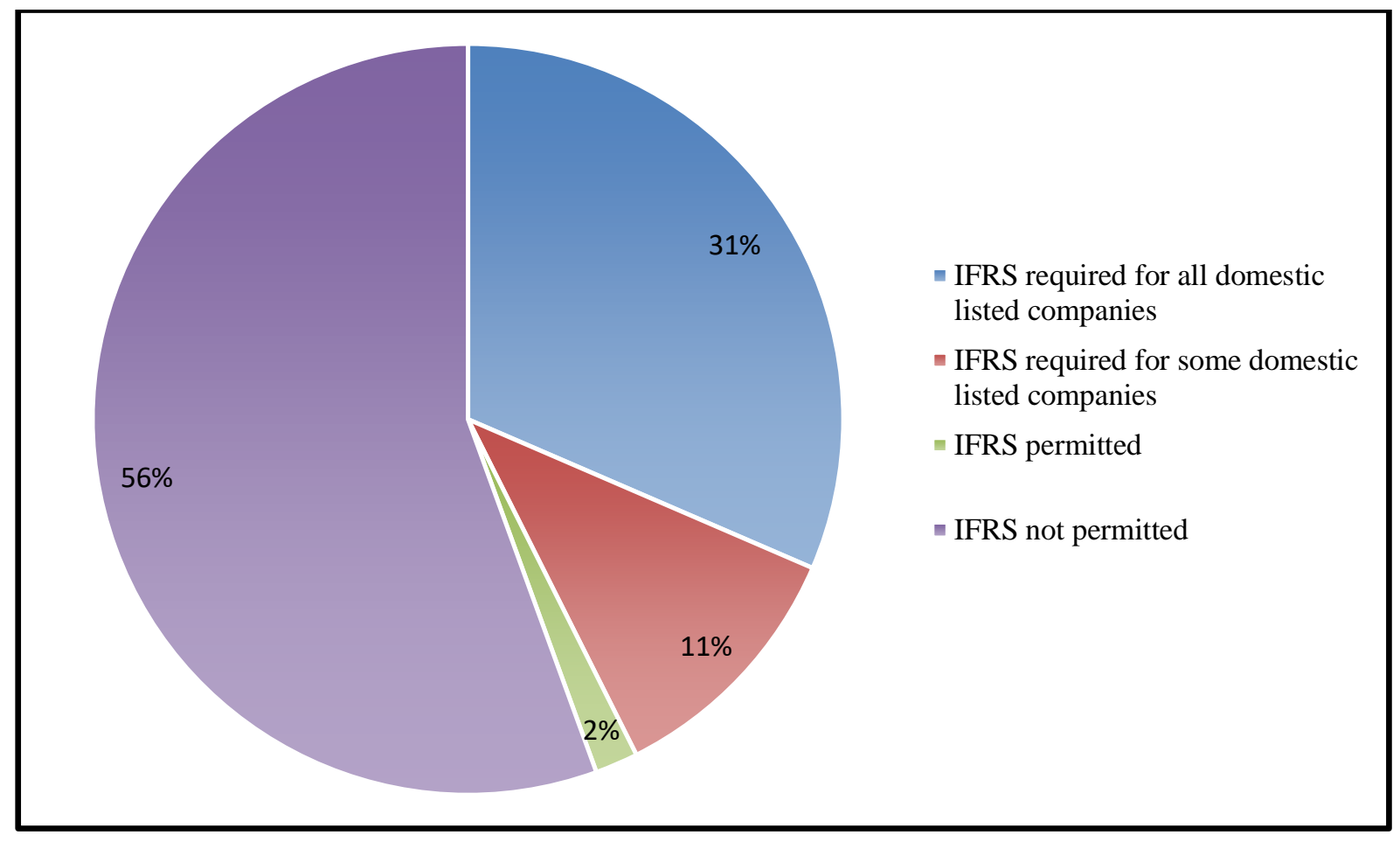

Figure 3.4: IFRS jurisdictions in Africa

Source: Compiled from Table 3.2 
Also, all 24 jurisdictions in Africa have made a public commitment to support IFRS as a single worldwide set of high-quality accounting standards and have incorporated it into their laws or regulations. This pronouncement makes IFRS adoption in African countries mandatory for all countries that have adopted IFRS. The next section will discuss the relevant accounting theories that guide the decision of African countries to adopt IFRS.

\subsection{Some relevant theories relating to accounting information}

Researches emphasise that IFRS adoption can be associated with informational change due to its inherent propensity in eliminating the information challenges confronting the existing and potential investors in foreign markets (Beneish et al., 2015). Hence, it is pertinent to examine some of the current theories relating to accounting information. Given this, the following underpinning relevant theories of accounting information are discussed. Firstly, the agency theory (Alchian $\&$ Demsetz, 1972; Jensen \& Meckling, 1976). Secondly, decision-usefulness theory (AAA 1966; Chambers, 1955). Thirdly, the institutional theory (Hawley, 1981; DiMaggio \& Powell, 2000). Fourthly, the information asymmetry theory (Ackerloff, 1970) and lastly, the stakeholder theory (Freeman, 1984).

\subsubsection{Agency theory}

Agency theory started as an economic theory by Alchian and Demsetz (1972) and later improved upon by Jensen and Meckling (1976). Essentially, agency theory explains the entity's contractual relationship between the owners and the management. According to the theory, agency relationship arises when the owners of the resources, called the principal (the shareholders), hire other individuals, refer to as agents (managers), to perform certain legal, economic activities on behalf of the principal. These activities are binding on the principal through the delegation of authority over the economic resources of the entity (Efobi, 2017; Jensen \& Smith, 2000). This means that the entity duties are delegated in a particular to increase the efficiency of the entities, on the assertion that the agent is having an ethical behaviour relating to agent's professional competence (Gomo \& Pantea, 2016).

Lambert (2001:4) explains why the agency theory is of interest to the researchers in financial accounting. This is because it takes into cognisance the conflicts of objective, the incentive problems, and strategy of monitoring the difficulties. The theory believes that when there are conflicting decisions, the principal or agent will select the best option that will maximise his interest (Davis \& Prince, 2010). Additionally, agency theory believes that individual acts in their 
self-interest and the critical things for an entity to do is to put in place a well-functioning mechanism, that will be of benefits to all parties, including the organisation. Given this, the primary available source of information for the principals is the financial reporting that must be prepared with high-quality accounting standards that comprise some rules and regulations that will guarantee the reliability of the report.

Consequently, the decision to adopt IFRS could be a strategy to reduce the divergence of interest between the two parties. Since the benefits derived when IFRS is adopted will influence the shareholders to favour the adoption of IFRS. Additionally, they believe that with the adoption of IFRS, the discretionary accounting choices by the managers and the information asymmetry will reduce.

Invariably, agency theory has been criticised. For example, Hirsah and Friedman (1986) report that agency theory failed to address any organisational problems but only reports that there is a difference of interest among the entities. Nevertheless, the accounting standard-setters are of the opinion that the appropriate approach to resolve these differences is the constant improvement of the accounting standards for the usefulness of the stakeholders, especially the shareholders.

\subsubsection{The decision-usefulness theory}

The primary purpose of the financial statement is to present an understandable, relevance, reliability, and comparability accounting information to users (Van Greuning et al., 2011:4). Furthermore, it has been emphasised in the literature the importance of decision-making in investment, especially when investors were confronted with the condition of investment and economic uncertainty (Smith, 2003:43). Kribat (2009) affirms the importance of decision making under uncertainty that it may require the development of the relevant behavioural framework. This scenario influenced researchers in economics and finance to develop theories with more emphasis on financial accounting, focusing on decision usefulness of accounting information. The theories further assist in the empirical development in the quest for IASB conceptual framework for accounting (Smith, 2003:43).

The decision-usefulness theory was emphasised by Chambers (1955) as an outcome of the assumption of the management that there shall be an information providing system that will serve as a basis for making the economic decision and predicting the alternative approach of interest to the users. Such an accounting system should be valid, consistent and relevant to the decision it intended to facilitate. Mardin (2012) and Staubus (2000:1) opine that the users in taking economic 
decisions applied financial reporting in the past minimally. They reported that most of the accounting literature failed to discuss the primary objective of providing financial information useful in making economic decisions. Because of this, there is the need for reliable, efficient and faithful accounting information, which will be of a high standard in assisting the users in making economic decisions. The authors further explained that the accounting statement must have the capability of predicting future changes in the residual equity if it is to be of maximum useful.

Furthermore, a committee established by the American Accounting Association (1966) favoured the decision-usefulness theory. The Committee opines that the decision-usefulness approach is the most relevant principle in choosing the method of accounting measurement that has the predictive capability of financial accounting information. In the opinion of the Committee, the extent the investors can predict the certainty of future occurrence of economic and financial results, when relying on accounting information in making an economic decision, the higher the usefulness of the information to the users and for the standard-setter to choose the appropriate accounting measurements. Therefore, the standard-setter will be able to determine the zero levels of error margin of the best alternative that will enable the investors to predict the outcome of economic events.

Additionally, Christensen (2010) explains that conceptual frameworks for financial reporting emphasise that financial reporting should provide useful financial information to capital providers. According to the author, it will enable them to decide whether to continue their investment or disinvest in a particular entity by relying on published financial reporting by the entity. The investor will react to the published financial reporting and decide the need and authenticity of the reality of financial reports to rely upon in predicting the outcome of future economic events. This shows that reliable accounting information must have the ability to predict economic events because prediction is very relevant to the economic decision process.

However, the decision-usefulness theory is one of the most critical concerns of the standards setters, and there is a consensus among accounting researchers that the introduction of IFRS will improve the usefulness of financial reporting by facilitating the comparability, transparency and the reliability of financial statements internationally (Kribat, 2009; Kimeli, 2017 as well as Mardini 2012). Thus, it shows that the primary objective of financial information is to provide useful information to users to enable them to predict the economic and financial decisions accurately. This objective can only be achieved if the firm is using a high-quality international accounting standard such as IFRS. 
There are criticisms against this theory. AAA (1966), Armstrong (1977), and Gambrell (2019) report that the problem of the decision-usefulness theory is that the interest of different users of accounting information was not defined. Similarly, the accounting professionals are of the different pinions that the primary objective of financial reporting is to provide useful information for economic decisions. On the contrary, the opposition argued that financial statements were prepared mainly to report on the stewardship of the management. Nevertheless, the importance of financial report is its decision usefulness, and it is essential for the entity that is reporting to make the financial report more useful to the various users by complying with all the accounting standards rules and regulations.

\subsubsection{Institutional theory}

The management scholars developed the institutional theory in the 1970s, such as Meyer and Brown (1977), DiMaggio and Powel (1983), \& Friedland et al., (1991). Among them, DiMaggio and Powel (1983) research work constitutes a significant development in the institutional theory. They examined why organisations have the same degree of similarity. Therefore, they studied how an organisational structure can be embraced to bring acceptability to another organisation. They further mentioned that organisational forms confront with a lot of power and challenges in their environment that will enable them to have a similar identity with each other, especially if they are in the same line of business.

Although the institutional theory is a foremost robust theoretical framework in organisation investigation, the concept has also been the focus of some researchers in accounting, like Covaleski and Dirsmith (1988), Broardbent et al. (2001), Brignal and Modell (2000), Rollins and Bremser (1997), Fogarty (1996), Phan (2014), and Aldemir and Uysal (2017) have used the institutional theory in their studies. More importantly, these authors Fogarty (1996) and Phan (2014), have used the institutional theory as an examination of accounting standard-setting development. Dillard et al. (2004) emphasise that institutional theory is gaining more relevance in accounting research as a theoretical framework for the study of accounting practice in an entity.

Fernando and Lawrence (2014), Dillard et al. (2004), DiMaggio and Powel (1983) emphasises that isomorphism (one of the dimensions of institutional theory) is a compelling process that forces one unit of an organisation in a particular domain to adapt (corporate reporting) the same features and practices of another group that operates under the same conditions of the environment. They explained that the isomorphic process would make the organisations become homogeneous in a 
particular domain and familiarise with the anticipation of a broader society to avoid any variance or deviation that may cause criticism.

DiMaggio and Powel (1983) identify three types of isomorphic processes as coercive isomorphism, mimetic isomorphism, and normative isomorphism. In the case of coercive isomorphism, it occurs when the entity changes its institutional practices due to forces from internal or external, especially from the organisations they depended on. Coercive isomorphism is caused by powerful influence and the difficulties of acceptability that may affect the operations of the entity. Given this, the organisation day-to-day running activities would change because the organisation was forced to adopt a particular practice (such as the selection of accounting procedures). In the case of mimetic isomorphism, DiMaggio and Powel (1983) explain that this happens when an organisation is making efforts to emulate another organisation existing institutional practices because of legitimacy and uncertainty. The last one is normative isomorphism that was explained by DiMaggio and Powel (1983) as a pressure emanates from norms, customs, and beliefs of a group, especially a professional group, to adopt a specific institutional practice for all the members in the group. As relates to the adoption of international accounting standards, the anticipation that accountants will observe and comply with the generally accepted international accounting principles where he works is a form of normative isomorphism (Deegan, 2010:358).

Phan (2014) explains that normative isomorphism occurs due to pressures from professional accountancy bodies. Rodrigues and Craig (2007) opine that normative isomorphism is evident in many countries, due to the more considerable influence of professional accountancy bodies in the process of adoption of IFRS. Additionally, Rodrigues and Craig (2007); Chand et al. (2010) and Gillis (2011) report that the Big Four international accounting firms (i.e., PwC, Deloitte, KPMG, and Ernst \& Young) play essential roles in the worldwide adoption of IFRS. This represents a normative pressure from the professional accounting bodies. Consequently, their roles assumed to be a significant international force behind the process and development of international accounting standards, especially in developing countries.

The institutional theory emphasises that the adoption of IFRS by developing countries, especially in Africa, maybe due to pressures from international organisations because of their inability to develop their reliable accounting standards. Therefore, IFRS is considered as a legitimate, current, and a single set of high-quality global accounting standards by numerous international organisations. Such as the World Bank (WB), the International Monetary Fund (IMF), the United 
Nations (UN), the European Union (EU), the International Organisation of Securities Commissions (IOSCO), World Trade Organisation (WTO), the Organisation for Economic Cooperation and Development (OECD), and the International Accounting Standards (IASB) (Lasmin, 2011).

Thus, the theory indicates that an organisation or a country may succumb to pressure to change from one policy to the other to achieve legitimacy. However, it argued that many developing countries achieve the status of IFRS through authoritative political and economic organisation bodies worldwide. The essence of this will be paramount to researchers in the field of accounting.

\subsubsection{The information asymmetry theory}

The information asymmetry theory was originated from the work of Ackerloff academic paper on the "market for lemons" perspectives, which relates quality and uncertainty (Ackerloff, 1970). The seminal article shows how a market with unbalanced information can cause a total disappearance or offer with poor quality where harmful products (lemons) wipe out the good ones. This concept was introduced in 1970, and it emphasised that the quality of goods reduces due to differences in the quality of available information to the buyer and seller, thus, causing information asymmetry. Ackerloff (1970) argues that information asymmetry enables the seller to sell goods of less than the average market value. However, the author further reported that it is only the sellers that always have reliable information about the product. Hence, it caused problems for the buyers if the decision was based on wrong or incomplete information. The empirical evidence for the theory came from the market for used cars, but the model is also valid in some other markets such as financial markets. Thus, in financial markets, the lemon's perspective shows that in the absence of disclosing reliable information, the financial markets will believe that the entity is a lemon (faulty). This means that the inability to make available reliable and efficient information to the users is equivalent to inadequate or poor quality information.

Consequently, the concept influences the managers to make available efficient information that affects the behaviour of users in making decisions, even in the absence of any accounting regulations (Deegan, 2010:63). Mwangi et al. (2014) explain that the financial market is imperfect, and parties to the market are information deficient. Therefore, it hindered them in carrying out their financial transactions without a link. In order to alleviate this problem, financial reporting serves as a link or intermediary to both parties (internal and external) to have access to financial information of the reporting entity. 
Furthermore, Kimeli (2017) reports that non-disclosure by the managers of adequate and reliable financial information of an entity will lead to disequilibrium information needs of the users, hence causing information asymmetry. This shows that in the presence of information asymmetry, the managers with bad and unpleasant news may not disclose such information at that time. Subsequently, when the undisclosed information is now known, the market will react to the regulator likewise and alleging the firm for contravening the rule of not disclosing relevant information to the public.

Accordingly, the financial report assists in reducing the problem of information asymmetry by prescribing specific standards to be followed when disclosing accounting information and at the same time prescribing penalties for not disclosing certain relevant information. These requirements will enable the disclosure of all relevant information by the entity that is fundamental for the users to base their investment and economic decisions. Consequently, the adoption of IFRS will go a long way in reducing the information asymmetry because it contains much minimum information to be disclosed in the financial statement than national accounting standards (Ball, 2016). Furthermore, the principal purpose of developing IFRS is to make the financial reporting to be more transparent and easily compared in achieving this; the financial statement must be free from information asymmetry.

Auronen (2003) explains that the primary strength of asymmetry information is the ability to explain previously unexplained economic phenomena and acknowledge the information as the market determinant. Nevertheless, further explained that there are some criticisms against the information asymmetry such as over-dependence on the regulation of financial markets since it dictates the absolute minimum and quality of information to be disclosed. Also, it considers asymmetries in one direction, but there may be information differences in favour of another party since people might have access to different information.

\subsubsection{The stakeholder theory}

Freeman (1984:86) defines a stakeholder as "any group or individual who can affect or is affected by the achievement of the organisation objectives." Furthermore, the definition was redefined as "those groups who are vital to the survival and success of the corporation" (Freeman et al., 2004). Also, the authors further mentioned that the stakeholder theory emphasises that an organisation has implicit and explicit contracts that emanate from various stakeholders and is accountable for 
the success of these contracts. Similarly, Kimeli (2017) opines that these contracts enable the firm to establish a status to suit its trading conditions and negotiations with the stakeholders.

Consequently, in an attempt to identify who are the stakeholders, Clarkson (1995:106) restricts a shareholder to person or group that have, or claim, ownership rights, or interests in a corporation and its activities, past, present or future. Thus, those who have a financial interest in the firm. In the study of Orts and Strudler (2002), they emphasise the risk element as a critical characteristic of stakeholders since they parted their financial assets as investment in the firm's capital for uncertainty. Hence, these different views held as whom the stakeholders are posed many challenges to the mangers in deciding the set of individuals or groups to pay more attention to.

Moreover, the basic concept of stakeholder is the redefinition of the organisation which means what the organisation should be and how it should be conceptualised (Freeman, 1984:86). Friedman and Miles (2006:1-4) opine that the organisation is assumed to be a conglomeration of stakeholders who are saddled with the responsibilities to manage their welfares. The authors identified the main groups of the shareholders as those who have classifiable links with the firm and otherwise as customers, employees, local communities, suppliers and distributors and shareholders. Also, the otherwise groups are the media, the public in general, business partners, future generations, past generations, academics, competitors, non-governmental organisations, trade unions, financiers, government, regulators, policymakers, etcetera. The managers, acting as the agent of the firm, are in the position to fulfil the needs of stakeholders for the survival and continue the existence of the firm. However, failure of the managers to perform satisfactorily or breaching the duty of care, the stakeholders may institute action against them.

Consequently, the definition of stakeholder, the purpose of the organisation, the responsibilities of the manager, and the concepts explained above are identified as normative and positive stakeholder theories in the literature (Fountaine et al., 2006). Thus, the idea of the normative (ethical) branch of the stakeholder theory perspective explains how the managers or shareholders should act and their perception about the objectives of the firm (Friedman \& Miles, 2006). Also, it emphasises that irrespective of the status of shareholders, they should be treated fairly by the organisation, and the issue of stakeholder power should not be the concern (Deegan, 2010:347). Another approach to the stakeholder concept is the positive (managerial) branch of shareholder theory, which is concerned about how the anticipations of particular shareholder groups (typically influential stakeholders) may have more or less effect on organisation strategies. Therefore, based upon this perspective, the stakeholders' groups can be identified according to their materiality influences on 
the organisation. Nevertheless, all the stakeholders have a minimum right to be provided with information concerning their relationship with the firm since it is the responsibility of the firm to provide such information as it affects the stakeholders in general.

However, the primary objective of the general purpose financial reporting only makes provision for the primary users of financial reporting. The primary users, such as present and potential investors, lenders and other creditors who use financial reporting to make investment decisions, were only emphasised in the objective (Christensen, 2010).

Similarly, the responsibility of the manager to provide diversified information to all the groups of stakeholders creates many challenges for the accountants in reporting their stewardships. In this process, the IFRS framework has limited the scope of the financial reports to the users who have a classifiable relationship with the organisation. Deegan (2010:348) opines that the focus on primary stakeholder theory is a contradiction of the perspective of the ethical branch of stakeholder theory who emphasises that all stakeholders have the right to be provided with information.

\subsubsection{The relevant theoretical underpinning}

When researching the relevance of accounting standards as a framework to prepare financial statements by the reporting entities for users to take the decision, the decision usefulness theory provides the appropriate guideline. Consequently, the theoretical justification that will address the research problem for this study is the decision usefulness theory. This is based on the premise that the adoption of IFRS will enable the financial report to be more accurate, comprehensive and comparable. Therefore, making it more useful for the decision-making process by the users. Beneish et al. (2015) report that the uniformity of financial reporting standards worldwide has improved the decision usefulness of financial statements. It also assists the investors in having more confidence in the financial reports and rely on it for investment decision making. Equally, the globalisation of capital markets has called for high-quality international accounting standards. The standards that will be more transparent and useful to users in making the economic decision. Also, that will influence more flows of FPI than relying on national accounting standards.

The effect of IFRS adoption on FPI is assumed to be significant since the adoption will enhance the usefulness of financial reporting in making investment decisions. Consequently, the adoption of IFRS is supposed to change the perception of investors about the reliability and usefulness of financial statements in making investment decisions. The relevance of accounting information to investors influences the application of the theory of decision-usefulness. Hence, the theory will 
assist to empirically determine the explanatory power of accounting information in enhancing the flow of FPI. The next section will discuss the methodological choice and consider the relevance to the positivism philosophical assumptions.

\subsection{Overview of the literature on IFRS}

Ankarath et al. (2010:7) report that, in 2001, the IASB developed IFRS as a set of single international accounting standards. The standards, according to the authors, would protect the interests of the public, especially investors, to ensure the efficient allocation of resources in the global economy. Pacter (2014:9) reports that IFRS developed by the IASB are worldwide accounting standard rules and regulations to be used by all the listed companies in the preparation of their financial statements. The author further explains that the IASB achieved the vision to develop a unified set of high quality, understandable and enforceable global accounting standards that require high quality, transparent and comparable information in financial reporting to be useful to participants in world capital markets and other users in making investment decisions.

Kothari et al. (2010) explain that the essence of having unified global accounting standards is to enable capital providers to allocate their capital efficiently. The efficient allocation of resources can only be achieved if the cost of obtaining accounting information is low. The IASB emphasised that for capital to be allocated efficiently, financial statements must be transparent and comparable, and this can only be achieved through the adoption of a single set of accounting standards universally. Chen et al. (2014) also explain that the decrease in the cost of capital and the reduction of information asymmetry brought about by the adoption of IFRS would enable capital providers to allocate their capital efficiently.

In the view of Nyor (2012), IFRS are principle-based accounting standards that emphasise a broader rule with multiple methods for the treatment of each item, while GAAP is rule-based. IFRS requires more disclosures of useful accounting information in the financial statements (Ankarath et al., 2010: 2). Danescu and Batos (2016) are of the view that the adoption of a single set of high-quality international accounting standards will ensure that the financial reporting of an entity comes closer to the truth of the economic reality of corporate entities because more relevant and useful accounting information will be disclosed. They further explained that accounting as a profession might lose their credibility and reality internationally if entities are allowed to present financial statements following local accounting standards with less useful accounting information disclosure. Additionally, the local accounting standards would put the reliability of financial 
statements at risk because of differences in accounting practices and rules. This situation would make comparable financial reporting difficult and would hinder the flow of foreign investment. Thus, uniform accounting practices will aid the efficient allocation of scarce resources in global capital markets and enhance foreign investment.

Chen et al. (2014), Gordon et al. (2012), and Kolsi and Zehri (2013) express that entity that makes use of internationally accepted accounting standards, namely IFRS, when preparing their financial statements assume to have more influence in attracting foreign capital. Such a financial statement would be of high quality, transparent, and comparable with similar entities worldwide. Manyara (2013) and Sabin (2019) found that there is an association between the adoption of IFRS and foreign investments in countries that adopt IFRS. Assenso-Okofo et al. (2011) observe that capital has become an international product, and it would require developing countries to strengthen their institutions that regulate accounting disclosures and practices to consider the adoption of international accounting standards that would then enable them to attract more foreign capital.

Besides, Ben-Othman and Kossentini (2015), Christensen et al. (2013), Judge et al. (2010), and Nnadi \& Soobraroyen (2015) explain that accounting standards and the quality of financial reporting are fundamental components of a country's institutional infrastructure. Additionally, financial reporting prepared following internationally accepted accounting standards would ensure transparency, comparability of financial statements and reduction in information asymmetry and would assist investors in reducing the risks and uncertainty in investments. They also note that investors rely on financial statements for making investment decisions.

Olamide and Ajibade (2016) observe that the adoption of a single set of high-quality international accounting standards in financial reporting would consequently reduce the problems of accounting diversity and encourage more participation in global capital markets. They also observe that it would be a prerequisite for enhancing foreign investments worldwide. Thus, consistent with the benefits of IFRS in financial reporting is the expectation that foreign investments would improve in a country that adopted IFRS.

It has been emphasised that the adoption of IFRS will bring economic prospects to the adopting countries as advocated by standard-setters, accounting firms, analysts, and, most especially, the proponents of IFRS (Ball, 2016). Similarly, Brown and Tarca (2012) observe that a country's choice to use IFRS is obviously to achieve the benefits of adoption in terms of the flow of foreign investments. Consequently, most research findings support the view that the adoption of IFRS 
influences the usefulness of accounting information in making investment decisions The following studies found an increase in improvement of the value relevance of financial information in deciding between the adoption of IFRS (i.e. Adebimpe \& Ekwere, 2015; Aharony et al., 2010; Ahmed et al., 2013; Bhat et al., 2010; Jermakowicz et al., 2007; Morricone et al., 2009; Muhibudeen, 2015; Olugbenga, 2016; \& Pascan, 2014).

Also, in the extant literature, Ball (2016); Brown and Tarca (2012); Cascino and Gassen (2011); Chen et al., (2014); Kothari et al., (2010) and Pacter (2014:27) posit that IFRS will improve the efficient allocation of capital since it is assumed that using IFRS will make the financial statement more transparent and comparable. The use of IFRS also reduces the degree of information asymmetry of financial statements. Also, it reduces the cost of transactions, which will benefit international capital market participants. Similarly, IFRS adoption will result in the capital markets of adopting countries being recognised internationally, particularly the equity and debt markets (Brown, 2011). Capital markets benefit from IFRS by improving liquidity and by reducing the cost of capital, thereby influencing institutional and individual foreign investors (Bruggemann et al., 2013; Christensen et al., 2013; Daske et al., 2008; Li \& Shroff, 2010).

Foreign investors experience problems in interpreting international financial statements due to unfamiliar reporting standards resulting from the application of local accounting standards in the preparation and presentation of financial statements. Iyoha and Owolabi (2012) argue that with the adoption of a common set of international accounting standards, countries can expect to lower the cost of information processing and the auditing of financial statements. Additionally, countries will be expected to become familiar with one common set of international accounting standards rather than with various local accounting standards. Thus, the harmonisation of different accounting standards has apparent advantages in terms of comparability, understandability, and reliability of financial information across companies and countries to keep local and attract foreign capital.

According to (Lin et al. 2019; Opare et al. 2019; and Yip and Young, 2012), the adoption of IFRS increases the comparability of financial statements, therefore removing the barrier for cross-border capital investments. Hence countries that adopt IFRS are assumed to experience more inflow in FPI since the financial statements prepared according to IFRS framework can be compared globally. Cascino and Gassen (2010) argue that the comparability of financial information is considered by policy-makers and researchers to be an essential tool for investors in decisionmaking, and the efficient allocation of resources. 
Taiwo and Adejare (2014) emphasise that having a single set of financial reporting standards worldwide would eliminate the need for the restatement of financial statements to suit the purpose of investment in another economy, thus facilitating the cross-border movement of capital and greater integration of global financial markets. Also, it was revealed that entities adopting IFRS exhibit higher accounting quality during post-adoption than during pre-adoption. Making IFRS adoption more beneficial can bring dynamic changes in international markets.

Ocansey and Enahoro (2014) affirm that there is a movement of business towards the global economy and have accelerated the need to move towards global accounting standards. Similarly, Aharony et al., (2010), Gordon et al., (2012) and Shima and Gordon (2011) state that the adoption of IFRS would result in improved investment flow since IFRS can be associated with increased transparency in financial reporting, reduced information asymmetry and a reduction in the cost of processing financial information. Chen et al. (2011) conclude that IFRS promotes foreign investment since it reduces information processing costs for foreign investors, while Gordon et al. (2012) explain that benefits exist in terms of trade and foreign investment when IFRS is adopted.

Likewise, Ahmed and Duellman (2011) emphasise that the adoption of IFRS would benefit investors because of the comparable high quality of financial information resulting from unified accounting standards. It would enable investors to have more confidence in the financial statements being presented by the reporting entity that could easily be compared with similar entities in another economy. Ball (2006) and Haslam et al. (2016) explain that the far-reaching benefits of IFRS adoption include a range of significant economic occurrences in international capital market liquidity, corporate investment efficiency, and foreign capital flows for adopting countries.

Ball (2016) explains that the adoption of IFRS would improve corporate governance by providing managers with timely and accurate financial information for decision-making purposes. Iyoha and Owolabi (2012) illustrate that the benefits of applying one consistent set of reporting standards in subsidiaries from different countries would accrue to companies, while investors would develop, among other benefits, more confidence in the information being presented in the financial statements that they could understand and use.

Despite all the benefits that can be achieved when a country adopts IFRS, there are still some studies against the adoption of IFRS, especially in developing countries. Bilgic and Ibis (2013), Callao et al. (2007), Tsalavoutas et al. (2012), Yasas, and Perera (2019) conclude that after the 
adoption of IFRS no improvement was experienced in the value relevance of accounting information. The fundamental difference in these findings might due to different accounting environments where the research was conducted, reflected in the mixed results on the value relevance of financial information after IFRS adoption. Lang et al. (2006) report that there may be a possibility of differences in financial reporting findings relative to different accounting environments. However, the adoption of IFRS may enhance the relevance of accounting information than using local accounting standards due to its potential of disclosing more reliable accounting information and influence the flow of foreign investments.

Iyoha and Owolabi (2012) report that the non-availability of professional accountants and the cost of implementing a new accounting system would be a challenge in developing countries. Additionally, the high cost of training employees and difficulties in understanding the complex, always changing, and too voluminous nature of IFRS constitute significant challenges. Ahmed et al. (2013) stress that since IFRS is principle-based, it may cause misrepresentation of financial statements, especially in a country where the level of corruption and investor protection are deficient. The adoption of IFRS would not bring uniformity in the manner in which entities report their financial information due to the influence of local forces on accounting practices (Ball, 2016). The cost of the development, preservation, and functioning of a complex institutional structure required for IFRS adoption to translate it into practice, is costly, especially in developing countries with limited institutional infrastructure. Thus, in adopting IFRS, the institutional support in the adopting countries that would act as a catalyst for high-quality accounting standards, are essential.

The goal of IAS regulations with mandatory IFRS is to improve the transparency and comparability of financial statements across countries. The goal is to trigger the credibility and relevance of financial reporting against the national accounting standard, which is unfamiliar to foreign investors. It would also encourage more flow of FPI (equity and debt). Since IFRS has been developed, these assumptions have been significant concerns for the accounting researchers on the justification for achieving the goal.

The next section discusses the empirical relationship between IFRS adoption and FPI inflow as a contextual issue for this thesis. The findings from each empirical study will establish whether the goal of IASB, including the proponents of IFRS, has been achieved. Hence the conclusions of the empirical would reveal gaps in the literature to substantiate further empirical research on the effect of the adoption of IFRS on FPI, which is the focus of this thesis. 


\subsection{The empirical relationship between IFRS and FPI}

Many past studies that have attempted to empirically examine the association between IFRS and foreign investments mainly focused on FDI, but unfortunately, FPI received less attention. However, the literature reveals that some researches focussed on the relationship between IFRS and FPI. As previously discussed, the primary purpose of developing IFRS is to make the financial statements more transparent and comparable globally for foreign investors to make meaningful investment decisions (Amiram, 2012; Beneish et al., 2015; Gordon et al., 2012). It shows that countries that adopt IFRS are expected to experience more flows in their FPI. Nevertheless, there was no consensus in the empirical findings presented in the literature that IFRS indeed had a positive and significant relationship with FPI. They came out with different findings using sample countries from developed and developing countries to justify their conclusions.

For example, Beneish et al. (2015), in their study of macroeconomic evidence on the impact of mandatory IFRS adoption on equity and debt markets, conclude that IFRS has a significant effect on both debt and equity. Also, Yu and Wahid (2014) examined the accounting standards and international portfolio holdings. Their results reveal that the ability to reduce investment in investee countries with a greater accounting distance significantly weakens when accounting distance is reduced in the countries of both investors and investees who adopt IFRS. In the study of DeFond et al. (2011), the impact of mandatory IFRS adoption on foreign mutual fund ownership and the role of comparability is examined. The authors found that mandatory IFRS adoption attracts more significant cross-border equity investment in countries with strong implementation credibility.

Kwarbai et al. (2016) examined the effect of accounting standards and foreign direct investment inflow in selected African countries for the years 1980 to 2015 using stepwise regression analysis, with the Granger casualty test and the Hausman test. Data from six African countries, which included Egypt, Nigeria, Kenya, Morocco, Tunisia, and South Africa, were collected. The results show that the adoption of IFRS influences increases foreign investment inflow to African countries.

In another study, Adetula et al. (2014) determined the impact of IFRS adoption and foreign investment in Nigeria. They used both secondary and primary data. Primary data were collected from managers and preparers of financial statements in companies that adopted IFRS. Fifty-five questionnaires were administered and graded with a five-point Likert scale. Secondary data were 
obtained from the World Development Indicator. One sample t-test was used to test the primary data, while the secondary data were analysed using correlation and regression analysis. The results show that there is a positive relationship between foreign investment inflow and IFRS adoption.

Olugbenga et al. (2016) examined the significant effect of IFRS adoption on Nigerian quoted entities. The aim was to investigate the opinion of the preparers and users of financial statements regarding the impact of foreign investors on quoted entities that adopted IFRS in Nigeria. A questionnaire approach was adopted in collecting the data from one hundred and sixty-five participants. The data were analysed using the statistical tool of regression analysis. The evidence reveals that there was a positive and significant impact of foreign investors on quoted entities that use IFRS in preparing their financial statements.

A study by Efobi et al. (2014) shows the implication of IFRS adoption on foreign investments in a sample of 90 countries in developed and developing countries between the period of 2002 and 2010. The system generalised method of moments estimation technique was used to estimate the data. The results show that IFRS attracts foreign investments, and institutional development plays a significant role in this regard.

Lee and Fargher (2010) carried out a study on whether the adoption of IFRS encourages crossborder investments. The study aimed to look at the effect of IFRS adoption on investors' home equity bias in different countries worldwide, including African countries. The study was based on the premise that the adoption of IFRS would lead to more efficient capital allocation in the form of cross-border investments, especially with an increase in the level of equity investment. The sample comprises 40 countries split into 21 adopting countries and 19 non-adopting countries. The study period covers 2002 to 2008 . The outcomes reveal that the adoption of IFRS is associated with an increase in cross-border equity investment. Also, the study shows that an increase in the comparability of financial statements increased investors' allocation of foreign equity.

Amiram (2012) investigates the association between the adoption of IFRS and foreign investment decisions in 73 countries. Data were sourced from the Coordinated Portfolio Investment Survey (CPIS) between 1997 and 2001 to 2006 and analysed using the ordinary least square regression (OLS) model. The results reveal that foreign equity portfolio investment increases in countries that adopt IFRS.

Emeni (2014) also conducted a study on the relationship between IFRS adoption and foreign investment in Africa. Data were collected from 46 countries in Africa. The ordered logistic 
regression (OLR) technique was employed to analyse the data. The results reveal that foreign investment has a positive, but no significant relationship with the adoption of IFRS in Africa. Gordon et al. (2012) tested the basic argument that the adoption of IFRS by a country increases foreign investment inflows. The sample includes 124 developed and developing countries and covers the period from 1996 to 2008. OLS was employed to analyse the data. The results show that the developing countries witnessed an increase in foreign investment inflow when adopting IFRS, in contrast to the developed countries.

Florou and Pope (2012) studied the mandatory IFRS adoption and institutional investment decisions by looking at their effects on the international holdings of institutional investors. The period covered 2003 to 2006, using information from 24 countries. The authors found that there was a significant and positive increase in cross-border investment in equity and debt of institutional investors in IFRS adopting countries. Their study also reveals that the increase was restricted to countries that have vigorous enforcement and reporting incentives.

Also, existing literature has reported the empirical studies carried out by various researchers. For example, Hamberg et al. (2013), Hong et al. (2014), and Khurana and Michas (2011) studied the relationship between IFRS adoption and foreign portfolio investment (equity and debt). Their studies cover both developed and developing countries. Their findings show that the adoption of IFRS increases the flow of foreign portfolio investment (equity and debt) in adopting countries.

Contrary to the empirical results that emphasise a positive relationship between IFRS adoption and FPI, a few researchers found negative shreds of evidence. For example, Nnadi and Soobaroyen (2015) provide empirical evidence for IFRS adoption and foreign investment in Africa. Thirtyfour countries for 20 years were used, and data were collected from reports on the Observance of the Standards and Codes of the World Bank, from the IFRS Foundation database. The data were analysed using the Pooled OLS regression model. The results show that the comparability effect of full IFRS adoption indicates a negative impact on foreign investment in African countries.

Similarly, Efobi (2017) found a negative and insignificant relationship with FPI in Africa. Adetula et al. (2014) found that there is a positive but not significant relationship between foreign investment inflow and IFRS adoption in their empirical study. Also, Efobi et al. (2014) found that African countries would benefit more from IFRS adoption by improving their institutional framework. 
Also, Kwarbai et al. (2016) observed that IFRS adoption alone could not guarantee an increase in foreign investment inflows into African countries. Similarly, Sherman and De Klerk (2015), in their study on IFRS and foreign-owned companies in South Africa, found that there was no significant and positive relationship with foreign-owned companies that may influence FPI. Despite the different empirical findings from the literature, the benefits of IFRS are still expected to be substantial, especially in developing countries, in terms of encouraging flows of foreign investments due to standardised financial reporting. The next section will discuss some of the determinant factors that may influence the decision of a country to adopt IFRS.

\subsection{Factors influencing the adoption of IFRS in Africa}

Joshi et al. (2013) and Roberts et al. (2005:146) explain that an accounting system is the product of a multifaceted process that can be influenced by several economic, institutional, and political factors that may be internal or external. Nobes (1998) also explains that accounting is influenced by its immediate environments, such as culture, economic development, taxation, and etcetera. Also, the development of international accounting standards is a function of cultural values and country-specific institutional factors. Consequently, this section discusses various factors that influence the decision process of adopting IFRS among the selected countries.

There is substantial extant literature that empirically examined some of the factors that are assumed to influence the decision to adopt IFRS, such as culture, economic growth, capital market development, level of education, foreign operation, the legal system, political system, taxation, external pressure, and investors protection (Kolsi \& Zehri, 2013; Gordon et al., 2012; Jaggi \& Low, 2000; Pricope, 2016; Shima \& Yang, 2012; Zeghal \& Mhedhbi, 2006, Zehri \& Chouabi, 2013). These studies were mainly focussed on developed countries with little research carried out in developing countries, so their findings may not reflect the actual picture in Africa.

For example, Zeghal and Mhedhbi (2006) conducted research to identify factors affecting the adoption of accounting standards. Their results show that the highest literacy rates, the existence, and liquidity of capital markets, and culture are factors that influence the adoption of IFRS accounting standards in developing economies. Shima and Yang (2012) examined factors affecting the adoption of IFRS. They conclude that factors such as equity financing, taxation, the legal system, political and economic ties, inflation, economic development, education, and culture were identified as factors that can influence the adoption of IFRS. Also, Salem et al. (2017) explain that culture and the influence of Big Four accounting firms influenced the adoption of IFRS in most 
African countries. Because of this, there is a need to examine some of the factors influencing the adoption of IFRS on the continent of Africa.

Stainbank (2014) investigated factors that affect the adoption of IFRS in African countries using 32 countries as a sample. Also, the study used five variables, namely, economic growth, education level, economic openness, culture, and a relative capital market size, to determine the factors that influence the adoption of IFRS in Africa. The study used logistic regression to analyse the data. The results indicate that economic growth, market capitalisation, and cultural ties are more significant in influencing the adoption of IFRS in African countries.

This section, therefore, discusses some of the determinant factors that influence the process of IFRS adoption in selected African countries. Table 3.2 indicates that only $30 \%$ of African countries have required all their listed companies to adopt IFRS. It is necessary to investigate the reason for this heterogeneity in African countries' decision to adopt IFRS despite the benefits to be derived.

Many countries all over the world have adopted IFRS as an international accounting standards framework (see Table 3.1), but 70\% of African countries either partially adopted IFRS or resisted the adoption of IFRS. FPI investors base their decisions to diversify their capital from one economy to another on the reliability and efficiency of financial information.

However, there may be a problem of comparability if the financial statements of the investor and investee countries are different. Foreign investors, therefore, also need a thorough understanding of factors that influence the process of IFRS adoption in a country (Judge et al., 2010). However, some of the significant determinants factors that influence the decision to adopt IFRS are discussed below.

\subsubsection{Culture}

Culture plays a prominent role in explaining the choice of relevant and appropriate accounting systems in each nation. Hofstede (2011) explains that culture is the shared motives, values, beliefs, identities, and interpretations or meanings of significant events that result from everyday experiences of members and are transmitted across generations. Culture influences emotion, motivation, behaviour, and interactions. Culture can significantly influence an accounting system (Cieslewicz, 2014). Besides, cultural norms and values have been reported to be varied according to the influence of the external environment (Doupnik \& Salter, 1995). Concerning accounting 
culture, researchers have shown that countries that were influenced or colonised by Anglo-Saxons have more developed and sophisticated accounting systems than non-Anglo-Saxon culture (Zehri \& Chouaibi, 2013). They mentioned that the Anglo-Saxon culture had a significant impact on many national cultures all over the world, especially countries that were colonised by the AngloSaxons. This means that countries with Anglo-Saxon culture may likely adopt the same accounting system, and it will be easier for them to adopt IFRS. Zeghal and Mhedhbi (2006) emphasise that countries with an Anglo-Saxon culture will be more likely to adopt IFRS. This is evident from the large numbers of people from the Anglo-Saxon origin in the project of the IASB (Zehri \& Chouaibi, 2013). There is the likelihood that IFRS adoption will be easier for countries of the same and relevant culture.

\subsubsection{Educational level of a country}

Zehri and Chouaibi (2013) explain that the complex nature of accounting standards requires advanced educational knowledge in various disciplines. The adoption of IFRS by a country needs a high level of professional expertise and academic qualifications to facilitate the interpretation and use of the standards. Bananuka et al. (2019) and Sarapaivanich et al. (2019) report that education is the foundation and bedrock of the sophisticated and complex IFRS accounting systems. The adoption of IFRS will require a high level of educational competence as well, professional and technical expertise from the preparer of the financial statements. These educational attributes will enable them to understand and interpret the standards. McGuire et al. (2012) explain that a high level of education in a country would lead to a lower rate of lawsuits concerning accounting offences. Developing countries with low levels of education may find it challenging to implement IFRS appropriately and to abide by all the rules and regulations of IFRS.

\subsubsection{Capital market development}

The availability of a capital market in a country is considered to be one of the significant ingredients for economic development and growth due to its vital role in enabling optimal capital allocation. Likewise, the quality of financial reporting dramatically contributes to the smooth performance of the capital market (Zeghal \& Mhedhbi, 2006). Ball (2016) emphasises that one of the significant benefits of IFRS adoption focuses on the equity and debt markets, which facilitate the efficient movement of capital. The author explained further that this could only happen inefficient and virile capital markets since the information provided by entities to capital markets should adhere to information disclosure requirements demanded by each stock exchange. Zehri 
and Chouaibi (2013) are of the view that the quality of information available in capital markets will be a significant determinant in the development and efficiency of the capital markets. They further report that the adoption of IFRS should facilitate effective functioning of capital markets to protect investors' interests in international capital markets. Jemakowicz and GornikTomaszewski (2006) affirm that a country's capital market that is opened to international investors is prone to the adoption of IFRS for more inflows of foreign investments. Also, countries with less advanced capital markets may have a higher urge and interest to adopt IFRS to enable them to generate more foreign investment flows. Thus, the adoption of IFRS constitutes a strategy to unify domestic capital markets with international capital markets. Countries with functional capital markets may likely adopt IFRS.

\subsubsection{Foreign operations or trade openness}

Foreign operations or trade openness refers to the activities of an entity or country that are based or conducted in another country. It reflects the economic activities a country engages in with the rest of the world. The more a country conducts foreign operations, the more the tendency to adopt global accounting standards (Nnadi \& Soobaroyen, 2015). Ramanna and Sletten (2010) posit that countries that depend on international trade and foreign investment are expected to adopt IFRS. According to Lau and Ma (1997), international trading partners have a significant influence on economic development, especially in the financial and accounting practices of its local trading partners. Given this, there may be a propensity for trading partners to adopt the standards they use. African countries predominantly rely on foreign partners. Because of this, there may be a tendency to adopt IFRS.

\subsubsection{Investor protection}

Houqe et al. (2012) emphasise that the quality of the financial statements would improve where a country's investor protection policy offers stronger security for the investors. Jamal et al. (2008) state that accounting diversity all over the world may persist after the adoption of IFRS if there is inadequate investor protection. The essence of having a single set of accounting standards (IFRS) worldwide is to improve the quality of accounting information. Investors must be adequately protected by law to encourage the movement of capital since investor protection is an essential ingredient that could influence an increase in the flow of foreign investments. However, even where a country has weak investor protection, there is the possibility of adopting IFRS (Hope et al., 2006). The adoption of IFRS would enable such a country to improve its investor's protection 
strategy by bonding with the requirements of IFRS. Thus, it implies that the influential investor's protection serves as a determinant factor for the adoption of IFRS.

\subsubsection{Economic growth}

The prevailing economic situation in a country is a significant factor that can determine the development of an accounting system. Accounting development is a complement of economic growth and should never be dissociated with economic development. Zeghal and Mhedhbi (2006) report that where a country is experiencing an increase in business and economic activities due to a high level of economic growth, this would result in a corresponding rise in the social and communication functions of accounting. Moreover, the situation would create a demand for highquality accounting standards. As an economy sees improvements in the volume of complex economic transactions, the accounting process would become more sophisticated. Such transactions create a need for high-quality accounting standards that are transparent, which would further improve economic growth (Judge et al., 2010). High levels of economic growth would influence the adoption of IFRS in developing regions such as Africa. Countries with a weak and low economic growth rate would see this as an opportunity to adopt IFRS to attract foreign investment.

\subsubsection{Taxation}

Tax is one of the fiscal policies of governments for the stabilisation of their economies. Most fiscal tools are adopted to acquire government revenue. The primary purpose of the tax is to raise cheap revenue, and it can also be used as an instrument for government economic and social policy regulations. Molin and Jiraskova (2014) define tax as a mandatory, non-refundable and nonequivalent payment to a public budget made for a general-purpose. This shows that taxation might deviate from the accounting concepts of income because the relationship between accounting and tax is not always the same. The taxation system has a significant influence on accounting rules and regulations in some countries, but in others, it has little or no effect on accounting reporting. For example, code law countries have a standard tax and financial reporting regulations, while common law countries keep the tax and financial reporting regulations separate from each other (Roberts et al., 2005:152-154).

Taxation, as an essential resource, can enhance the development of accounting systems because of its crucial role in generating revenue for the government. Moreover, the ability of a government to manage and control the tax system is essential (Shima \& Yang, 2012). Taxation is one of the 
regulatory strategies that would influence the adoption of IFRS if the government has total control of the resources. Fakile et al. (2013) and Shima and Yang (2012) emphasise that the ability of a government to overlook a nation's resources and economic goals may lead to inefficiency of financial accounting rules. They further explain that the purpose of financial accounting rules is oriented towards satisfying regulatory needs such as taxation and compliance issues rather than the information needs of investors alone.

\subsubsection{The legal system and the rule of law}

The legal system of a country can be divided into a codified legal system and a legal system of common law (common law is the system of law that is based on a judge's decisions and customs rather than on written laws). The legal system and the rule of law are the major determinants of various accounting standards. Kolsi and Zehri (2013) argue that a country with coded law would take more cognisance of accounting data for economic intervention. In a country with common law (also called Anglo-Saxon orientation countries), the authors explain that the method of governance is the financial market where the interest of the shareholders and creditors, not that of the state, takes priority. The state only puts in place a regulatory framework for the capital markets to function appropriately. This type of legal system promotes accounting culture more and improves the globalisation of accounting standards more (Zehri \& Chouaibi, 2013). Countries with a conventional law system, therefore, have a higher chance of adopting IFRS. Irrespective of the law enacted in a country, the paramount thing is the implementation of the law, which has to do with the importance of the rule of law.

$\mathrm{Yu}$ and Guernsey (2009) explain that the rule of law promotes economic growth, development, and the protection of human rights worldwide. However, Hallward-Driemeler and Pritchett (2015) emphasise that developing countries have a very low ranking of the rule of law, and this phenomenon may hinder the growth of economies. The rule of law is simply a system that protects the rights of citizens from governmental power abuse. It is a legal-political system that enables the government to create order in the economic, political and social functions in-country (Yu \& Guernsey, 2009). The rule of law is a theory of governance that encourages order to prevent the excessive abuse of the government's power.

Court efficiency is paramount in implementing various aspects of the law. Many developing countries have reformed their economic laws, especially the new investment laws or codes, to encourage broad legal protection for multiple types of investments (Cremona, 2003:137). In 
another development, the IMF, the World Bank, and the UN render financial assistance for the implementation of the rule of law in some developing countries to reduce the high rate of corruption that scare the foreign investors away (Yu \& Guernsey, 2009). This indicates that these bodies champion the course of implementing the rule of law since they see it as a factor that can bring about sustainable economic development. The development of any nation hinges on the rule of law. Given this, the legal system is one of the factors that can influence the adoption of IFRS in Africa.

\subsubsection{Political system}

The most crucial aim of international accounting standards is to enable transparency and accountability in financial reporting. This can only be achieved if a country has a high level of economic and political freedom that can catalyse the growth in accounting standards. Zehri and Chouaibi (2013) state that accurate and relevant disclosure of accounting information by using internationally accepted accounting standards is an outcome of the political approach and the application of scientific and empirical judgment. A country with a low level of political freedom will deprive its citizens of all types of independence, which would eventually affect accounting policy. A democratic country with an excellent political atmosphere would have a developed accounting system, such as South Africa.

\subsubsection{External pressure}

Al-Omari (2010) and Phan (2014) report that pressures from major international economic and political organisations, such as the World Bank, the International Monetary Fund, and the World Trade Organization, force developing economies, such as African countries, to adopt IFRS. The financial assistance of the IMF and the WB is attached to the adoption of IFRS in the developing countries. Developing countries are sensitive to coercive, normative and mimetic institutional pressures from various economic and political international organisations that want to affect the adoption of IFRS as a single set of accounting standards (Al-Omari, 2010; Awuku, 2016; Judge et al., 2010: Phan, 2014). The influence of this factor on the decision process to adopt IFRS has not been tested in the literature. It was added to the model used in this study.

All these determinants factors influence the decision process to adopt IFRS in developing countries, especially among the adopting countries. Any significant changes in any of these factors in a particular economy will significantly affect the accounting regulations and policies in such a country. 


\subsection{Summary of the chapter}

This chapter reviewed the relevant literature on the adoption of IFRS as a unified set of international accounting standards. The discussion started by examining the historical background of IFRS, the Conceptual Framework, the jurisdictions of IFRS worldwide, and the status in Africa. The various relevant accounting theories and overview of the literature on IFRS were discussed. The chapter also reviewed the literature on factors that could influence the adoption of IFRS in Africa. From the literature review, it is believed that the adoption of IFRS would make financial statements more transparent and comparable. It would also reduce the cost of capital and the degree of information asymmetry, which would increase the inflow of FPI.

There are divergent opinions and empirical findings on the effect of a single set of accounting standards (IFRS) on foreign investments, especially in developing countries. Some results show that the adoption of IFRS would influence foreign investments, while others believe that the adoption of IFRS does not have a significant influence on foreign investment inflow. The literature also revealed that the weak institutional structures in Africa, the complex nature of IFRS, and the inability of professionals to interpret and understand IFRS, may hinder the implementation of IFRS. Thus it shows that the possible effect of IFRS adoption on FPI is still unclear; it is yet to be resolved. Based on these findings from the literature review, this thesis aims to extend the empirical evidence by examining the effect of IFRS adoption on FPI inflow in Africa. The next chapter presents the research design and methodology. 


\section{CHAPTER FOUR: RESEARCH DESIGN AND METHODOLOGY}

\subsection{Introduction}

The literature review on the previous two chapters laid the foundation for the process of addressing the research questions asked in this study. This chapter presents the research design, and methodology process employs to solve the research problem and address the research questions stated in Chapter 1 of this thesis. The research design and methodology is considered to be the overall approach of conducting research which comprises all the research processes from identifying the philosophical assumptions, theoretical underpinning to the collection and analysis of data.

For a thorough understanding of the step-by-step process of the research and methodology adopted for this thesis, the 'research onion' approach, developed by Saunders, Lewis, and Thornhill (2012), is explored. The research onion approach that is employed to explain the research design and methodology process in this thesis has been applied by some researchers in their various researches, such as, (Gerber, 2015; Ihuah \& Eaton, 2013, as well as Mafuwane, 2012). Saunders et al. (2012:128) developed the concept of a research onion for the research process. The concept comprises of philosophical assumptions, for example, ontological assumptions (i.e. positivism, realism, interpretivism, and pragmatism) and the epistemological assumptions or research method (i.e. deduction, induction and abduction). Also, the concept includes the methodological choice (i.e. quantitative, qualitative and mixed-method) and the research strategy/ strategies. Time horizon (cross-sectional and longitudinal) and techniques and procedures (data collection and data analysis) are also part of the research onion concepts. Their understanding of this process is graphically represented in Figure 4.1 below. 


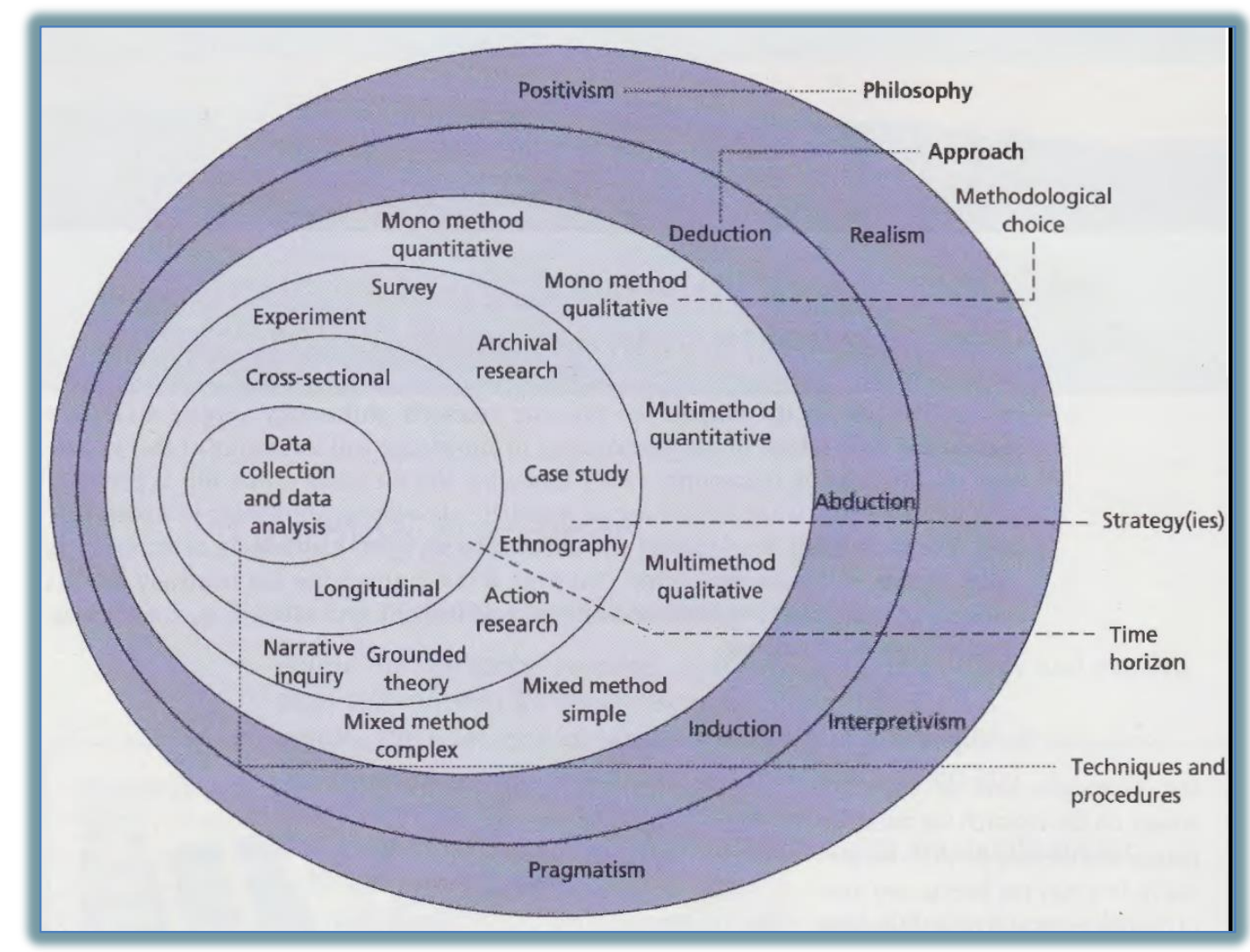

\section{Figure 4.1: The research onion}

Source: Saunders et al. (2012:128)

This study adopts the research onion (Figure 4.1) developed by Saunders et al. (2012:128) as a model for the research design and methodology to address the research problem of this thesis. The chapter comprises ten sections to discuss each concept of the research onion in detail and its applicability to this thesis. Section 4.1 is the introduction, which summarises the previous chapter and the focus of this current chapter. Section 4.2 revisits the research questions expressed in Chapter 1. Section 4.3 discusses the philosophical assumptions underlying the study. Its understanding is essential since there are different schools of thought, and the choice of the research philosophy is founded on the ontological view of the researcher about the world.

Furthermore, Section 4.4 discusses the concepts of epistemological assumptions, deductive and inductive approaches of the thesis, and the most appropriate logic perspective for the thesis will be identified. Section 4.5 discusses the most suitable methodology for the study by examining different methods and selecting the most appropriate method. Section 4.6 focuses on the research strategy associated with the identified philosophy of the thesis. Since the research onion emphasises various approaches, the most relevant one would be selected for this thesis based on 
philosophical assumptions. Section 4.7 discusses the time horizon, which is either cross-sectional or longitudinal or both. In the case of cross-sectional design, it involves the collection of data on different variables over multiple periods for the same unit (country). The longitudinal design investigates the same situation continuously over some time to reveal the stability of the occurrence (Bryman \& Bell, 2015:61-67). Section 4.8 focusses on the research technique and procedures such as data collection and the statistical analysis of the findings. It explains the data collection and data analysis approaches. Furthermore, Section 4.9 demonstrates the research onion diagram for this thesis. It shows the particular paradigm and approaches that apply to the thesis. The summary of the chapter is contained in Section 4.10, which also introduces the focus of the subsequent chapter.

\subsection{Research problem and research questions}

The research methodology employs in the thesis must be closely related to the research questions, thus making it pertinent to consider the research questions again. To make it align with the research methodology process. Given this, this section revisits the research problem and research questions discussed in Chapter 1 of this thesis.

For many years, there has been a move towards a single set of high-quality international accounting standards. This drive has become more pronounced after the end of the Second World War (Ortega, 2017). Thus the idea of a single set of accounting standards came into reality in 2001 when IASB developed IFRS. Many countries worldwide have adopted IFRS, including certain African countries (Ball, 2016; Gordon et al., 2012).

Accounting researchers predicted that the introduction of IFRS would improve the usefulness of financial reporting and facilitate the comparability, transparency, and reliability of financial statements internationally (Kribat, 2009; Kimeli, 2017; Mardini, 2012). It shows that a country that adopts IFRS will present more credible and reliable financial statements that foreign investors can rely on in making investment decisions and at the same time, increasing foreign investments.

In the extant literature, Amiram (2012), Ball (2016), Beneish et al. (2015), Brown and Tarca (2012), Cascina and Gassen (2010), Chen et al. (2014), DeFond et al. (2010), Hamberg et al. (2013), Hong et al. (2013), Khurana and Michas (2011), Kothari et al. (2010), Lee and Fargher (2010), Pacter (2014), and $\mathrm{Ng}$ (2015) posit that IFRS adoption will improve the efficient flow of foreign capital in the adopting countries. Consequently, contrary to the empirical results mentioned above that emphasise a positive relationship between IFRS adoption and foreign investments, a 
few researchers found contradictory evidence. Such as Adetula et al., (2014), Efobi (2017), Efobi, et al., (2014), Kwarbai et al., (2016), Nnadi \& Soobaroyen (2015), \& Sherman \& De Klerk (2015).

Based on these findings, it revealed that there was no consensus in the empirical results presented in the literature that IFRS adoption indeed had a positive effect on foreign investments. Ball (2016) reports that after a decade of developing IFRS, there is little evidence on whether it has achieved its aim to influence FPI in the adopting countries. Thus, the effect of IFRS adoption on foreign investments in Africa remains unknown and uncertain. Additionally, many of these empirical researches were carried-out in advanced economies while only a few studies were carried out in the developing countries. Their findings may not reflect the situation in Africa. This thesis fills this gap in the literature by examining the pre and post effect of the adoption of IFRS on FPI in Africa. Hence, the research problem centres on the extent to which IFRS adoption has influenced the inflow of FPI in adopting countries in Africa. The empirical findings will assist in confirming or refuting the suggestions of the proponents of IFRS that will improve the inflows of foreign investments in the adopting countries.

For this purpose, the research questions, earlier discussed in Chapter 1 of this thesis, are re-stated as follows: What is the significant difference in FPI inflows between before and after the adoption of IFRS among adopting IFRS countries in Africa? Furthermore, to what extent is the magnitude of the significant difference in FPI inflows among countries that adopted IFRS and countries that did not adopt IFRS in Africa? While the last research question is: What factors predict the probability of adoption of IFRS in Africa? Answers to all these research questions will enable the thesis to achieve the set objectives, particularly the primary objective, which is to examine the effect of the adoption of IFRS adoption on FPI in Africa. The next section will discuss the paradigmatic assumptions and perspectives.

\subsection{Paradigmatic assumptions and perspectives}

The starting point in research design and methodology is to determine the philosophical framework (paradigm) that underpins the study. Collis and Hussey (2014:43-44) emphasise that research methodology includes the philosophical position of the researcher, which dictates the type of research to be conducted. On the other hand, it relates to how the researcher perceives the world under study and the philosophical assumptions on what constitutes research under investigation (Neuman, 2014:92). The particular assumption will determine the research approach and research paradigm. The research philosophy, therefore, helps the researcher to simplify the research design 
to understand the procedure that would be suitable for the study (Ihuah \& Eaton, 2013). Thus, getting to a clear understanding of the research paradigm or philosophical framework and perspectives is the first issue that should be addressed when conducting research.

Coolian (2014:274) defines a research paradigm as a fundamental way of thinking and scientific behaviour in conducting research. Collis and Hussey (2014:43) opine that a research paradigm is a philosophical framework that determines how scientific research is conducted and that includes the researcher's assumptions about people's knowledge and their perception about the real world. Similarly, Bryman and Bell (2011:35) explain that a paradigm is the collective beliefs and ordinances that direct the researcher on the research approach. Additionally, Kivunja and Kuyini (2017) report that a research paradigm explains how researchers view the world that is investigating, that is, the perception, thinking, and the shared beliefs that will assist in understanding the nature of research data to be collected and the interpretation. Further explained that it focusses on the methodological aspects that inform the type of research methods to be utilised and the approaches of data analysis. A paradigm can be seen as a way of investigating a particular social event to gain an understanding and to offer an explanation.

Based on the different definitions of a paradigm explained above, the researchers will have different alternative views about the reality of the world, their study, and the research approach in solving the research problems. Thus, having a different paradigm shows that there are competing alternative methodologies to social research according to different philosophical assumptions about social reality (Neuman, 2014:93). Therefore, the research paradigm employs by the researchers will depend on their perceptions of what real-world truth is (ontology) and how they know it to be real truth or what makes a claim about it true (epistemology). Furthermore, the four research philosophies suggested in Figure 4.1 are discussed below, and the appropriate philosophy identified. This will enable the thesis to identify the relevant paradigm that is suitable.

\subsubsection{Philosophy: ontological (the nature of reality) and axiological (role of values) assumptions}

Ontology refers to the philosophical study of the nature of being or the nature of reality (Collis \& Hussey, 2014:47). Crotty (2003:10) defines ontology as the study of being. It is concerned with what kind of world we are investigating, with the nature of existence, and with the structure of reality as such. Similarly, Jankowicz (2005:106) defines ontology as the branch of metaphysics 
that deals with the nature of existence. Guba and Lincoln (1994:108) state that ontological assumptions are those that respond to the question of what is there that can be known.

Bryman and Bell (2011:32-33) explain that ontology is also involved like social entities, although it stems from a branch of metaphysics that deals with abstract objects. The authors further explained that the person who asks the central question of 'what there is that can be known' basically takes the objectivist or constructivist position. In the case of objectivism, it is an ontological stance that emphasises social entities. Entities have meaning that is independent of the social actors. Likewise, constructivism is an ontological view that explains social entities. Axiology relates to the researcher's view of the role of values in the study process. However, the four popular philosophical assumptions (positivism, realism, interpretivism, and pragmatism) have different axiological values that determine whether the researcher is value-neutral or not when the data are collected.

The identification of a suitable philosophical foundation for the study determines the research design and methodology that will anchor the approach the researcher uses. Hence, it is necessary and vital for this thesis to understand the philosophical domain that guides this research. Meanwhile, Figure 4.1 identifies four ontological philosophies that guide the study. These are discussed below.

\subsubsection{Positivism}

Positivism is a paradigm that stems from natural science, and it provides an approach to researching the scientific way (Collis \& Hussey, 2014:43). Further, positivism has its origin in the philosophy of realism, and it is still extensively used in social sciences research (Bisman, 2010). Additionally, the positivism paradigm defines a worldview to research as the scientific method of investigation through the experimentation, observation, and experience that constitute the basis of understanding the human behaviour and the scientific explanation of the reality (Kivunja \& Kuyini, 2017). It also assumes that the reality is singular, objective and independent from the investigator (Collis \& Hussey, 2014:43-44). This thesis is observing some variables (IFRS, FPI, and covariates) for a certain period to formulate hypotheses to explain the effect of IFRS as a reality in influencing the FPI.

Also, Sarantakos (2012:33-34) states that positivist ontology has the belief that anything that can be perceived through human senses is absolute. Therefore reality exists as an external to rational thinking and perception. This belief is that knowledge can be gained from the description of sense 
experience. On the other hand, Coolican (2014:248) posits that positivism is concerned with measuring a paradigm to test the hypotheses by using a quantitative approach that is founded on the philosophical position of science.

Also, positivism is focused only on phenomena that can be studied scientifically. In social sciences, this means that social events should be measured and observed. Collis and Hussey (2014:44) explain that based on the assumption that social events can be measured, positivism is therefore related to the quantitative approach of mathematical analysis of the research data. Thus, to study this research problem, data that support the theoretical framework are collected to test the hypotheses to generalise the outcome through the use of a quantitative research method. These data are sourced from existing theories, composed of variables, to develop the hypotheses that are tested to accept or reject the hypotheses. The rejection of the hypotheses will lead further to the development of a theory.

Similarly, Abiola (20013) reports that the positivist adopts a rational approach to understanding human behaviour and explaining the impact of behavioural and social issues on phenomenon through testing of hypotheses. Accordingly, the positivists believe that human behaviour can be reduced to the position of generalised laws where the individual is not significant. Positivism investigates relationships, causes, and effects through empirical validation and statistical analysis to test hypotheses (Neuman, 2013:96-97). This implies that the outcome of the research would enable the discovery of laws that concern human behaviour and that can be scientifically confirmed.

Positivism is an extremely objectivist view of a single common reality. This research approach emphasises that the world is real, and the truth of this can be investigated by adopting a scientific approach that suits the discovery (Bisman, 2010). Neuman (2003:97) posits that positivism can be seen as an approach of relating deductive reasoning with the empirical observation of specific phenomena to discover universal laws that can be generally employed in predicting or explaining events that utilise the quantitative methodology.

Additionally, Saunders et al., (2012:134) emphasise that positivist research is carried out with a value-free approach that separates the researcher from the research data so that the researcher could maintain an objective position. This implies that the researcher is independent of the collected data. Such an approach incorporates the underlying assumption of realism, which emphasises that there is a single concrete reality 'out there' that can be studied objectively and without bias to get 
to the truth. This shows that fact is material. However, adopting a positivist philosophy in research shows that the researcher has an objective position about reality since the researcher is independent of the object under study. Thus, when reality exists independently of research, the empirical study of such investigation is considered to be objective. However, ontological research with the reflection of social reality and having the accounting relationship is assumed to be less objective since it is non-empirical, and it is the outcome of thought process, which is subjective (Hines, 1989).

Researchers working within a positivist paradigm usually adopt a quantitative method and analyse data using statistical tools to test a hypothesis that would lead to new knowledge. Thus, positivism emphasises that it is possible to summarise human behaviour as a set of generalised laws where the recognition of the individual is insignificant. In such a situation, the research seeks to confirm the nature, causes, and effect of relationships among the variables (Bisman, 2010).

This philosophical stance believes that there is a world based on strict laws that can be discovered and predicted with the use of quantitative techniques. In the opinion of Tuli (2010), the positivist employs validity, exactness, and generalisability as part of quantitative research since they intend to describe, predict and verify empirical relationships in controlled settings.

\subsubsection{Realism}

Like positivism, realism is also related to the approach of scientific enquiry for the development of knowledge. It also assumes a scientific method for the discovery of new knowledge. This approach involves the collection of research data and a clear understanding of that data. It emphasises that an object that is 'real' so that its existence is unrelated to the human psyche or perception and thinking is independent of human beliefs (Cooper et al., 2006:22). Realism also shares the views of positivism that the natural and social sciences should apply the same method in the collection of research data and interpretation and that the social actor is independent (Bryman \& Bell, 2015:28-29). It is another philosophical stance that explains the characteristics of scientific practice.

There are two types of ontological realism, direct or empirical realism and critical realism. According to direct realism, 'what you see is what you get': this shows that what we experience about the world with our senses is real. On the other hand, critical realism assumes that what we experience with our senses is just an image of the real things in the world, not the things themselves. This means that critical realism emphasises that there is the existence of a world of 
materials object either perceived or not perceived, and the sensation it creates. Also, there is the mental processing after the perception of the phenomenon employing our senses to have an understanding of it, whether it is true or not (Searle, 2015:15-20). The study of business and management concerns the social world that we live in, and the researcher aims to gain an understanding and knowledge of current happenings. This means that it can only be possible if the researcher thoroughly understands the social structures where the happenings emanate. Hence, the critical realist explains that our knowledge of reality is an outcome of social changes that cannot be understood independently from the social actors (Dobson et al., 2007). While the direct realist assumes that the world is rather unchanging, and the critical realist concludes that the social world is not static, but ever-changing. According to Healy and Perry (2010), critical realism concerns the multiple perceptions of a single mind-independent reality, unlike positivism, which is about a single concrete reality. Thus, critical realism emphasises that there is a different degree of perception, so there are differences between realities and how human beings perceived reality.

Despite increasing interest in utilising other ontological assumptions such as interpretivism in carrying out accounting research has been and continues to be dominated by positivism inclined in objectivism ontology (Bisman, 2010). Further emphasises that it is based on the underlying assumption that a scientific approach, where positivism stems from, is more appropriate to generate findings, explanations, and predictions of accounting events to evaluate alternative methods of accounting measurements. Thus, all these attributes that are common in natural sciences make them more prominent and successful, and if social sciences can adopt the approach, there is a tendency that the similar success can as well be recorded. Also, Riahi-Belkaoui (2012:397) emphasises that a positive approach to the formulation of accounting theory is a popular paradigm with high supremacy over other procedures in the accounting literature.

\subsubsection{Interpretivism}

Interpretivism (anti-positivist) focuses on inquiry to understanding the existence of the world from the individual's perspective by examining subjective knowledge. Bryman and Bell (2015:28) opine that interpretivism holds that the subject matter of social sciences is different from natural science and that there must be a research strategy that emphasises how distinct humans are from the objects studied in the natural sciences. Collis and Hussey (2014:45) highlight that interpretivism assumes that social reality is not objective as portrayed by positivism, but instead highly subjective, since people's perception fashions it. However, there is a level of interaction 
between the reality that the researcher is studying and the perception of the researcher when using an interpretative approach to research.

Furthermore, Cooper et al. (2006:21) posit that interpretivism approaches the research by interacting with the social entity since simple basic laws may be insufficient to know about complex social events. Accordingly, the interpretivist believes that it is impossible to separate occasions in the social world from the researcher's opinion. It emphasises the investigation of social phenomena (through the collection of quantitative research data) for understanding (Collis $\&$ Hussey, 2014:45). Also, the findings from the investigation are not derived from statistical analysis, but from the qualitative research, which is subjective. Unlike positivism, interpretivism is not based on a generalisation of laws or the prediction of the outcome of an event to solve the critical problems of evaluating the alternative approach of accounting measurement (RiahiBelkaoui, 2004:398).

\subsubsection{Pragmatism}

Pragmatists explain that preferring one philosophical assumption over another may not be realistic or ideal in a practical sense and that the particular position will depend on the research questions. This is founded on the belief that the world can be interpreted in multiple ways and that there is no single point of judgment that can adequately describe the world. Thus, the truth of the reality of the world may not be accomplished by using the positivism or interpretivism approach (Kivunja and Kuyini, 2017). Consequently, a strategy that will be more practical and pluralistic will involve the two methods that will be more appropriate. In view of this, the pragmatic approach (mixed approach) was developed to solve the two opposing views of the positivists and the interpretivism (Alise \& Teddlie, 2010). However, this does not mean that pragmatists are compelled to use multiple methods individual researchers have freedom of choice and employ the research approach that would give the most credibility to the research data (Collis \& Hussey, 2014:55). Given the above discussion of possible approaches to research, the next section, 4.3.5, discusses the relevant philosophical assumption that is appropriate to be employed in this study.

\subsubsection{The appropriate philosophy adopted for this research}

The positivist approach is more relevant for this thesis, according to the explanation of all the paradigms discussed above. The positivist ontology is regarded as objective, external to the researcher and independent from social actors. A researcher who adopts a positivism philosophical assumption remains as objective as possible about the research to minimise bias. Thus the 
researcher views the world as objective, independent of the researcher, and value-free (Cooper $e t$ al., 2006:20).

The historical overview on accounting standards discussed in Chapter 3 revealed that the formulation of a single set of accounting standards worldwide resulted from the joint efforts of various nationals, regionals, and international accounting standard setters, such as the FASB, the IASB etcetera. Thus, the accounting standard setters created an absolute reality that influences the possibility of representing accounting statements faithfully as economic reality (Elkhashen \& Ntim, 2018). Mattessich (2003) reports that the reality created becomes facts and form part of roles, morals, economics, and legislation. In this case, IFRS was developed as a reality, and it has become a standard for preparing financial statement worldwide. Elkhashen and Ntim (2018) express that financial statement represents economic reality and the truth-value of a financial statement depends on whether it enables users to engage with the world. Thus, the fundamental truth of accounting is economic reality. However, reality comprises of activities that can be studied from certain philosophical assumptions (Collis \& Hussey, 2014:44). In this case, the positivist paradigm is the point of view from which this study is carried out.

Moreover, the positivist ontological assumption employs in this study shows that financial reporting standards are a reality and exist externally and independently of accounting information in thought, language, and research. Hence, the significant role of financial reporting is to communicate that reality objectively. Mckernam (2001) believes that accounting is closely tied to objective reality. It appears then that financial statement as reality is prepared for representing the economic reality truthfully since only the truth will help the users taking economic decisions.

The next stage, according to Figure 4.1, is the reasoning process, in other words, deduction, induction, or abduction. The reasoning process is significant for the construction of theory and observation testing. Thus, the different reasoning processes are discussed below, leading to the choice of the appropriate reasoning approach.

\subsection{The research approach and reasoning process}

The next stage of the research onion is the research approach which comprises of deduction, induction, and abduction as the process of reasoning. They are significant for the construction of theory and observation testing. This section will discuss these approaches. 


\subsubsection{Deductive reasoning (theory to observation)}

Deductive reasoning is the dominant reasoning process in natural science where laws provide a basis of explanation, allow the expectation of phenomenon and predict their occurrences for control (Collis \& Hussey, 2014:43-44). The fundamental objective of accounting theory is to provide a basis for the prediction and explanation of accounting behaviour and phenomenon (Riahi-Belkaoui, 2004:108). The deductive approach starts with propositions and logically proceeds to develop a universal law, in this case, to develop accounting techniques (RiahiBelkaoui, 2004:111). It uses data to test hypotheses related to the theory to make generalisations.

In the application of deductive reasoning in the process of developing an accounting theory, an objective statement must initially be stated. After that, logical formal reasoning based on the definitions, concepts, axioms, and assumptions that can assist with achieving the stated objectives (Zalaghi \& Khazael, 2016). Wilson (2010:12-14) opine that deductive reasoning involves the development of assumptions based on the existing theory (composed of variables) and utilising appropriate research procedures to test the hypotheses.

The research involves the formulation, testing, and verification of the hypotheses to determine whether the formulated hypotheses are supported or not supported. Additionally, Crowther and Lancaster (2012:23) explain that deductive reasoning develops theories or hypotheses and test them through the process of empirical observation to determine their validity. The theory (comprising of variables) to be tested must be functional and useful for measurement to allow a generalised pattern.

Furthermore, Beiske (2007) opines that deductive research examines a particular theory and test whether it applies to that specific situation. The positivism paradigm employs in this study is linked with the quantitative research approach, inclined to objectivism and deductive reasoning. It can be argued that deductive reasoning explores new solutions to old problems. From an accounting perspective, which involves in prediction and justification of accounting behaviour, deductive reasoning involves in formulation and testing of assumptions making it more applicable to quantitative research. Since quantitative method, which stems from natural sciences, is mainly concerned with observations and measurements which can be made objectively and nearby to the reality (Tuli, 2010). 


\subsubsection{Inductive reasoning (observation to theory)}

This approach begins with observation and measurement and proceeds towards generalisation. It involves developing a theory using a data-driven approach and a qualitative research method (Bryman \& Bell, 2015:26). Collis and Hussey (2014:7) express that inductive research is concerned with moving from individual observation to a statement of general patterns from the specific to the general. The generalisation has to be tested, and it may be verified or rejected. In the end, research theories are developed (Zalaghi \& Khazael, 2016). It is the opposite of deductive reasoning, and it adopts old solutions to solve present problems. This study uses quantitative research to address the research problems, rendering the inductive approach irrelevant to this context.

\subsubsection{Abductive approach}

This approach is related to pragmatic philosophical reasoning that embraces both quantitative and qualitative methods for research inquiries. The abductive approach combines deductive and inductive reasoning. In addition, 'data collection is used to explore a phenomenon, identify themes and patterns, locate this in the conceptual framework and test this through subsequent data collection and so forth' (Saunders et al., 2012:144). Thus, using an abductive approach involves moving from the empirical to theoretical dimensions of analysis, which is not appropriate for this study.

\subsubsection{Research reasoning process adopted in this study}

This research in the field of accounting aimed to set forth a process or procedure that the primary users of financial information can employ to predict accounting behaviour and phenomena. The research was approached from a positivist point of view, using deductive reasoning to guide the process. The application of deductive logic to accounting in this study started with the development of hypotheses, followed by the structural approach to derive the accounting principles that will form the basis of accounting techniques (Riahi-Belkaoui, 2004:111-112).

Thus, deductive reasoning is employed to answer the research questions in this thesis. The main research question would be answered by examining the existing literature in Chapters 2 and 3 on FPI and IFRS. Chapter 2 revealed that FPI could be influenced by push (external), e.g., IFRS and pull factors (internal). Because of this, the first hypothesis is formulated using related theories (comprising of variables identified in the literature review). This aided in the development of a 
mathematical model that would be processed with the use of analytical, statistical tools to address the research questions.

After that, deductive reasoning is also utilised to answer the other two research questions. Research question two asked whether there is any significant difference in FPI inflow between adopting and non-adopting countries in Africa and tested the hypothesis if there is any considerable effect between FPI inflow of countries that required all their listed companies to use IFRS and those countries that are classified as not adopting IFRS according to this research. Research question three would be answered by also developing a hypothesis and formulating a model of the factors that influence the probability of adoption of IFRS in the selected African countries. The acceptance or rejection of the hypotheses would form the basis for predicting the future usefulness of accounting standards. Methodological choice

Methodological choice represents the third layer in Figure 4.1. Creswell (2014:25) expresses that the selection of methodology is determined by the composition of the research problem and the research question the researcher intends to answer. Similarly, the ontological paradigm adopted for the study will influence the choice of research methodology. Figure 4.1 depicts three principal research methodologies, namely quantitative, qualitative, and mixed-method. These are subsequently discussed below:

\subsubsection{Quantitative research method}

The quantitative research method is a research method that examines a social or human problem. It is characterised by testing a theory comprising of variables and analysis of the trends with statistical tools (Creswell, 2014:29). The mathematical tools assist in identifying whether the outcome support or contradicts the expected predictions generalisation of the hypothesis. Because of this process of deriving a hypothesis using a quantitative method, positivism leans towards the quantitative research method because of the objectivity it suggests (Jankowicz, 2005:123). Quantitative research enables the researcher to gain an understanding and knowledge of the research problem and to formulate hypotheses to be tested. The data collected are in the form of numbers and numerical quantification that enable the processing in mathematical form and the summary of findings in the statistical way (Golafshani, 2003). The quantitative method, which has a relationship with the positivist paradigm, presumes that the world is observable and full of measurable facts. Therefore, the quantitative process entails experimental and survey work (Creswell, 2014:34). It is regarded as suitable for this study since the study adopts the positivist 
paradigm that advocates for the use of the quantitative approach that will enable the research to be more specific in the description of the relationships among the variables analysed.

\subsubsection{Qualitative research method}

The qualitative research method is a research method involves investigating social or human problems within a research setting that is systematic and methodical it is undergirded by an ontology and epistemology of interpretivism and subjectivism (Creswell, 2014:30-33) Qualitative research is mostly related to inductive logic and in some research, abductive reasoning can be employed. Techniques such as action research, case study, ethnography, grounded theory, and narrative can be utilised in qualitative research. Because of this, the qualitative approach is not appropriate for this study.

Moreover, another method that is explained in the literature is the mixed-method. Teddie and Tashakkori (2009:4) reveal that mixed-method stems from the logical philosophical assumption. A mixed-method approach is selected in the case where the quantitative and qualitative methods together would provide the best understanding of the research problems (Creswell, 2014:36). Thus, the deductive or inductive reasoning or the two logics may be employed to solve the research problems. This reveals that the adoption of a mixed-method in a single study will involve the collection and analysis of research data using quantitative and qualitative methods drawn from different paradigms (Ihuah \& Eaton, 2013). The mixed-method is not considered suitable for this study, as it is best used to explore human experiences in real settings.

\subsubsection{Methodological choice adopted in this study}

The three methodological choices suggested by the research onion in Figure 4.1, as discussed above, aimed to identify the appropriate methodology choice for the study. Invariably, both research methods emphasised different ways of proffer solution to the research problem, which is based upon the research philosophy, research approach, and research strategies. Consequently, based on the significant characteristics of the research methods discussed above, it can be deduced that the quantitative research method is a more appropriate choice for this study. Creswell (2014:33) further explain that the quantitative research method is most relevant to solve research problems when trends of data need to be emphasised. Hence, it is best suited when the study is focused on investigating variables that can influence the effect. For this thesis, the quantitative method would be employed to examine the trend in FPI during pre and post IFRS adoption in African countries. As stated earlier, quantitative research is associated with the ontology and 
epistemology positivism inclined to be objective and related to deductive reasoning, which this thesis is utilising to address the research questions.

\subsection{Research strategy}

Figure 4.1 identifies eight different research strategies, namely experiments, surveys, archival research, case studies, ethnography, action research, grounded theory, and narrative inquiry. The experimental and survey research strategies are related to quantitative research, while the remaining six methods are related to qualitative research (Creswell, 2014:34). Experimental research and survey research is discussed in this section since they are associated with the methodological choice for this study.

\subsubsection{Experimental research}

Experimental research (after the fact) has its origin in scientific research with a strong relationship to natural science. It often examines the relationship between independent variables and dependent variables by generating hypotheses and allows the researcher intervention to modify the variables to suit its purpose (Cooper \& Schindler, 2014:192). Further explained that it develops causal relationships between dependent and independent variables, tending to be explanatory. It is associated with quantitative research as it examines the probability of change between the dependent variable (the effect) and the independent variable (the cause). Simon and Goes (2013) explain that the major characteristics of an experimental research design are that it enables the researcher to manipulate the independent variable to influence the outcome of the research. They also explained that experimentation is not always feasible in social research, but it is ideal for identifying a phenomenon that had already occurred and for obtaining data to examine the possible relationship between the cause and the effect variables.

\subsubsection{Survey research}

Survey research has a relationship with deductive reasoning, and it is the type of quantitative research that is being used in explanatory, descriptive, but not frequently applied in exploratory study (Neuman, 2014:49). The use of questionnaires, structured observation and interviews are more prominent as data collection strategies. The data collected can be used to explain the purpose of a relationship between variables and assist in building a model. Survey research is most relevant in describing a trend in a population when a survey or questionnaire is administered to a sample 
of a larger population. The focus is not so much on testing the relationships between the variables (Creswell, 2014:35).

The two research strategies explained above are not relevant to this study, which investigates the relationship between independent variables (the cause) and effect without the manipulation of the data that existed before the study. Quantitative ex post facto research, which is the opposite of experimental research, is more appropriate since it is not possible to manipulate the data or researcher has to control the variables (Manyara, 2013). It is an alternative means of experimental research to examine the extent of the probability that the independent variable can influence the dependent variable (Simon \& Goes, 2013). The authors explained that an ex post facto research design is appropriate for research where it is not possible to manipulate or change the data since they were already in existence before the investigation. This means that the researcher cannot manipulate a method of investigating the events that have occurred. Furthermore, applying the ex post facto research design makes it possible to test hypotheses about the relationship between independent and dependent variables. In addition, it is an appropriate research method that pursues truth and at the same time, seeks solutions to the research problems through the analysis of collected data (Lowe, 2016).

\subsubsection{Research strategy utilises for this study}

This study examines the effect of IFRS adoption on FPI flow in Africa. The hypotheses are developed and tested to determine the extent of the probability that the adoption of IFRS has influenced FPI. Secondary data were collected for the dependent, and the independent variables and all the data were already in existence and could not be manipulated by the researcher. Therefore, making the ex post facto research design to be more appropriate and utilise for the study since the data have already been determined before the research is conducted and the researcher has no control over the data to manipulate them.

\subsection{Time horizon in research}

The two-time horizons in research identified in the research onion in Figure 4.1 are longitudinal and cross-sectional designs. The longitudinal design also called panel data (or a combination of time-series and cross-section data), is a type of research that employs the observation method that does not allow any interference in the variables to be investigated (Brink et al., 2006:101). It is useful in the collection of data for the same subject repeatedly over some time to determine the extent of changes over a long period. It is more appropriate to examine changes or the behaviour 
of variables over some time. Bryman and Bell (2015:66) emphasise that the longitudinal research design understanding of variables behaviour over some time is feasible and allows for the determination of the relationship among the variables. More data over a more extended period will enhance results. Brink et al. (2006:102) emphasise that a longitudinal research design is descriptive and explanatory, which is useful for applied research. It also has the propensity to determine the pattern of data behaviour efficiently to predict an event.

\subsubsection{A cross-sectional design}

A cross-sectional design is a research tool to gather information relating to the different cases to be investigated at a specific point in time to examine the pattern of relationships between them (Bryman \& Bell, 2015:61-63). This shows that the study is limited to a particular time. The focus is on current phenomena, so it is not always possible to include changes that occurred outside the specific periods (Brink et al., 2006:101). A cross-sectional study can be exploratory, explanatory, or descriptive, but it relates to descriptive studies. A cross-sectional study is therefore not suitable for analysing data over a long period or the cause and effect of variables (independent and dependent variables).

\subsubsection{Time horizon utilises in this study}

Based on the above discussion, the appropriate time horizon for this research is a longitudinal research design, also called panel data (or a combination of time-series and cross-section data). This study worked with data collected over a long period (22 years for pre and post-adoption) to achieve the objectives to observe changes in the variables. The thesis makes use of secondary data that existed before the study started. This eliminates interference or manipulation of data by the researcher since the study philosophy ontology paradigm is positivism inclined in objectivism, which makes the researcher independent of the research being investigated. The information was collected on each variable, such as dependent variables (FPI) and independent variables (IFRS and covariate variables) as a basis for the prediction of the future phenomenon. The longitudinal design or panel data is utilised since it possesses the relevant attributes that conform to the appropriate time horizon for this study.

\subsection{Research technique and procedures}

The last layer of the research onion in Figure 4.1 focuses on research techniques and processes. This section discusses the research techniques to be employed in the course of this research work 
to achieve the objectives and address the research questions. The primary methods to consider are the conceptual framework, the population of the study, selection of the units for the study, data collection method, model specification, and the methods of estimation.

\subsubsection{The Conceptual framework for the study}

The primary purpose of this study is to examine the effect of IFRS adoption on FPI inflows in Africa. Given this, the literature reviewed in Chapters 2 and 3 critically examined the literature currently available on FPI and IFRS to postulate a theoretical underpinning (comprising of variables) for the study. Furthermore, the relevant theories and models that could be useful to develop a conceptual framework and hypotheses for the study were identified. Hence, these enable the study to recognise the scientific approach for solving the research questions and compare the findings with similar work of other scholars on the effect of IFRS adoption on FPI.

Consequently, based on the theoretical background and the literature reviewed in Chapters 2 and 3 , the conceptual framework is derived at as shown in Figure 4.2, reflecting on the decisionusefulness theory, previously discussed, that the relevance of accounting standards (IFRS) is allencompassing which should guide the decisions regarding the economic and investment choices (AAA, 1966). In view of this, the decision-usefulness theory suggests a positive relationship between IFRS adoption and FPI inflows into the adopting countries. Hence, a priori assumption in this thesis is a positive link between IFRS adoption and FPI. The relationship between the dependent variable FPI and the primary explanatory variable, IFRS, including the identified covariates, is examined. Furthermore, the determinant factors that may influence the adoption of IFRS are also tested. Therefore, the conceptualisation model developed for this thesis identifies the association between FPI (dependent variable) and IFRS (main explanatory variable) as well as control variables as the independent variables.

Similarly, the possible determinant factors of IFRS are also shown in the diagrammatical form in Figure 4.2 below. The figure serves as a blueprint developed for this thesis and aims to address the research problems and research questions. It also represents as a guide in achieving the objectives of the thesis. Also, the estimated variables are explicit in the paradigm presented in Figure 4.2 to describe how the variables presumed to link to each other.

The conceptual framework shown below is developed for this study based on the literature review in Chapters 2 and 3. Figure 4.2 shows the association of factors influencing FPI as not unidirectional but multidirectional. Many variables can affect it. Nevertheless, it depicts the 
observed effect of IFRS on FPI, including some control variables. It also explains some of the factors that determine the adoption of IFRS.

It relies on the empirical studies of Amiram (2012), Beneish et al. (2015), Ben-Othman and Kossentini (2015), and Efobi (2017). In consonance with the decision-usefulness theory, (earlier discussed in Chapter 3) the framework suggests that with the adoption of IFRS, it will influence the usefulness of accounting information by making it more transparent and enhance the comparability of financial statements globally. The proponents of IFRS, suggest that a single set of global accounting standards would enable comparability of financial statements prepared in one jurisdiction with similar firms in another jurisdiction trigger an efficient allocation of foreign capital (Judge et al., 2010).

Amiram (2012), Beneish et al. (2015), Ben-Othman and Kossentini (2015), and Efobi (2017) further suggest that the adoption of IFRS will invigorate capital market participants' activities in the adopting counties, who require more transparent, coherent, and reliable financial information for making investment decisions, especially FPI. Ariyo (2007:4) observe that one of the acclaimed strategies often adopted to influence existing and potential foreign investors is the presentation of credible and reliable financial statement. Foreign investors proved their desire for a vibrant capital market where they can get reliable and high-quality financial information, preferably at a lower cost. Hence it is assumed that all these can be achieved through the adoption of IFRS as a unified single-set of accounting standards as against using the national accounting standards, which reflects much accounting diversity that rendered financial statement incomparable and hindered the flow of FPI (Walton \& Aerts, 2007:17).

Due to the importance of foreign investments in economic development, especially in developing countries, attention has been given recently to IFRS adoption as a factor influencing FPI. The adoption of IFRS, however, is considered to be a major contributor to foreign investments worldwide (Ng, 2015; Nnadi \& Soobaroyen, 2015). Amiram (2012), Beneish et al. (2015), BenOthman and Kossentini (2015), and Efobi (2017) explain that the adoption of IFRS is likely to influence economic development through the provision of adequate foreign capital. In this way, certain African countries have adopted IFRS as a way to develop their economies.

The framework in Figure 4.2 identifies the link between FPI, IFRS adoption, as a main explanatory variable, as well as covariates. Apart from IFRS, the conceptual framework also identifies some standard (control variables) determinant factors that can influence the adoption of IFRS in Africa. 
The framework reveals that factors that can trigger inflows of FPI are multidirectional, in the sense that it can be influenced by many factors, such as inflation rate, interest rate, exchange rate, economic growth, trade openness, corporate tax rate, market capitalization, regulatory quality, and corruption. These are benchmark factors that are assumed in the literature to influence foreign investments (see Chapter 2). Similarly, the conceptual framework further recognises some of the determinant factors of IFRS such as culture, level of education, the legal system, political system, external pressure, investor protection, market capitalization, economic growth, trade openness, and corporate tax.

The framework adopts the definition of IMF for FPI (see Chapter 2, section 2.2.2). It stated the components of FPI as investments in equity and debt markets. The literature emphasises that these categories of investors require more use of financial statement than any other investors (Amiram, 2012). Because of the usefulness of financial statement to FPI investors (equity and debt securities) necessitated this conceptual framework to examine the link between IFRS and FPI. Thus, the dependent variable for this study is the FPI inflows for each estimated country. It is represented by the total inflows in the US dollar of equity and debt securities in a particular country. It is measured with a natural logarithm of FPI (lnFPI) in this study. This method is in line with the technique used by Amiram (2012) and Chen et al. (2014) to measure foreign investments. Based on the conceptual framework adopted for this thesis in Figure 4.2, the estimated variables were discussed in section 4.8 .7 


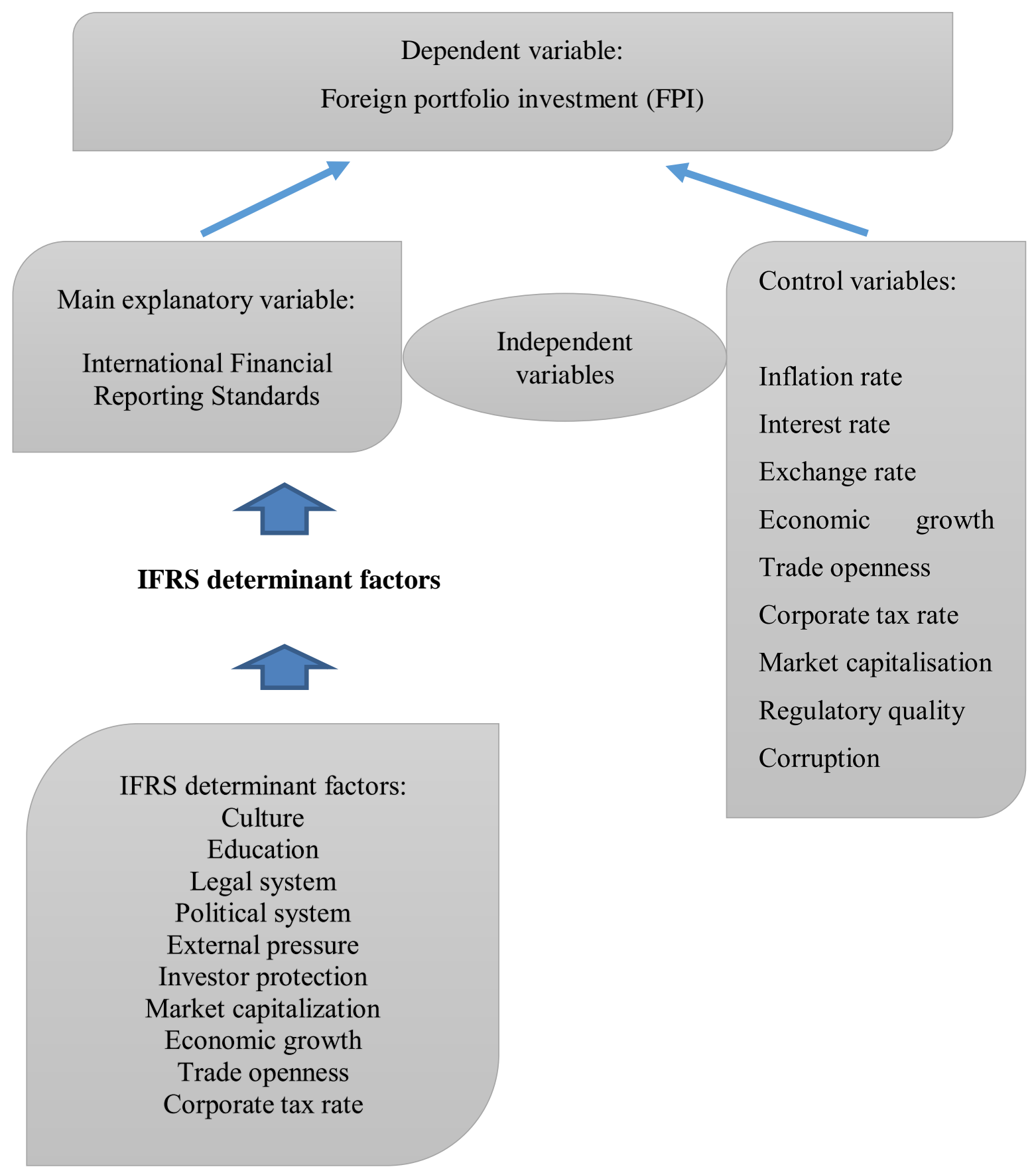

Figure 4.2: The research paradigm illustrating the conceptual framework for the study Source: Researcher's findings 


\subsubsection{The population of the study}

A population is the full set of units out of which the sample selection of the study can be chosen for statistical analysis (Collis \& Hussey, 2014:51). The target population employed in this study comprised 54 African countries, as identified by the United Nations' Conference on Trade and Development (2017:86-88). They are Algeria, Angola, Benin, Botswana, Burkina Faso, Burundi, CapeVerde, Cameroon, Central African Republic, Chad, Comoros, Congo Republic, Cote D'Ivoire, Democratic Republic of Congo, Djibouti, Egypt, Equatorial Guinea, Eritrea, Ethiopia, Gabon, Gambia, Ghana, Guinea-Bissau, Guinea, Kenya, Lesotho, Liberia, Libya, Madagascar, Malawi, Mali, Mauritania, Mauritius, Morocco, Mozambique, Namibia, Niger, Nigeria, Rwanda, Sao Tome Principe, Senegal, Sierra Leone, Seychelles, Somalia, South Africa, South Sudan, Sudan, Swaziland, Tanzania, Togo, Tunisia, Uganda, Zambia and Zimbabwe. This delimitation of the population helped to define and identify the sources of data accurately to answer questions relating to the attributes of the target population (Zikmund et al., 2013:387).

\subsubsection{Selection of the countries for the study}

The literature identifies different alternatives for selecting sample plans for a study, which can be broadly divided into probability and non-probability sampling methods (Alvi, 2016:12 \& Zikmund et al., 2013:392). In the case of probability sampling, the chances of a unit being chosen from the entire population are equal (Collis \& Hussey, 2014:197). It shows that every member has an equal chance of being selected from the total population. It enables inferences to be made about the nature of the population using statistical analysis. However, for this study, which employs nonsampling techniques, all the selected countries (i.e., adopted and non-adopted IFRS countries) were chosen from the total population.

\subsubsection{The selected countries for analysis}

Table 4.1 below depicts the countries chosen according to their peculiar characteristics relating to IFRS jurisdiction status. It indicates each country's IFRS status classifications and their respective year of adoption, where relevant.

Column (a) shows countries that have fully adopted IFRS. These countries required all their domestic listed companies to adopt IFRS. According to the literature review in Chapter 3, 17 countries fall into this category. Still, two of these countries, marked with an asterisk, Kenya and Zimbabwe, were abandoned from the analysis due to incomplete data. 
Column (b) shows countries where IFRS was required for some listed companies. Six countries fall into this category, but four of them, marked with asterisks, are abandoned due to the nonavailability of other relevant data. In column (c), a country where IFRS is permitted is indicated. This particular classification means that the listed companies have an option to use either IFRS or national accounting standards for the preparation of financial statements (IFRS, 2017). Column (c) shows only one country, which is Liberia, with other relevant data as well. Finally, the last column, (d) depicts countries that are not permitted to use IFRS. In this classification, there are 30 countries, but 13 countries, marked with asterisks, have incomplete data and therefore were abandoned for this study.

Table 4.1: IFRS status classifications in Africa with the relevant year of adoption

\begin{tabular}{|c|c|c|c|}
\hline $\begin{array}{l}\text { Countries fully } \\
\text { adopted IFRS } \\
\text { (required for all the } \\
\text { listed companies) }\end{array}$ & $\begin{array}{l}\text { Countries where } \\
\text { IFRS required for } \\
\text { some listed } \\
\text { companies } \\
\text { (b) }\end{array}$ & $\begin{array}{l}\text { Countries where } \\
\text { IFRS permitted } \\
\text { (listed companies } \\
\text { have an option to } \\
\text { use either IFRS or } \\
\text { National Accounting } \\
\text { Standards) } \\
\text { (c) }\end{array}$ & $\begin{array}{l}\text { Countries where } \\
\text { IFRS not permitted } \\
\text { (d) }\end{array}$ \\
\hline Botswana & Angola & Liberia & Algeria* \\
\hline Gambia & Eritrea* & & Benin \\
\hline Ghana & Lesotho* 2009 & & Burkina Faso \\
\hline Kenya* & Libya* & & Burundi \\
\hline Malawi & Madagascar* 2005 & & Cabo Verde \\
\hline Mauritius & Morocco & & Cameroon \\
\hline Mozambique 2007 & & & C African $\mathrm{R}^{*}$ \\
\hline Namibia & & & Chad* \\
\hline Nigeria & & & Comoros* \\
\hline Rwanda & & & Cote d'Ivoire \\
\hline
\end{tabular}




\begin{tabular}{|c|c|c|c|}
\hline $\begin{array}{l}\text { Countries fully } \\
\text { adopted IFRS } \\
\text { (required for all the } \\
\text { listed companies) } \\
\text { (a) }\end{array}$ & $\begin{array}{l}\text { Countries where } \\
\text { IFRS required for } \\
\text { some listed } \\
\text { companies } \\
\text { (b) }\end{array}$ & $\begin{array}{l}\text { Countries where } \\
\text { IFRS permitted } \\
\text { (listed companies } \\
\text { have an option to } \\
\text { use either IFRS or } \\
\text { National Accounting } \\
\text { Standards) } \\
\text { (c) }\end{array}$ & $\begin{array}{l}\text { Countries where } \\
\text { IFRS not permitted } \\
\text { (d) }\end{array}$ \\
\hline Sierra Leone 2010 & & & D R of Congo* \\
\hline South Africa. 2005 & & & Djibouti* \\
\hline Swaziland 2009 & & & Egypt \\
\hline Tanzania & & & E. Guinea* \\
\hline Uganda & & & Ethiopia* \\
\hline Zambia & & & Gabon* \\
\hline \multirow[t]{11}{*}{ Zimbabwe* 2005} & & & Guinea \\
\hline & & & Guinea Bissau \\
\hline & & & Mali \\
\hline & & & Mauritania* \\
\hline & & & Niger \\
\hline & & & Rep of Congo* \\
\hline & & & Sao Tome Principe \\
\hline & & & Seychelles \\
\hline & & & Senegal \\
\hline & & & Somalia* \\
\hline & & & South Sudan* \\
\hline
\end{tabular}




\begin{tabular}{|c|c|c|c|}
\hline $\begin{array}{l}\text { Countries fully } \\
\text { adopted IFRS } \\
\text { (required for all the } \\
\text { listed companies) }\end{array}$ & $\begin{array}{l}\text { Countries where } \\
\text { IFRS required for } \\
\text { some listed } \\
\text { companies } \\
\text { (b) }\end{array}$ & $\begin{array}{l}\text { Countries where } \\
\text { IFRS permitted } \\
\text { (listed companies } \\
\text { have an option to } \\
\text { use either IFRS or } \\
\text { National Accounting } \\
\text { Standards) } \\
\text { (c) }\end{array}$ & $\begin{array}{l}\text { Countries where } \\
\text { IFRS not permitted } \\
\text { (d) }\end{array}$ \\
\hline & & & Sudan \\
\hline & & & Togo \\
\hline & & & Tunisia \\
\hline
\end{tabular}

Source: Deloitte (2017); IFRS (2017) (Note* indicates countries with incomplete data)

For this study, the population is therefore classified into two groups. Those that required all the listed companies to use IFRS and those that have not. Table 4.1, column (a) shows the countries that required all the listed companies to use IFRS (subsequently referred to as the adopting countries). In contrast, columns (b), (c) and (d) are combined to form a single group of countries that have not required all their listed companies to use IFRS (subsequently referred to as nonadopting countries). Also, the inclusion of columns (b) and (c) separately as a variable in the model would not have a significant effect on the total result due to their small number. Therefore, columns (b), (c), and (d) are classified as countries that did not adopt IFRS for this study. Table 4.2 summarises the samples of the selection.

Table 4.2: Summary of subpopulations selected for the study

\begin{tabular}{|l|l|}
\hline Total number of countries that form the population (all African countries) & $\mathbf{5 4}$ \\
\hline Countries with incomplete data (see Table 4.1) & $\mathbf{( 1 9 )}$ \\
\hline Countries classified as non-adopted IFRS with relevant data (b, c, and d) & $\mathbf{2 0}$ \\
\hline Countries classified as adopted IFRS with relevant data (a) & $\mathbf{1 5}$ \\
\hline $\begin{array}{l}\text { Study population assume to represent the population of } 54 \text { countries (adopted } \\
\text { and not-adopted IFRS) (20+15) }\end{array}$ & $\mathbf{3 5}$ \\
\hline
\end{tabular}

Source: Researcher's findings

Table 4.2 shows the total number of countries that form the population as 54 African countries. Similarly, 15 countries are categorised as adopted countries, while 20 countries are identified as 
non-adopting countries. Also, 19 countries are abandoned due to incomplete information. The year 2005 is used as a reference year as the year that marks a turning point in the international accounting environment when many countries all over the world abandoned their national accounting standards for IFRS (Daske et al., 2008). The next section explains the procedures of collection of various data as emphasised under the conceptual framework based on the selected countries.

\subsubsection{Data collection method and its appropriateness to the thesis}

The basis of data collection in research is to obtain useful information about the identified variables to be tested to determine their causal relationships. Also, the data collected enable the researcher to address the research problems, achieving the objective of the study, and making predictions about future probabilities and trends (Martins et al., 2018). Secondary data are employed for this thesis based upon the philosophical assumption employ, which is objectivism that regards data to be external to the researchers. Thus, secondary data refer to information that is made available by another researcher or body, and that is being used for new research purposes and cannot be manipulated.

The problem with secondary data is the authenticity and reliability of the data collected since they were not primarily collected by the researcher but by other persons or entities. However, to solve this problem, data were sourced from various databases of globally recognised agencies. Importantly, such as the IMF publication on financial statistics (e.g., Balance of Payment and International Investment Position), the World Development Indicators published by the World Bank, the World Governance Indicator, Transparency International, etcetera. Most empirical studies in finance, economics, and accounting have similarly used different data obtained from these world economic and political agencies (Ben-Othman \& Kossentini, 2015; Efobi, 2017; Gordon et al., 2012; Ng 2015). Which means that these agencies provide a meaningful and reliable global financial and economic data for each country on various issues that affect worldwide economic development. Data were also sourced from the IFRS database on the use of IFRS by jurisdictions, the PwC website, and the Deloitte website. Secondary data were obtained from the agencies as mentioned above for 15 adopting countries (for a period of 22-year, 1994 -2015) and 20 non-adopting IFRS countries (for a period of 11-year, (2005-2015) on various estimated variables (FPI, IFRS, and covariates) to enable the statistical processing in mathematical form. 
For the adopting IFRS countries, data were collected for a period of 11-year (1994-2004) before the implementation of IFRS and 11-year period (2005-2015) after the adopting and implementation of IFRS (i.e. making 22-year of data collected) to evaluate the difference in the FPI inflow. Also, data were collected for non-adopting IFRS countries for a period of 11-year (2005-2015) as well to enable comparison of any difference in FPI inflows of the adopting and non-adopting IFRS countries.

Furthermore, this type of data collected that contains observations of multiple countries over multiple periods are referred to as panel data or longitudinal data, or a combination of time-series and cross-section data (Bryman \& Bell, 2015:66). Panel data involves the repetition of observations of a particular variable over some time. For example, characteristics of Botswana in terms of all variables are observed repetitively for periods under study. It shows that an individual country's specific features are obtained over a stipulated period. Thus in the case of this thesis, 15 adopted countries' characteristics, in terms of variables, are observed over the specified period while 20 non-adopted countries feature are obtained as well. It was emphasised in the literature that in a panel data analysis, individual characteristics of the sample of a unit (in this case, country) over specific periods are observed (Hsiao, 2003:1). It indicates that panel data analysis provides multiple observations on each of the selected countries over the periods on the estimated variables (FPI, IFRS, and covariates). The significance of using secondary data in the form of panel data for this thesis is that it will assist in observing the reality of the world without any interference or manipulation of the variables.

Bryman and Bell (2015:66) explain that the longitudinal research design or panel data gives a more feasible understanding of variables characteristics over some time and allows for the determination of the strength of the relationship among the variables. Priest (2006) posits that panel data research is the only method that can uncover the attributes of variables as they manifested in the patterns of association among them. This is following the paradigm employ in this thesis. For this purpose, 15 cross-section observations and 11-time series observations on the variables are observed for pre and post IFRS adoption for the adopted countries. While 35 cross-section observations and 11time series for the adopted and non-adopted countries. This approach will enrich the empirical analysis, which may not be achieved if the thesis adopts only cross-section or time-series data.

Consequently, most researchers in the field of accounting standards have empirically examined the effects of IFRS adoption on foreign investments by employing panel data analysis (e.g., Amiram, 2012; Beneish et al., 2015; Ben-Othman \& Kossentini, 2015; Efobi, 2017; Gordon et al., 
2011; Ng, 2015). Additionally, these researchers used different types of panel data estimators (e.g., ordinary least square, fixed-effects model, random-effects model, and dynamic system generalised method of moment) for analysis depending on the objective of their studies (Amiram, 2912; Efobi, 2017; Ng, 2017; Nnadi \& Soobaroyen, 2015). The system-generalised method of moment (SGMM) is estimated in this thesis to check for the problem of endogeneity between the independent and dependent variables. Given the above, this thesis will also employ the different types of panel data estimators, mentioned, for the analysis. This technique, panel data, and all the different estimators are discussed later in this chapter.

\subsubsection{Model specifications}

Two different regression approaches will be used in this thesis for statistical estimation. This is because of the nature of the objectives of the study that are twofold. First, a panel data regression model using pooled ordinary least square (POLS), fixed-effects model (FEM), random-effects model (REM), and the system-generalised method of moment model (SGMM) is specified to estimate the effect of the adoption of IFRS on FPI in Africa. In the first regression estimation model, FPI is employed as the dependent variable. Second, a logit regression model is applied to estimate the factors that determine the probability of adoption of IFRS in Africa, using IFRS as the dependent variable.

For the first data estimation that examines the effect of IFRS on FPI, the thesis relies on the combined work of Amiram (2012), Beneish et al., (2015), Ben-Othman and Kossentini (2015), Gordon et al., (2012), Kwarbai et al., (2016), as well as Ng, (2015). They examined the causal relationship between IFRS adoption and foreign investments in the developed and developing countries using a panel data regression model and reported a positive correlation between IFRS adoption and FPI.

However, the decision-usefulness theory employed as a theoretical underpinning for this thesis emphasises that accounting standards, such as IFRS, should guide the decisions regarding the economic and investment choices by investors (AAA, 1966), thus suggesting a positive relationship between IFRS adoption and FPI. Given this, a priori assumption in this thesis proposes a positive link between IFRS adoption and FPI in adopting countries.

On the other hand, the study also incorporates some covariates: inflation rate, interest rate, exchange rate, economic growth rate, regulatory quality index, corruption, capital markets, trade openness, and corporate tax rate. These are the benchmark factors that are assumed to influence 
the inflow of foreign investments (Ben-Othman and Kossentini, 2015; Gordon et al., 2012; Ng, 2015). Furthermore, these covariates have been differently investigated both in developing and developed countries in the prior empirical literature that examined the effects of IFRS adoption on foreign investments (e.g., Beneish et al., 2015; Ben-Othman \& Kossentini, 2015; Efobi, 2017; Nnadi, \& Soobaroyen, 2015; and Ng, 2015). Given this, they are found relevant to be included in the model for this thesis. These covariates have been previously discussed in Chapter 2 under the literature review. And also mentioned in this chapter under the variables descriptions.

In the empirical literature, it was reported that with the adoption of IFRS, the quality of the financial statement would be more enhanced and transparent (Amiram, 2012; Shima and Young, 2012). Tweedie (2006) opines that IFRS adoption will make the capital markets stronger and stable to influence the inflows of FPI, especially in the developing economy and improving the economic growth of the adopting countries. Therefore, examining the effect of IFRS adoption on FPI by investigating the pre- and post-adoption, as the main objective of this thesis, will provide evidence of the effect of IFRS adoption on FPI.

Subsequently, to address the main objective and other secondary objectives of this thesis, a panel data regression model is employed. This technique is to enable the objectives of the thesis to be achieved. Additionally, to address the research questions and to assess the hypotheses. Gujarati (2007:652) and Hsiao (2003:5) emphasise that using a cross-sectional data set or time-series data set alone, instead of panel data estimate, cannot enrich the empirical findings. Since either of them will not be able to provide accurate estimates of the coefficients of the model.

This thesis, therefore, starts by estimating the general panel data regression model by examining the linear relationship between the independent and dependent variables. Additionally, the selection of the variables, dependent and independent, for the model estimates relies on the existing literature reviewed in this thesis in Chapter 2 and 3. It is also motivated by the conceptual framework explained in Figure 4.1 of this thesis. Hence, the specific panel data model estimated in this thesis is described as follows (Hsiao, 2003:5):

$$
\ln Y_{i t}=\beta_{0}+\beta_{1} X_{i t}+\beta_{2} Z_{1 i t}+\beta_{3} Z_{2 i t}+\cdots \mu_{i t}
$$

where, $\ln Y_{i t}$ Denotes the logarithm of the dependent variable, lnFPI, for a country "i" in a year "t," $X$ is the primary explanatory variable, IFRSFA, for a country " $\mathrm{i}$ " in a year " $\mathrm{t}$ " and $Z_{1}, Z_{2}, \ldots$ represent the various covariates included in the equation for a country "i" in a year "t." The parameters $\beta_{1,} \beta_{2}, \beta_{3} \quad \beta_{n}$ represent the coefficients of the explanatory variables and control 
variables, and similarly, $\beta_{0}$ stands for the vector of the constant parameter that measures the variation in the dependent variable against the coefficient of each independent variable, ' $\mu_{i t}$ ' represents the scalar of the error term, while $f$ is some functions of the linear combination of $X_{i t}$ and $Z_{1 i t}, Z_{2 i t}$ Furthermore, the explicit form of the general model is stated as follows:

$$
\begin{aligned}
\ln F P I_{i t}= & \beta_{0}+\beta_{1} I F R S F A_{i t}+\beta_{2} I N F_{i t}+\beta_{3} I N T_{i t}+\beta_{4} \ln E X R_{i t}+\beta_{5} E G_{i t}+\beta_{6} T O P_{i t}+ \\
& \beta_{7} T A X_{i t}+\beta_{8} \ln M C A P_{i t}+\beta_{9} R E G_{i t}+\beta_{10} C O R_{i t}+\mu_{i t} \ldots \ldots \ldots \ldots \ldots \ldots \ldots \ldots \ldots \ldots \ldots \ldots \ldots \ldots \ldots \ldots . . .
\end{aligned}
$$

where: $\operatorname{lnFPI}$ is the proxy for the logarithm of foreign portfolio investment; (the dependent variable measurement $(\ln F P I)$ include 1-year time-lagged value [(i.e. $\ln F P I(-1)]$ that controls for the endogeneity of the explanatory variables). IFRSFA is the dichotomous measure of International Financial Reporting Standards for the pre-adoption and post-adoption; INF stands for inflation rate; INT represents interest rate; $\ln E X R$ is the logarithm of exchange rate; $E G$ stands for economic growth rate; TOP measures trade openness; TAX represents the corporate tax rate; $\ln M C A P$ is the proxy for the logarithm of market capitalisation; REG represents regulatory quality index; $C O R$ measures the corruption level.

Equation 4.2 is split into Model 1 A and Model 1B. Model 1A captures the effect of the benchmark factors that assume to influence the FPI inflows before adopting and implementation of IFRS in the selected African countries that have fully adopted IFRS from 1994-2004. Model 1A is estimated as a control for the variables that trigger the inflow of FPI before adopting IFRS. These factors have been discussed in the literature review in Chapter 2 of this thesis. Model 1A is stated as follows:

\section{Model 1A}

$$
\begin{aligned}
\ln F P I_{i t}= & \beta_{0}+\beta_{1} I N F_{i t}+\beta_{2} I N T_{i t}+\beta_{3} \ln E X R_{i t}+\beta_{4} E G_{i t}+\beta_{5} T O P_{i t}+\beta_{6} T A X_{i t}+ \\
& \beta_{7} \ln M C A P_{i t}+\beta_{8} R E G_{i t}+\beta_{9} C O R_{i t}+\mu_{i t} \ldots \ldots \ldots \ldots \ldots \ldots \ldots \ldots \ldots \ldots \ldots \ldots \ldots \ldots \ldots \ldots \ldots \ldots \ldots \ldots \ldots \ldots \ldots
\end{aligned}
$$

Also, Model 1A is augmented with IFRS adoption variable, IFRSFA, to capture the effect of IFRS adoption on FPI after the adoption and implementation of IFRS in Model 1B. The model is based on the whole period of 22 years. The findings will indicate the significance of IFRS in influencing the flow of FPI before and after the adoption. The dependent variable measurement ( $\ln F P I)$ includes 1-year time-lagged value [i.e. $\ln F P I(-1)]$ that controls for the endogeneity of the explanatory variables. Thus, Model 1B with IFRS adoption variable is stated as follows: 


\section{Model 1B}

$$
\begin{aligned}
& \ln F P I_{i t}=\beta_{0}+\beta_{1} I F R S F A_{i t}+\beta_{2} I N F_{i t}+\beta_{3} I N T_{i t}+\beta_{4} \ln E X R_{i t}+\beta_{5} E G_{i t}+\beta_{6} T O P_{i t}+ \\
& \beta_{7} T A X_{i t}+\beta_{8} \ln M C A P_{i t}+\beta_{9} R E G_{i t}+\beta_{10} C O R_{i t}+\mu_{i t}
\end{aligned}
$$

where: $\ln F P I_{i t}$ represents the logarithm of FPI as the dependent variable in the country ' $\mathrm{i}$ ' at period't' The dependent variable measurement ( $\ln F P I)$ includes 1-year time-lagged value [i.e. $\ln F P I(-1)]$ that controls for the endogeneity of the explanatory variables). IFRSFA stands for International Financial Reporting Standards full adoption, IFRSFA $i t$. The error term, $\mu$, comprises country-fixed effects and the time-specific effects. Thus, Equation 4.4 estimates that FPI is influenced by IFRS adoption in addition to benchmark factors (covariates tested in Equation 4.4) to address the first research question and to test the hypothesis formulated in Chapter 1.

To achieve the second objective that examines the effect of the adoption of IFRS on FPI inflow among the adopting and non-adopting countries, Equation 4.5 below is estimated. IFRS variable, IFRSFA, is proxy by using the dummy variable to consider the status of adoption where IFRS adopting country is coded 1 , and the non-adopting country is coded 0 . Model 2 addresses the second research question and test the formulated hypothesis, as described in Chapter 1 . The equation is stated as follows:

\section{Model 2}

$$
\begin{aligned}
\ln F P I_{i t}= & \beta_{0}+\beta_{1} I_{F R S F A_{i t}}+\beta_{2} I N F_{i t}+\beta_{3} I N T_{i t}+\beta_{4} \ln E X R_{i t}+\beta_{5} E G_{i t}+\beta_{6} T O P_{i t}+ \\
& \beta_{7} T A X_{i t}+\beta_{8} \ln M C A P_{i t}+\beta_{9} R E G_{i t}+\beta_{10} C O R_{i t}+\mu_{i t} \ldots \ldots \ldots \ldots \ldots \ldots \ldots \ldots \ldots \ldots \ldots \ldots \ldots \ldots \ldots \ldots \ldots \ldots \ldots
\end{aligned}
$$

where $\ln F P I_{i t}$ represents the logarithm of FPI as the dependent variable in the country ' $\mathrm{i}$ ' at period't' The dependent variable measurement ( $\ln F P I$ ) includes 1-year time-lagged value [i.e. $\ln F P I(-1)]$ that controls for the endogeneity of the explanatory variables). IFRSFA represents International Financial Reporting Standards fully adopted.The descriptions of other variables remain as explained earlier in Equations 4.2. Consequently, Models 1A and 1B will be estimated with a panel data regression model using POLS, FEM, REM, and SGMM. While SGMM estimator will be used to estimate Model 2 to achieve the first two objectives of this thesis. The estimation techniques employ for the statistical analyses are explained below. 


\subsubsection{Methods of estimation}

This thesis employs panel data as a method of analysis. Moreover, in a typical panel data analysis, especially in this situation, the following basic preliminary estimation techniques are necessary, and they are discussed below (sub-section 4.8.6.1-4.8.6.3) before the description of panel data estimation.

\subsubsection{Descriptive statistics summary}

The descriptive statistics are used to summarise the data in a meaningful way and to describe the observations. The descriptive statistics procedures show numerical univariate summary statistics for all the variables in a single table. This includes the mean, standard deviation, minimum, maximum, and coefficient of variation values. The standard deviation measures the level of variation of all variables from their mean value. Although the standard deviation is not usually used to compare two distributions. For this purpose, the coefficient of variation (CV) is computed. That is to compare FPI inflow before and after the adoption of IFRS.

The $\mathrm{CV}$ is the ratio of standard deviation and the absolute value of the mean in percentage. The $\mathrm{CV}$ is used to compare the measurements of the dispersion of two distributions to cut the effects of factors such as inflation (Bajpai, 2009:129; Taylor, 2007:53). The authors explained further that distribution with lesser CV shows greater uniformity and consistency, while a distribution with greater distribution is more variable than others. Thus, $\mathrm{CV}$ is computed purposely to compare the degree of variability of FPI inflows before and after the adoption of IFRS. Since FPI inflow is the primary variable that needs to be compared. The graph that depicts the trends of FPI inflows before and after the adoption of IFRS is presented for the analysis.

Additionally, the Wilcoxon signed-rank test (WSRT) is employed to compare the significant difference in FPI between the pre and post IFRS adoption by using "R." WSRT is a nonparametric test designed to measure the significant difference of a variable on two different occasions. In this case, the difference in FPI inflow between pre and post-IFRS adoption among the adopted countries. WSRT converts the variable, FPI, into ranks to compare the difference in FPI inflow between pre and post IFRS adoption. Similarly, the effect of the test can also be calculated by dividing the WSRT z-value (neglecting the negative sign) with the square root of the total number of observations of the pre and post. That is, using " $r$ " to measure the effect of FPI volume will be stated as follows: $\mathrm{r}=\mathrm{z} /$ square root of $\mathrm{N}=$ total number of observations. The result will assist in determining the effect of the volume by using the Cohen ranking approach of the effect. According 
to Cohen, .1=small effect, .3=moderate effect, and .5=large effect. This technique was used in the study of Erin et al. (2018) when determining the pre and post-impact of IFRS on the profitability of listed companies.

\subsubsection{Pearson correlation matrix}

The next estimation technique is the Pearson correlation matrix. It determines the extent of a bivariate relationship between the estimated variables to know if there is any linear association between any of the variables (Jaccard \& Becker, 2010:441). It is also used to determine the presence of multicollinearity among the estimated variables. The authors further remarked that this occurs in a situation where two or more independent variables are perfectly associated. Consequently, the presence of any perfect or precise linear association among any or a few of the variables will indicate the occurrence of multicollinearity. According to Efobi (2017), the presence of multicollinearity can be treated in two ways, either to drop the variable or to estimate them differently. This implies that the two affected variables will not be evaluated together in the same model to avoid any spurious findings from the regressions.

\subsubsection{1. Variance inflation factor (VIF)}

The variance inflation factor (VIF) will be used to perform the collinearity diagnostics test on the estimated variables. The VIF test is to identify the presence of multicollinearity that may not be obvious in the correlation matrix. Two values will be estimated, the Tolerance and VIF values. Tolerance value measures the value of how much of the variability of the particular independent is not explained with the other explanatory variables in the model. Given this, if this value is minimal (i.e. less than 10), it shows that the multiple correlations with other explanatory variables are high, indicating the presence of multicollinearity. On the other hand, VIF measures the inverse of the tolerance value. Thus, VIF values that are greater than 10 indicates the possibility of multicollinearity.

\subsubsection{Unit root test}

Similarly, it was emphasised that the common problem in a panel data analysis is the nonstationarity of the data (Choudhary \& Bajaj, 2013). The unit root test using the common Augmented Dickey-Fuller (ADF) test and Im Pesaran and Shin (IPS) test is carried out to examine the properties of the panel data for the presence of stationarity and to address the problem. This 
thesis uses these tests also to confirm the basic features of panel data and to examine the stationarity or non-stationarity of the variables.

The four preliminary estimation approaches explained above are all necessary but not suitable enough to justify the cause-and-effect relationship between FPI and IFRS adoption and all other covariates, so inference may not be reached. For this purpose, the panel data regression model using the pooled ordinary least square (POLS) regression model, the fixed-effects model (FEM), and the random-effects model (REM) to examine the effect of IFRS adoption on FPI are estimated. The purpose of using these three different types of the panel data regression estimation is to evaluate the one with the highest explanatory power for the analysis (Efobi, 2017; Olokoyo, 2013; Salawu, 2007). Gujarati (2007:666) explains that a particular type of panel data regression may seem inappropriate in every situation. However, the system-generalised method of moments (SGMM) is employed to address the probable problem of endogeneity, usually associated with the panel data regression analysis. These statistical estimators are discussed below.

\subsubsection{Panel data regression analysis}

Panel data regression analysis involves the pooling of repeated observations on a cross-sectional section over several given periods (Baltagi, 2008:1). It is a longitudinal, or panel, data set comprising multiple observations collected from individuals (households, firms, countries) in this case countries, in a given research sample over a long period (Hsioa, 2014:1). In the opinion of Brooks (2014:647), panel data evolve in a situation where observations exist in both crosssectional and a time-series dimension. For example, in this study, data were collected on FPI and other independent variables in thirty-five countries for twenty-two years, and a single regression is run instead of running a regression for each country.

Importantly, using the panel data regression analysis would give more information than pure timeseries or cross-sectional samples. Also, allowing more degrees of freedom and efficient regression estimation, detecting additional features of data compared to the use of cross-sectional samples (Brooks, 2014:647). Also, it is an appropriate approach for longitudinal data analysis since it permits regression analysis both in units, short and long time scopes (Olokoyo, 2013). In this case, this study is considering a cross-section of 15 countries over 22 years for pre and post-adoption periods for the adopted countries and 20 countries for 11 years.

The benefits and some limitations of using panel data have been emphasised in the literature (Baltagi, 2008:3-6; Gujarati, 2007:651-652; Hsiao, 2014:4-10, and Kennedy, 2003:231-232). They 
observed that since panel data concerns individuals, firms, states, countries, et cetera, in this case, countries, on cross-sections with time-series data over time, there is a tendency towards heterogeneity in these units, which cannot be controlled. Using the panel data technique can check this individual heterogeneity. Additionally, the authors further mentioned that panel data analysis gives more informative data, improves efficiency by using data with more variability and less collinearity and more degrees of freedom, and minimises bias if units were aggregated. Thus, it shows that the main focus of panel data is on how to check the effect of unobserved heterogeneity to obtain valid inference on the same parameters, $\boldsymbol{\beta}$ (Hsiao, 2014:11).

Gujarati (2007:651-652) explains that panel data is more appropriate to study the dynamics of change than cross-sectional data, which hide a large number of changes. It identifies and measures the effects that cannot be detected when using pure cross-sectional or time-series data, therefore generating accurate predictions for the individual's outcomes. In this situation, a reliable statistical parameter will be made in the models to predict the usefulness of accounting standards, IFRS, in influencing FPI in the adopting countries in Africa. There is a related issue that panel data simplify computation and statistical inference, therefore, making it possible to carry out more complicated behavioural models instead of using pure cross-sectional or time-series data.

Similarly, estimation with panel data makes the empirical investigation more meaningful and authoritative compared with pure cross-sectional and time series analysis (Baltagi, 2008:7). For example, instead of running 35-time series regressions for each of the countries (adopting and nonadopting) or run the regression for 11 cross-sectional regressions for each year, a panel data model will combine all the observations $\left(35^{*} 11=385\right)$ and run a regression. Since this thesis is applying a balanced panel data regression analysis, where each cross-section of a country has the same number of observations, the outcome of the effects of IFRS adoption on FPI would be more reliable. The reason is that panel data allow for control over unobservable heterogeneity arising from individual country's effect (Gujarati, 2007:651).

Despite all the identified benefits of using panel data regression, some limitations of the technique have also been mentioned by different authors. They discovered that since the application of panel data involves the combinations of cross-sectional and time-series data, most of the problems identified, such as the issue of heterogeneity, collinearity, and short-time series dimensions, maybe a problem. In this study, all the envisaged shortcomings embedded in the use of panel data have been adequately taken care. For example, on the issue of short-time series dimension, panel data makes available several techniques for relevant changes (Baltagi, 2008:7). Critical attention must 
be paid when it is being adopted for the analysis against the other alternatives because of various assumptions of the intercept, the regression (or slope) coefficients, and the error term that have to be made.

A balanced panel data model approach used in this thesis indicates that none of the selected countries has any missing value. The balanced panel data regression model is estimated in such a way that it enables the intercept (constant terms) and the slope coefficients to vary over individual countries and over time (Gujarati, 2007:655). Hence, the pooled regression estimated model, as described in Equation 4.1, is represented as a general basic framework adopted in this thesis for a panel data regression model.

$$
\ln Y_{i t}=\beta_{0}+\beta_{1} X_{i t}+\beta_{2} Z_{1 i t}+\beta_{3} Z_{2 i t}+\cdots+\mu_{i t}
$$

where, $\ln Y_{i t}$ denotes the logarithm of the dependent variable, lnFPI, for a country " $\mathrm{l}$ " in the year "t," while $f$ is some function of the linear combination of $X_{i t}, Z_{1 i t}$, and $Z_{2 i t} X$ is the primary explanatory variable, IFRSFA, for a country $\mathrm{i}$ in year $\mathrm{t}$, and $Z_{1}, Z_{2}, \ldots$ represents the covariates included in the equation for a country " $i$ " in a year "t." The parameters $\beta_{1,} \beta_{2}, \beta_{3}, \beta_{n}$ represent the coefficients of the explanatory variables and control variables. Similarly, $\beta_{0}$ stands for the vector of the constant parameter that measures the variation in the dependent variable against the coefficient of each independent variable, while ' $\mu_{i t}$ ' represents the scalar of error term stated as follows:

$$
\mu_{i t}=C_{i}+\gamma_{t}+\varepsilon_{i}
$$

where $C_{i}$ represents the country-specific fixed effects and $\gamma_{t}$ denotes the time-specific effect. While $\varepsilon_{i t}$ equals distributed component with zero mean and the same variance $\sigma^{2}$ over time and across the country.

Thus, Equation 4.8 is a basic general model for the estimation of panel data employed in this thesis. Although this may not apply to all the estimators used in this study since the specific estimation method will depend on the assumption made about the intercept, the slope coefficients, and the error term (Gujarati, 2007:655). For this limitation concerning the degree to which the intercept and the slope of coefficients vary with " $i$ " (for a country) in the year " $t$ " (year) must be ascertained since there are several options that can be taken about the intercept and the slope of coefficient (Gujarati, 2007:654). 
Consequently, stipulating and estimating a more restrictive model motivates the necessity to adopt various estimators of panel data (POLS, FEM, and REM) to choose the best approach that has the highest explanatory power for the analysis (Olokoyo, 2013). The literature emphasises that most of the empirical studies that examined the relationship between IFRS adoption and FPI employed a panel data regression model. They used panel data estimators such as POLS, FEM, REM, and SGMM (e.g. Amiram, 2012; Beneish et al., 2015; Ben-Othman \& Kossentini, 2015; Efobi, 2017; Gordon et al., 2011; $\mathrm{Ng}, 2015)$.

\subsubsection{Pooled ordinary least squares regression model (POLS)}

This technique of statistical estimation intends to investigate the association between explanatory variables and explained variable to determine the predictive coefficient of the independent variables that are predicting of "Y" on " $\mathrm{X}$ " (Efobi, 2017). It is also referred to as the constantcoefficient model (CCM). It is a more straightforward statistical method when compared with FEM and REM (Olokoyo, 2013). The problem of POLS is the ability to disregard the possible differences among the variables. It assumes that the FPI value is the same in all the countries or the country adopted IFRS in the same year. Thus, it pooled all the observations and ran a standard regression by ignoring the potential difference among the variables. It does not take into consideration the particular characteristics of dependent and independent variables, which may distort the actual association between $\mathrm{Y}, \mathrm{X}$, and $\mathrm{Z}$ (control variables). This reflects the weakness of pooled regression analysis.

Gujarati (2007:655) explains that it is assumed that the slopes coefficients of all independent variables are similar. This assumption seems to be too restricted. For example, this assumption means that all the 35 selected countries under investigation in this thesis have the same characteristics in terms of technology, political system, tax policies, etcetera, which is not possible. Thus, denying the heterogeneity or individuality that may exist among the 35 selected countries and weaken the reliability of the parameter estimates of the model.

Given the possibility of POLS neglecting the cross-section (countries) and time-specific effects, a cross-sectional dependence test is computed to ascertain the presence of specific effects. If the result of the test is statistically significant, it shows that POLS will not be reliable. Still, if the result is not substantial, it means, there is no cross-section dependence, and POLS may be used for the analysis. Because of this restricted assumption, which may distort the actual relationship between the cause and effect, so there is a need to select among the three-panel data estimator 
alternatives POLS, FEM, and REM to consider the particular characteristics of each country in the sample. Nevertheless, this study estimates the POLS regression model based on its power to measure the strength of the relationship between independent and dependent variables in a model. Equation 4.9 indicates the POLS model when all the observations are pooled together, and the regression is run.

\subsubsection{Fixed-effects regression model estimation}

The fixed-effects model is a statistical model with fixed, not random, parameters. Hsiao (2003:95) highlights that FEM is a mathematical regression model where the parameters and the group mean are considered fixed and time-invariant. It assists in checking for unobserved heterogeneity or specific effect when it is constant over time (time-invariant). The time effects are viewed as transitions or discrete changes of a state, which is specifically related to the period it occurs and not carried over within a cross-sectional unit (Greene, 2003:283).

The fixed-effects model takes into consideration each country's particular uniqueness with the assumption that the intercept, $\boldsymbol{\beta}$, may have correlated with one or some of the independent variables, $\boldsymbol{X}$ or $\boldsymbol{Z}$ (Gujarati, 2007:656). The intercept may vary across the 35 individual countries, but each country's intercept is time-invariant. However, it shows that the time-varying specific effects in the model are not checked, rendering the model not free from the endogeneity problem in the estimation.

Nevertheless, the FEM is more appropriate because it checks for the presence of each country's unobserved heterogeneities that may occur due to an individual specific country time-invariant (Greene, 2003:285 \& Gujarati, 2007:656). Hence, the unobserved variables are therefore determined by the country and year fixed effect because the fixed effect regression model intercept varies across individuals (hear countries), but it is time-invariant. The FEM estimation allows the intercept, $\boldsymbol{\beta}_{\mathbf{0} \boldsymbol{i}}$, to differ among the cross-sections (countries) and making the slope coefficients of individual intercept remain fixed and not vary over-time, meaning that it is time-invariant.

In FEM, it is assumed that the individual or heterogeneity effects are fixed parameters to be assessed, and the remainder disturbance term or an error term is expected to be individually and identically distributed with mean zero. Similarly, the error terms, $\boldsymbol{\mu}_{\boldsymbol{i t}}$ and $\boldsymbol{X}_{\boldsymbol{i t}}$ and $\boldsymbol{Z}_{\boldsymbol{i t}}$ are independent. Thus, FEM takes cognisance of the different intercepts, especially in cases where individual-specific intercepts may be correlated with one or more independent variables (Olokoyo, 2013). It is relevant where the emphasis is on a specific group of cross-section, and the inference 
to be made is related to the nature of their peculiar characteristics. For this purpose, this thesis is examining the effects of IFRS adoption on FPI in the selected two groups of countries in Africa. The findings will enable the inference to be made concerning the influence of IFRS in attracting FPI in Africa.

\subsubsection{Random-effects regression model estimation}

Kennedy (2000:227) emphasises that the random-effects model has a general intercept and an error term that comprises of two components, e.g. $\varepsilon_{i}+\mu_{i}$. Where $\varepsilon_{i}$ denotes the traditional random error term that is distinct to each observation with a mean value of zero. And $\mu_{i}$ is an error term. It indicates the extent of the intercept of the $i$ th cross-sectional unit (here country), which is different from all the intercepts. It suggests that the individual differences in the intercept values are already included in the random error term $\varepsilon_{i t}$.

Moreover, the REM consists of many parameters since it exhausts data for the population. Therefore, there is a tendency of loss of degrees of freedom, which can be avoided if the error term that indicates the degree of intercept can be random. REM will be more appropriate if the inference is drawn from a large population to reduce the loss of degrees of freedom (Baltagi, 2000:13). It is also suitable in a situation where the intercept of individual cross-section (country) is uncorrelated with the independent variables. Thus, the REM equation relating to this study is stated below by referring to Equation 4.10.

$$
\ln Y_{i t}=\beta_{0 i}+\beta_{1} X_{i t}+\beta_{2} Z_{1 i t}+\beta_{3} Z_{2 i t}+\cdots+\mu_{i t}
$$

From the initial Equation 10 on FEM, instead of having $\beta_{0 i}$ as fixed, it can be assumed to be a random variable that has a mean value of $\beta_{0}$. Therefore, the differences in the intercept values of each country can now be explained as follows:

$$
\beta_{0 i}=\beta_{0}+\varepsilon_{i}
$$

Where $\mathrm{i}=1,2,3, \ldots \ldots N$ (represents the total number of the selected countries) $\boldsymbol{\varepsilon}_{\boldsymbol{i}}$ denotes random error term with a mean value of zero and variance of $\boldsymbol{\sigma}_{\varepsilon}^{2}$. Invariably, it shows that the selected countries are from a larger population of such countries and their mean value for the intercept $\left(=\beta_{0}\right)$ and the country's' individual differences in the intercept values are shown in $\boldsymbol{\varepsilon}_{\boldsymbol{i}}$

If Equation 4.11 is substituted into Equation 4.12, the equation will be written as follows: 


$$
\begin{aligned}
\ln Y_{i t} & =\beta_{0}+\beta_{1} X_{i t}+\beta_{2} Z_{1 i t}+\beta_{3} Z_{2 i t}+\cdots \boldsymbol{\varepsilon}_{\boldsymbol{i}}+\mu_{i t} \\
& =\beta_{0}+\beta_{1} X_{i t}+\beta_{2} Z_{1 i t}+\beta_{3} Z_{2 i t}+\cdots \boldsymbol{\rho}_{i t} \ldots \ldots
\end{aligned}
$$

where $\rho_{i t}=\varepsilon_{i}+\mu_{i t}$

The $\boldsymbol{\rho}_{i t}$ represents the composite error terms that consist of two different components as explained in Equation 4.12, where $\boldsymbol{\varepsilon}_{\boldsymbol{i}}$ denotes the unobservable cross-section error component, while $\boldsymbol{\mu}_{\boldsymbol{i}}$ is the combined error term for cross-section and time series components.

The previous sections (4.8.6.5-4.8.6.7) discussed the panel data regression analysis with three different estimators POLS, FEM, and REM, as relevant to the statistical analysis. The primary concern is to identify the most appropriate alternative to be adopted for the study. Firstly, a test of error cross-sectional dependence that applies to a variety of panel models such as Breusch-Pagan LM (1979) and Pesaran scaled LM (2004) is estimated to verify the appropriateness of POLS based on its residual. Likewise, the Hausman chi-square test is computed to determine the best alternative between the FEM and REM.

\subsubsection{The GMM estimation approach}

The literature emphasised that including a lagged dependent variable in panel data may lead to subjective results due to the problem of endogeneity (Gitto et al., (2015). This is a situation where the explanatory variable is correlated with the error term. Thus, the instrumental variable approach is customarily used to address the problem. In this case, the GMM estimator is adopted to solve the problem.

There are four methods of solving the problem of endogeneity, namely, the generalised method of moment (GMM) estimator, the instrumental-variable (IV) estimator, the maximum-likelihood estimator (MLE) and the generalised least-squares (GLS) estimator (Hsiao, 2014:89). Gitto et al. (2015) explain that GMM is more recognised in solving the problems of potential endogeneity. It is the most common handy tool used when there is the presence of endogeneity between the dependent and error term.

The generalised method of moment (GMM) technique estimator is used to test any relationship between the explanatory variables and error term in this thesis. For example, if there is no relationship between all the explanatory variables in the system, it means that they are orthogonal (non-overlapping) to one another (Brooks, 2003:190). Thus, it is uncommon for economics variables like those utilised in this study (FPI inflows, economic growth, inflation, etcetera.) not 
to be orthogonal. In this situation, their actual value in the model may be influenced by other variables in the error term, making the explanatory variables not completely endogenous.

Furthermore, in a situation like this, (Efobi 2017 and Kennedy, 2000:143) explains that the problem of autoregression may arise, and it is essential to account for it to avoid a situation where the explanatory variable is correlated with the error term. Kennedy (2000:132) emphasises that GMM provides a unifying framework for analysis, and it is a convenient approach to estimation in a situation where the computation of traditional estimation methods is complicated. For this study and to consider the potential endogeneity of some explanatory variables, the GMM regression model is estimated.

However, Arellano and Bond (1991) developed the GMM estimators to check for the endogeneity of the lagged dependent variable in a dynamic panel model, especially when there is a correlation between the explanatory variable and the error term in a model. Additionally, it was also designed to check for any omitted variable bias and unobserved panel heterogeneity. Additionally, to check the measurement errors in the data and autocorrelation within panels or groups. Kimeli (2017) explains that it is essential in empirical studies that examine the effect of IFRS adoption on foreign investments to check for the robustness of the model to establish its validity. This research is thus making use of GMM to check for the strength of the model used, especially in a panel data regression analysis of this type.

Klemm and Van-Parys (2012) emphasise that the GMM estimator is reliable for a panel data analysis even if the number of the groups (in this case, country) goes to perpetuity. It can be used to estimate panel data for wide panels, for example, large $N$ (countries) and small $T$ (time). In addition, it can be used for the long panels that are small $N$ and large $T$. Thus, and this thesis employs wide panels since the number of the countries tested, $N$, is large, in this case, 15 selected IFRS adopted countries with short time, $T, 11$ years for pre and 11 years for post-IFRS adoption. Similarly, for the adopting and non-adopting countries, the wide panel is equally relevant since the countries comprise both the adopted and non-adopted from 2005-2015. Thus, $N$ is 35 , and $T$ is 11 years, making the GMM pertinent estimators for this thesis to check for the robustness of the estimated model.

The GMM estimators are classified into two: the difference-GMM and system-GMM (SGMM). In the case of the difference-GMM, Arellano and Bond (1991) correct the endogeneity by transforming all the regressors through data differencing to get the difference between the two sets 
of data. In the process of first transforming, the fixed effects are removed. It was highlighted that this process of first differentiation is not appropriate in an unbalanced panel data because it may cause the results not to be strong enough. Since this thesis is estimating a balanced panel data, the technique will be more appropriate.

Similarly, Arellano and Bover (1995) and Blundell and Bond (2000) explain that the SGMM, like the difference-GMM, also corrects for the endogeneity in the different perspectives by introducing more instruments to improve the estimator's competencies. In this situation, $Y_{i t}$ and $X_{i t}$ Variables are used as instruments. In addition, the instruments are transformed to become uncorrelated with the fixed effects to address the problem of endogeneity.

The SGMM also improved on the first autoregressive model through the transformation of the equation, and finally, it employed the orthogonal deviations, which reduced the data loss compared to what was obtained in the difference GMM. The idea of using SGMM is that it takes cognisance of the unobserved country-specific effects, and it will also be used in this thesis as a robustness check. From the initial model, the autoregressive model is considered as follows

$$
Y_{i t}=\beta_{1} Y_{i t-1}+\beta_{2} X_{i t}+\omega_{i t}=\varepsilon_{i}+\pi_{i t}
$$

where, $Y_{i t}$ stands for the dependent variable while $Y_{i t-1}$ means the lag variable (i.e., at time t-1), and $X_{i t}$ represents the exogenous variables (main explanatory variable and covariates) assumed to include lag value. $\varepsilon_{\mathrm{i}}+\pi_{i t}$ represent the composition of error terms.

Furthermore, Equation (4.16) is transformed by the first difference to remove the fixed effect since it does not vary with time, but there is still the problem of endogeneity due to the lag variable being correlated with the error term, that is, $\beta_{1} Y_{i t-1}$ is correlated with $\Delta \omega_{i t}$ In order to eliminate the individual country's unobserved specific effect, the model (including the covariates) is converted to the first difference. The resulting equation is as follows:

$$
\Delta Y_{i t}=\beta_{1} \Delta Y_{i t-1}+\beta_{2} \Delta X_{i t}+\Delta \omega_{i t}
$$

$\Delta Y_{\text {it }}=Y$-value at t minus $Y$-value at $t$ - 1 , etc., while $\Delta \omega_{i t}=\varepsilon_{\mathrm{i}}+\pi_{i t}$ represents the components of the error terms.

In another vein, the SGMM is also assumed that Equation 4.15 is a random walk model and $Y$ as a dependent variable is a persistent variable. Therefore the application of difference GMM estimator may be biased, and the estimation of ' $\boldsymbol{\beta}$ ' as a parameter to be estimated for the lag 
variable may not be efficient (Blundell and Bond, 2000). In this situation, the SGMM estimator will be more appropriate. Additionally, using the SGMM will enable data to be transformed to minimise data loss. Also, the SGMM provides for computing of the standards errors and test statistics. That is robust to heteroscedasticity and the panel data-specific autocorrelation.

Furthermore, to determine the validity of the instruments in the model, the $A R\langle 1\rangle$ (the autoregressive model with lag 1 (order 1) and $A R\langle 2\rangle$ the autoregressive model with lag 2 (order two) is computed to test the null hypothesis that there is no autocorrelation of first and secondorder (Arellano \& Bond, 1991). The authors expressed further that for the instrument to be valid, the probability value of $A R\langle 2\rangle$ Should be higher than 0.05 ( $p$-value $>0.05$ ) whereas the probability value of $A R\langle 1\rangle$ should be less than 0.05 ( $p$-value $<0.05$ ). Based on this assumption, the findings from the estimated model would be assessed. This is to establish the validity of the instrument employed in SGMM. Also, to verify any problem of over-identifying the parameter of the instruments in the statistical model. A large portion of current empirical studies investigating the effects of IFRS adoption on foreign investments employed SGMM as an estimator (e.g., BenOthman \& Kossentini, 2015; Beneish et al., 2015; Efobi, 2017).

\subsubsection{Variables descriptions and measurements for the panel data regression model}

This section describes the measures of variables employed in the panel data regression model. Furthermore, it is grouped into three different variables the dependent variable, the main explanatory variable, and the covariates as control variables.

\subsubsection{Dependent variable: FPI}

$\operatorname{lnFPI}_{\text {it }}$ is the natural log of foreign portfolio investment in the country i at period t. It is measured as the dependent variable for this study. It represents the total inflows in the US dollar of equity and debt in a country. It is a proxy for a natural logarithm of FPI (lnFPI) due to large values that are involved, which may affect the normal distribution of data. The advantage of using the natural logarithm is that it reduces the impact of scale effect or outlier that may affect the distribution of the data. Hence, it helps to normalise the distribution of the data. This method is in line with the approach used by Amiram (2012) and Chen et al. (2014) to measure foreign investments. Similarly, this study adopts the same approach.

Moreover, this technique is contrary to other studies. For example, Efobi et al. (2014) used the proportion of net foreign investment and gross domestic product (GDP) to measure foreign 
investment, while Chen et al. (2014) employed the absolute value of the aggregate inflow of foreign investment. These approaches may not be able to capture the actual inflows of FPI in the context of this thesis. For this purpose, the logarithm of the real value of FPI inflow is obtained to measure FPI. The thesis makes use of annual data from the Balance of Payments and International Investment Positions (BOP/IIP) from 1994 to 2015 on portfolio investments in liabilities (equity and debt). The total portfolio investment holdings in assets and liabilities by each country were estimated according to the Coordinated Portfolio Investments Survey (CPIS). It is the standard framework for compiling cross-border position statistics (IMF, 2017:1-2). The information provides the value and composition of a country's position in external assets and liabilities compared with the rest of the world.

\subsubsection{The main explanatory variable: IFRS adoption}

IFRSFA $_{i t}$ represents a country $\mathrm{i}$ at period t that has adopted IFRS. In this thesis, the independent variables are grouped into the main explanatory variable and control variables. The main explanatory variable is IFRS adoption, and it represents the dominant variable. It is defined as the total use of IFRS by the listed companies in each adopted country. It excludes countries that have not required all their listed companies to use IFRS. IFRS is a proxy for IFRSFA, using the dummy variable. A dummy variable is a dichotomous variable that takes the value of ' 0 ' or ' 1 ' to specify the absence or presence of a variable. This measure is relevant because the first objective is considering the pre-and-post-effect of countries that have adopted IFRS. Therefore, the period before the adoption is measured as " 0 " (absence) while the period after the adoption is scored as " 1 " (presence). It is estimated based on the date the country specifically adopted and implemented IFRS. Chen et al. (2014); Efobi, (2017), Gordon et al. (2012), and Ng (2015) adopt the dummy variable to measure IFRS in their various studies. Given this, this thesis is adopting the same approach to measure IFRS to achieve the first and second objective of this thesis.

Similarly, in achieving the second objective, a dummy variable is also employed. For this reason, adopting countries are coded as ' 1 ' while non-adopting countries are coded ' 0 ' (see Tables 4.1 and 4.2). Thus, columns $\mathbf{b}$, $\mathbf{c}$, and $\mathbf{d}$ in Table 4.1 are classified as non-adopting IFRS countries and coded ' 0 '. While countries in column a were adopting IFRS countries and coded ' 1 ' The grouping of countries into adopting and non-adopting will assist the thesis to examine the significance of FPI inflow among countries that have adopted IFRS and countries that have not. 
Data were sourced from Deloitte (2017), IFRS (2018), and the websites of the various countries who use IFRS. These sources provided relevant information concerning the IFRS status of different countries and the year of adoption.

\subsubsection{Control variables}

The covariates, as control variables, are the identified extraneous variables in the literature that may influence the dependent variable in the statistical estimation (Vogit \& Johnson, 2011:83). Kwarbai et al. (2016) emphasised that IFRS adoption alone cannot warrant inflows of FPI in the context of Africa. Similarly, Chen et al. (2014) posit that measuring the effect of IFRS on foreign investment necessitates control for confounding effects that affect the inflows of foreign investments.

In this thesis, the following covariates are included: inflation rate, interest rate, exchange rate, economic growth rate, regulatory quality index, corruption, capital markets, trade openness, and corporate tax rate. In the literature, these variables were identified as those benchmark factors that influence the inflows of foreign investments (Gordon et al., 2012; Gumus et al., (2013); Ng, 2015; Rodriguez-Pose \& Cols, 2017). Similarly, the literature also emphasised a link between IFRS adoption (main explanatory variable) and FPI. Hence, the inclusion of these covariates in the model, along with IFRS adoption, is to ensure that the findings are not due to overlooking certain variables that may also influence FPI inflows. These covariates have been differently examined in the prior studies that examined the effects of IFRS adoption on foreign investment (e.g., Amiram (2012); Beneish et al., 2015; Ben-Othman \& Kossentini, 2015; Efobi, 2017; Nnadi, \& Soobaroyen, 2015; and Ng, 2015). They are described below, including their measurements.

The inflation rate $(I N F)$ is captured using the annual consumer price index rate. It is one of the essential indicators that measure the economic stability of a country, and foreign investors always prefer an economy that is more stable to invest their capital (Gumus et al., 2013). It was further reported that persistent increases in the inflation rate might have a negative effect on FPI inflows. Hence, inflation is measured as a controlling factor because of its link with FPI. Data on the inflation rate were sourced from the World Development Indicators (World Bank, 2015) database.

The interest rate (INT) is measured using the real rate of interest. It was reported that FPI flows to the developing countries are highly sensitive to interest rate movements (Gumus et al., 2013). Data on interest rates were sourced from the World Development Indicators (World Bank, 2015) and the International Monetary Fund (IMF, 2015). 
The exchange rate $(\ln E X R)$ represents the logarithm of the real exchange rate, which is defined as the relative national price levels between the two economies. The most common definition of the real exchange rate is the nominal exchange rate adjusted by price levels. The real exchange rate will assist in determining the living standards in two countries, which will be a factor to be determined by foreign investors before diversifying their capital. It is measured using the logarithm of the foreign exchange rate measured with the national currency per special drawing rights (SDR) yearly average. SDR represents the unit of account of the IMF and its value in terms of the dollar. It is determined daily based on the spot exchange. It was reported that highly effective exchange rate policies, especially the rules that affect the repatriation of the investment returns and capital, would influence the inflows of FPI (Rodriguez-Pose \& Cols, 2017).

Additionally, sudden and unexpected volatility or fluctuation in the exchange rate may affect the decision of foreign investors in the allocation of resources. Thus, it indicates that the exchange rate plays a significant role in influencing FPI. Exchange rate data were sourced from the International Monetary Fund (IMF, 2015) and the World Development Indicator (World Bank, 2015).

Economic growth rate $(E G)$ is a proxy for the GDP per capita of a country in US dollars. Waqas et al. (2015) report that the stability of the economic growth rate will influence significant changes in foreign portfolio investment. Related to this, Zeghal and Mhedhbi (2006) find a positive relationship between IFRS and economic growth in developing countries. The variable plays a bidirectional role, and it can influence both FPI and IFRS. Economic growth rate data were sourced from the World Development Indicator (World Bank, 2015).

Trade openness $(T O P)$ is measured as a country's exports plus imports divided by the GDP. This measurement shows the extent to which an economy is opened to the whole world (Matadeen et al., 2011; Nnadi \& Soobaroyen, 2015). It was reported that the more an economy is assumed to be opened externally, the higher the tendency of adopting IFRS, and the more it influences FPI (Ramanna \& Sletten, 2010). Because of this relationship with FPI and IFRS adoption, it is additionally considered as one of the covariates. Data on trade openness were collected from the World Development Indicator (World Bank, 2015).

Corporate tax rate $(T A X)$ is also considered as a covariate in this thesis and measured as corporate tax rates. Taxes play the most significant role in influencing the FPI decision, especially in contributing to the nature of foreign capital diversification (Desai \& Dharmapala, 2007; Langli \& Willekens, 2017). For this reason, the corporate tax rate is measured based upon its influence on 
determining the movement of capital internationally. Data on the corporate tax rate were collected from the World Development Indicator (WDI, 2015 \& PwC, 2015)

Market capitalisation ( $\ln M C A P)$ represents the total value of all listed companies in countries under study. Its value is estimated by multiplying its stock's current price by the total number of outstanding shares. Market capitalisation is a proxy using the logarithm of its total value. It serves as an indicator of change in the stock market. It is expected that with the adoption of IFRS, the capital market will experience more flows of FPI that will increase the market capital liquidity. Chen et al. (2011) emphasise that access to equity capital investment, FPI, is positively linked to IFRS adoption. Thus, because of this relationship in terms of capital allocation, it is considered in the model. Data on market capitalisation were sourced from the World Development Indicator (World Bank. 2015) and various countries's stock exchange websites.

Regulatory quality $(R E G)$ is measured in units that range from -2.5 to +2.5 . The regulatory quality variable is introduced into the regression model as a factor that can predict the inflows of FPI. The variable explains the capability of the government to formulate and implement policies that will encourage foreign investors (Gordon et al., 2012). In the view of Rodriguez-Pose and Cols (2017), the regulatory quality index serves as an excellent signal to foreign investors that their investments are well protected, thus influencing FPI. The regulatory quality index data were sourced from the World Governance Indicators database (World Bank, 2015).

Corruption $(C O R)$ is measured on a scale of ' 0 ' to ' 10 ' of Transparency International Development Corruption Perceptions Index. It is a proxy in the model as a variable that describes the investment environment in a particular country that may influence FPI. This implies that a country with a high level of corruption may not record a high volume of foreign investments due to fear of uncertainty. Jain et al. (2017) emphasise that investor uncertainty about the investment environment, influenced by the high level of corruption in a country, and may impede the inflows of FPI. The corruption data were sourced from various years of the Transparency International Development (CPI, 2015).

\subsubsection{Logit regression model: determinant factors of IFRS adoption}

For the second research model, as mentioned earlier in Section 4.8.5, a logistic regression model is employed to examine the factors that influence the probability of adoption or non-adoption of IFRS in Africa. This is to achieve the third objective of this thesis that investigates the determinant factors of IFRS adoption. This is important, particularly in research like this that examines the 
effect of IFRS on FPI in Africa. More so, the report shows that only 30\% of African countries have required all their listed companies to make use of IFRS, while 70\% are yet to adopt (IFRS, 2018). This implies that despite the hoped-for advantages of global uniform accounting standards, many countries in Africa are, however, hitherto to adopt IFRS since 2005 of its inception.

Investigation of institutional factors that may determine the adoption or non-adoption is crucial when examining the effect of IFRS on specific contextual issues as in this research (that examines IFRS adoption on FPI in Africa). The findings will assist the accounting standard setters in understanding the factors that motivate the adoption of IFRS in the adopting countries, thus assisting them in formulating policies that will enable the non-adopting countries to abandon their national accounting standards for IFRS.

The studies of Kolsi and Zehiri (2015); Shima and Yang (2012), as well as Zehri and Chouaibi (2013) identify factors that can influence the adoption or non-adoption of IFRS, such as culture, economic growth, market capitalisation, level of education in each country, trade openness, the legal system, political system, and tax. None of these studies focused on African countries, so their findings may not reflect the actual picture for Africa. In addition to the factors identified by these authors, this research includes external pressure and investor protection as variables (see Chapter 4 and Figure 4.2). The variables would enable the model to capture more factors that can influence the adoption of IFRS in Africa. These factors, to the best of the knowledge of this researcher, have not been empirically examined in the context of African countries, especially the investor protection and external pressure.

The logistic regression model is employed to achieve objective three of the thesis that investigates the determinant factors influencing the probability of adoption or non-adoption of IFRS. The reason is that the dependent variable, IFRS, for objective three, is in the form of a dichotomous variable that measures ' 1 ' if the country adopts IFRS and ' 0 ' if otherwise. Hence the logit regression will be more appropriate. Kolsi and Zehri used this model (2013), Zeglar and Mhedhbi (2006), as well as Zehri and Chouaibi (2013) aimed at the determinant factors of IFRS.

\subsubsection{Logistic regression model specification}

In the application of the logistic regression model, Gujarati (2007:618-619) observes that the estimated standard errors are asymptotic, which means their behaviour is limited due to the method of maximum likelihood adopted. Also, the statistical value of ' $z$ ' is used instead of ' $t$ ' statistic value to estimate the significance of the coefficient. Similarly, it was also observed that the Wald 
$\mathrm{chi}^{2}$ is useful in the logistic regression model. It determines the measure of goodness of fit rather than the conventional measure of $R^{2}$.

Nevertheless, it is not of as much importance as the coefficients of each variable. Another observation is in the areas of hypotheses testing. Instead of using the traditional method of ' $F$ ' statistic test in the linear regression model, the likelihood ratio (LR) is used under the logit regression model for testing the hypothesis.

Additionally, the estimated coefficient measures the change in the logit model due to a unit change in a specific independent variable, keeping all other variables constant. The value helps in calculating the probability of countries falling into a particular category (adopt or non-adopt as classified under Table 4.1 and 4.2). Thus, it shows the direction of the relationship of the independent variables that have the likelihood of propensity to influence the adoption and nonadoption of IFRS. For this purpose, the positive value indicates that an increase in a unit of an independent variable will result in an increase in the probability of a country adopting IFRS. In contrast, a negative coefficient value symbolises that an increase in the unit of an independent variable will result in a decrease in the probability of adopting IFRS.

Another feature of the logit recession model is the odds ratios. It is estimated by calculating the antilog of the various slope coefficients. The odds ratios indicate the change in the likelihood of any independent variable belonging to one of the groups (adopting and non-adopting) when its value increases by one unit. At the same time, other things remain constant (Gujarati, 2007:619). The author explained further that the ordinary least squares regression assumes linearity between the dependent and independent variables, but in the case of the logit model, it is non-linear.

Also, the probability value must lie between 0 and 1 in the logit regression model. Furthermore, in the case of the error terms, it is assumed to be normally distributed, but this is not the case when the dependent variable takes the value of 0 or 1 . For these reasons, the logistic regression model is more appropriate for the estimation of the variables to achieve objective 3 . Thus, the logistic regression model is stated below:

\section{Model 3}

$$
\begin{aligned}
& \operatorname{LogitIFRS}_{i t}=P_{i t} /\left(1-P_{i t}\right)=\alpha_{0}+\alpha_{1} C U L_{i t}+\alpha_{2} E D U_{i t}+\alpha_{3} L S_{i t}+\alpha_{4} P S_{i t}+ \\
& \alpha_{5} E X P R E_{i t}+\alpha_{6} I P_{i t}+\alpha_{7} \ln M C A P_{i t}+\alpha_{8} E G_{i t}+\alpha_{9} T O P_{i t}+\alpha_{10} T A X_{i t}+
\end{aligned}
$$

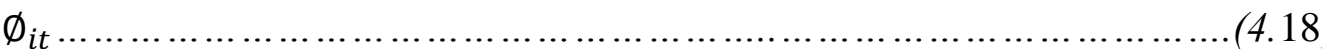


where, $\mathrm{P}_{\mathrm{it}}$ represent the probability of IFRS adoption in the country $\mathrm{i}$ at time $\mathrm{t}$. Also $\alpha_{0}$ represents the log of the odds, while $\alpha_{1}-\alpha_{10}$ are the odds ratios representing the change in the predicted probability of IFRS adoption, P(IFRS $=1)$, when the value of a predictor increases by a unit. $\emptyset_{i t}$ stands for a scalar of disturbance term that represents some other variable that may affect the model.

\subsubsection{Variable description and measurement for the logit regression model}

$\operatorname{LogitIFRS}_{\text {it }}$ measures the logit of IFRS. The binary measures are adopted to measure the value of IFRS in this case. The measurement is categorised into two binary values " 1 " and " 0 " to reflect the countries that have adopted IFRS and otherwise (Gordon et al., 2012; Kolsi \& Zehri, 2015, \& Nandi \& Soobaroyen, 2015). The total number of countries, in this case, is 35, comprising both adopted and non-adopted. Data were sourced from Deloitte (2017), IASB/IFRS databases, and PwC database (see Table 4.1 and 4.2). Furthermore, LogitIFRS $_{i t}=1$ (if a country adopts IFRS) and $\operatorname{LogitIFRS}_{i t}=0$ (if a country does not adopt IFRS). Thus, $P_{i t} /\left(1-P_{i t}\right)$ represents the odds ratio in favour of adopting countries, where $P_{i t}$ is the predicted probability of adoption. It is the ratio of the probability that a country will adopt IFRS to the probability that a country will not adopt IFRS.

$C U L_{i t}$ represents the culture in the country $\mathrm{i}$ at period $\mathrm{t}$ and is proxy for the Anglo-Saxon or nonAnglo-Saxon country with dummy 1 for Anglo-Saxon and 0 for non-Anglo-Saxon countries. Countries with a certain familiarity and language would assume to adopt IFRS. Data for culture were sourced from World Factbook. $E D U_{i t}$ represents the educational level of country i at period t. Where the level of education is considered below, it will be a severe barrier to the adoption of IFRS (Zeghal \& Mhedhbi, 2006). This is measured as the adult literacy rate to estimate the educational attainment percentage of the population aged fifteen years and over that can read and write. Data were collected from the World Development Indicators database. $L S_{i t}$ measures the rule of law in a particular country $i$ at period $t$ and estimates in ranges approximately -2.5 (weak) to +2.5 (strong). The rule of law enhances the inflow of FPI. Data were sourced from the World Governance Indicators, 2017. $P S_{i t}$ represents the measure of political stability in the country $i$ at period $\mathrm{t}$ with values ranging from -2.5 (weak) and +2.5 (strong) measured by the World Governance Indicators. It is believed that a politically stable environment will enable the accounting environment to thrive.

$E X P R E_{i t}$ indicates the external pressure in the country $\mathrm{i}$ at period t. Data were sourced from the Fund for Peace (2017) on Fragile State Index, which measures the different external pressures that 
faced each country. FSI was developed in the 1990s by the Fund for Peace to focus on the measurement of pressures in various categories experienced by different countries worldwide, such as cohesion, economic, political rights, and social and, most importantly, the intervention of external force. The external pressure data from the FSI is used in this thesis. This is to consider the influence and impact of pressures by external bodies on the economic issues of a state such as multilateral bodies through the large scale loans, foreign aid, and control of finances and management of the state's economic policies. The FSI methodology employs both quantitative and qualitative methods to generate data on twelve different indicators relating to external pressures. They use 0-10 scores for each indicator where the lower figure indicates less pressure, and higher scores indicate high external pressures.

$I P_{i t}$ is investor protection in a particular country $\mathrm{i}$ at period $\mathrm{t}$. It measures the extent to which investors are protected in a country. This variable is measured with the business extent of disclosure index ( 0 less disclosure to 10 more disclosure). It is assumed that a weaker investor protection country may likely adopt IFRS to improve the financial reporting and make their financial statements comparable (Hope et al., 2006). Data were sourced from the World Development Indicators. Other variables, market capitalisation, economic growth, trade openness, and tax rate, were described and measured as in the first research model (see Section 4.7.7.3).

\subsubsection{Post estimation statistical tests}

Additionally, to determine the validity of the models adopted, various post estimation or statistical diagnostic tests are computed based on the relevance of each model. The tests are Diagnostic test, using the histogram and Jarque-Bera statistics, the Wald test, the Cross-sectional dependence test across the selected countries, the unit root test, the Hausman chi-square test, and Arellano-Bond estimator for autocorrelation $A R\langle 1\rangle$ and $A R\langle 2\rangle$ are computed to estimate the validity of the variables in the model. Also, an average marginal effect is computed, using dydx of margins, to estimate the slope of the logistic regression line of all independent variables at their means.

Jarque-Bera test is computed to determine the normal distribution of the selected data, while the Wald test is employed to test the real value of the parameter according to the estimated variables. In the case of the cross-sectional dependence across the selected counties using Bruesch-Pegan LM, Pesaran scaled LM, and Pesaran CD tests are evaluated to determine if there is cross-section dependence in the data or not. The unit root test is computed to assess the stationarity of the data. Also, Hausman chi-square test to determine the best alternative between REM and FEM is 
estimated; finally, the Arellano-Bond test is computed to test for the autocorrelation $A R\langle 1\rangle$ and $A R\langle 2\rangle$ in the model.

\subsection{The particular paradigm and approaches employed for the thesis}

The figure below shows the explicit framework of the philosophy and strategies adopted for the study, which is represented by a research onion shown in Figure 4.1. The discussion in this chapter explained the possible assumptions of each research philosophy and approach based on Figure 4.1. The figure guides the choice of a particular paradigm and method adopted for this study. Therefore, Figure 4.3 shows a clear philosophical perception and the strategies adopted for this study.

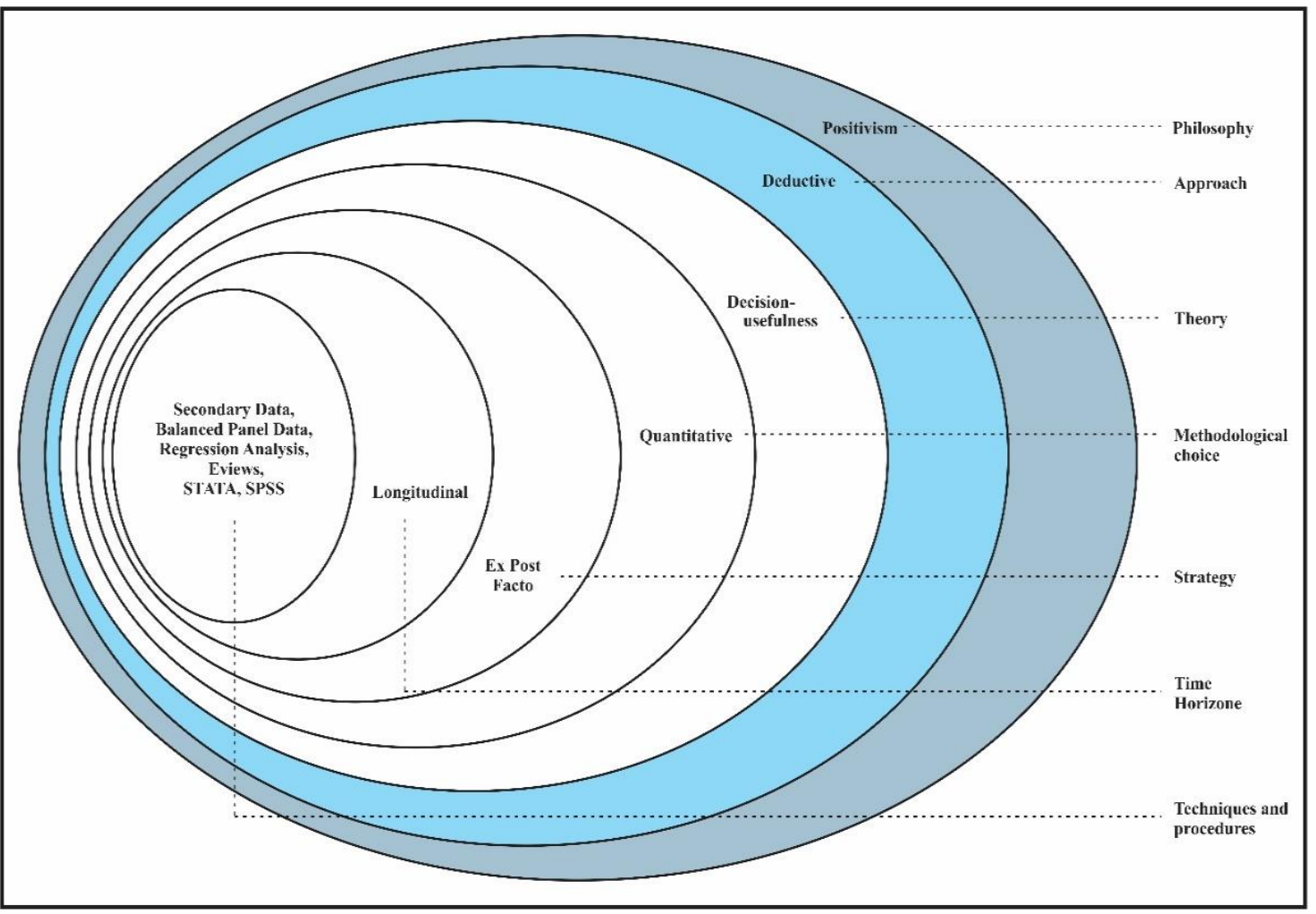

Figure 4.3: The explicit philosophical perception and approaches adopted for the thesis

Source: Researcher's onion process

Figure 4.3 depicts the philosophical perspective appropriate for this study, which is positivism, inclined to the deductive reasoning to understand the real-world occurrence as relating to this research. Deductive reasoning is assumed to be more significant in the process of developing accounting theory. It involves the development of assumptions based on the existing theory. In this study, the decision-usefulness theory is employed. 
Furthermore, the research adopts a quantitative method, which is more appropriate when the study is investigating the effect. In addition, ex post facto research design is applied in this study due to the nature of the data collected, which are secondary data devoid of being manipulated by the researcher. Also, longitudinal, as the time horizon is considered to be more appropriate to examine changes or the behaviour of variables over some time since the data collected are for twenty-two years' trend. The study uses a panel data regression analysis model (FEM, REM, OLS, and SGMM) as estimators with the E-views statistical package for the quantitative analyses.

\subsection{Summary of the chapter}

The chapter adopted the 'research onion' for the process of the research design and methodology for the thesis. It explained the specific philosophical stance of this research and the procedures used to address the research questions (Figure 4.3). The chapter identified positivism and objectivism as appropriate to solve the research problem.

The chapter started with an introduction that discussed the concept of the research onion (Figure 4.1), followed by an overview of the chapter. The research problem and questions were revisited. Because the purpose of the chapter was to examine the techniques and procedures of addressing the research problem and answer the research questions, this was followed by a general discussion on the research design and methodology based on Figure 4.1. The research philosophy, the ontological paradigm utilised in this thesis, is closely related to objectivism. With a positivist philosophy and deductive reasoning. Furthermore, various financial information theories were discussed, while the appropriate one that underpins this study was identified as the decisionusefulness theory.

The quantitative research method, compared to the other methodological choice, was considered appropriate for this study since it relates to a positivist paradigm. Besides, the ex post facto design, as the opposite of experimental research, is utilised, because it eliminates the tendency of the researcher to manipulate the data. The study employs longitudinal research as a time horizon using secondary sources to collect data for the periods under review. Based on the nature of data collected, the thesis, therefore, identified a panel data regression model using the pooled ordinary least square, fixed-effects, random-effects, and system generalised method of moment regression model as appropriate for the statistical analyses. In conclusion, the appropriate research paradigm and approaches adopted for this thesis to develop a framework for the effect of IFRS on FPI are shown in Figure 4.4. The next chapter focuses on data presentation, analysis, and interpretation. 


\section{CHAPTER FIVE: DATA ANALYSIS AND INTERPRETATION OF FINDINGS}

\subsection{Introduction}

The previous chapter focused on the research design and methodology to address the research problem. It discussed the various philosophical assumptions, relevant accounting theories, data collection approaches, and statistical models. The chapter identified positivism as the ontological paradigm pertinent to this study. Which includes objectivism and deductive reasoning, to address the research problem. Furthermore, it ascertained the decision-usefulness theory as an appropriate theoretical underpinning for this research. Similarly, the panel data regression model is found to be relevant for the data analysis due to the nature of the data collected.

This chapter focuses on the presentation of data, analysis, and the interpretation of results and findings. The main research question that guides this thesis is the research question one (i), as stated below, while the other research questions (ii and iii) are secondary. They are:

(i) What is the significant difference in FPI inflows between before and after the adoption of IFRS among adopting IFRS countries in Africa?

(ii) To what extent is the magnitude of the significant difference in FPI inflows among countries that adopted IFRS and countries that did not adopt IFRS in Africa?

(iii) What factors predict the probability of adoption of IFRS in Africa?

To achieve the objectives and to address the research questions with the appropriate associated hypotheses, this thesis employed a panel data regression model (see Chapter 4) for the statistical estimation. This chapter is divided into ten sections. Section 5.1 covers the introduction and explains the highlights of the current chapter. Sections 5.2 to 5.8 present the empirical results and findings as follows: descriptive statistics summary, correlation matrix, the panel data regression analyses, and the logit regression analysis results. The results are interpreted and discussed to highlight the findings to meet each of the objectives of the thesis. Similarly, the findings are then used to answer the research questions and to test the hypotheses in Chapter 1. The last section summarises the chapter. 


\subsection{Empirical results and findings}

Sections 5.2 to 5.9 present the empirical results of the effect of the adoption of IFRS on FPI in 15 selected countries that have adopted IFRS and 20 countries that have not adopted IFRS (see Tables 4.1 and 4.2). The analyses start from the discussion of the descriptive statistics and correlation matrix. The results of the panel data regression model using the pooled ordinary least square (POLS), fixed-effects model (FEM), and (REM) are presented and discussed with consideration of each objective. The system generalised method of moments (SGMM) estimator is computed to solve the problem of endogeneity that is common in the panel data analysis and for the robustness of the model.

The statistical tests included the diagnostic test, using the histogram and Jarque-Bera statistics (which is estimated to determine whether the data to be estimated are normally distributed), Wilcoxon signed-rank test (WSRT), difference-in-difference (DID) test, the unit root test, the Wald test, the cross-sectional dependence test, the Hausman chi-square test, and the ArellanoBond estimator autocorrelation $A R\langle 1\rangle$ and $A R\langle 2\rangle$ to estimate the validity of the variables in the model and the average marginal effect.

\subsubsection{Diagnostic: Normality test (Objective 1)}

The diagnostic test was conducted to assess the validity of the panel result estimates whether the variables employed are normally distributed. That is to assess if the residuals from the panel data regression analysis for the first objective are symmetrically distributed. Thus, the normality test using the histogram and Jarque-Bera statistic was performed. The Jarque-Bera (JB) is applied to test whether the residuals of the estimated variables are normally distributed (Gujarati, 2007:151153). Besides the error term to be normally distributed, the Skewness (S) must be 0, and the Kurtosis (K) equals 3. JB statistics test the combined hypothesis that $3=0$ and $K=3$. For this purpose, the null hypothesis that the residuals from the panel data regression in Equation 4.5 are symmetrically distributed is tested.

The results presented in Figure 5.1 below indicates that the panel data model did not deviate significantly from a normal distribution. This is evident from the value of the Jarque-Bera statistics of 0.16 and a probability value of 0.92 , which is not statistically significant at either $5 \%$ or $1 \%$ levels. This result implies that the null hypothesis is accepted that the estimated panel model residuals are normally distributed. Likewise, the value of $\mathrm{S}$ and $\mathrm{K}$ are 0 and 3, respectively. It shows that the estimated variables are normally distributed. This implies that the results, as 
interpreted, based on the parameter estimates, are reliable. The outcome of this test has further strengthened the validity of the estimated parameters in the panel model.

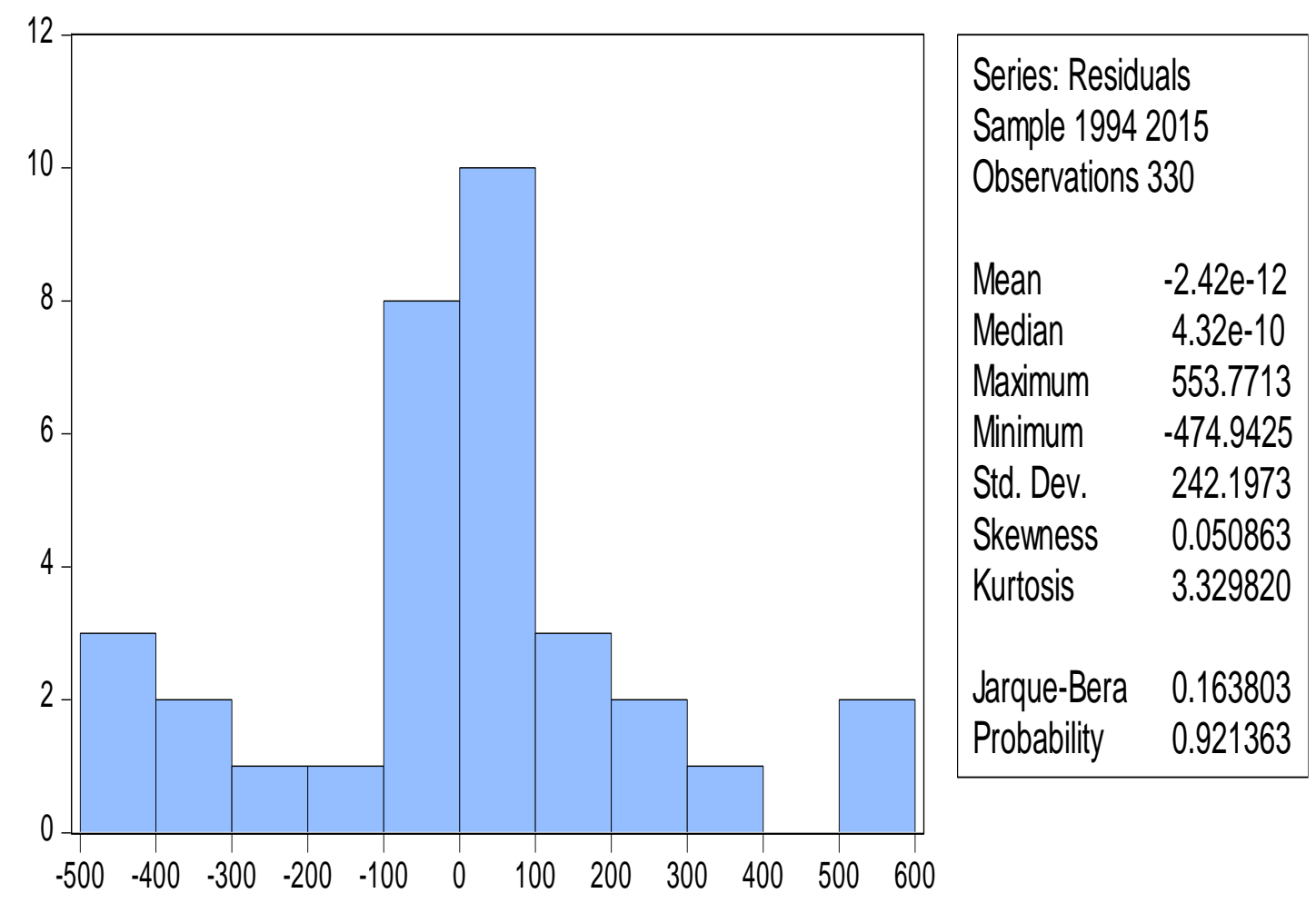

Figure 5.1: Normality test for pre-and-post-effect of IFRS adoption on FPI

Source: Results generated from data analysis using E-views statistical software package

\subsection{Descriptive statistics before the adoption of IFRS (1994-2004): adopting countries}

The summary of the descriptive statistics for the variables is presented in Tables 5.1 and 5.2 concerning the periods under investigation. Table 5.1 shows the results of the descriptive statistics for dependent and explanatory variables for the period before the adoption (1994-2004) for the 15 adopting countries. Table 5.2 presents the descriptive statistics of the variables after the adoption of IFRS (2005-2015) for adopting IFRS countries. The apportionment of the period into two shows clearly the differences in the mean values of FPI inflows before and after the adoption of IFRS and other covariates. 
Table 5.1: $\quad$ Descriptive statistics before IFRS adoption (adopted countries) (1994-2004)

\begin{tabular}{|c|c|c|c|c|c|c|}
\hline Variable & Observation & Mean & $\begin{array}{c}\text { Standard } \\
\text { Deviation }\end{array}$ & Minimum & Maximum & $\begin{array}{c}\text { CV in } \\
\text { percentage }\end{array}$ \\
\hline $\operatorname{lnFPI}$ & 165 & 7.47 & 2.41 & 0.00 & 19.27 & 32.26 \\
\hline INF & 165 & 0.13 & 0.15 & -0.03 & 0.83 & 1.53 \\
\hline INTR & 165 & 0.10 & 0.11 & -0.43 & 0.35 & 1.10 \\
\hline $\operatorname{lnEXR}$ & 165 & 2.67 & 3.73 & -6.57 & 8.29 & 1.39 \\
\hline EG & 165 & 0.02 & 0.06 & -0.47 & 0.36 & 3.00 \\
\hline TOP & 165 & 0.70 & 0.33 & 0.09 & 1.70 & 0.47 \\
\hline TAX & 165 & 0.30 & 0.05 & 0.15 & 0.45 & 0.16 \\
\hline $\operatorname{lnMCAP}$ & 165 & 7.30 & 3.15 & 0.00 & 11.64 & 0.43 \\
\hline REG & 165 & -0.00 & 0.00 & -0.01 & 0.01 & 0.00 \\
\hline COR & 165 & 0.03 & 0.01 & 0.00 & 0.06 & 0.33 \\
\hline
\end{tabular}

Note: $\operatorname{lnFPI}=$ natural logarithm of foreign portfolio investment; INF = inflation rate; INTR = interest rate: $\operatorname{lnEXR}=$ natural log of exchange rate; $E G=$ economic growth rate; $T O P=$ trade openness; $T A X=$ corporate tax rate; InMCAP = natural log of market capitalisation; $R E G=$ regulatory index $; C O R=$ corruption

Source: Author's calculation from the research data using E-views statistical package version

An examination of Table 5.1 reveals important statistical findings. The mean value of FPI for the period before the adoption is 7.47 with minimum and maximum values of 0 and 19.27, respectively. This finding is an indication that the countries appear not to have recorded impressive FPI inflow for the period. The coefficient of variation (CV) (see Chapter 4) of FPI is $32.26 \%$ before the adoption of IFRS, which is considered to be too high to give an accurate estimate (Couto et al., 2013). Table 5.1 also shows that the $\mathrm{CV}$ of other variables is low. The result is compared with the period after the adoption in Table 5.2. This is in order to show the degree of variability in FPI before and after the adoption of IFRS.

Table 5.1 also shows the descriptive statistics of the covariates. Following Table 5.1, the mean values of the inflation rate, INF, and the interest rate, INT, are $13 \%$ and $10 \%$, respectively. The results reveal that the inflation rate is higher than the interest rate, which might be one of the reasons why the countries did not record impressive performance in FPI flow during the period. A high inflation rate may erode the returns from the investments and thus cause a reduction in FPI.

The average exchange rate, $\operatorname{lnEXR}$, of domestic currency to the United States of America (USA) is 2.67 dollars, according to Table 5.1. If this log figure is transposed, the equivalent of 14.4 to $1 \$$. This seems to be too high, and it indicates the weakness of the exchange rate to convertible 
currency in these countries. This situation might not be favourable for foreign investors when repatriating their capital and returns.

Additionally, the mean value of economic growth, EG, and trade openness, TOP, are 0.02 and 0.70 , respectively. The economic growth rate indicates that the selected countries experienced a growth rate of $2 \%$ during the period. The results further showed that the trade openness was averaged at $70 \%$, which means the extent to which these countries are opened to the external world. This high percentage shows that they allowed their economy to be more open than closed to other parts of the world, and there is a tendency to be exposed to various international pressures.

The tax rate, TAX, average mean value shows a value of $30 \%$ with a maximum value of $45 \%$. It shows that the corporate tax rate seems to be higher compared with the worldwide corporate tax rates at an average of $23.03 \%$ (Temin, 2019). This finding may increase the cost of investment and discourage further foreign investments. Also, the mean value of market capitalisation, InMCAP, average 7.30 is closed to the maximum value of 11.64. The mean value of regulatory quality, REG, is -.00 . The regulatory index is measured as a score between -2.5 to +2.5 . This mean value $(-.00)$ indicates zero before and after the adoption, compared to the standard measure adopted in this thesis. Table 5.1 further shows that the rate of corruption, COR, is 0.03 of the CPI. The CPI is measured in ranges. This finding indicates that the higher the index, the lower the level of corruption in that country, and vice versa. A score of 0.03 shows that the rate of corruption before the adoption was very high among the selected countries. This is because the index point of 0.03 is further away from the maximum score of 10 . Table 5.2 below gives descriptive statistics after the adoption and implementation of IFRS. The outcome provides a basis for comparing the two periods (pre-and-post) under investigation. 
Table 5.2: Descriptive statistics after IFRS adoption (adopted countries) (2005-2015)

\begin{tabular}{|c|c|c|c|c|c|c|}
\hline Variable & $\begin{array}{c}\text { Observati } \\
\text { ons }\end{array}$ & Mean & $\begin{array}{c}\text { Standard } \\
\text { Deviation }\end{array}$ & Minimum & Maximum & $\begin{array}{c}\text { CV in } \\
\text { percentage }\end{array}$ \\
\hline lnFPI & 165 & 8.46 & 1.74 & 0.00 & 11.34 & 20.56 \\
\hline IFRSFA & 165 & 0.81 & 0.38 & 0.00 & 1.00 & 46.91 \\
\hline INF & 165 & 0.07 & 0.06 & -0.35 & 0.50 & 85.71 \\
\hline INTR & 165 & 0.08 & 0.07 & -0.42 & 0.26 & 87.50 \\
\hline lnEXR & 165 & 3.51 & 3.62 & -4.31 & 8.86 & 1.03 \\
\hline EG & 165 & 0.03 & 0.04 & -0.22 & 0.17 & 1.33 \\
\hline TOP & 165 & 0.74 & 0.26 & 0.21 & 1.32 & 35.13 \\
\hline TAX & 165 & 0.28 & 0.04 & 0.15 & 0.35 & 14.28 \\
\hline lnMCAP & 165 & 7.70 & 3.39 & 0.00 & 11.97 & 44.02 \\
\hline REG & 165 & -0.00 & 0.01 & -0.01 & 0.02 & 0.00 \\
\hline COR & 165 & 0.03 & 0.01 & 0.02 & 0.06 & 33.33 \\
\hline
\end{tabular}

Note: $\operatorname{lnFPI}=$ natural log of foreign portfolio investment; IFRSFA = international financial reporting standards full adoption: $I N F=$ inflation rate; INTR = interest rate: $\operatorname{lnEXR}=$ natural log of exchange rate $E G=$ economic growth rate; $T O P=t$ rade openness; $T A X=$ corporate tax rate; InMCAP = natural log of market capitalisation; $R E G=$ regulatory index; $C O R=$ corruption;

Source: Author's calculation from research data

There is ample evidence from the descriptive statistics that the mean value of lnFPI after the adoption of IFRS is higher than before the adoption. It is clear from Table 5.2 that the mean values before and after IFRS adoption are 7.47 and 8.46, respectively. Thus, showing an improvement of 0.99 in the average value of FPI after the adoption of IFRS.

Besides, the coefficient of variation (CV) of FPI after the adoption of IFRS indicates $20.56 \%$ compared with $32.26 \%$ before IFRS adoption. The result indicates a lower percentage of CV. According to (Couto et al. 2013; Bajpai, 2009:129; Taylor, 2007:53), the lower the percentage value of the $\mathrm{CV}$, the better the accuracy of the estimate (see Chapter 4). They emphasised that a $\mathrm{CV}$ percentage between $12 \%$ and $20 \%$ is a better estimate. However, after the adoption, the CV of FPI (the main variable of concern) is lower than before the adoption estimating to be more accurate than before the adoption. Similarly, the CV of certain covariates indicates low percentages such as $\operatorname{lnEXR}$, EG, TAX, and REG.

Furthermore, IFRS adoption average mean value indicates the average of the number of years for which the selected countries have adopted IFRS. The table shows that the countries had adopted 
IFRS for an average of less than one year $(.8181 * 12=9.82$ months $)$. This is because the adoption of IFRS is still relatively new in Africa (Gordon et al., 2012). Nevertheless, the more years the country is using IFRS, the stronger the effect on foreign investments flow (Efobi, 2017),

The mean value of inflation, INF, after the adoption is $7 \%$ compared to the period before, which is approximately $13 \%$. This considerable improvement in curtailing the rate of inflation shows that with the adoption of IFRS, there are more proactive macroeconomic policy measures to influence foreign investors. Among them is the reduction of the inflation rate to maintain economic stability and attract more investors. The interest rate, INT, mean is approximately $8 \%$ after the adoption compared to $10 \%$ before the adoption. This mean shows a marginal reduction but is still higher than the rate of inflation in the same period. Another significant variable is economic growth, EG, which shows an improvement in the mean value from $2 \%$ to $3 \%$ before and after the adoption, respectively. This substantiates the expectation of proponents of IFRS that it would improve the economic growth of the adopting countries.

Likewise, the trade openness, TOP, mean shows that the countries are more exposed to the external world with a mean value of $74 \%$ after the adoption compared to $70 \%$ before the adoption. The corporate tax rate, TAX, average value changed from $30 \%$ before the adoption to $28 \%$ after the adoption. The reduction in the average tax rate can be assumed to be a result of the government tax regulation to influence more foreign investment plans and mobilisation of capital after the adoption of IFRS. Similarly, the mean value of market capitalisation, lnMCAP, 7.70 improved, compared to 7.30 before the adoption. This finding indicates that with the adoption of IFRS, capital markets became more functional and witnessed more participation by foreign investors. This development might be due to an improvement in the quality of financial information prepared using IFRS. Hence the adoption of IFRS may have solved the problem of capital scarcity and improved the economic growth in Africa, as suggested by the proponents of IFRS.

Furthermore, the regulatory quality index, REG, before the adoption was -0.00 , and after the adoption, it was -0.00 . The corruption, COR, mean was 0.03 before the adoption and 0.03 after the adoption. The regulatory quality index does not reflect any improvement after the adoption compared to the period before the adoption, as indicated above. The finding indicates a poor implementation of government policies during the periods of investigation. On average, the rate of corruption was not improved. Hence it indicates that governments are not conscious of the consequence of a high-rate of corruption on foreign investments flow before and after the adoption of IFRS. These descriptive findings before and after the adoption show that the mean values of 
most of the estimated variables (such as lnFPI, INF, EG, TOP, TAX, lnMCAP) improved after the adoption of IFRS. Theoretically, one can argue that these variables enhanced the overall performance of FPI after the adoption and the implementation of IFRS in the selected countries.

\subsubsection{Wilcoxon signed-rank test (WSRT)}

In addition to the traditional method of using descriptive statistics, this thesis employed the Wilcoxon signed-rank test (WSRT) to determine the level of FPI before and after IFRS adoption (see Chapter 4 and Appendix A2.1). The findings also indicate the effect of FPI volume before and after IFRS adoption periods. The results of the test are presented in Tables 5.2a and 5.2b below.

Table 5.2a: Wilcoxon signed-rank test comparing FPI volume before and after IFRS adoption: adopting countries

\begin{tabular}{|c|c|c|c|c|}
\hline \multirow{2}{*}{} & \multirow{5}{|c|}{ WSRT descriptive statistics } \\
\hline & & \multicolumn{3}{|c|}{ Percentiles } \\
\cline { 2 - 5 } & & 25th & 50th (Median) & 75 $^{\text {th }}$ \\
\hline PRE & 165 & 7.08775 & 7.95085 & 8.29601 \\
\hline POST & 165 & 7.83024 & 8.61289 & 9.11168 \\
\hline
\end{tabular}

Source: Researcher's computation IBM SPSS 25

Tables 5.2b: Wilcoxon signed-rank test showing a significant level of FPI (before and after)

\begin{tabular}{|c|c|}
\hline \multicolumn{2}{|c|}{ WSRT Test Statistics } \\
\hline $\mathbf{Z}$ & POST - PRE \\
\hline Asymp. Sig. (2-tailed) & $\mathbf{- 7 . 9 7 9 b}$ \\
\hline
\end{tabular}

a. Wilcoxon signed ranks Test

b. Based on the negative rank

Source: Researcher's computation using IBM SPSS 25 version

The issues of concern from these findings are the $\mathrm{Z}$-value and the related significance level, as presented in Table 5. 2. The results show a highly statistically significant difference in FPI volume before and after the adoption period, $\mathrm{Z}=-7.98, \rho<.001$. The finding could have been the case caused by the larger number of observations (165) in both periods. Furthermore, the effect of the 
volume (represented by $\mathrm{r}$, see Chapter 4) of FPI before and after the adoption is computed as follows: $r=Z$ /square root of total observations (N), i.e., pre and post observations (see Table 5.2a). $\mathrm{N}=(165 * 2=330)$. Thus, $\mathrm{r}=7.98$ (from Table 5.2b) $/ \sqrt{330}=7.98 / 18.17=0.44$. Based on Cohen's (1998) standard of interpretation, 0.44 indicates an effect greater than a medium effect and near to a larger effect. In addition, Table 5.2a shows that the median (Md) volume on FPI increases from pre-adoption $(\mathrm{Md}=7.95)$ to the post-adoption $(\mathrm{Md}=8.61)$. These findings clearly show that IFRS adoption has a significant effect on influencing FPI in the adopted countries.

\subsubsection{Trend analysis of the effect of the adoption of IFRS on FPI (1994-2015), adopting countries}

The trend analysis of the FPI of the countries before and after the adoption of IFRS was computed. The trend results (see Appendix A) show the trend analysis of the FPI of the selected countries before and after the adoption of IFRS. The common feature of this figure is that it shows an improvement in the volumes of FPI after the adoption of IFRS. However, these improvements are more significantly noticeable in one country than another. For example, the trend indicates more improvements in FPI after the adoption in countries, such as Tanzania, Malawi, Mauritius, South Africa, Ghana, and Nigeria. Another important observation is that apart from Nigeria, which adopted IFRS in 2012, all the other countries adopted IFRS earlier, indicating that the longer the period of IFRS adoption, the more significant the improvement in FPI flow (Landman et al., 2012).

The descriptive statistics intend to corroborate the findings from the panel regression model. The next section presents the correlation analysis to determine any presence of multicollinearity among the variables.

\subsection{Correlation analysis - IFRS adopting countries (1994-2015)}

The correlation analysis results are presented in Table 5.3. The estimated variables were tested for the bivariate linear relationship. This test is to determine the influence and effect of each variable on each other. Equally, to test any presence of multicollinearity among them. The existence of multicollinearity among the variables will indicate a near to perfect or precise linear association (i.e., correlation near -1 and +1 ) among a few or all explanatory variables of a regression model. The table reveals that there was no occurrence of multicollinearity whatsoever among the variables examined since none of the variables shows any sign of perfect or exact relationship among themselves. 
It is clear from Table 5.3 that the relationship between FPI and IFRSFA is positive, with a correlation coefficient of 0.26 . This positive value indicates a direct relationship between the adoption of IFRS and FPI. The implication is that countries that have adopted IFRS will record a positive correlation between IFRS and FPI. Thus, the adoption of IFRS exhibits a direct positive link with FPI inflow. Consequently, the more the countries adopt IFRS, the higher the volume of FPI inflow. Furthermore, FPI shows a positive relationship with each of the explanatory variables as well, except the interest rate, tax, and the exchange rate with a negative correlation coefficient of $-0.04,-0.00$, and -0.12 , respectively. The interest rate shows an inverse relationship with FPI, likewise with tax and exchange rates. 
Table 5.3: Correlation analysis, IFRS adopted countries 1994-2015

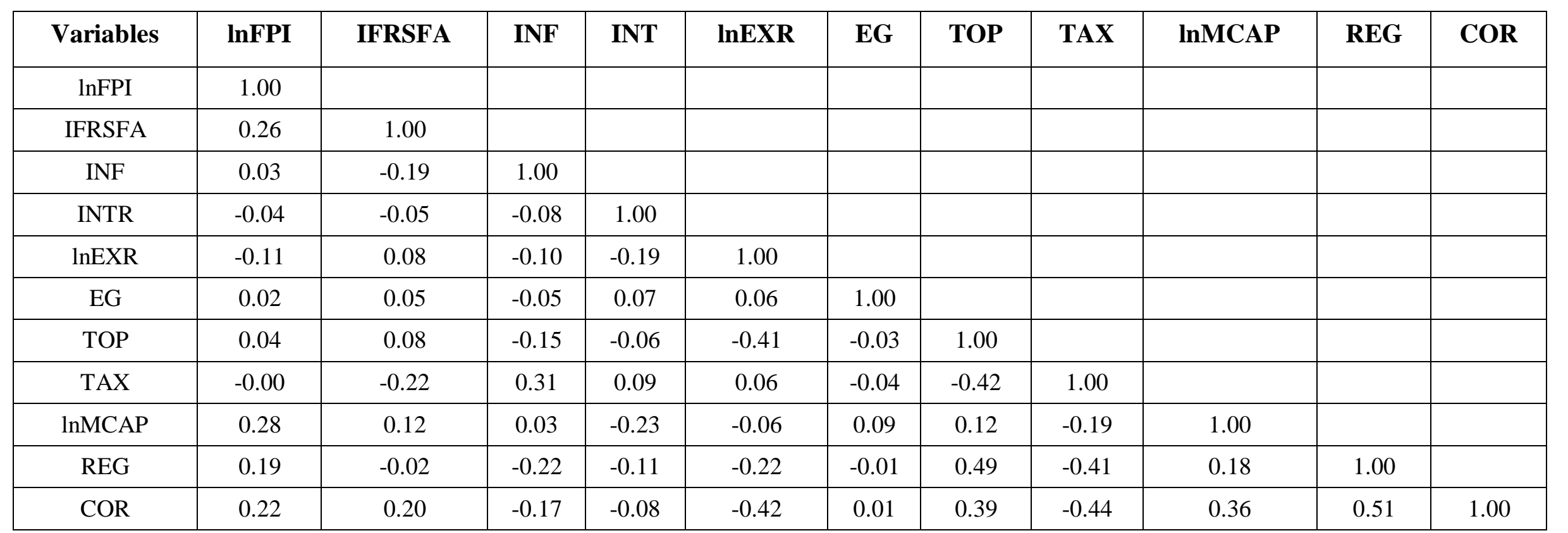

Note: InFPI = natural log of foreign portfolio investment; IFRSFA = international financial reporting standards full adoption: INF = inflation rate; INTR = interest rate: InEXR

$=$ natural log of exchange rate; $E G=$ economic growth rate; TOP = trade openness; $T A X=$ corporate tax rate; InMCAP = natural log of market capitalisation; $R E G=$ regulatory index; $C O R=$ corruption;

Source: Results obtained from data analysis using E-views statistical package 


\subsubsection{Variance inflation factor (VIF)}

Furthermore, the variance inflation factor (VIF) is also estimated to capture any presence of multicollinearity among the variables estimated that are not obvious in the Pearson correlation matrix. The baseline of interpreting VIF are 1 not correlated; between 1 and 5 are moderately correlated, while higher than 5 is highly correlated. The VIF results are presented in Table 5.3a below. From the table, it shows that there is no presence of any multicollinearity among the estimated variables. Since none of the tolerance value of each of the explanatory variables is less than .10, or a VIF value above 10. The VIF value supports this finding because the value for each of the explanatory variables is far below the baseline of 10. This finding indicates that the multicollinearity assumption is not violated. These findings are not surprising because the Pearson correlation matrix also shows that there is no problem of multicollinearity among the variables.

Table 5.3a: Estimation of variance inflation factor (VIF)

\begin{tabular}{|c|c|c|}
\hline \multicolumn{3}{|c|}{ Coefficients $^{\mathrm{a}}$} \\
\hline \multirow[t]{2}{*}{ Model } & \multicolumn{2}{|c|}{ Collinearity Statistics } \\
\hline & Tolerance & VIF \\
\hline IFRSFA & .843 & 1.186 \\
\hline INF & .806 & 1.241 \\
\hline INT & .837 & 1.194 \\
\hline $\operatorname{lnEXR}$ & .587 & 1.702 \\
\hline EG & .968 & 1.033 \\
\hline TOP & .526 & 1.900 \\
\hline TAX & .640 & 1.562 \\
\hline $\operatorname{lnMCAP}$ & .803 & 1.246 \\
\hline REG & .517 & 1.935 \\
\hline COR & .480 & 2.082 \\
\hline
\end{tabular}

Note: IFRSFA = International Financial Reporting Standards Fully Adopt; INF = inflation rate; INTR =binterest rate: $\ln E X R=$ natural log of exchange rate; $E G=$ economic growth rate; $T O P=$ trade openness; $T A X=$ corporate tax rate; InMCAP = natural log of market capitalisation; $R E G=$ regulatory index; $C O R=$ corruption;

Source: Author's calculation from the research data using SPSS statistical package

The next section estimates the unit root test, which shows the order of integration of the variables. Table 5.4 presents the results. 


\subsection{Unit root tests (adopted countries)}

The common problem in a panel data analysis is the non-stationarity of the data (Choudhary \& Bajaj, 2013). The unit root test using the common Augmented Dickey-Fuller (ADF) test and Im Pesaran and Shin (IPS) test was carried out to examine the properties of the panel data for the presence of stationarity. Similarly, studies such as Kutu and Ngalawa (2016) and Omolade and Ngalawa (2014) suggest the use of more than one method of panel unit root test. This is to be sure of the order of integration (i.e. the minimum number of differences that is necessary to be sure of getting a stationary series) of the variables to be included in a particular model. The reason behind this might not be unconnected to the fact that a non-stationary variable constitutes an outlier among other variables, and the inclusion can significantly influence the outcome of the empirical analysis. For this thesis, both the IPS and ADF methods of panel unit root tests were adopted for the sake of consistency. Their results are presented in Table 5.4 below.

Table 5.4: Unit root test results (adopted countries) 1994-2015

\begin{tabular}{|c|c|c|c|c|}
\hline Variables & \multicolumn{4}{|c|}{ Panel unit root test method } \\
\hline & Im, Pesaran and Shin IPS & \multicolumn{2}{c|}{ ADF Fisher } \\
\hline & IPS statistics & $\begin{array}{c}\text { Order of } \\
\text { integration }\end{array}$ & $\begin{array}{c}\text { ADF Fisher } \\
\text { statistics }\end{array}$ & $\begin{array}{c}\text { Order of } \\
\text { integration }\end{array}$ \\
\hline $\operatorname{lnFPI}$ & -3.18 & $\mathrm{I}(0)$ & 103.75 & $\mathrm{I}(1)$ \\
\hline IFRSFA & -4.47 & $\mathrm{I}(1)$ & 252.56 & $\mathrm{I}(1)$ \\
\hline INF & -2.93 & $\mathrm{I}(0)$ & 100.06 & $\mathrm{I}(0)$ \\
\hline INTR & -3.66 & $\mathrm{I}(0)$ & 198.57 & $\mathrm{I}(0)$ \\
\hline $\operatorname{lnEXR}$ & -4.89 & $\mathrm{I}(1)$ & 47.76 & $\mathrm{I}(0)$ \\
\hline EG & -4.98 & $\mathrm{I}(0)$ & 299.08 & $\mathrm{I}(0)$ \\
\hline TOP & -2.04 & $\mathrm{I}(0)$ & 62.87 & $\mathrm{I}(0)$ \\
\hline TAX & -3.88 & $\mathrm{I}(1)$ & 155.73 & $\mathrm{I}(1)$ \\
\hline $\operatorname{lnMCAP}$ & -3.05 & $\mathrm{I}(1)$ & 300.46 & $\mathrm{I}(1)$ \\
\hline REG & -4.95 & $\mathrm{I}(1)$ & 328.88 & $\mathrm{I}(1)$ \\
\hline COR & -5.25 & $\mathrm{I}(1)$ & 381.43 & $\mathrm{I}(1)$ \\
\hline
\end{tabular}

Source: Author's calculation using E-views statistical package

It is evident from Table 5.4 that all the variables are either stationary at levels or after the first difference. This result implies that they are suitable for all the analyses. The two methods of panel unit root test give the same levels of integration for each variable. These results speak volumes about the consistency level of the panel unit root results. Furthermore, the results indicate that 
apart from the FPI, INTR, TOP, INF, and EG that are stationary at levels, all other variables in the table are stationary after the first difference, that is, the integration of order one $I(1)$. Thus, the unit root test results indicate that all the estimated variables employed for the panel data regression analysis are statistically stationary, either at their levels or after the first difference. This finding shows that the panel data regression results are consistent and reliable for the investigation to examine the effect of IFRS adoption on FPI. The subsequent sections will present the panel data regression estimates.

\subsection{Panel data regression estimating the benchmark variables before IFRS adoption}

\subsubsection{Regression results of benchmark variables before IFRS adoption (REM option)}

The panel regression analysis in Table 5.5, including only adopting countries, reflects the estimated coefficients of benchmark variables assumed to influence FPI before the adoption of IFRS (see Chapter 4). The statistical estimation techniques adopted for the analysis are four (POLS, FEM, REM, and SGMM), as earlier explained in Chapter 4. This approach of using different statistical estimations in the panel data is relevant to accommodate each of the technique's strengths and weaknesses (Gujarati, 2007:666). It will enable the appropriate approach for the analysis. In this situation, REM is an appropriate option for the analysis to estimate the panel data regression for the pre-adoption period according to the findings from Hausman test (see Appendix E).

The Hausman test is conducted to know which of the two estimated panel models (i.e., FEM or REM) is more suitable for the analysis. The results of the Hausman test are presented in the lower section of Column 4, Table 5.5. The Hausman test reveals that the chi-square probability is not significant at a 5\% level ( $p$-value $=0.98)$. Hence the null hypothesis is accepted, while the alternative hypothesis is rejected, therefore, making REM to be more appropriate for the estimation. Rejecting the null hypothesis according to the Hausman test, does not make the fixedeffect estimator usable for the regression analysis of the benchmark factors. Consequently, it is vital to examine the influence of these standard variables that are assumed to influence foreign investments before the introduction of IFRS variable into the model. They are used as the control variables in this thesis, as explained earlier in Chapter 4. Firstly, Table 5.5 presents the benchmark estimation results. 
Table 5.5: Regression coefficients (standard error) of factors assumed to influence FPI before IFRS adoption: adopting countries (1994-2004) REM option

\begin{tabular}{|c|c|c|c|c|}
\hline \multicolumn{5}{|c|}{ Dependent variable: FPI } \\
\hline $\begin{array}{c}\text { Independent variable } \\
\text { (1) }\end{array}$ & $\begin{array}{l}\text { POLS } \\
(2)\end{array}$ & $\begin{array}{c}\text { FEM } \\
(3)\end{array}$ & $\begin{array}{c}\text { REM } \\
\text { (4) }\end{array}$ & $\begin{array}{c}\text { SGMM } \\
\text { (5) }\end{array}$ \\
\hline $\mathrm{C}$ & $\begin{array}{l}4.65 \\
(1.98)^{* *}\end{array}$ & $\begin{array}{c}4.23 \\
(2.91)\end{array}$ & $\begin{array}{c}3.26 \\
(2.23)\end{array}$ & - \\
\hline INF & $\begin{array}{c}1.60 \\
(1.32)\end{array}$ & $\begin{array}{l}-0.73 \\
(0.70)\end{array}$ & $\begin{array}{l}-0.83 \\
(0.67)\end{array}$ & $\begin{array}{c}0.16 \\
(0.45)\end{array}$ \\
\hline INTR & $\begin{array}{c}0.58 \\
(1.73)\end{array}$ & $\begin{array}{l}-0.01 \\
(0.70)\end{array}$ & $\begin{array}{l}-0.05 \\
(0.69)\end{array}$ & $\begin{array}{c}0.22 \\
(0.61)\end{array}$ \\
\hline $\operatorname{lnEXR}$ & $\begin{array}{l}-0.10 \\
(0.07)\end{array}$ & $\begin{array}{c}0.03 \\
(0.16)\end{array}$ & $\begin{array}{c}0.04 \\
(0.13)\end{array}$ & $\begin{array}{c}0.11 \\
(0.09)\end{array}$ \\
\hline EG & $\begin{array}{c}0.84 \\
(2.63)\end{array}$ & $\begin{array}{l}-0.04 \\
(1.00)\end{array}$ & $\begin{array}{c}0.04 \\
(0.98)\end{array}$ & $\begin{array}{l}1.11 * * \\
(0.55)\end{array}$ \\
\hline TOP & $\begin{array}{l}-1.25 \\
(0.79)\end{array}$ & $\begin{array}{l}-0.44 \\
(0.54)\end{array}$ & $\begin{array}{l}-0.35 \\
(0.53)\end{array}$ & $\begin{array}{l}-0.26 \\
(0.20)\end{array}$ \\
\hline TAX & $\begin{array}{l}7.88 * \\
(4.30)\end{array}$ & $\begin{array}{c}8.60 \\
(3.18)^{* *}\end{array}$ & $\begin{array}{l}8.81 \\
(3.14)^{* *}\end{array}$ & $\begin{array}{c}1.49 \\
(1.09)\end{array}$ \\
\hline $\operatorname{lnMCAP}$ & $\begin{array}{l}0.17 * * \\
(0.06)\end{array}$ & $\begin{array}{l}-0.10 \\
(0.32)\end{array}$ & $\begin{array}{c}0.05 \\
(0.21)\end{array}$ & $\begin{array}{l}-0.25 \\
(0.20)\end{array}$ \\
\hline REG & $\begin{array}{c}121.71 * * \\
(34.57)\end{array}$ & $\begin{array}{l}-9.90 \\
(22.17)\end{array}$ & $\begin{array}{c}-5.92 \\
(21.80)\end{array}$ & $\begin{array}{c}16.26 \\
(7.63)^{* *}\end{array}$ \\
\hline $\mathrm{COR}$ & $\begin{array}{c}3.28 \\
(18.94)\end{array}$ & $\begin{array}{c}45.45 \\
(19.38)^{* *}\end{array}$ & $\begin{array}{c}43.74 \\
(18.81)^{* *}\end{array}$ & $\begin{array}{l}-3.97 \\
(9.88)\end{array}$ \\
\hline $\operatorname{lnFPI}(-1)$ & - & - & - & $\begin{array}{c}0.49 \\
(0.11)^{* * *}\end{array}$ \\
\hline $\begin{array}{c}\text { Total panel (balanced) } \\
\text { observations }\end{array}$ & 165 & 165 & 165 & 120 \\
\hline R-Squared & 0.21 & 0.91 & 0.09 & - \\
\hline F-statistic & 4.47 & 66.51 & 1.75 & - \\
\hline Prob(F-statistic) & 0.00 & 0.00 & 0.08 & - \\
\hline Durbin-Watson & 0.16 & 1.27 & 1.21 & - \\
\hline Hausman $X^{2}$ Test & - & - & 2.44 & - \\
\hline P-Value $X^{2}$ Test & - & - & 0.98 & - \\
\hline $\operatorname{AR}(2)$ & - & - & - & 0.93 \\
\hline $\operatorname{AR}(1)$ & - & - & - & 0.00 \\
\hline
\end{tabular}


Note: $C=$ constant $; \operatorname{lnFPI}=$ natural log of foreign portfolio investment; INF = inflation rate; INTR = interest rate: $\ln E X R=$ natural log of exchange rate $; E G=$ economic growth rate; $T O P=$ trade openness $; T A X=$ corporate tax rate; $\operatorname{lnMCAP}=$ natural log of market capitalisation; $R E G=$ regulatory index; $C O R=$ corruption. $* * * * *$ and $*$ denote significant levels at 1\%, 5\% and 10\% respectively. Number in parentheses is the standard error of the coefficient.

Source: Results generated from data analysis using E-views statistical software package (see Appendices $B \& D$-H)

Table 5.5, Column 2, shows the OLS regression results. From the findings, only three variables are positively and significantly related to FPI. They are TAX at 10\%, MCAP at a 5\%, and REG at a $5 \%$ level of significance with FPI. These findings may not be relied on, since they may be prone to a specific effect or heterogeneity influence that may affect the interpretations of the results.

Consequently, to determine the presence of the specific effect, a cross-section dependence test (correlation) was computed to test for the null and alternative hypotheses. The results are presented in Table 5.6 below.

Table 5.6: Cross-sectional dependence test), pre-IFRS adoption

\begin{tabular}{|c|c|c|c|}
\hline \multicolumn{3}{|c|}{ Null hypothesis: No cross-section dependence (correlation) in residuals } \\
\hline Test & Statistic & d.f. & Prob. \\
\hline Breusch-Pagan LM & 347.89 & 105 & 0.00 \\
\hline Pesaran scaled LM & 16.76 & & 0.00 \\
\hline Pesaran CD & 0.82 & & 0.41 \\
\hline
\end{tabular}

Source: Results generated from data analysis (see Appendix C)

The results indicate that the null hypothesis is rejected and the alternative hypothesis accepted, that there is cross-section dependence (correlation). POLS is, therefore, not appropriate for the analysis due to the presence of a cross-section effect. To reduce the problem of cross-section dependence, FEM and REM were computed.

Consequently, in order to reduce the problem of cross-sectional dependence, which may affect the interpretation of findings, a panel data regression model approach is estimated using the fixedeffects and random-effects models. The outcome will ascertain the level of consistency in the panel data results, and also it will determine the best appropriate model for the analysis. Furthermore, the Hausman test was conducted to know which of the two estimated panel models (i.e., FEM or REM) is more suitable for the analysis. The results of the Hausman test are presented in the lower section of Column 4, Table 5.5. The Hausman test (in Appendix E) reveals that the chi-square 
probability is not significant at a 5\% level (p-value $=0.98$ ). Hence the null hypothesis is accepted, while the alternative hypothesis is rejected, therefore, making REM to be more appropriate for the estimation.

Column 4, Table 5.5, shows that TAX and COR are positive and statistically significant at a 5\% level with FPI before the adoption. The positive and significant effect of TAX implies that a percentage increase in the corporate tax rate increases FPI by 8.80 , with one unit of TAX increase, and all other variables remain constant. Tax in any form is supposed to reduce the earnings of the payer, either individually or as a corporate body. In the case of a corporate entity, it will affect the equity shareholders' return. Hence, the corporate tax rate is expected to have an inverse relationship with foreign investments. Contrarily, it shows a positive relationship with FPI. This finding indicates that the selected countries' investment environments are not sensitive to tax policies. Nevertheless, it is consistent with the studies of Attar and Temel (2002) and Klemn and Van Parys (2012). They found that the corporate tax rate has a positive effect on foreign investments in an inferior investment environment.

Similarly, COR is positive and significant at a 5\% level with FPI. It indicates that a one-unit increase in the rate of corruption will increase the FPI by 43.73. Hence, it shows that the level of corruption has decreased since the higher score of the corruption index implies a less corrupt economy and more flows of FPI. This finding is in support of Daude and Stein (2007), who found that low levels of corruption have a positive effect on foreign investment.

Another area of interest from the findings is that the R-square value is 0.09 . This percentage shows that $9 \%$ of the total variation of all the predictable independent variables on FPI can be explained, while other variables can explain the remaining $91 \%$.

Consequently, the thesis further considered the use of the systemic generalised method of moments (SGMM) to control for the problem of endogeneity of the lagged dependent variable and serial correlation problem. The SGMM estimation results are presented in Column 5, Table 5.5.

The SGMM model shows that EG and REG variables are positively and significantly related to FPI at 5\% levels. This finding is in support of Sarno et al. (2016), who found that economic growth influences changes in FPI significantly. Similarly, REG, which indicates the degree to which the government policies are being formulated and implemented, is also significant and positively related to FPI at a 5\% level. This result confirms the finding of Rodriguez-Pose and Cols (2017) 
that sustainable government policy will have a significant effect on the investment environment of a country to attract foreign investments.

Another major issue in this result is the lagged value of the dependent variable, FPI (-1). It shows a positive and highly significant level of $1 \%$. These positive findings mean that the present year inflow of FPI will dictate the future inflow of the FPI. The result is following the findings of Anyanwu and Yameogo (2015), who tested the agglomeration (accumulation) effects by relating the current inflow of foreign investments with the past inflow. They found that the current year foreign investments will be a function of future inflow.

The post-estimation tests, autoregressive $\langle A R\rangle 1$ and $\langle A R\rangle 2$ models are estimated to verify that there is no autocorrelation of the first order and the second order in the model. The finding will assist in confirming that all the instruments used for the estimation are valid and not overidentifying (i.e., indicating that all the variables are accurate instruments). Thus, the results from Table 5.5 confirm that there is no autocorrelation in the model as reported by the $\langle A R\rangle 1$, which is 0.00 (less than 0.05 ), while $\langle A R\rangle 2$ is 0.93 greater than $0.05 \%$. The findings indicate the robustness of the model.

According to the SGMM estimator results, which controls for the presence of endogeneity in the model, EG and REG variables are positively significantly correlated with FPI before the adoption of IFRS. Thus, the remaining seven independent variables are not reflecting any level of significance to FPI. This result is in support of the literature that the actual theoretical framework for the determination of foreign investments is yet to be actualised (Gordon et al., 2012). Nevertheless, this model has assisted in checking for specific variables that are the critical driver that influence the inflow of foreign investments before including the IFRS adoption variable in the total model to examine its effect on FPI. In this way, the results from SGMM indicates that EG and REG are the significant drivers of FPI in these countries before the adoption of IFRS.

\subsubsection{Panel data regression coefficients (standard error) of the effect of post-IFRS adoption on FPI: adopting countries}

The regression analysis estimates for Model 1B in Equation 4.4 examine the effect of IFRS adoption on FPI of the adopted countries (Table 4.1 and 4.2). To achieve this objective, Model 1A was augmented with the IFRS adoption variable. In essence, all the proposed estimators' methods for the panel data analysis (pooled regression model, fixed-effects model, and random-effects 
model) are computed to choose the best alternative, especially between the fixed-effects model and random-effects model.

Table 5.7: Panel data regression coefficients (standard error) with IFRS adoption variable and covariates (1994-2015)

\begin{tabular}{|c|c|c|c|c|}
\hline \multicolumn{5}{|c|}{ Dependent Variable: FPI } \\
\hline $\begin{array}{l}\text { Independent variable } \\
\text { (1) }\end{array}$ & $\begin{array}{l}\text { POLS } \\
\text { (2) }\end{array}$ & $\begin{array}{l}\text { FEM } \\
\text { (3) }\end{array}$ & $\begin{array}{c}\text { REM } \\
\text { (4) }\end{array}$ & $\begin{array}{c}\text { SGMM } \\
\text { (5) }\end{array}$ \\
\hline $\mathrm{C}$ & $\begin{array}{c}5.05 \\
(1.19)^{* * *}\end{array}$ & $\begin{array}{c}3.98 \\
(1.37)^{* *}\end{array}$ & $\begin{array}{c}3.80 \\
(1.45)^{* *}\end{array}$ & - \\
\hline IFRSFA & $\begin{array}{c}1.37 \\
(0.23)^{* * *}\end{array}$ & $\begin{array}{c}0.91 \\
(0.17)^{* * *}\end{array}$ & $\begin{array}{c}0.89 \\
(0.16)^{* * *}\end{array}$ & $\begin{array}{c}0.24 \\
(0.11)^{* *}\end{array}$ \\
\hline INF & $\begin{array}{c}1.35 \\
(0.98)\end{array}$ & $\begin{array}{l}-0.01 \\
(0.72)\end{array}$ & $\begin{array}{c}0.12 \\
(0.69)\end{array}$ & $\begin{array}{l}-0.07 \\
(0.51)\end{array}$ \\
\hline INT & $\begin{array}{c}0.45 \\
(1.20)\end{array}$ & $\begin{array}{c}0.68 \\
(0.76)\end{array}$ & $\begin{array}{c}0.68 \\
(0.76)\end{array}$ & $\begin{array}{c}0.12 \\
(0.43)\end{array}$ \\
\hline $\operatorname{lnEXR}$ & $\begin{array}{c}-0.06 \\
(0.03)^{*}\end{array}$ & $\begin{array}{l}-0.04 \\
(0.14) \\
\end{array}$ & $\begin{array}{c}0.01 \\
(0.11) \\
\end{array}$ & $\begin{array}{c}0.22 \\
(0.14) \\
\end{array}$ \\
\hline EG & $\begin{array}{l}0.01 \\
(2.01)\end{array}$ & $\begin{array}{c}0.49 \\
(1.15)\end{array}$ & $\begin{array}{c}0.40 \\
(1.14)\end{array}$ & $\begin{array}{c}0.18 \\
(0.49)\end{array}$ \\
\hline TOP & $\begin{array}{c}-1.18 \\
(0.48)^{* *}\end{array}$ & $\begin{array}{l}-0.20 \\
(0.44)\end{array}$ & $\begin{array}{l}-0.28 \\
(0.44)\end{array}$ & $\begin{array}{c}0.33 \\
(0.36)\end{array}$ \\
\hline TAX & $\begin{array}{c}6.93 \\
(2.63)^{* *}\end{array}$ & $\begin{array}{c}0.95 \\
(2.37)\end{array}$ & $\begin{array}{c}1.31 \\
(2.35)\end{array}$ & $\begin{array}{l}-3.05 \\
(2.10)\end{array}$ \\
\hline $\operatorname{lnMCAP}$ & $\begin{array}{c}0.15 \\
(0.05)^{* * *}\end{array}$ & $\begin{array}{c}0.02 \\
(0.14) \\
\end{array}$ & $\begin{array}{c}0.03 \\
(0.12) \\
\end{array}$ & $\begin{array}{c}0.07 \\
(0.14)\end{array}$ \\
\hline REG & $\begin{array}{c}108.53 \\
(36.96)^{* * *}\end{array}$ & $\begin{array}{c}93.72 \\
(17.17)^{* * *}\end{array}$ & $\begin{array}{c}93.81 \\
(17.12)^{* * *}\end{array}$ & $\begin{array}{c}31.70 \\
(16.62)^{* *}\end{array}$ \\
\hline $\mathrm{COR}$ & $\begin{array}{c}3.33 \\
(12.25) \\
\end{array}$ & $\begin{array}{c}98.24 \\
(13.29)^{* * *} \\
\end{array}$ & $\begin{array}{c}94.14 \\
(13.00)^{* * *}\end{array}$ & $\begin{array}{l}-0.32 \\
(0.96) \\
\end{array}$ \\
\hline $\operatorname{lnFPI}(-1)$ & - & - & - & $\begin{array}{c}0.40 \\
(0.11)^{* * *}\end{array}$ \\
\hline $\begin{array}{c}\text { Total panel (balanced) } \\
\text { observations }\end{array}$ & 330 & 330 & 330 & 300 \\
\hline R-Squared & 0.22 & 0.77 & 0.38 & - \\
\hline F-Statistic & $9.10^{* * * *}$ & $43.79 * * *$ & $19.74 * * *$ & - \\
\hline Durbin-Watson stat & 0.21 & 0.81 & 0.80 & - \\
\hline Hausman $X^{2}$ Test & - & - & 3.81 & - \\
\hline P-Value $X^{2}$ Test & - & - & 0.95 & - \\
\hline
\end{tabular}




\begin{tabular}{|c|c|c|c|c|}
\hline \multicolumn{5}{|c|}{ Dependent Variable: FPI } \\
\hline $\begin{array}{c}\text { Independent variable } \\
\text { (1) }\end{array}$ & POLS & FEM & REM & SGMM \\
$(\mathbf{2})$ & $(3)$ & $(\mathbf{4})$ & (5) \\
\hline $\mathrm{AR}(2)$ & - & - & - & 0.32 \\
\hline $\mathrm{AR}(1)$ & - & - & - & 0.00 \\
\hline
\end{tabular}

Note: $C$ = constant; IFRSFA = International Financial Reporting Standards full adoption; EG = economic growth rate; $I N F=$ inflation rate; INTR = interest rate: $\operatorname{lnEXR}=$ natural log of exchange rate; $\operatorname{lnMCAP}=$ natural log of market capitalisation; $R E G=$ regulatory index; $T A X=$ corporate tax rate; $T O P=$ trade openness; $C O R=$ corruption; $* * * * *$ and $*$ denote significant levels at 1\%, 5\% and $10 \%$ respectively. Number in parentheses is the standard error of the coefficients.

Source: Results generated from data analysis using E-views statistical software package (see Appendices I \& K-O)

The results presented in Table 5.7, POLS Column indicates that the following variables have a significant effect on lnFPI. They are: IFRS, which is positive and significant at a $1 \%$ level to FPI, lnMCAP and REG are positive and significant at a $1 \%$ level to lnFPI, respectively, Also, the TOP and $\operatorname{lnEXR}$ indicate a negative and significant level at a 5\% and $10 \%$ levels to $\operatorname{lnFPI}$ respectively. These results are shown from the probabilities value of each of these variables in the estimated model results in Colum 2, Table 5.7. The approach of POLS might not be sufficient to explain the relationship between the independent variables and the dependent variable since the results are prone to a specific effect/heterogeneity influence that might undermine the reliability of the parameter estimates in the estimated model.

A cross-sectional dependence test is conducted to ascertain if there is any specific effect on the results. Table 5.8 presents the result of the cross-sectional dependence test. It shows that the null hypothesis is rejected and the alternative hypothesis is accepted. This result indicates that there is cross-sectional dependence in the POLS estimated panel model. This result implies that it is not appropriate to pool the data. Therefore, the POLS regression results are not reliable for this estimate.

Table 5.8: Cross-sectional dependence test, post-IFRS adoption

\begin{tabular}{|c|c|c|c|}
\hline \multicolumn{4}{|c|}{ Null hypothesis: No cross-section dependence (correlation) in residuals } \\
\hline Test & Statistic & d.f. & Prob. \\
\hline Breusch-Pagan LM & 275.97 & 105 & 0.00 \\
\hline Pesaran scaled LM & 11.79 & & 0.00 \\
\hline Pesaran CD & -0.12 & & 0.90 \\
\hline
\end{tabular}

Source: Author's computation from research data (see Appendix J) 
Consequently, the panel data regression model was used to reduce the problem of cross-sectional dependence. Both the fixed-effects and random-effects models are computed to ascertain the level of consistency in the panel data results and to determine the best appropriate model for the analysis. The results are also presented in Table 5.7, Columns 3 and 4.

From Table 5.7, it is clear that there are similarities in the results of the fixed and random effect models. All the variables that are significant under the FEM are also significant under the REM. That is IFRSFA, REG, and COR. Although, their coefficients are slightly different, necessitating the selection of the best alternative by computing the Hausman chi-square.

The Hausman test was conducted to know which of the two estimated panel models (i.e., FEM or REM) is more suitable for the analysis. The results of the Hausman test are presented in the lower section of Column 4, Table 5.7. The Hausman test (in Appendix D4) reveals that the chi-square probability is not significant at a 5\% level ( $\mathrm{p}$-value $=0.95)$. Hence the null hypothesis is accepted, while the alternative hypothesis is rejected, therefore, making REM to be more appropriate for the estimation.

\subsubsection{REM regression results comparing the pre-and post-effect of IFRS adoption on FPI: adopting countries}

Column 4, Table 5.7, shows the results of the REM. From the findings, three variables, namely IFRSFA, REG, and COR, are highly significant and positive to $\operatorname{lnFPI}$ at a $1 \%$ level under REM estimator. IFRSFA represents the variable that measured IFRS as a dummy variable (see Chapter 4). Similarly, the coefficient of IFRSFA is also positive and highly significant at a $1 \%$ level to lnFPI in all the other estimators, apart from SGMM estimator, which is significant at 5\% level as indicated in Table 5.7. This finding shows that the adoption of IFRS influences a significant and positive change in FPI inflows. This result is in support of the empirical findings of Amiram (2012), Beneish (2015), and $\mathrm{Ng}$ (2015), who adopted the view that IFRS adoption triggers the inflow of FPI in the adopting countries.

Also, the findings upheld the suggestion of proponents of IFRS that it will influence the inflow of foreign investments in the adopting countries (McCreevy, 2005 \& Tweedie, 2006). However, this finding is contrary to the results of Efobi (2017) and Nnadi and Soobaroyen (2015), who found a negative relationship between IFRS adoption and foreign investments inflows. This finding is also evident in the descriptive statistics presented in Tables 5.1 and 5.2, which reflected an increase in FPI between the pre-and-post adoption periods. Additionally, Tables 5.2a and 5.2b that presented 
the WSR test corroborates this finding by showing significant differences in the pre-and-post IFRS adoption on FPI.

The R-square statistic shows 38\% (see Colum 4, Table 5.7). The finding indicates that all the estimated independent variables, including IFRS, can jointly explain 38\% variation in $\operatorname{lnFPI}$. Although this level of variation may low, it is possible, for example, in a study of this nature, due to the enormous amount of unexplainable variables that may influence the inflows of FPI. Thus, a percentage above $20 \%$ may still be reliable for policy consideration. However, the overall significant test of the combined independent variables reveals that the estimated model is significant at a $1 \%$ level according to the probability value of the F-statistics, as indicated in Table 5.7. It shows that all the variables included in the model will jointly influence FPI inflow significantly; this implies that the model is a better fit. The finding from Table 5.7 also reveals that the Durbin-Watson statistics close to 1 in REM, which is appropriate, especially when considering the nature of the dependent variable (FPI) that can be influenced by many variables. This finding implies that the serial correlation does not constitute a problem in the analysis. However, these results have clearly shown that there is a highly significant and positive effect of IFRS adoption on FPI inflow after the adoption of IFRS in the selected countries.

On the other hand, corruption has a positive and highly significant effect on FPI. The coefficient was positive and highly significant at a $1 \%$ level with lnFPI with a coefficient of 94.14, as shown in Table 5.7. This outcome indicates that with the adoption of IFRS, a 1-unit increase in the Corruption Perception Index of the selected countries will generate an increase of 94.14 in FPI. It can be deduced that the highly significant level of corruption with FPI resulted in more inflow of FPI in IFRS adopting countries. Because the higher the corruption index means a less corrupt economy, it shows that the more a country is free of corruption and has fewer corruption incidents, the higher the value of the FPI.

The third variable with a significant effect with the lnFPI is the quality of regulatory authority. It is only positive and significant at a $1 \%$ level to lnFPI. Table 5.7 further shows that a 1 -unit increase in the regulatory quality index will enhance an increase in FPI by 93.81. This finding shows how proactive a government is in formulating and implementing policies in adopting countries. The more positive the variable, the more effective government policies are implemented in these countries. The result implies that the selected countries are more proactive in formulating and implementing strategies resulting in the higher value of the FPI. It shows that FPI thrives in an environment where the policies of regulatory authorities are strictly adhered to and well-executed. 


\subsubsection{SGMM results of the effect of IFRS adoption on FPI}

The SGMM findings for the effect of IFRS on FPI are presented in the last column of Table 5.7. The results point to the consistency of the outcomes of various techniques of analysis used to investigate the effect of the adoption of IFRS on the FPI of the countries that fully adopted IFRS. Certain variables that are significant under the two-panel data models (fixed-effects model and random-effects model) are also significant under the SGMM dynamic panel data analysis. These variables are IFRSFA and REG, and they are positive and significant at 5\% level respectively, with their lagged values according to Column 5, Table 5.7. The implication of this is that these variables have positive and significant individual effects on lnFPI in these countries (see Table 5.7). The estimation of the SGMM controls for the endogeneity problem in the model (as explained in Chapter 4). According to the literature, SGMM produces the most reliable parameter estimates among panel data models. Thus, it also confirms the positive and statistical significance of IFRSFA coefficient on $\operatorname{lnFPI}$.

Furthermore, the post estimation tests $A R\langle 1\rangle$ and $A R\langle 2\rangle$ support the model that there is no autocorrelation, and the estimated instruments (explanatory variables) are not over-identifying. The results show that the $A R\langle 1\rangle$ the probability value is $(0.000)$ which is less than $0.05 \%$ while $A R\langle 2\rangle$ is (0.32) greater than $0.05 \%$ in the model (see Table 5.7). These results are in line with the assumption of the probability value for autoregression, as discussed in Chapter 4. Also, the lagged dependent variable, lnFPI (-1), indicates a highly significant and positive value at a $1 \%$ level, indicating a strong influence of the future foreign investment inflows.

These findings confirmed the statistical significance of the IFRSFA coefficient on FPI. It shows that the analysis supports the fact that the adoption of IFRS by these selected counties has a significant effect on their FPI after the implementation of IFRS.

Furthermore, Table 5.7 reveals that none of the estimated macroeconomic indicator variables (i.e. INF, INT, EXR, EG) is statistically significant with FPI inflow based on the panel data regression estimators (FEM, REM, and SGMM). The findings further bolster the relevance of adopting a single set of uniform international accounting standards (e.g. IFRS) in attracting FPI.

\subsubsection{Hypothesis testing, before and after effect of IFRS adoption on FPI}

The first hypothesis stated in Chapter 1 was that: there is no significant effect on the volume of FPI before and after the adoption of IFRS in adopting countries. From the panel data analysis, 
Table 5.7, the test of the statistical significance of IFRSFA in the REM and SGMM show that the IFRS coefficient is positive and highly significantly correlated to FPI inflow. Therefore, the null hypothesis is rejected since the probability value of IFRSFA in the REM and SGMM estimator are significant at $1 \%$ and $5 \%$ level respectively. Similarly, the descriptive statistics, the Wilcoxon Signed Rank Test, including the correlation matrix, support this finding. Thus, the alternative hypothesis is accepted, showing that there is a significant and positive effect in the volume of FPI inflow after the adoption of IFRS.

\subsubsection{Discussion of the findings of the effect of IFRS adoption on FPI before and after the adoption}

The primary objective of this thesis is to examine the effect of the adoption of IFRS on FPI in adopting countries. This objective is achieved by comparing the magnitude of significant differences in FPI inflows before (11-year) and after (11-year) the adoption. The outcome will establish the relevance of a single set of uniform accounting standards (i.e. IFRS) as one of the major determinants of foreign capital. Firstly, the substantial adoption of IFRS by these countries have a highly significant effect on the volume of inflow of FPI. The panel data analysis supports this result as the REM and SGMM results confirmed it. For example, IFRSFA is positive and highly significant at a 1\% level to lnFPI under REM and at 5\% level under SGMM. The finding suggests that foreign investors are more attracted to these economies after the adoption of IFRS than before the adoption, as shown in Table 5.7. This finding is also in line with the findings of Asiemo (2013), Ball (2006), and Beneish et al. (2015), who concluded from their separate studies that the adoption of IFRS influences FPI significantly and positively in the adopting countries.

Moreover, the descriptive analysis, likewise, the trends of FPI was compared to show further the extent of the magnitude of changes in the FPI inflow. These were considered before and after the adoption of IFRS. The results indicated a positive trend for virtually all the countries, according to Figure 1 in the appendices. The results from the trend further justify the assumption that there was a significant change in the volumes of FPI inflow into these countries after the adoption of IFRS.

Secondly, another variable that shows a significant effect on lnFPI is REG. This result implies that foreign investors focused on the strength of regulatory authorities before investing in the selected economies. It can be argued that countries that are weak when implementing the policies relating to regulatory procedures are assumed to receive less credence from foreign investors. The 
implication is that IFRS can only thrive where there is a vibrant and supportive regulatory framework. This result is in support of the findings of Efobi (2017) and Sherman and Klerk (2015) that where the regulatory authorities, especially, those relating to the implementation of international accounting standards in a country are not well harmonised, it may affect the main purpose of unified international accounting standards.

Thirdly, corruption is an important factor that influences positively and significantly to $\operatorname{lnFPI}$ in these selected countries. Finding from this thesis revealed a significant relationship between IFRS adoption and lnFPI that a country with a high scored of CPI rate is more likely to witness an impressive FPI since the high score of CPI indicates a less corrupt country. According to Pankaj et al. (2017), foreign investors are very mindful of corruption prevalence in a country before diversifying their capitals. A country that is prone to corruption carries more risk and danger for foreign investors. Thus it is assumed that a likely corrupt country portends more risk and danger to foreign investors. Asiedu (2003) and Bissoon (2011) emphasise that the quality of a country's regulatory authority, better control of corruption, the better rule of law, and political stability plays a significant role in accelerating the inflow of foreign investments. Hence the significant correlation of COR and REG to lnFPI after the adoption supports these empirical studies. The general implication of the findings on the effect of the adoption of IFRS on FPI is that IFRS is positive and significantly correlated to $\operatorname{lnFPI}$ in the selected African countries.

Despite the significant effect of IFRS adoption in influencing the flow of FPI, many African countries are yet to require all their listed companies to adopt IFRS framework in preparing their financial statements. Consequently, (i.e., see Chapter 4, Tables 4.1 and 4.2), a total number of 20 African countries are identified in this group. Because of this, the second objective is investigating the effect of IFRS adoption on FPI inflow of the adopting and non-adopting countries.

\subsection{The effect of IFRS adoption on FPI, adopting and non-adopting countries (Objective 2)}

The second objective examines the effect of IFRS adoption on FPI inflows among the adopting and non-adopting countries (see Tables 4.1 and 4.2) in Africa between 2005 and 2015. The finding from this objective is assumed to corroborate the outcome related to objective one further.

For this purpose, the IFRS variable is used to classify the adopting and non-adopting countries, using a dummy variable (previously discussed in Chapter 4). Thus, the IFRSFA variable for the first group of countries that adopted IFRS is scored 1, while the second group of countries 
classified as non-adopting countries are scored 0 (see Tables 4.1 and 4.2). In essence, the dynamic panel estimation technique, SGMM, is utilised to estimate the model. First, the preliminary estimations, that is the diagnostic test, the descriptive statistics, the correlation matrix, and the unit root tests were computed before the SGMM regression analysis was estimated.

\subsubsection{Diagnostic test: Normality test for objective two dataset}

The results, as shown in Figure 5.2 below, have JB statistics of 0.58 and the probability of 0.74 . The JB statistics findings imply that the null hypothesis is accepted that the estimated panel model residuals are normally distributed. Likewise, the value of $\mathrm{S}$ and $\mathrm{K}$ are 0 and 3, respectively. It shows that the estimated variables are normally distributed. This implies that the data are reliable for all the estimates.

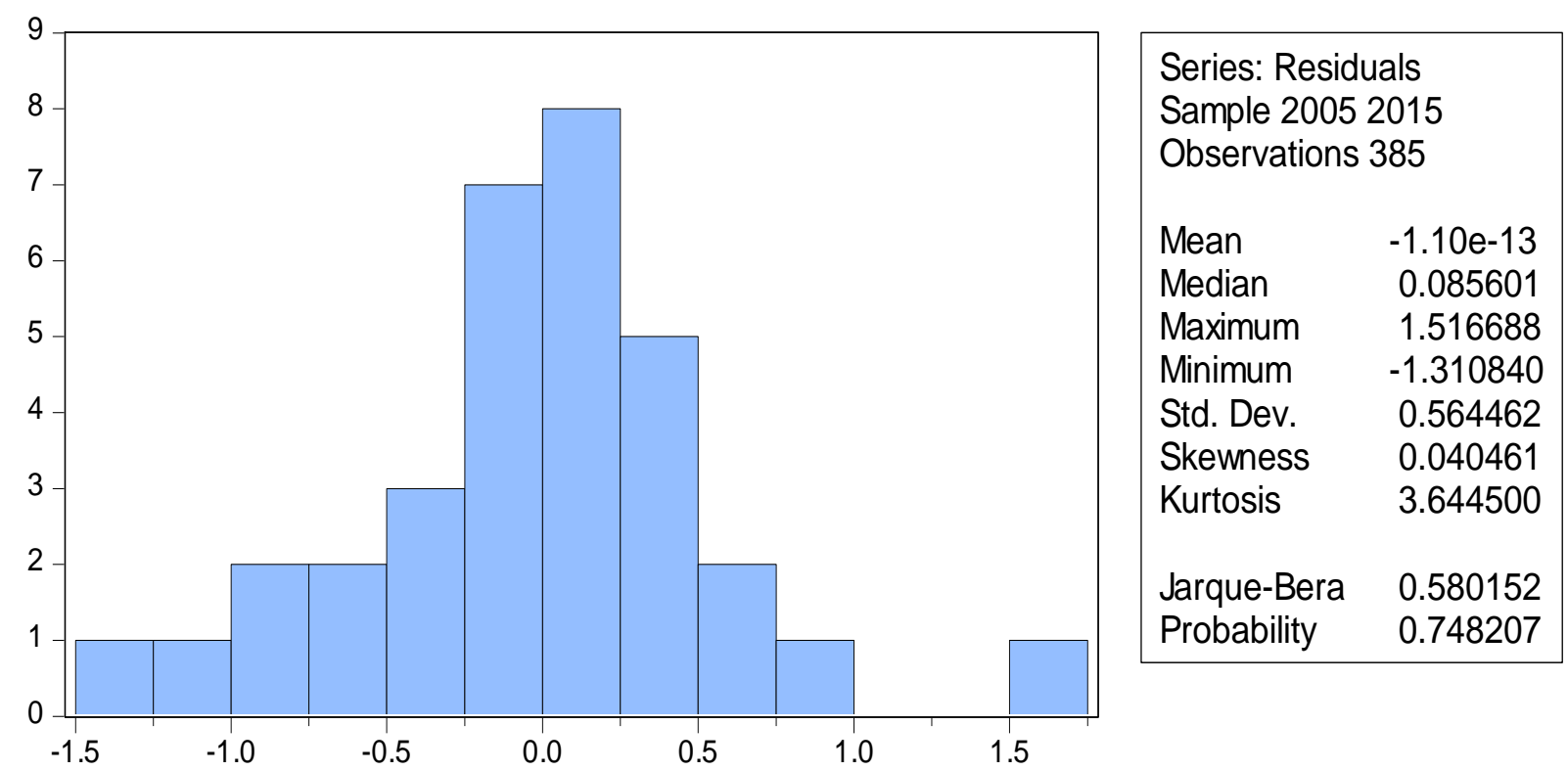

Figure 5.2: Normality test for adopting and non-adopting IFRS countries

Source: Results generated from data analysis using E-views statistical software package

\subsubsection{Descriptive statistics for adopting and non-adopting countries (2005-2015)}

Table 5.9 shows the mean values of FPI in adopting and non-adopting countries for the period after adoption. The mean value of the adopting countries is 8.46 , with a standard deviation of 1.75 , while the non-adopting countries' mean value is 6.59 , with a standard deviation of 3.53 . This finding shows that adopting countries experienced more inflow in the volume of FPI than the nonadopting countries. Also, Table 5.9 further reveals a wider variation in FPI inflows standard deviation in non-adopting countries than adopting countries with a mean value of 3.53 against 1.75 in adopting countries. The findings show that FPI inflow data in adopting countries are closer to 
the mean value. The results are indicating that they are not widely spread, showing some level of uniformity among the adopting counties in terms of FPI.

Additionally, the coefficient of variation was estimated to compare the degree of variability of the FPI inflow between the adopting and non-adopting IFRS countries, since standard deviation is not usually used to compare two distributions (see Chapter 4). The CV is the ratio of the standard deviation and absolute mean value; thus, the variable is measured on the same ratio. In this situation, the $\mathrm{CV}$ is computed to compare the distribution between FPI inflows in the adopting and non-adopting counties. The major variable of concern is FPI inflow. For the adopting countries, CV was 20\% (standard deviation/mean, 1.75/8.46), while for non-adopting countries, CV was 53\% (3.53/6.59). This result implies that FPI data distribution in the adopting countries shows a lower CV (20\%), which means that there are greater uniformity and consistency in FPI data than nonadopting countries with $53 \% \mathrm{CV}$.

Furthermore, Table 5.9 shows significant disparities from the mean values of certain control variables. For example, the mean value of $\operatorname{lnEXR}$ in the adopting countries was 3.51, while in the non-adopting countries, it was 5.11. This finding indicates a weakness in the currency of nonadopting countries. Likewise, the EG mean value was higher in the adopting countries than nonadopting countries. This result indicates the strength of IFRS adoption in influencing FPI for economic growth.

Similarly, lnMCAP indicates a mean value of 7.71 compared to 1.33 in non-adopting countries. This finding shows that IFRS adoption plays a dynamic role in capital market operations. It influences more activities in the capital markets. It can be argued that the adoption of IFRS in these countries has enhanced the development of the capital market compared to the non-adopting countries. The TAX, COR, and REG mean values indicate that the adopting countries enjoyed more advantages than the non-adopting countries, as shown in Table 5.9. The results also show a significant difference between the TOP mean value of non-adopting countries and adopting countries. The TOP mean value is higher in non-adopting countries than in adopting countries. This finding indicates that the economy of non-adopting countries is more exposed externally to attract FPI. 
Table 5.9: Descriptive statistics for IFRS adopting and non-adopting countries (20052015)

\begin{tabular}{|c|c|c|c|c|c|c|c|c|c|c|}
\hline \multirow{2}{*}{$\begin{array}{c}\text { Variable } \\
\text { S }\end{array}$} & \multicolumn{4}{|c|}{$\begin{array}{c}\text { IFRS adopting countries } \\
\text { (2005-2015) }\end{array}$} & \multicolumn{5}{c|}{ Non-adopting IFRS countries } \\
\cline { 2 - 11 } & Mean & $\begin{array}{c}\text { Std. } \\
\text { Dev. }\end{array}$ & Min & Max & CV \% & $\begin{array}{c}\text { Mea } \\
\text { n }\end{array}$ & $\begin{array}{c}\text { Std. } \\
\text { Dev. }\end{array}$ & Min & Max & CV \% \\
\hline InFPI & $\mathbf{8 . 4 6}$ & 1.75 & 0.00 & 11.35 & 20.00 & $\mathbf{6 . 5 9}$ & 3.53 & 0.00 & 10.35 & 53.56 \\
\hline IFRSFA & 3.42 & 1.19 & 1.00 & 4.00 & 34.79 & 0.00 & 0.00 & 0.00 & 0.00 & 0.00 \\
\hline INF & $\mathbf{0 . 0 8}$ & 0.07 & -0.36 & 0.50 & 87.50 & $\mathbf{0 . 0 7}$ & 0.08 & -0.02 & 0.37 & 114.28 \\
\hline INT & $\mathbf{0 . 0 9}$ & 0.08 & -0.42 & 0.26 & 88.88 & $\mathbf{0 . 0 6}$ & 0.07 & -0.17 & 0.35 & 116.66 \\
\hline InEXR & $\mathbf{3 . 5 1}$ & 3.63 & -4.31 & 8.87 & 103.41 & $\mathbf{5 . 1 1}$ & 2.21 & 0.65 & 9.30 & 43.24 \\
\hline EG & $\mathbf{0 . 0 3}$ & 0.04 & -0.22 & 0.18 & 133.33 & $\mathbf{0 . 0 2}$ & 0.03 & -0.07 & 0.19 & 15.00 \\
\hline TOP & $\mathbf{0 . 7 4}$ & 0.27 & 0.21 & 1.33 & 36.48 & $\mathbf{1 . 1 6}$ & 1.18 & 0.00 & 7.22 & 101.72 \\
\hline TAX & $\mathbf{0 . 2 8}$ & 0.05 & 0.15 & 0.35 & 17.85 & $\mathbf{0 . 3 0}$ & 0.05 & 0.20 & 0.40 & 16.66 \\
\hline LnMCAP & $\mathbf{7 . 7 1}$ & 3.40 & 0.00 & 11.97 & 44.09 & $\mathbf{1 . 3 3}$ & 3.49 & 0.00 & 11.14 & 26.24 \\
\hline REG & 0.00 & 0.01 & -0.01 & 0.02 & 00.00 & -0.01 & 0.00 & -0.02 & 0.00 & 0.00 \\
\hline COR & $\mathbf{0 . 0 4}$ & 0.01 & 0.02 & 0.07 & 25.00 & $\mathbf{0 . 0 3}$ & 0.01 & 0.01 & 0.06 & 33.33 \\
\hline
\end{tabular}

Note: $\operatorname{lnFPI}=$ natural log of dependent variable/ IFRSFA = International Financial Reporting Standards fully adopt; $I N F=$ inflation rate $; I N T R=$ interest rate $: \operatorname{lnEXR}=$ natural log of exchange rate $;$ EG = economic growth rate; TOP = trade openness; $T A X=$ corporate tax rate $; \operatorname{lnMCAP}=$ natural log of market capitalisation; $R E G=$ regulatory index $;$ COR = corruption $;$ min = minimum $;$ max = maximum

Source: Author's calculation from the research data using E-views statistical package

\subsubsection{The correlation matrix of the effect of IFRS adoption on FPI when comparing the adopting and non-adopting countries}

The correlation matrix, presented in Table 5.10, shows the bivariate relationship among all the variables featured in the analysis. It ranges from -1 to +1 . It measures the direction $(-1$ or +1$)$ and strength (coefficient) of a linear relationship among the variables. The correlation matrix is computed to observe the manner of the relationship between each estimated variable. It also tests if there is any problem of multicollinearity among the variables. However, any presence of multicollinearity shows that there is a perfect or linear relationship between one or more explanatory variables. Obviously, from Table 5.10 it shows that there is no presence of any multicollinearity among the variables since all the variables reveal a moderate strength of the linear relationship. 
Furthermore, the relationship that is of utmost importance in the results is the ones between IFRSFA and lnFPI. It is clear from Table 5.10 that the value of the relationship between FPI and IFRSFA is 0.23 and positive. It indicates a direct relationship between IFRSFA and FPI. It implies that IFRS adopting countries will record a positive relationship with lnFPI. It should be noted that the dummy variable employs to capture IFRS reflects the extent of the adoption of IFRS. The results indicate that in a situation where countries require all their listed companies to adopt IFRS, the country may experience a positive relationship with FP1inflow. Table 5.10 also indicates the direction and strength of covariates in the model. The results show that INF, INT, InEXR, EG, TOP, and TAX all have a negative relationship with lnFPI, while lnMCAP, REG, and COR indicates a positive relationship with $\operatorname{lnFPI}$. 
Table 5.10: Correlation matrix for IFRS adopting and non-adopting countries including covariates 2005-2015

\begin{tabular}{|c|c|c|c|c|c|c|c|c|c|c|c|}
\hline Correlation & InFPI & IFRSFA & INF & INT & InEXR & EG & TOP & TAX & LnMCAP & REG & COR \\
\hline InFPI & 1 & & & & & & & & & & \\
\hline IFRSFA & 0.23 & 1.00 & & & & & & & & & \\
\hline INF & -0.12 & 0.09 & 1.00 & & & & & & & & \\
\hline INT & -0.03 & 0.25 & 0.09 & 1.00 & & & & & & & \\
\hline $\operatorname{lnEXR}$ & -0.13 & -0.22 & -0.07 & -0.11 & 1.00 & & & & & & \\
\hline EG & -0.06 & 0.10 & 0.11 & 0.06 & -0.10 & 1.00 & & & & & \\
\hline TOP & -0.06 & 0.02 & -0.06 & -0.09 & -0.05 & 0.01 & 1.00 & & & & \\
\hline TAX & -0.19 & 0.03 & 0.20 & 0.25 & 0.06 & 0.03 & 0.16 & 1.00 & & & \\
\hline $\operatorname{lnMCAP}$ & 0.42 & 0.47 & 0.08 & -0.05 & -0.38 & 0.13 & -0.12 & -0.24 & 1.00 & & \\
\hline REG & 0.37 & 0.28 & -0.25 & -0.07 & -0.30 & 0.05 & -0.11 & -0.42 & 0.52 & 1.00 & \\
\hline COR & 0.24 & 0.05 & -0.19 & -0.08 & -0.37 & 0.06 & 0.09 & -0.35 & 0.35 & 0.60 & 1.00 \\
\hline
\end{tabular}

Note: Note: $\operatorname{lnFPI}=$ natural log of dependent variable; IFRSFA = International Financial Reporting Standards fully adopt; INF = inflation rate;

$I N T R=$ interest rate $: \operatorname{lnEXR}=$ natural log of exchange rate; $E G=$ economic growth rate; TOP = trade openness; TAX = corporate tax rate;

$\ln M C A P=$ natural log of market capitalisation $; R E G=$ regulatory index $; C O R=$ corruption;

Source: Author's calculation from the research data using E-views statistical package 


\subsubsection{Variance inflation factor (VIF)}

Furthermore, to establish the level of collinearity that may not be evident in the correlation matrix, the tolerance and VIF values are performed. It provides an index that estimates how much the variance of the computed regression parameter is increased because of collinearity. It shows the amount of percentage the variance is inflated for each explanatory variable coefficient. For example, if the tolerance value is less than .10, it indicates the presence of multicollinearity. While the VIF value above 10 indicates the presence of multicollinearity as well. The VIF results are presented in the table below. From the table, it shows that there is no presence of multicollinearity in the model as none of the explanatory variables shows a value less than .10. Also, the VIF value for all the independent variables is less than 10. These findings confirm that there is no presence of multicollinearity in the model. Hence, the multicollinearity assumption is not violated. This finding, therefore, supports the outcome of the Pearson correlation matrix as well.

Table 5.10a: Measure of the degree of multicollinearity using the variance inflation factor (VIF)

\begin{tabular}{|c|c|c|}
\hline \multicolumn{2}{|c|}{ Coefficients $^{\text {a }}$} \\
\hline \multicolumn{2}{|c|}{ Model } & \multicolumn{2}{|c|}{ Collinearity Statistics $^{\text {a }}$} \\
\cline { 2 - 4 } & Tolerance & VIF \\
\hline (Constant) & & 1.612 \\
\hline IFRSFA & .620 & 1.208 \\
\hline INF & .828 & 1.241 \\
\hline INT & .806 & 1.336 \\
\hline $\operatorname{lnEXR}$ & .749 & 1.041 \\
\hline EG & .961 & 1.187 \\
\hline TOP & .843 & 1.387 \\
\hline TAX & .721 & 1.944 \\
\hline $\operatorname{lnMCAP}$ & .514 & 2.683 \\
\hline REG & .373 & 2.202 \\
\hline COR & .454 & \\
\hline
\end{tabular}

a Dependent variable: $\ln F P I$

Note: IFRSFA = International Financial Reporting Standards fully adopt; INF = inflation rate; INTR = interest rate: $\ln E X R=$ natural log of exchange rate $; E G=$ economic growth rate; $T O P=$ trade openness; $T A X=$ corporate tax rate; $\operatorname{lnMCAP}=$ natural log of market capitalisation; $R E G=$ regulatory index; $C O R=$ corruption;

Source: Author's calculation from the research data using SPSS statistical package 


\subsubsection{Unit root test for the adopting and non-adopting countries}

The results of the unit root test are presented in Table 5.11 as appendix E3. It shows that all the variables are stationary after the first difference. Panel data analysis requires that all the variables estimated in the panel model must be stationary. Therefore, all variables in this study have shown to be combinations of I(1)and I(0), as indicated in Table 5.11 below.

Table 5.11: Unit root test results for the adopting and non-adopting countries

\begin{tabular}{|c|c|c|c|c|}
\hline \multirow{2}{*}{ Variables } & \multicolumn{4}{|c|}{ Panel unit root test method } \\
\cline { 2 - 5 } & \multicolumn{2}{|c|}{ Im, Pesaran and Shin IPS } & \multicolumn{2}{c|}{ ADF Fisher } \\
\cline { 2 - 5 } & IPS statistics & $\begin{array}{c}\text { Order of } \\
\text { integration }\end{array}$ & $\begin{array}{c}\text { ADF Fisher } \\
\text { statistics }\end{array}$ & $\begin{array}{c}\text { Order of } \\
\text { integration }\end{array}$ \\
\hline lnFPI & -3.9085 & $\mathrm{I}(1)$ & 145.2642 & $\mathrm{I}(0)$ \\
\hline IFRSFA & -2.6541 & $\mathrm{I}(0)$ & 297.3791 & $\mathrm{I}(0)$ \\
\hline INF & -2.9566 & $\mathrm{I}(0)$ & 286.0595 & $\mathrm{I}(0)$ \\
\hline INTR & -2.5436 & $\mathrm{I}(0)$ & 379.9689 & $\mathrm{I}(0)$ \\
\hline $\operatorname{lnEXR}$ & -2.7058 & $\mathrm{I}(1)$ & 221.4113 & $\mathrm{I}(1)$ \\
\hline EG & -2.6781 & $\mathrm{I}(0)$ & 247.8240 & $\mathrm{I}(0)$ \\
\hline TOP & -2.8794 & $\mathrm{I}(0)$ & 538.2861 & $\mathrm{I}(1)$ \\
\hline TAX & -2.5439 & $\mathrm{I}(0)$ & 208.7455 & $\mathrm{I}(1)$ \\
\hline $\ln \mathrm{MCAP}$ & -29876 & $\mathrm{I}(0)$ & 92.6735 & $\mathrm{I}(0)$ \\
\hline REG & -3.3088 & $\mathrm{I}(0)$ & 269.9691 & $\mathrm{I}(0)$ \\
\hline COR & -3.4828 & $\mathrm{I}(1)$ & 350.8042 & $\mathrm{I}(1)$ \\
\hline
\end{tabular}

Note: $\operatorname{lnFPI}=$ natural logarithm of foreign portfolio investment; INF = inflation rate; INTR = interest rate: $\operatorname{lnEXR}=$ natural log of exchange rate; $E G=$ economic growth rate; $T O P=$ trade openness; $T A X=$ corporate tax rate; InMCAP = natural log of market capitalisation; $R E G=$ regulatory index; $C O R=$ corruption

Source: Author's calculation from the research data 


\subsubsection{SGMM regression results of the effect of IFRS adoption on FPI among the adopting and non-adopting countries}

The SGMM estimator is used to estimate the second objective of the thesis to determine the effect of IFRS adoption on FPI inflow in adopting and non-adopting IFRS countries. The SGMM approach is more advantageous to other estimators because it controls the endogeneity problem of all the explanatory variables in a panel data with an application of methods of moment condition that use all the orthogonal condition between the lagged dependent variables and the error term (Efobi, 2017). Also, the problem of endogeneity is properly taking into consideration through the use of internal instruments and SGMM techniques (Gujarati, 2007:651-652).

The main problem with the SGMM approach is the validity of the estimated internal instruments employed. However, to make sure that internal instruments are not over-identified, the autocorrelation AR (1) and AR (2) are estimated (see Chapter 4).

The SGMM regression technique was estimated for the natural logarithm of FPI as the dependent variable and IFRS as main explanatory variables, including certain covariates. The panel data consists of adopting and non-adopting IFRS countries for a maximum of 35 countries from 200515 (see Table 4.2). The dummy variable was employed to estimate the IFRS variable, and it was coded as 1 for adopting countries and 0 for non-adopting countries as earlier explained under the methodology chapter. The panel regression results using the SGMM estimator are presented in Table 5.12 below. 
Table 5.12: SGMM regression results for the effect of IFRS adoption on FPI in adopting and non-adopting countries 2005-2015

\begin{tabular}{|c|c|}
\hline \multicolumn{2}{|c|}{ Dependent variable: FPI } \\
\hline Independent variable & SGMM results \\
\hline $\operatorname{lnFPI}(-1)$ & $0.35(0.02)^{* * *}$ \\
\hline IFRSFA & $0.72(0.09)^{* * *}$ \\
\hline INF & $-0.31(0.30)$ \\
\hline INT & $0.35(0.42)$ \\
\hline $\operatorname{lnEXR}$ & $-0.09(0.22)$ \\
\hline EG & $-1.81(1.53)$ \\
\hline TOP & $0.42(0.04)^{* * *}$ \\
\hline TAX & $3.36(1.03)^{* *}$ \\
\hline $\operatorname{lnMCAP}$ & $0.04(0.04)$ \\
\hline REG & $-37.68(10.18)^{* *}$ \\
\hline COR & $23.32(6.09)^{* *}$ \\
\hline Total panel (balanced) observation & 315 \\
\hline Number of countries & 35 \\
\hline $\mathrm{AR}(2)$ & 0.97 \\
\hline $\mathrm{AR}(1)$ & 0.02 \\
\hline
\end{tabular}

Note: $\ln F P I(-1)=$ time lag of dependent variable; IFRSFA = International Financial Reporting Standards full adoption; INF = inflation rate; INTR = interest rate; $\operatorname{lnEXR}=$ natural log of exchange rate; $E G=$ economic growth rate; $T O P=$ trade openness; $T A X=$ corporate tax rate; InMCAP = Natural log of market capitalisation; $R E G$ $=$ regulatory index; COR $=$ corruption; $* * * * *$ and $*$ denote significant levels at $1 \%, 5 \%$ and $10 \%$ respectively. Number in parentheses is the standard error of the coefficient.

Source: Results generated from data analysis using E-views statistical software package for SGMM (see Appendices $P$ and $Q$ )

Table 5.12 shows that the SGMM estimator results indicate a significant and positive relationship between IFRSFA and $\operatorname{lnFPI}$ at a $1 \%$ level. The results indicate that the coefficient of IFRSFA is 0.72 , and it is positive and statistically significant at a probability level of $1 \%$ to $\operatorname{lnFPI}(\beta=$ $0.72, \rho \leq 0.01)$. This finding implies that the adoption of IFRS will generate a 0.72 increase in FPI in adopting countries. The result corresponds with the finding of Landman et al. (2012) that 
the longer a country has been using IFRS, the more improvement there would be in the flow of foreign capital.

Also, this finding indicates the effect of the comparability of IFRS status in Africa between the adopting and non-adopting countries. The results showed that the variable that measures the IFRS adoption, IFRSFA, is positive and significantly related to $\operatorname{lnFPI}$ at a $1 \%$ level. This outcome corroborates the empirical findings from objective one and still holds that the adoption of IFRS plays a vital role in attracting FPI in the adopting countries. Putting this finding in a more systematic approach, the adoption of IFRS influences more transparency and comparability of financial statement. More so, it reduces the cost of obtaining relevant accounting information by foreign investors and reduces the degree of information asymmetry, hence, trigger the inflows of foreign investments (Amiram, 2012). This finding also in agreement with the proponent of IFRS that substantial adoption of IFRS will be the main factor that can influence foreign capital and improve the inflows of foreign investments for economic development purposes (McCreevy, 2005; Tweedie, 2006). Besides, this finding is contrary to the empirical study of Nnadi and Soobaroyen (2015), who found a negative relationship between IFRS and foreign investments.

The TOP, which measures the degree of a country's trade openness, is positive and significant at a $1 \%$ level to $\operatorname{lnFPI}$. This result indicates the extent to which an economy is open to the world. This finding corresponds with the empirical result of Nnadi and Soobaroyen (2015) that an open economy would be more attractive to foreign investors than a closed economy. The tax rate is positive and highly significant at a 5\% level to lnFPI. Although a negative association is envisaged, it is consistent with the studies of Attar and Temel (2002) and Klemn and Van Parys (2012) that the corporate tax rate has a positive effect on foreign investments in an inferior investment environment.

Other variables in the model that are also significant are REG and COR. REG is negative and significant at a 5\% level to lnFPI, while COR is positive and highly significant at a 5\% level. These findings show that they exert a significant effect on FPI inflow into these countries. Again, this finding is similar to what was obtained in the analysis in the first objective. Where the REG and COR variables had a significant effect on lnFPI. These results further underscore the importance of corruption and activities of the regulatory authorities in the behaviour of the FPI. Moreover, the lagged value of FPI (-1) is positive and highly significant at a $1 \%$ level, indicating that the current volume of FPI will determine the future volume. 
The post estimation tests $A R\langle 1\rangle$ and $A R\langle 2\rangle$ support the model that there is no autocorrelation, and the estimated instruments (explanatory variables) are not over-identifying. The results show that the $A R\langle 1\rangle$ the probability value is (0.000) which is less than $0.05 \%$ while $A R\langle 2\rangle$ is $(0.97)$ greater than $0.05 \%$ in the model (see Table 5.7). Thus, it shows that the model is of good fit and useful for inference.

\subsubsection{Difference-in-difference (DID) test of FPI inflows (adopting and non-adopting countries)}

The findings from the SGMM estimator indicate that IFRS adoption is highly significant and has a positive relationship to FPI in Model 1. In contrast, it was negative and not significant to FPI in Model 2. Furthermore, the WSRT was conducted to determine the extent of the magnitude of the difference in FPI inflow between the adopting and non-adopting countries. The DID estimation evaluates the difference in pre-and-post lnFPI of the adopting countries minus the pre-and-post lnFPI of non-adopting countries (see Appendix R). The summary of the WSRT result is presented in Table 5.13 below.

Table 5.13: Difference-in-differences test of pre-and-post FPI inflows in adopting and non-adopting IFRS countries

\begin{tabular}{|c|c|c|c|}
\hline IFRS status & Pre-IFRS & Post-IFRS & Difference \\
\hline Non-adopted countries & 2.17 & 6.59 & 4.42 \\
\hline Adopted countries & 7.47 & 8.46 & 0.99 \\
\hline Difference & 5.30 & 1.87 & -3.43 (DD) \\
\hline
\end{tabular}

Source: Extracted from the WSRT results (see Appendix T)

Table 5.13 indicates that before the implementation of IFRS, the adopting countries recorded a higher volume in FPI inflow, with an average difference of 5.30 between the adopting and nonadopting countries. Consequently, after the implementation of IFRS, the difference in FPI between the adopting and non-adopting counties was drastically reduced to 1.87 .

Furthermore, the DD mean value is -3.43 , from Table 5.13. The probability value of -3.43 is .0003 , according to the normal distribution table (Jaccard \& Becker, 2010:625). This finding implies that the p-value is less than $5 \%$ (p-value $\leq 0.05$ ). This finding indicates that there is a highly significant difference in the volume of FPI in adopting countries compared to non-adopting countries. This result is also evident from the SGMM results presented in Model 1, Table 5.12, which showed a 
positive and significant effect of IFRSFA on FPI. This finding indicates that the adoption of IFRS has a higher significant and positive effect on FPI inflow in adopting countries compared to nonadopting countries.

\subsubsection{Hypothesis testing of the effect of IFRS adoption on FPI among the adopting and non- adopting countries}

The second hypothesis was that there is no significant effect in the FPI of countries that adopted IFRS and countries that did not adopt IFRS. The estimation approach for the second objective was SGMM. It showed that the coefficient of IFRSFA is significant and positive at a $1 \%$ level for FPI. Hence, the alternative hypothesis is accepted that IFRS adoption has a significant and positive effect on the volume of FPI inflow in adopting countries. Also, the findings from the DID confirm this level of significance of IFRS to FPI.

\subsubsection{Discussion of the results of the effect of IFRS on FPI inflow among the adopting and non-adopting countries}

The second objective examines the effect of IFRS adoption on FPI inflow by investigating the effect of IFRS adoption on FPI. Again, panel data analysis using SGMM was applied for the analysis, and results yielded some relevant findings on the relationship between IFRS and $\operatorname{lnFPI}$ in the model.

Firstly, the results showed that countries that have adopted IFRS recorded a significant and positive effect on FPI. This finding is evident from the SGMM statistical estimate of the second objective. The finding indicated that IFRS has a significant and positive effect on lnFPI. Also, this result supports the outcome related to the objective one, which showed a significant and positive effect of IFRS adoption on FPI after the adoption of IFRS. This result further underscores the importance of the adoption of IFRS as it constitutes an essential driver of FPI in the adopting countries. According to Efobi et al. (2014), the adoption of IFRS gives more confidence to foreign investors and boosts internal investment climates. Therefore, the results of this analysis support these findings.

Trade openness (TOP) is highly significant and positive to FPI at a $1 \%$ level. This result indicates that these countries have open-door policies that influence external investors. This finding confirms the empirical results of Bartels et al. (2013), Buckley et al. (2014), and Nnadi and Soobbaroyen (2015) that an open-door policy will influence the flows of foreign investments. 
The results related to this second objective also showed that the regulatory authority (REG) and corruption (CORR) are significant at a 5\% level respectively, to $\operatorname{lnFPI}$. These two variables were also significant in the estimation concerning objective one (Table 5.5), where only the adopted countries were considered. These findings showed that IFRS is significantly enhanced FPI inflow in a country where the level of corruption is deficient, and the government regulatory authority implements their policies accordingly. These findings are in line with the empirical findings of Christensen et al. (2011), Marquez-Ramos, (2011), and Nnadi and Soobaroyen, (2007) that reduction in the level of corruption and implementation of government policies will positively influence foreign investments.

The findings from this section enable the thesis to address the second objective of investigating the effect of IFRS on FPI among the adopting and non-adopting countries in Africa. For this purpose, the effect of IFRS on FPI is estimated using the dummy variables that proxy the adopting (i.e. scored as 1) and non-adopting countries (i.e. scored as 0) in the model. The reason for this second objective is to examine whether the findings will consolidate the primary objective of this thesis or not. The findings from the pursuit of the first and second objectives correspond since the two results show that the adoption of IFRS has a positive and significant effect on lnFPI in the adopting countries. These findings necessitate the investigation of the third objective that examines the determinant factors that influence the probability of the adoption of IFRS, P(IFRS $=1)$, in African countries.

\subsection{Analysis of the determinant factors that influence the probability of IFRS adoption: a logistic regression approach (Objective 3)}

Even though the findings confirm that the adoption of IFRS has a significant and positive effect on FPI, only $30 \%$ of African countries have fully adopted IFRS (IFRS, 2018). This section examines why there is heterogeneity in the African countries' decision to adopt IFRS.

Ten determining factors were identified in the existing literature, as discussed in Chapter 3. These factors are essential in the process of deciding the likelihood of adopting IFRS. The findings will assist in making inferences about the specific factors that influenced the adoption of IFRS in selected countries. Against this background, this section empirically estimates ten determinant factors (earlier identified in the literature, see Chapter 4) using the logistic regression technique. However, the normal distribution test is estimated before the logistic regression model. Thus, the logistic regression model is to determine the nature of the distribution of the dataset. Although, 
logistic regression does not suggest any assumptions regarding the distribution scores for the independent variables, nevertheless, it is computed. The result of the diagnostic test is presented in Figure 5.3 below.

\subsubsection{Diagnostic test: Normality test for objective three dataset}

The findings indicate that the JB statistics is 3.39 , with the probability of 0.18 . It shows that the null hypothesis is accepted that the estimated panel model residuals are normally distributed. Besides, the value of $\mathrm{S}$ and $\mathrm{K}$ are 0 and 3, respectively. This finding indicates that the estimated variables are fit for the analysis.

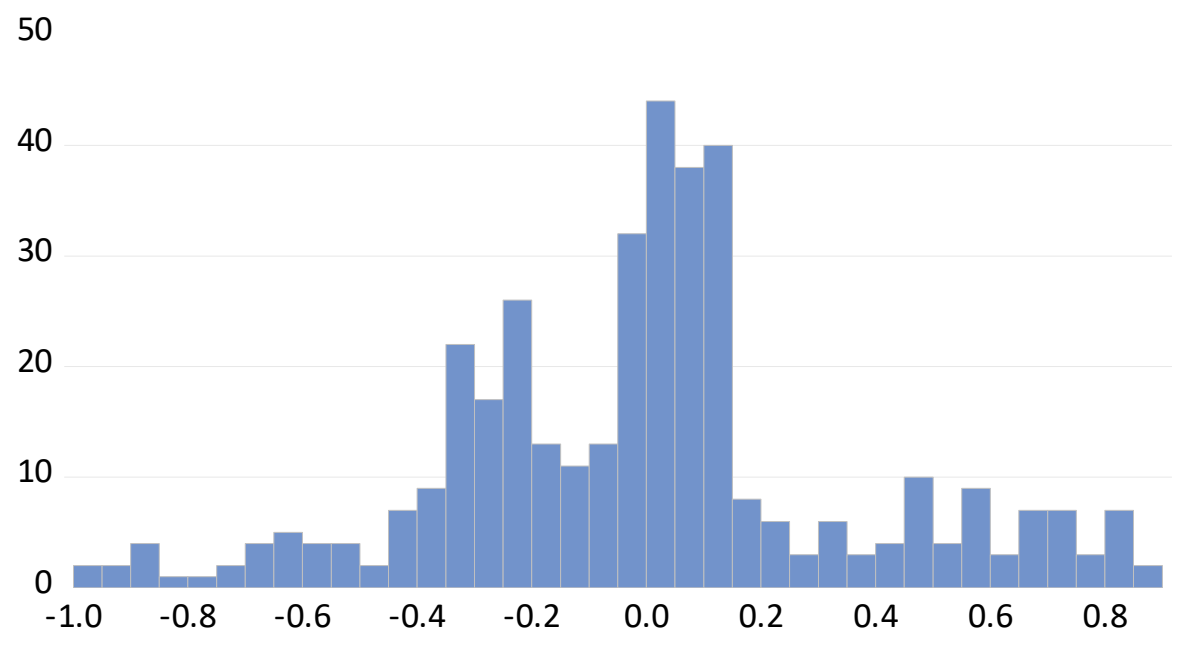

\begin{tabular}{|c|c|}
\hline \multicolumn{2}{|c|}{ Series: Residuals } \\
\hline \multicolumn{2}{|c|}{ Sample 1385} \\
\hline \multicolumn{2}{|c|}{ Observations 385} \\
\hline Mean & $-5.24 \mathrm{e}-17$ \\
\hline Median & 0.015800 \\
\hline Maximum & 0.878231 \\
\hline Minimum & -0.952967 \\
\hline Std. Dev. & 0.358702 \\
\hline Skewness & 0.131605 \\
\hline Kurtosis & 3.377550 \\
\hline Jarque-Bera & 3.398006 \\
\hline Probability & 0.182866 \\
\hline
\end{tabular}

Figure 5.3: Normality test for determinant factors dataset (logistic model)

Source: Results generated from data analysis using E-views statistical software package

\subsubsection{The correlation matrix of the determinants of IFRS adoption}

The Spearman correlation matrix, presented in Table 5.10, shows the relationship among all the variables estimated in the model. It ranges from -1 to +1 . It measures the direction $(-1$ or +1$)$ and strength (coefficient) of a linear relationship among the variables. The primary concern is to observe the manner of the association between each variable estimated and to test if there is any presence of multicollinearity among the variables because logistic regression model is sensitive to high correlations among the predictor variables. However, any presence of multicollinearity shows that there is a perfect or linear relationship between one or more explanatory variables. The findings from Table 5.15 indicate that there is no presence of multicollinearity among the estimated variables since all the variables reveal a moderate strength of the linear relationship. 
From the correlation matrix results table, nearly all the estimated variables show coefficients of less than $50 \%$, while the highest correlation coefficient is 0.64 . This result is statistically acceptable since it is far below the critical cut-off of $75 \%$ (Salem et al., 2017). The findings show that there is no multicollinearity problem; hence, the outcome of the logistic regression model is assumed to be reliable. Additionally, the results indicate a positive correlation between IFRS and $C U L, E D U$, $L S, P S, I P, \ln M C A P$, and EG, while EXPRE, TOP, and TAX reveal negative correlations. The positive correlations suggest the likelihood of the variables in predicting the adoption of IFRS. Though, this correlation result is not sufficing enough to conclude on the likelihood of these significant factors as determinants of the probability of IFRS adoption, P(IFRS = 1), until the inferential statistics (logistic regression model) is estimated. 
Table 5.14: Correlation matrix for the determinants of IFRS adoption

IFRS CUL EDU LS PS EXPRE IP InMCAP EG TOP

IFRS 1.00

$\begin{array}{lll}\text { CUL } & 0.64 & 1.00\end{array}$

EDU $\quad 0.34 \quad 0.48 \quad 1.00$

LS $\quad 0.42 \quad 0.37 \quad 0.59 \quad 1.00$

$\begin{array}{llllll}\text { PS } & 0.30 & 0.34 & 0.44 & 0.69 & 1.00\end{array}$

$\begin{array}{llllll}\text { EXPRE }-0.27 & -0.30 & -0.39 & -0.49 & -0.51 & 1.00\end{array}$

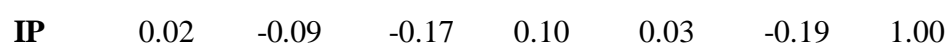

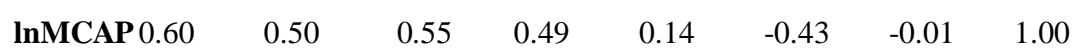

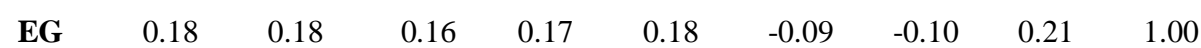

$\begin{array}{lllllllllll}\text { TOP } & -0.02 & -0.03 & 0.25 & 0.18 & 0.17 & -0.20 & 0.06 & 0.01 & 0.06 & 1.00\end{array}$

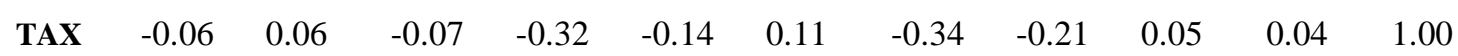

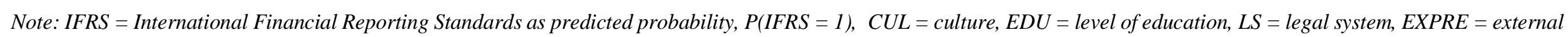

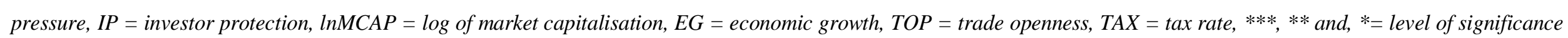
at 1\%, 5\%, and 10\% respectively. (see Chapter 4 for the description and measurement of the variables).

Source: Results generated from data analysis using Stata statistical software package. 


\subsubsection{Logit regression model: determinant factors of IFRS adoption}

The third objective is to estimate the determinant factors that predict the probability of the adoption of IFRS, P(IFRS = 1), in the selected African countries using the logit regression model. For this reason, culture, level of education, the legal system, political system, external pressure, investor protection, market capitalisation, economic growth, trade openness, and corporate tax rate are estimated. They are estimated as explanatory variables using the binary logit regression model to identify their statistical associations concerning the estimated probability of adopting IFRS. Using this regression technique is relevant since the dependent variable, IFRS is measured as a dummy variable. The dummy variable means that ' 1 ' is assigned when a country adopts IFRS and ' 0 ' when a particular country did not adopt IFRS. The main reasons for adopting the logit regression model to achieve objective three are discussed in Section 4.8.8, Chapter 4. Table 5.15 presents the logit regression results.

Table 5.15: Logit regression model results on determinant factors of IFRS

\begin{tabular}{|c|c|c|c|c|c|cc|}
\hline Variable & $\begin{array}{c}\text { Coeffic } \\
\text { ient }\end{array}$ & $\begin{array}{c}\text { Robust } \\
\text { Std. } \\
\text { Error }\end{array}$ & $\begin{array}{c}\text { Z- } \\
\text { Statistics }\end{array}$ & $\begin{array}{c}\text { Prob. P> } \\
|\mathbf{z}|\end{array}$ & $\begin{array}{c}\text { Odds ratio } \\
(\mathbf{O R})\end{array}$ & \multicolumn{2}{|c|}{$\begin{array}{c}\text { [95\% Conf. } \\
\text { Interval] (OR) }\end{array}$} \\
\hline C & -5.23 & 1.86 & -2.80 & $0.01^{* *}$ & 0.01 & 0.00 & 0.21 \\
\hline CUL & 3.31 & 0.47 & 7.07 & $0.00^{* * *}$ & 27.26 & 10.90 & 68.17 \\
\hline EDU & -7.44 & 1.48 & -5.00 & $0.00^{* * *}$ & 0.00 & 0.00 & 0.01 \\
\hline LS & 130.00 & 71.43 & 1.82 & $0.07^{*}$ & $2.87 \mathrm{e}+56$ & 0.00 & $1.9 \mathrm{e}+12$ \\
\hline PS & 107.13 & 53.07 & 2.02 & $0.04^{* *}$ & $3.37 \mathrm{e}+46$ & 22.52 & $5.03 \mathrm{e}+91$ \\
\hline EXPRE & 25.46 & 15.50 & 1.64 & 0.10 & $1.14 \mathrm{e}+11$ & 0.01 & $1.78 \mathrm{e}+24$ \\
\hline IP & 18.25 & 8.75 & 2.09 & $0.04 * *$ & $8.39 \mathrm{e}+07$ & 2.99 & $2.35 \mathrm{e}+15$ \\
\hline lnMCAP & 0.51 & 0.10 & 5.36 & $0.00^{* * *}$ & 1.67 & 1.38 & 2.01 \\
\hline EG & -4.70 & 4.38 & -1.07 & 0.28 & 0.01 & $1.71 \mathrm{e}-06$ & 48.65 \\
\hline TOP & 0.30 & 0.13 & 2.27 & $0.02 * *$ & 1.35 & 1.04 & 1.76 \\
\hline TAX & 9.70 & 3.72 & 2.61 & $0.01 * *$ & 16380.7 & 11.06 & $2.43 \mathrm{e}+07$ \\
\hline
\end{tabular}

$$
\begin{array}{llr}
\text { Wald } \quad X^{2} & \text { Prob }>\text { chi2 } 0.00 & \text { Pseudo } R^{2} 0.56 \\
(10, \mathrm{~N}=385) & & \\
=98.09 & &
\end{array}
$$

Note: $C=$ constants $; C U L=$ culture, $E D U=$ education, $L S=$ legal system, EXPRE = external pressure, $I P=$ investor protection, $\ln M C A P=$ market capitalisation, $E G=$ economic growth, $T O P=$ trade openness, $T A X=$ corporate tax rate, $* * *, * *$ and, $*=$ level of significance at 1\%, 5\%, and $10 \%$ respectively. (see Chapter 4 for the description and measurement of the variables).

Source: Results generated from data analysis using Stata statistical software package (see Appendixes $S$ and T) 
Table 5.15 shows the predicted likelihood of the estimated variables that are statistically significant and positive with IFRS, while others are not. Those variables are culture (CUL), level of education $(E D U)$, the legal system $(L S)$, political system $(P S)$, investor protection $(I P)$, market capitalisation (InMCAP), trade openness (TOP), and corporate tax rate $(T A X)$. It shows that they have substantial effects as determinant factors to predict the probability of adoption of IFRS, P(IFRS = 1), in Africa. At the same time, external pressure $(E X P R E)$ and economic growth $(E G)$ is not statistically significant as factors that determine the probability of IFRS adoption when considering the log of odds and odds ratios in Table 5.15. Whereas Table 5.16 shows that EXPRE is significant but at the 10 per cent level, not highly significant. This finding implies that EG does not in any way influence the probability of the decision to adopt IFRS by these countries.

The estimated regression coefficients (Column 2, Table 5.15) show how the log odds of a determining factor predict the probability of adopting IFRS, P(IFRS = 1), are affected by each variable. Thus, it indicates the change in the logarithmic odds of IFRS for a 1-unit increase in the independent variable. In the case of culture, $C U L$, it has estimated regression coefficient value of 3.31 with the probability value of $0.00(\beta=3.31, \rho \leq 0.01)$, indicating a positive and statistically significant value at a $1 \%$ with a predicted probability of IFRS, P(IFRS $=1)$. This result implies that the log odds of adopting IFRS (versus non-adopting) increases by 3.31 times if the country is Anglo-Saxon, P(IFRS = 1), than non-Anglo-Saxon, holding all other variables constant. The implication of this positive and robust significant level with the probability of IFRS adoption, $\mathrm{P}(\mathrm{IFRS}=1)$, is that the countries based their probability of adopting IFRS on the cultural link. Thus, the likelihood of adopting IFRS is supported by Anglo-Saxon country ( $C U L)$.

Also, the estimated regression coefficient of $E D U$ is negative -7.44 with the probability value of $0.00(\beta=-7.44, \rho \leq 0.01)$, highly significant at a $1 \%$ level with a predicted probability of IFRS adoption, $\mathrm{P}(\mathrm{IFRS}=1)$. This finding implies that $E D U$ as a determinant factor is less likely to predict the probability of adoption of IFRS because it is negative. Thus, the logarithmic odds of adopting IFRS decreases on average by 7.44 if the value of $E D U$ increases by 1-unit. It shows that the level of education, $E D U$, does not predict the probability of IFRS adoption.

Furthermore, the estimated coefficient of $L S$ shows how the log odds of LS, as a determinant factor, predict the probability of adopting IFRS, P(IFRS $=1)$, is affected. $L S$ has an estimated coefficient of 130.00 with a probability value of 0.07 ( $\beta=130.00, \rho \leq 0.10)$. It is significant at a $10 \%$ level with P(IFRS = 1). It shows that the log odds of adopting IFRS rise on average by 130.00 if LS increases by 1-unit. The finding implies that the legal system as a determinant factor influences 
the probability of IFRS adoption, P(IFRS = 1), holding all other variables constant. Besides, the political system, $P S$, has an estimated regression coefficient of 107.13 with a probability value of $0.04(\beta=107.13, \rho \leq 0.05)$. It is significant at a $5 \%$ level. This finding implies that the log odds of adopting IFRS, P(IFRS = 1), rise on average by 107.13 if $P S$ increases by 1-unit. It indicates that $P S$, as a determinant factor, can predict the likelihood of adopting IFRS, P(IFRS = 1). This outcome implies that the possibility to adopt IFRS hinges on the extent of the development of the political system, $P S$, in these countries. As noted in the literature, for proper implementation and accurate disclosure of accounting information, the political and economic terrain of a country must not be unpredictable (Salem et al., 2017).

Investor protection, $I P$, has an estimated coefficient value of 18.24 , with a probability value of $0.04(\beta=18.24, \rho \leq 0.05)$, significant at a $5 \%$ level with $\mathrm{P}(\mathrm{IFRS}=1)$. It shows that the logarithmic odds of adopting IFRS increase on average by 18.24 if $I P$ increases by 1-unit. This finding indicates that $I P$, as a determinant factor, can influence the likelihood of the adoption of IFRS, P(IFRS = 1). This result is in support of the empirical findings of Houqe et al. 2010 that adequate investor protection enhances the increase in the quality of financial statements.

Additionally, market capitalisation $(\ln M C A P)$ has an estimated regression coefficient of 0.51 with the probability value of $0.00(\beta=0.51, \rho \leq 0.01)$, demonstrating that it is highly significant to the predicted probability of IFRS adoption, P(IFRS $=1)$. This positive and significant level indicates the relevance of improved market capitalisation as a factor to determine the probability of the adoption of IFRS. Likewise, the log odds of adopting IFRS increases by 0.51 if $\ln M C A P$ increases by one USD (\$). The improvement in market capitalisation of a country signifies as a determinant factor for the probability of adopting IFRS, P(IFRS =1), This finding might be as a reason that IFRS was developed to cater to the needs of capital market participants (Ben-Othman \& Kossentini, 2015).

Similarly, trade openness (TOP) has an estimated regression coefficient of 0.30 and the probability value of $0.02(\beta=0.30, \rho \leq 0.05)$ indicating a positive and highly significant factor in the predicted probability of IFRS adoption. Also, it makes higher as a determinant factor of the likelihood of adopting IFRS. Furthermore, TAX has estimated coefficient value of 9.71 with the probability value of $0.01(\beta=9.70, \rho \leq 0.05)$. The result shows that $T A X$ is positive and significant with the predicted probability of IFRS adoption, P(IFRS $=1)$. Thus, assume to be a determinant factor that can influence the likelihood of the adoption of IFRS. These findings 
indicate that African countries are assumed to base their decisions on the probability to adopt IFRS on all these factors that are positive and significant in this model.

Another statistical interpretation in terms of the odds ratio (see Table 5.15 and Appendix U2), is presented in the column odds ratios (OR) in Table 5.15. It explains the straightforwardness interpretation in the logit model. It represents the change in odds of being in one of the categories of outcome (IFRS 0,1 ) when the value of a predictor increases by 1 -unit (Tabachnick \& Fidell, 2013:461). To interpret this, the logit IFRS adopt is represented by ' 1 ' while non-adopt is represented by ' 0 ' (as earlier explained in Chapter 4). For this purpose, when the odds ratio is greater than 1, it describes a positive relationship, meaning that as any of the independent variable increases by a unit, the odds ratio of a determinant factor to influence the probability of adoption of IFRS increases in times as likely to adopt IFRS. If the odds ratio of the independent variable decreases, it shows a negative relationship with the probability of adopting IFRS, because an odds ratio, less than 1 indicates that for every increase in a unit of an independent variable there is less likely for the adoption of IFRS. Column 6, Table 5.15, presents the value of the odds ratio for each of the independent variables.

Thus, reflecting on Table 5.15, the independent variables that are positive and significant as determinant factors that can influence the probability of IFRS adoption, P(IFRS $=1$ ), are $C U L$, $L S, P S, I P$, InMCAP, TOP, and TAX. This outcome implies that their odds ratios are greater than 1 (see Column 6). It reveals how many times higher the odds of the probability of IFRS adoption are for each one-unit increase in the independent variable.

For instance, in Table 5.15, the odds ratio of $C U L$ is approximately 27.27 , that is, if $C U L$ is from Anglo-Saxon country, P(IFRS = 1), it is around 27.26 times as likely to adopt IFRS than the nonAnglo-Saxon country, holding all other variables constant in the model. Also, the odds ratio for InMCAP increases by 1.67 times. It is indicating that for a dollar increase in $\ln M C A P$ the probability of IFRS adoption is around 1.67 times against non-adopting IFRS country.

In the case of the estimated odds ratio of $E D U$, it displays an odds ratio of less than 1 . This finding indicates that for every additional level of education attained, the probability of IFRS adoption is 0.01 times less likely to adopt IFRS. Likewise, the odds ratio of TOP is 1.35 times likely higher to adopt IFRS than non-adopting IFRS countries. Furthermore, the estimated odds ratio of $L S, P S$, $I P$, and TAX as determinant factors that can influence the probability of IFRS adoption, P(IFRS = 1), indicates that their individual odds ratios are greater than 1, hence, reporting an increase in the 
probability of adoption of IFRS. Additionally, all these variables are also a significant predictor of the likelihood to determine the probability of adopting IFRS, according to Table 5.15.

On the other hand, the confidence intervals of the odds ratios $(95.0 \% \mathrm{CI})$ for each of the variable is presented in the last column of Table 5.15. It shows the lower and upper values CI. It gives a range of values of 95 per cent confidence as an accurate representation of the actual value of the odds ratios. As displayed in Table 5.15, for example, the confidence interval for CUL (OR = 27.26) ranges from 10.90 to 68.17 . Although the odds ratio indicates 27.26 , there is a confidence that this actual value of OR lies somewhere between the range of 10.90 and 68.17 , which indicates a reasonable wide range of values. Similarly, as shown in Table 5.15, none of the estimated odds ratios indicates a confidence interval of 1 ; hence, the equal likelihood of IFRS adoption and nonadoption does not exist.

Table 5.15 also indicates that EXPRE and $E G$ variables have no individual relationship or significance at any level as factors that determine the probability of adoption of IFRS, P(IFRS = 1), in the selected countries. It shows that the probability to determine the factors that influence the adoption of IFRS is not based on these variables since they are not statistically significant to the probability of IFRS adoption., P(IFRS = 1). This finding means that they did not determine the probability of adoption of IFRS among the selected countries in Africa. Additionally, to further establish the ability of these variables as determinant factors that influence the probability of IFRS adoption, $\mathrm{P}(\mathrm{IFRS}=1)$, the post-estimation result using the average marginal effect is computed and discussed below.

\subsubsection{Post-estimation test, average marginal effect (AME)}

Marginal effects are alternative post estimation approaches by which the probability of variables in the logistic regression model can be made intuitively meaningful. According to Cameron and Trivedi (2010:343), marginal effect measures the effect on the conditional mean of regressand of a change in 1-unit of the regressors. In this situation, it measures the effect on the predicted probability, $\mathrm{P}(\mathrm{IFRS}=1)$, of a change in 1-unit of estimated independent variables. It means that it measures the change in outcome as a function of the change in the independent variable, holding all other results in the model constant.

Marginal effect for the categorical independent variable (i.e. CUL as binary in this current case) shows how the predicted probability, P(IFRS $=1)$, changes as the binary independent variable (i.e. CUL) changes from 0 to 1 , after holding all other variables at their mean in the model constant. 
On the other hand, marginal effects for continuous variables measure the instantaneous rate of change. That is, if the independent variable increases by 1 , then P(IFRS $=1)$ would increase by similar value.

According to Leeper (2017), there are three types of marginal effects: marginal effects at the mean, average marginal effects, and marginal effects at representative values. In the case of marginal effect at means, it calculates the marginal effects of each variable at the means of the covariates. In contrast, average marginal effects calculate marginal effects at every actual observed specific value of independent variable and average across the resulting estimates, that is, variables whose values not otherwise fixed. The marginal effects at representative estimate calculate the marginal effect of each variable at a specific combination of independent variable values.

The average marginal effects are particularly useful since it leads to superior estimates over other types (Cameron \& Trivedi, 2010:343; Leeper, 2017). The authors reported that average marginal effects produce a single quantity summary that reflects the full distribution of independent variables instead of arbitrary prediction. Additionally, it can covey a reasonable amount of information concerning the effect of each covariate on the result, captures variability than marginal effects mean. The marginal effects at means differ with the levels of the covariates; hence it is appropriate to estimate the average of all marginal effects of the independent variables patterns observed in the dataset. Based on the usefulness of average marginal effects over other types, it will be suitable and appropriate to use as a post estimation test in this thesis. Table 5.16 presents the results of average marginal effects.

Table 5.16 shows the dy/dx of average marginal effects, the standard error, the z-statistics, and the probability value of all the estimated variables. dy/dx means the difference in the estimated dependent variable for a change in the explanatory variables. It indicates for each variable (i.e. $C U L, E D U, L S, P S, E X P R E, I P, \ln M C A P, E G, T O P$, and $T A X)$ the likely effect of the average change in regressand $\mathrm{P}(\mathrm{IFRS}=1$ ) when a regressor (as listed) change by 1 -unit. From Table 5.16, all the estimated variables, apart from EG, are significant and likely to predict the factors that determine the adoption of IFRS. This result supports the earlier findings on predicted values (logarithmic odds of IFRS adoption) and odds ratios presented in Table 5.15, where all the estimated variables, apart from $E G$ and EXPRE, are likely to predict the probability of adopting IFRS. In this post-estimation results, EXPRE is however positively significant. 
Furthermore, Column 2, Table 5.16 the first row indicates the effect of how the predicted probability, $\mathrm{P}(\mathrm{IFRS}=1)$, changes as the binary independent variable $C U L$ changes from 0 to 1 , after holding all the other variables constant. Thus, the predicted probability of adopting IFRS increases by 0.29 with $C U L$, regardless of all other variables. It shows that there will be a 29 percentage point increase in the probability of adopting IFRS if the country is Anglo-Saxon. Likewise, the probability of adopting IFRS increases by 11.42, with a 1-unit increase in the value of $L S$. Similarly, the probability of adoption increases by 9.42, with a 1-unit increase in $P S$ and 2.24 with EXPRE, respectively. Also, the probability of adoption increases by 1.60 , with a 1-unit increase in $I P$. While it increases by 0.05 with a 1 -unit increase in $\ln M C A P$. Furthermore, a 1-unit increase in the value of TOP increases the probability of adoption by 0.03 and 0.85 with TAX, respectively. These results indicate the average effect of a 1-unit increase in each of these independent variables as the probability of IFRS adoption, regardless of other values. It shows the higher points of the likelihood of individual estimated independent variable in the probability of adopting IFRS, P(IFRS = 1).

In another vein, for $\ln M C A P$, the probability of adopting IFRS would be 5 percentage points higher if one USD\$ increases the value. In comparison, the TOP as a factor that determines the probability of adopting IFRS would be 3 percentage points higher if the value increases by 1-unit. Similarly, $T A X$ as a determinant factor of the probability of adopting IFRS is 85 percentage points higher if the rate is increased by 1 per cent. Equally, the probability of $L S, P S, E X P R E$, and $I P$ as determinant factors that determine the probability of IFRS adoption increased by more than 100 percentages points higher with a 1-unit increase in their respective value, holding all other variables constant. Thus, as these variables increase, the likelihood of adopting IFRS increases by their respective higher points, meaning that the probability of influencing the adoption of IFRS increases by their higher points.

Considering the average marginal effects of $E D U$ and $E G$ as well, their results give -0.65 and 0.41 respectively. These results indicate that as their value increases the probability of adopting IFRS decreases by 65 percentage points for $E D U$, while that of $E G$ decreases by 41 percentage points. From these results, apart from $E D U$, which is negatively significant, $E G$ has no significant effect as a determining factor that can influence the probability of IFRS adoption in Africa. 
Table 5.16: Post-estimation test results, using average marginal effect (AME)

\begin{tabular}{|c|c|c|c|c|}
\hline Variable & $\mathbf{d y} / \mathbf{d x}$ & $\begin{array}{l}\text { Delta-method } \\
\text { Std. Error }\end{array}$ & Z-Statistics & Prob. P> $|\mathbf{z}|$ \\
\hline CUL & 0.29 & 0.03 & 11.29 & $0.00^{* * *}$ \\
\hline EDU & -0.65 & 0.10 & -6.86 & $0.00^{* * *}$ \\
\hline LS & 11.42 & 6.27 & 1.82 & $0.07^{*}$ \\
\hline PS & 9.42 & 4.26 & 2.21 & $0.03^{* *}$ \\
\hline EXPRE & 2.24 & 1.26 & 1.77 & $0.08^{*}$ \\
\hline IP & 1.60 & 0.72 & 2.23 & $0.03^{* *}$ \\
\hline lnMCAP & 0.05 & 0.01 & 8.03 & $0.00^{* * *}$ \\
\hline EG & -0.41 & 0.38 & -1.08 & 0.28 \\
\hline TOP & 0.03 & 0.01 & 2.24 & $0.03^{* *}$ \\
\hline TAX & 0.85 & 0.30 & 2.83 & $0.02^{* *}$ \\
\hline
\end{tabular}

Note: $C U L=$ culture, $E D U=$ education, $L S=$ legal system, EXPRE = external pressure, IP = investor protection, $\ln M C A P=\log$ of market capitalisation, EG = economic growth, TOP = trade openness, TAX $=$ corporate tax rate, $* * *, * *$ and, * = level of significance at 1\%, 5\%, and 10\% respectively. (see Chapter 4 for the description and measurement of the variables).

Source: Results generated from data analysis using Stata statistical software package (see Appendix U)

\subsubsection{Hypothesis testing: IFRS determinant factors}

The null hypothesis for the third hypothesis was that there is no significant factor/s that influence/s IFRS adoption in African countries. The results from the analyses have shown that the null hypothesis is rejected. Consequently, the alternative hypothesis that there is (are) significant factor (s) that influence the adoption of IFRS in African countries are accepted. The individual estimates of variables such as culture, education, the legal system, political system, investor protection, market capitalisation, and corporate tax rate proved to be significant factors that influenced the adoption of IFRS.

Again, the test of overall significance has shown that all the variables used in the model will jointly and significantly be reliable as likely determinant factors of IFRS adoption. On this note, the null hypothesis is rejected, based on both the z-test probability and log of likelihood ratio chi-square value for the overall significance of the model. As indicated in Table 5.15, the value of the log of likelihood ratio chi-square, is approximately 98.09 , with a ' $p$-value' of 0.00 , thus, rejecting the null hypothesis and accepting the alternative hypothesis that there are determinant factors that influence the likelihood of IFRS adoption in African countries. 


\subsubsection{Discussion of the findings: IFRS determinant factors}

The logistic regression model was estimated to assess the likelihood of estimated variables on the probability that they will determine the adoption of IFRS. The model comprises of 10 independent variables, earlier discussed in Chapter 3, (CUL, EDU, LS, PS, EXPRE, IP, InMCAP, EG, TOP, and $T A X)$. The log-likelihood statistic, which explains the overall significance and strength of the estimated model, shows that all the variables estimated in the model jointly have a significant effect on the likelihood to adopt IFRS. It shows that all predictors were statistically significant to the probability of adopting IFRS, $X^{2}(10, \mathrm{~N}=385)=98.09, \rho \leq .001$, explaining that the model can distinguish between IFRS adopting and non-adopting countries. The model also explains the Pseudo $\mathrm{R}^{2}$ Statistics. That suggests the amount of variation in the dependent variable explained by the model. It shows that 56 per cent of the variability is explained by the set of independent variables in the model.

As revealed in Table 5.15, only eight variables (CUL, EDU, LS, PS, IP, InMCAP, TOP, and TAX) are statistically significant in the model, indicating that they are factors that can predict the probability of adoption of IFRS. Culture (CUL) is a variable in the model that represents individual countries' lineage in terms of colonisation, namely the Anglo-Saxon and non-Anglo-Saxon countries. It is positively and profoundly significantly with the probability to adopt IFRS, as a determining factor that influences the probability of IFRS adoption. It is believed that countries that were colonised by the English tend to embrace IFRS faster than countries that were colonised by the non-English colonial rulers. Results from the estimated logarithmic odds shown that culture is critical in determining the likelihood of the decision to adopt IFRS. The reason behind this might not be unconnected with the fact that IFRS originates from English-speaking countries.

However, this is evident from the first objective as almost $93 \%$ of countries that have substantially adopted IFRS were countries colonised by the British, apart from Mozambique, which was colonised by the Portuguese (see Column A, Table 4.1). This finding corresponds with the outcome from prior studies by Salem et al. (2017) that countries that belong to Anglo-Saxon countries will adopt IFRS more readily than non-Anglo-Saxon countries. This phenomenon is possible because these countries share a specific culture, and they are economically, legally, and politically familiar with each other, especially in terms of language (Salem et al., 2017). The highly significant effect of the culture on IFRS indicates that the countries selected for this analysis chose to adopt IFRS because of their familiarity with their colonial leaders. Besides, the average marginal effect result indicates a 29 percentage points increase as the likelihood of a determinant factor that influences 
the adoption of IFRS if the country is Anglo-Saxon. Besides, all other determinant variables show higher percentage points, therefore, as their value increases the likelihood of adopting IFRS increases, apart from $E D U$ and $E G$ which show a decrease in the probability of IFRS adoption.

The estimated logarithmic of odds of the level of education $(E D U)$ is negatively significant to the probability of IFRS adoption. This finding indicates that the level of education failed to support the adoption of IFRS. This result is in contrary to the earlier studies that examined the determinant factors of IFRS (i.e., Kolsi and Zehri, 2013; Salem et al. 2017; Zeghal and Mhedhbi, 2006) and found that education has a positive and significant link with the adoption of IFRS. It has been emphasised that the adoption and implementation of IFRS need competent professional expertise and accounting researchers to be able to make use of the complex and always changing IFRS, which are very scarce in Africa (Salem et al., 2017). Nonetheless, countries that adopted IFRS in Africa are mostly countries that share similar educational standards with their British Colonialists. The 15 selected adopting countries in this thesis fall into this jurisdiction, hence influenced their decision to adopt.

Similarly, the legal system (LS) estimated logarithmic of odds has a positive and significant value with IFRS. It implies that countries adopt IFRS based on the nature of their legal system. The Anglo-Saxon countries are predominantly using common law. This situation enables them to adopt IFRS. Thus, the 15 selected countries in this thesis are predominantly practising the common law system (also referred to as Anglo-Saxon oriented countries), and this enabled them to adopt IFRS. This result supports the finding from Zehri and Chouaibi (2013) that countries with a common law system have a higher tendency to adopt IFRS.

Also, the political system (PS) estimated logarithmic of odds has a positive and significant link with the probability to adopt IFRS. This outcome indicates that the political system of a country plays a vital role in the likelihood of adoption of IFRS. The higher the level of political freedom, the higher the tendency of adopting IFRS (Kolsi \& Zehri, 2013). It indicates that nearly all 15 countries selected for the analysis operate a democratic system of government, which is considered to be a prerequisite for the development of accounting standards. The finding from this thesis is contrary to the empirical result of Kolsi and Zehri (2013), who found that the political system does not have a significant effect on adopting IFRS. Thus, this finding indicates that 15 selected African countries who mostly share the same political system with their colonialists base their decision to adopt IFRS on the same political system ideology. 
Nevertheless, the significant levels of these variables - CUL, EDU, $L S$, and $P S$ - to the probability of IFRS adoption confirm the bond the selected countries for this thesis have with their past colonial master's power that influences their bids to adopt IFRS. This empirical finding further reveals that the probability of adoption of IFRS by the 15 selected countries in Africa have a connection with what they have inherited from their past colonial leaders. Since these factors that are significant to IFRS have to do with the systems, these countries have inherited from their colonial rulers, and it influenced their decisions to adopt IFRS. This finding is in support of Salem et al. (2017), that adoption and implementation of accounting standards (i.e. IFRS) in the developing countries such as Africa are linked to the inheritance and acceptance of rules and regulations from their colonialists, irrespective of their relevance to their current accounting environments. Similarly, Nobes and Parker (2008:6) state that accounting in developing countries is still strongly influenced by the former colonial British Empire more than any other source.

The results also show the investor protection index $(I P)$ to be another likely critical factor that influences the likelihood of adoption of IFRS in African countries. The estimated logarithmic of odds is positive and significant with IFRS. This result implies that investor protection in these countries offers secure protection for investors, especially in protecting the rights of the investors in the adopting countries. This result indicates that investor protection is likely to predict the determinant factor of IFRS adoption, in which countries base their decision to adopt IFRS. The evidence of a positive and significant relationship of investor protection with IFRS in this analysis supports the findings of Hope et al. (2006), Houqe et al. (2010), and Rahmaningtyas and Mita, (2017) that with the adoption of IFRS, there is the likelihood that it will significantly improve investor protection.

The log odds of market capitalisation (InMCAP), which indicates countries' capital market development, has also been shown by the results as an essential determinant factor that influences the probability of adoption of IFRS. The estimated logarithmic of odds of the InMCAP is positive and statistically significant to the probability of adopting IFRS, indicating that the level of the development recorded by the stock markets of the 15 selected countries forms an essential factor that likely predicts the likelihood of adoption of IFRS. The estimated logarithmic odds imply that the more developed a country's capital market, the higher the tendency to adopt IFRS. This result also confirms the findings of Ball (2016), Elkana (2017), and Jemakowicz and GornikTomaszewski, (2006) that there is a positive relationship between market capitalisation and IFRS since the adoption of IFRS will facilitate the efficient movement of foreign capital to the adopting 
countries. Therefore, the growth of the stock market is very suitable for the adoption of IFRS. The corporate tax rate (TAX) is also positive and statistically significant to IFRS. It implies that countries base their decision to adopt IFRS even on taxation. This finding supports the view of Shima and Yang (2012) that taxation $(T A X)$ is one of the government strategies that can influence the adoption of IFRS.

All other variables, EXPRE and $E G$, apart from the earlier mentioned 8 variables, failed the test of statistical significance when estimating the logarithmic odds and odds ratios in Table 5.15. It shows that individually, these variables EXPRE and EG do not support the adoption of IFRS in African countries, and they are not likely to influence the decision of the probability to adopt IFRS. The finding implies that they are not essential factors that influenced the adoption of IFRS in these countries. Nevertheless, Kolsi and Zehri (2013) find a significant relationship between economic growth and IFRS adoption in their studies, contrary to this finding, which might be due to the different measures adopted. Besides, the outcome from this thesis does not empirically confirm the opinion of Al-Omari (2010), Awuku (2016), and Phan (2014) that the developing countries are prone to external pressure from the various international economic organisations to adopt IFRS. Since the variable EXPRE is not significant to the probability of adopting of IFRS in this model. although it was positive and significant at a 10 per cent (not highly significant) when estimating the average marginal effect as post estimation test (Table 5.16). Nevertheless, the findings show that the estimated determinant variables in the model as a whole fit and worthwhile in predicting the likelihood of adopting IFRS.

\subsection{Summary of the chapter}

The chapter focuses on the presentation of data, analysis, and interpretation of the findings. This section summarises the empirical results from the statistical estimates. The findings addressed the research questions, the hypotheses, and the objectives of the thesis. The descriptive statistics, correlation, and panel data regression analyses were utilised to achieve the objectives of the thesis. Also, the findings from the panel data regression model were used to test the hypotheses. The SGMM was equally estimated to control for the endogeneity and robustness of the empirical findings. Also, the logistic regression model was used to determine factors that influence the probability of adoption of IFRS in Africa.

Additionally, some relevant statistical tests were estimated. For example, the unit root test that checks for the stationarity of the variables and diagnostic test that assesses the validity of the panel 
result estimates were computed. A cross-sectional dependence test that determines whether the pooled regression model would be used for the analysis was estimated. The Hausman test was computed to choose the best alternative between the fixed-effects and random-effects models. The Arellano and Bond tests to determine any serial correlation from the model were used. Similarly, the average marginal effect was computed to establish the ability of the various determinant factors that influence the probability of IFRS adoption, P(IFRS =1). The statistical findings from the estimates are briefly explained in this section.

The descriptive statistics showed an increase in the mean value of lnFPI after the adoption of IFRS compared with inflow before the adoption. Also, it showed impressive findings for covariate's mean values, especially after the adoption. For instance, the rate of inflation was reduced compared to the pre-adoption rate, and the economic growth rate was relatively improved compared to the pre-adoption period. Additionally, the tax rate also witnessed a reduction after the adoption. This outcome may indicate that there was a reduction in the cost of capital after the adoption. Subsequently, the mean value of the regulatory quality and corruption rate improved compared to the pre-adoption period.

A trend analysis was computed. The findings indicate the movements in the FPI of the selected countries before and after the adoption of IFRS. The noticeable common characteristics were the positive improvements in their FPI after the adoption, which is more pronounced in some countries. The correlation coefficient shows that there was no presence of multicollinearity among the estimated variables in the first objective. In the second objective, certain variables were highly correlated, which lead the model to be split into two to address the multicollinearity problem. A positive relationship between IFRS and lnFPI was shown in the first and second objective estimation. It assumes that any country that adopts IFRS is likely to have a positive and direct relationship with the flow of FPI than non-adopting countries.

Furthermore, to address the research questions and the corresponding hypotheses, the panel data regression analysis was used with the REM and the SGMM. The null hypothesis for the first research question was rejected based on the findings from the REM and the SGMM statistical estimators. The coefficient of IFRS variable, IFRSFA, was positively and significantly related to $\operatorname{lnFPI}$ in objective one. Hence, the answer to the first research question is that there was a positive and significant effect on the difference of the FPI inflows after the adoption and implementation of IFRS. 
The null hypothesis for the second research question was rejected. Because the SGMM estimation showed that the IFRS variable, IFRSFA, the coefficient was highly positive and significantly correlated to $\operatorname{lnFPI}$, this shows that: there was a significant effect in the flow of FPI into countries that have adopted IFRS compared to countries that have not adopted IFRS.

The null hypothesis for the third research question was rejected. Because the logit regression model showed that culture, the legal system, political system, investor protection, market capitalisation, and corporate tax rate have significant positive effects and influenced the probability of adopting IFRS in these countries. Therefore, the answer to this research question was that: there were factors that influenced the probability of adoption of IFRS in the selected African countries.

The findings from the various statistical estimates showed that the objectives of the thesis had been achieved. The outcomes addressed the research questions and formulated hypotheses. All the corresponding alternative hypotheses were accepted, and the null hypotheses rejected according to the findings from the statistical estimates employed. The next chapter, Chapter 6 , discusses the overall summary, conclusion, and recommendations of the thesis. 


\section{CHAPTER SIX: CONCLUSION AND RECOMMENDATIONS}

\subsection{Introduction}

The previous chapter focused on data analysis and interpretation and offered a discussion of the findings based on the results and concerning the research objectives. This final chapter gives a summary of the overall thesis. It highlights the main principles in each of the previous chapters. It also discusses the empirical findings, conclusion and limitations of the research. Additionally, the chapter offers recommendations that may be useful for policymaking and future research.

The most prevailing challenge confronting countries today is the problem of the effective mobilisation of foreign investments for sustainable economic development (Sarno et al., 2016). Gordon et al. (2012) reported that researchers have not been able to successfully determine factors that may effectively influence the inflow of foreign investments. For this reason, the proponents of IFRS assumed that the development of a single set of accounting standards, as opposed to unfamiliar national accounting standards, can be an important additional determining factor that may influence the inflow of FPI.

Before the development of IFRS, each country used its national accounting standards framework for the preparation of financial statements. This practice of using national accounting standards caused considerable variation and made financial statements incomparable and unfamiliar with other similar companies worldwide. These practices eventually constrained the inflow of foreign investments by restricting the decisions of capital market participants.

With the development of IFRS, the prospect was that it would improve the quality of financial statement so that it would be more transparent, reliable, and comparable with other similar listed companies globally. Thus, the adoption of IFRS was aimed at eliminating any barriers to crossborder investment globally, which would, in turn, influence the inflow of FPI and enhance economic growth. Based on these assertions, this thesis examined the link between the adoption of IFRS and FPI.

According to Ball (2016), a small proportion of the existing literature examines the relationship between IFRS and FPI. Thus, it remains unclear whether the adoption of IFRS facilitates a significant increase in foreign investment, especially in Africa. Amiram (2012) observed that there is little information on how the globalisation of accounting information affects FPI decisions. Moreover, most existing studies focused mainly on developed economies, with very few studies 
in Africa. Also, most of the previous empirical findings revealed inconsistent results. The literature suggests that the effect of IFRS adoption on FPI in Africa is still uncertain. The effect of IFRS on the inflow of FPI as a mean to facilitate effective mobilisation of foreign capital for sustainable economic growth was, therefore, the focus of this thesis.

\subsubsection{The purpose of the study: revisiting the research questions and objectives}

The research questions that guided this thesis are re-stated below:

(i) What is the significant difference in FPI inflows between before and after the adoption of IFRS among adopting IFRS countries in Africa?

(ii) To what extent is the magnitude of the significant difference in FPI inflows among countries that adopted IFRS and countries that did not adopt IFRS in Africa?

(iii) What factors predict the probability of adoption of IFRS in Africa?

To address the stated research questions and to statistically test the formulated hypotheses discussed in Chapter 1, the objectives were:

(i) examine the significant difference in FPI inflows in IFRS adopting countries in Africa by comparing the situation before and after the adoption;

(ii) investigate the significant difference in FPI inflows among IFRS adopting countries and nonadopting IFRS countries in Africa;

(iii) examine the factors that predict the probability of adoption of IFRS in Africa.

\subsection{Structure of the thesis}

In order to accomplish the objectives of this thesis, the research was divided into six chapters. The first chapter provided the foundation for the thesis by introducing the topic. The chapter then identified and discussed the research problem. The problem of the unknown and uncertain effect of IFRS adoption on FPI in Africa motivated this research. The IASB developed IFRS, and many countries worldwide have adopted it, including some African countries. However, the effect of its adoption on FPI has not been explored, especially in the African context, even though the primary purpose of developing IFRS was to cater to the needs of capital markets participants internationally. Thus, this development indicated that there is a dearth of the existing literature on 
the effect of the adoption of IFRS on FPI in Africa. Based on the identified research problem, this thesis aimed to address the problem, with the primary and secondary objectives, as mentioned in Chapter 1 of the thesis and re-stated above. The hypotheses that are relevant to the objectives were also included in Chapter 1.

The second and third chapters focused on the background of the thesis by reviewing the existing literature. In particular, Chapter 2 reviewed the relevant literature that buttresses the issues relating to foreign portfolio investments. It explained the various concepts of FPI and reviewed the existing literature on the trends of FPI, including the relevant theories of FPI, as well as some of the identified factors that can influence foreign investments in Africa. Similarly, Chapter 3 discussed the extant literature on various issues pertinent to IFRS worldwide, such as the history of accounting standards. Also, the relevant theories of accounting information were discussed. In addition, the empirical association between FPI and IFRS was also discussed. Furthermore, the chapter reviewed the literature on various factors that may influence the adoption of IFRS in Africa.

Chapter 4 discussed the research design and methodology for the thesis based on the research design by Saunders et al. (2012:128). The chapter also elucidated the philosophical assumptions used as the lens through which the researcher views and interprets the world. The ontology relevant to this thesis was positivism, which lends itself to deductive reasoning. The logic combines precise observations and explanations of how the variables, FPI, and IFRS, in addition to the covariates employed interact with each other to show the results using a quantitative research methodology.

The thesis was built on deductive reasoning with the primary focus of testing existing theories and formulating hypotheses. The chapter, therefore, also discussed five theoretical concepts that are relevant to accounting information. They are the agency theory, the decision-usefulness theory, the institutional theory, the information asymmetry theory, and lastly, the stakeholder theory. The importance of each of these theories was discussed in Chapter 4. While the decision-usefulness approach was adopted as the most appropriate and relevant theory for the thesis.

Quantitative research was adopted as the most suitable methodological approach (Creswell, 2014:29). Since this thesis investigated the effect of the adoption of IFRS on FPI, quantitative research was considered relevant. Furthermore, as discussed in Chapter 4, quantitative analysis is related to positivism. For this reason, secondary data were sourced from the IMF database, the IAS website, BoP/IIP, WGI, and the World Bank, among others, for the adopting and non-adopting 
countries. These data helped with the estimation process to achieve the objectives of the thesis. The data were presented, analysed and interpreted using the panel data regression model (pooled regression model, fixed-effects model, random-effects model, and system generalised method of moments) to address the research questions, to test the hypotheses, and to achieve the objective of the study. Besides, the system generalised method of moments was also employed as a check for the endogeneity in the models. Equally, the logistic regression model was used to estimate the factors that predict the likelihood of IFRS adoption. The estimated models included some covariates as control variables and as benchmark factors that assumed to influence FPI without IFRS adoption. The assumption was that these control variables might have an effect on FPI and equally affect the interpretation of the findings.

Chapter 5 presented the empirical analyses and the results by considering each of the objectives of the thesis. Also, the research questions and hypotheses were discussed to determine whether the results meet the set objectives. Consequently, all the alternative hypotheses were accepted, and the null hypotheses were rejected based on the findings from the estimates. The results revealed that the adoption of IFRS has a significant positive effect on the FPI of the adopting countries. The last chapter, which is the concluding chapter, addresses the conclusion and recommendations.

\subsection{Summary of the findings}

This section paraphrases the results of this thesis as a summary. The empirical findings from this research can stimulate specific policy-making processes, especially accounting stakeholders and regulators of accounting standards, as well as researchers in the accounting field. The findings of this thesis are as follows:

(i) Firstly, the findings showed a significant and positive increase in the volume of FPI inflows after the adoption of IFRS compares with before the adoption. Also, the statistical techniques utilised, to estimate the effect of IFRS adoption on FPI, indicated a significant and positive relationship between IFRS adoption and FPI after the adoption of IFRS in adopting countries. The findings indicated a high level of relevance of the unified accounting standard as a significant driver of FPI in adopting countries.

(ii) Secondly, the findings showed a significant and positive relationship between IFRS adoption and FPI in IFRS adopting countries, and it showed that IFRS adoption variable positively and significantly improves the flows of FPI in adopting countries as against the non-adopting IFRS countries. 
(iii) Further, the findings indicated that culture, the legal system, political system, investor protection, market capitalisation, trade operation, and corporate tax rate are all positive and significant factors that predict the likelihood of adoption of IFRS in African countries. While the level of education was significant and negative, it implies that the level of education does not support the probability of IFRS adoption in Africa. This finding is vital for heterogeneity in African countries' decisions to adopt IFRS.

\subsubsection{Positioning the findings against the background of the appropriate theory}

This thesis employed deductive reasoning to test the existing theories and formulate the hypotheses. The significant accounting information theories were discussed in Chapter 4 to identify the most relevant theory for this thesis. The major theories include the agency theory, the decision-usefulness theory, the institutional theory, the information asymmetry theory, and the stakeholder theory. The decision-usefulness theory was found to be a more dominant theoretical framework for this thesis. The decision-usefulness theory has also been applied in previous studies, as discussed in Chapter 4, together with other identified theories.

According to AAA (1966) and Chambers (1955), the theory is premised on the assumption that there is an information provision system that serves as a basis for taking economic and investment decisions. The information must be able to predict the alternative approaches of interest to the users, especially the capital providers. The theory emphasises that the information must be credible and should serve as a benchmark for any investment decision to reduce any information obstacles.

Subsequently, the adoption of IFRS is assumed to be an informational change that would eliminate information barriers facing the users of financial statements. Thus, the development of IFRS is aimed at improving the usefulness of financial reporting by facilitating the comparability and reliability of financial information worldwide (Kribat, 2009; Kimeli, 2017; Mardini, 2012). Based on the decision-usefulness theory, it can be inferred that after the adoption and implementation of IFRS, there would be a significant and positive increase in the inflow of FPI. Since the adoption of IFRS is assumed to enhance the usefulness of accounting information by making it more reliable, transparent, comparable and credible. These findings will influence the foreign investors to shift their capital to such an economy, consequently increasing the inflow of FPI.

The findings of this thesis correspond with the expectations of the decision-usefulness theory. The thesis found that the adoption of IFRS has a significant and positive effect on FPI inflows. In terms of the significant difference in FPI between before and after the adoption. Furthermore, when 
comparing the inflows of FPI between IFRS adopting and non-adopting countries, the findings revealed that countries that have adopted IFRS have a significant and positive association with FPI. This shows how the application of IFRS makes available reliable information for investors. The findings of this thesis, therefore, corroborate the decision-usefulness theory. Previous studies that have examined the effect of IFRS on FPI such as Aharony et al. (2010); Amiram (2012); Beneish et al. (2015); Chen et al. (2016), and Taiwo and Adejare (2014) conclude that the adoption of IFRS has a positive and significant effect on FPI since the financial statements are more reliable and useful for decision making. The empirical findings from this thesis are consistent with these findings.

\subsection{Research contributions}

This research contributes both theoretically and empirically to the existing literature on the effect of IFRS adoption on the inflow of FPI in African countries. The research showed the extent to which IFRS adoption provides truthful accounting information and useful, reliable financial reporting for the investment decision process. The thesis provided more proof that IFRS adoption positively and significantly influences the inflow of FPI. This advances the scope of knowledge that examines the nexus between IFRS and FPI.

Most of the previous studies examined the association between IFRS and FPI in advanced economies. Their findings may not reflect the specific situation in Africa. As far as is known to the researcher, this study is the first to investigate the effect of IFRS adoption on FPI in the African context. It contributes to the efficacy of the adoption of a single set of accounting standards in Africa. Considering the number of years for which data were collected (11-year before and 11year after the adoption of IFRS) together with the panel data regression models employed, the research contributes meaningfully to the body of existing literature.

This research made use of positivism as a philosophical assumption and deductive logic, which is aimed at the testing theory and formulating hypotheses. The theory was tested empirically based on the data collected from selected adopting and non-adopting countries in Africa. The findings validate the assumption of the theory that effective accounting standards provide useful information to investors for the investment decision process. This implies that IFRS provides optimal useful accounting information to users, which encourages them to move their capital to the adopting countries. The findings confirm this since it reveals a positive and significant 
relationship between IFRS and FPI in adopting countries. This result suggests that the theory can be applied to underpinning accounting information research.

\subsection{Policy recommendations}

The findings from this empirical research showed that countries that have adopted IFRS have a significant and positive relationship to the inflow of FPI. This visible result has consequences for policymakers. For this purpose, the following policy recommendations are suggested: First, policymakers such as standard setters and market regulators in non-adopting countries should consider the mandatory adoption of IFRS to improve the quality of accounting information.

Secondly, IFRS are developed purposely to meet the needs of capital market participants, but the findings of this research indicate that the market capitalisation variable is not significant to FPI. Thus, the capital markets should be developed as prerequisite and aid for improving the market capitalisation value of listed firms to enhance the benefits from IFRS adoption.

Thirdly, the findings showed a positive and significant link between IFRS and FPI in adopting countries. In order to sustain this development, this thesis recommends that countries should put all the mechanisms in place to monitor compliance with all the principles relating to IFRS requirements as specified by the Securities Exchange Commission (SEC). The findings from this thesis would be of significance to academics, various countries' regulators and accounting standard setters, especially in the non-adopting countries who may deem it fit to migrate to full adoption of IFRS in the near future.

\subsection{Limitations}

As with all empirical studies, this thesis has specific that should be acknowledged. First, the number of countries selected for the thesis may be a cause of concern. Only countries that have relevant and complete data, specifically for both dependent and independent variables, were used for the analysis. Despite this concern, this thesis included more countries than most other studies. Second, the findings may be different if dependent and explanatory variables are measured differently. Third, despite the consideration of some control variables in this thesis, other additional covariate variables identified in the literature that may affect FPI were not considered.

Fourth, the data for this thesis were exclusively secondary, which does not involve humans or other living beings. This approach is the dominant mode of investigating cross-sectional and time- 
series analyses data. The limitation is the authenticity and reliability of the data collected since they were not collected by the researcher, but by other recognised entities. In order to solve this problem, data were sourced from various databases of globally recognised agencies. Fifth, the period for this thesis was restricted to 1994-2015, consisting of two periods, before (1994-2004) and after (2005-2015) the adoption of IFRS.

Sixth, the research used FPI as the contextual focus, so there are other stakeholders whose decision making is also centred on accounting information. Thus, findings relating to the contextual focus may not generally apply to other users.

Despite all the limitations discussed above, the thesis provides a valuable theoretical framework to examine the effect of the adoption of IFRS on FPI in Africa. The thesis also provides findings that may be of relevance to policymakers and researchers.

\subsection{Suggestions for future research}

More research is warranted in suggested areas to complement these research findings and conclusions. Further research could reveal more information about the advantages and drawbacks of IFRS as an input that informs the investment and economic decision-making process.

Future research on the same topic but using a qualitative research approach, such as case studies, could also be helpful. Interviewing practitioners who have practical and first-hand experience, knowledge, and understanding of IFRS applications can, for instance, offer new insights. Research that investigates the effect on both developed and developing countries is also recommended. The outcome will likely produce more stimulating results since a particular country's environmental factors are essential when considering the implementation of any new accounting system such as IFRS.

This thesis focused on IFRS and FPI at the country level. Future researchers can further investigate the effect of IFRS on other background issues such as the links between IFRS and the reliability of accounting information, impairment of financial comparability and transparency at the firm level, and the level of compliance of IFRS by the listed firms. The findings could reveal the extent of the strengths and weaknesses of IFRS, which could, in turn, help determine whether the envisaged benefits have been accomplished or not. 
Since this research focused on the country level, it is pertinent to extend future studies to the levels of compliance with IFRS at the firm level. The findings could reveal the extent to which firms comply with IFRS and offer suggestions for the government policy structure. This can help the country achieve total compliance by the firms to ensure the achievement of IFRS benefits in terms of more inflow of FPI.

\subsection{General conclusion}

The adoption of IFRS as a framework for financial reporting is a significant development globally as it offers a uniform set of international accounting regulations that enhance the quality of accounting information. Using the panel data regression model involving two groups of countries, those who adopted and those who did not the thesis asserts that IFRS adoption is statistically significant and has a positive relationship with FPI in the adopting countries. Similarly, some estimated determinant factors were found to influence the adoption of IFRS in this research, which assisted in making inferences for countries that have not adopted IFRS. These findings indicated that the thesis achieved its goal of confirming the effect of adopting IFRS in influencing FPI. The findings of this study contribute to the existing literature that substantiates the positive and significant relationship between the adoption of IFRS and FPI in adopting countries. 


\section{REFERENCES}

Abiola, J. 2013. The impact of information and communication technology on internal control's prevention and detection of fraud. Leicester, UK: De Montfort University. (Thesis - PhD).

Ackerloff, G. 1970. The market for lemons: quality uncertainty and the market mechanism. Quarterly journal of economics, 84(3):488-500.

Adebimpe, O. \& Ekwere, R. 2015. IFRS adoption and value relevance of financial statements of Nigerian listed banks. International journal of finance and accounting, 4(1):1-7.

Adebowale, O. \& Lawson, D. 2018. How does access to formal finance affect household welfare dynamics? Micro evidence from Nigeria. GDI Working Paper No. 2018-024. Manchester: The University of Manchester.

http://hummedia.manchester.ac.uk/institutes/gdi/publications/workingpapers/GDI/GDI_WP2018 024_Adebowale_Lawson.pdf Date of access: 10 Jan. 2019.

Adetula, D.T., Nwobu, O. \& Owolabi, F. 2014. International financial reporting standards and foreign direct investment in Nigeria. International journal of commerce, business and management, 3(3):446-449.

AfDB/ASEA (African Development Bank/African Securities Exchanges Association). 2016. Memorandum of understanding to join forces to develop Africa's capital markets. https://africanexchanges.org/sites/default/files/

afdb_and_asea_sign_memorandum_of_understanding_to_join_forces_to.pdf Date of access: 12 Aug. 2017.

AEO (African Economic Outlook). 2017. Entrepreneurship and industrialisation. Paris: OECD, http://dx.doi.org/10.1787/aeo-2017-en Date of access: 20 March 2018.

Agarwal, R.N. 1997. Foreign portfolio investment in some developing countries: a study of determinants and macroeconomic impact. Indian economic review: 217-229.

Agenor, P.R. 1998. The surge in capital flows: analysis of 'pull' and 'push' factors. International journal of finance and economics, 3(1):39-57.

Agyapong, D. 2014. Stock market integration in West African monetary zone: a linear and nonlinear cointegration approach. Asian economic and financial review, 4(5):563-587.

Aharony, J., Barniv, R. \& Falk, H. 2010. The impact of mandatory IFRS adoption on equity valuation of accounting numbers for security investors in the EU. European accounting review, 19(3):535-578.

Ahmad, F., Draz, M.U. \& Yang, S.C. 2016. Foreign portfolio inflows and economic growth: evidence from ASEAN5. Actual problems of economics, 179(5):57-69.

Ahmad, F., Yang, S.C. \& Draz, M.U. 2015. Causality between foreign portfolio inflows and economic growth: evidence from china and India. International journal of economics and finance, 7(10):163-172. 
Ahmed, A.S. \& Duellman, S. 2011. Evidence on the role of accounting conservatism in monitoring managers' investment decisions. Accounting and finance, 51(3):609-633.

Ahmed, A.S., Neel, M. \& Wang, D. 2013. Does mandatory adoption of IFRS improve accounting quality? Preliminary evidence. Contemporary accounting research, 30(4):1344-1372.

Ahmed, S. \& Zlate, A. 2014. Capital flows to emerging market economies: a brave new world? Journal of international money and finance, 48:221-248.

Ajayi, S.I. 2006. Foreign direct investment in Sub-Saharan Africa: origins, targets, impact and potential. Nairobi: African Economic Research Consortium. www.oecd.org/trade Date of access: 16 Aug. 2018.

Akerlof, G.A. 1970. The market for "lemons": quality uncertainty and the market mechanism. The quarterly journal of economics, 84(3):488-500.

Alchian, A.A. \& Demsetz, H. 1972. Production, information costs, and economic organization. The American economic review, 62(5):777-795.

Aldemir, C. \& Uysal, T.U. 2017. Public accounting reform from institutional theory perspectives: case of Turkey. Accounting and corporate reporting: 277-293.

Alderighi, S., Cleary, S. \& Varanasi, P. 2018. The determinants of cross-border portfolio equity flows: new evidence from emerging markets. http://repository.essex.ac.uk/id/eprint/23310 Date of access: 12 September 2019

Alexander, D., Le Manh-Béna, A. \& Ramond, O. 2013. Can the conceptual framework be all things to all (wo) men? Comptabilité sans Frontières. The French Connection, Canada. https://hal.archives-ouvertes.fr/hal-00991959 Date of access: 12 July 2018.

Alise, M.A. \& Teddlie, C. 2010. A continuation of the paradigm wars? Prevalence rates of methodological approaches across the social/behavioral sciences. Journal of mixed methods research, 4(2):103-126.

Al-Omari, A.M. 2010. The institutional framework of financial reporting in Jordan. European journal of economics, finance and administrative sciences, 22(1):32-50.

Alvi, M.H. 2016. A manual for selecting sampling techniques in research. Pakistan: University of Karachi. mpra.ub.uni-muenchen.de Date of access: 10 Oct. 2018.

AAA (American Accounting Association). 1966. Report of committee on a statement of basic accounting theory (ASOBAT). Sarasota, Fla: American Accounting Association.

Amaya, C.A. \& Rowland, P. 2004. Determinants of investment flows into emerging markets. Borradores de Economía; 313.

http://repositorio.banrep.gov.co/bitstream/handle/20.500.12134/5331/BORRADOR\%20313.pdf? sequence=1 Date of access: 15 Nov. 2017.

Amiram, D. 2012. Financial information globalization and foreign investment decisions. Journal of international accounting research, 11(2):57-81. 
Amiram D. \& Frank, M.M. 2015. Foreign portfolio investment and shareholder dividend taxes. The accounting review, 91(3):717-740.

Ankarath, N., Mehta, K.J., Ghosh, T. \& Alkafaji, Y.A. 2010. Understanding IFRS fundamentals: international financial reporting standards. New Jersey: John Wiley \& Sons.

Anyanwu, J. C. \& Erhijakpor, A. E. 2004. Trends and determinants of foreign direct investment in Africa. West African journal of monetary and economic integration, 2(2):21-44.

Anyanwu, J.C. \& Yameogo, N.D. 2015. What drives foreign direct investments into West Africa? an empirical investigation. African development review, 27(3):199-215.

Arellano, M. \& Bond, S. 1991. Some tests of specification for panel data: Monte Carlo evidence and an application to employment equations. The review of economic studies, 58(2):277-297.

Arellano, M. \& Bover, O. 1995. Another look at the instrumental variable estimation of errorcomponents models. Journal of econometrics, 68(1):29-51.

Arias-Rodríguez, F., Delgado, D., Parra-Amado, D., Rincón-Castro, H., Rincón-Castro, H. \& Parra-Amado, D. 2016. Gross capital flows and their long-term determinants for developing economies: a panel co-integration approach. Borradores de economía; No. 932.

Armstrong, C.M., Barth, A.J. \& Riedl, E. 2010. Market reaction to the adoption of IFRS in Europe. The accounting review, 85:31-61.

Armstrong, M.S. 1977. The politics of establishing accounting standards. Journal of accountancy (pre-1986), 143(000002):76-79.

Ariyo, A. (2007). Accounting predictions and corporate performance in Nigeria. Ogere, Ogun State, Nigeria: Zaac Ososanya Trust Funds.

Ary, D., Jacobs, L.C., Irvine, C.K.S. \& Walker, D. 2018. Introduction to research in education. Boston: Cengage Learning.

Asfaw, H. 2015. Trade policy and economic growth in Sub-Saharan Africa: a panel data approach. American journal of trade and policy, 2(1):7-14.

Asiamah, M., Ofori, D. \& Afful, J. 2019. Analysis of the determinants of foreign direct investment in Ghana. Journal of Asian business and economic studies, 26(1):56-75.

Asiedu, E. 2006. Foreign direct investment in Africa: the role of natural resources, market size, government policy, institutions and political instability. World economy, 29(1):63-77.

Asiedu, E. \& Lien, D. 2004. Capital controls and foreign direct investment. World development, 32(3):479-490.

Asiemo, P. 2013. Managing the challenges of IFRS transition: an operator's perspective. The Institute of Chartered Accountants of Nigeria: 1-19.

http://www.icanig.org/documents/challenges-of-ifrs-adoption-ican.pdf Date of access: 13 March 2019. 
Assenso-Okofo, O., Ali, M.J. \& Ahmed, K. 2011. The development of accounting and reporting in Ghana. The international journal of accounting, 46(4):459-480.

Attar, P.K. \& Temel, A. 2002. Modelling private manufacturing investment in Turkey. METU studies in development, 29(1):109-122.

Auronen, L. 2003. Asymmetric information: theory and applications. Paper presented in the Seminar of Strategy and International Business as Helsinki University of Technology, 21 May. http://citeseerx.ist.psu.edu/viewdoc/download?doi=10.1.1.198.9252\&rep=rep1\&type=pdf Date of access: 21 Jan. 2018.

Awuku, A.A. 2016. IFRS adoption: costs and benefits for companies listed on Ghana club 100. Kumasi, Ghana: KNUST. (Dissertation - PhD).

AyodeleFolorunso, B., Ogunleye, A.G. \& Akanbi, B.L. 2019. Dynamic interactions among trade openness, foreign private capital inflows and economic growth in Nigeria (1970-2014). Journal of economics, 7(1):10-24.

Azam, M. \& Ahmad, S.A. 2013. The effects of corruption on foreign direct investment inflows: some empirical evidence from less developed countries. Journal of applied sciences research, 9(6):3462-3467.

Aziz, B., Anwar, Z. \& Shawnawaz, S. 2015. Determinants of foreign portfolio investment (FPI): empirical evidence from Pakistan. Asian journal of educational research and technology, 5(2):161-169.

Bajpai, N. 2009. Business statistics. India: Pearson.

Bakre, O.M. 2008. Financial reporting as technology that supports and sustains imperial expansion, maintenance and control in the colonial and post-colonial globalisation: the case of the Jamaican economy. Critical perspectives on accounting, 19(4):487-522.

Ball, R. 2001. Infrastructure requirements for an economically efficient system of public financial reporting and disclosure. Brookings-Wharton papers on financial services, 2001(1):127-169.

Ball, R. 2006. International Financial Reporting Standards (IFRS): pros and cons for investors. Accounting and business research, 36(sup1):5-27.

Ball, R. 2016. IFRS - 10 years later. Accounting and business research, 46(5):545-571.

Baltagi, B. 2008. Econometric analysis of panel data. 4th ed. New Jersey: John Wiley \& Sons.

Bardhan, P. 1997. Corruption and development: a review of issues. Journal of economic literature, 35(3):1320-1346.

Bartels, F.L., Napolitano, F. \& Tissi, N.E. 2014. FDI in Sub-Saharan Africa: a longitudinal perspective on location-specific factors (2003-2010). International business review, 23(3):516529.

Bartram, S.M. \& Dufey, G. 2001. International portfolio investment: theory, evidence, and institutional framework. Financial markets, institutions and instruments, 10(3):85-155. 
Basu, M.A. \& Srinivasan, M.K. 2002. Foreign direct investment in Africa: some case studies. IMF Working Papers No. 02/61. Washington, D.C: International Monetary Fund.

Beiske, B. 2007. Research methods: uses and limitations of questionnaires, interviews, and case studies. Munich: GRIN Verlag, BoD-Books on Demand.

www.grin.com/document/15458 Date of access: 13 Jan. 2019.

Bekaert, G. 1995. Market integration and investment barriers in emerging equity markets. The World Bank economic review, 9(1):75-107.

Belke, A. \& Volz, U. 2019. Flows to emerging market and developing economies-global liquidity and uncertainty versus country-specific pull factors. Review of development finance, 9(1):32-50.

Beneish, M.D., Miller, B.P. \& Yohn, T.L. 2015. Macroeconomic evidence on the impact of mandatory IFRS adoption on equity and debt markets. Journal of accounting and public policy, 34(1):1-27.

Ben-Othman, H. \& Kossentini, A. 2015. IFRS adoption strategies and theories of economic development: effects on the development of emerging stock markets. Journal of accounting in emerging economies, 5(1):70-121.

Bevan, A.A. \& Estrin, S. 2004. The determinants of foreign direct investment into European transition economies. Journal of comparative economics, 32(4):775-787.

Bhat, G., Callen, J.L. \& Segal, D. 2014. Credit risk and IFRS: the case of credit default swaps. Journal of accounting, auditing \& finance, 29(2):129-162.

Bilgic, F. \& Ibis, C. 2013. Effects of new financial reporting standards on value relevance: a study about Turkish stock markets. International journal of economics and finance, 5(10):126140.

Bisman, J. 2010. Postpositivism and accounting research: a (personal) primer on critical realism. Australasian accounting business and finance journal, 4(4):3-25.

Bissoon, O. 2011. Can better institutions attract more foreign direct investment (FDI)?

Evidence from developing countries. (In. International Conference on Applied Economics, 59-70.)

Bleaney, M. \& Greenaway, D. 2001. The impact of terms of trade and real exchange rate volatility on investment and growth in sub-Saharan Africa. Journal of development economics, 65(2):491500 .

Bless, C., Higson-Smith, C. \& Kagee, A. 2006. Fundamentals of social research methods: An African perspective. Cape Town, South Africa: Juta.

Blonigen, B.A. 2005. A review of the empirical literature on FDI determinants. Atlantic economic journal, 33(4):383-403.

Blundell, R. \& Bond, S. 2000. GMM estimation with persistent panel data: an application to production functions. Econometric reviews, 19(3):321-340. 
Bonga-Bonga, L. \& Kinfack, E. 2019. The growth effect of trade openness on African countries: evidence from using an Instrumental Variable Panel Smooth Transition Model. MPRA Paper No. 92111. https://mpra.ub.uni-muenchen.de/92111/ Date of access: 12 June 2019.

Boolaky, P.K. 2012. Accounting development and international financial reporting standards in small island economies: the case of Mauritius between 1960 and 2008. Journal of accounting in emerging economies, 2(1):4-29.

Bova, F. \& Pereira, R. 2012. The determinants and consequences of heterogeneous IFRS compliance levels following mandatory IFRS adoption: evidence from a developing country. Journal of international accounting research, 11(1):83-111.

Brahmasrene, T. \& Komain, J. 2001. Foreign direct investment in Thailand, what factors matter. Proceedings of the academy for international business, 1(2):13.

Breusch T, \& Pagan, A. 1979. A simple test for heterosckedasticity and random coefficient variation. Eeonometriea, 47:1287-1294.

Brignall, S. \& Modell, S. 2000. An institutional perspective on performance measurement and management in the 'new public sector. Management accounting research, 11(3):281-306.

Brink, H., Van der Walt, C. \& Van Rensburg, G. 2006. Fundamentals of research methodology for health care professionals. Cape Town: Juta.

Brink, N. \& Viviers, W. 2003. Obstacles in attracting increased portfolio investment into Southern Africa. Development Southern Africa, 20(2):213-236.

Broadbent, J., Jacobs, K. \& Laughlin, R. 2001. Organisational resistance strategies to unwanted accounting and finance changes: the case of general medical practice in the UK. Accounting, auditing and accountability journal, 14(5):565-586.

Brooks, C. 2014. Introductory econometrics for finance. 2nd ed. New York, USA: Cambridge University Press.

Brown, P. 2011. International Financial Reporting Standards: what are the benefits? Accounting and business research, 41(3):269-285.

Brown, P. \& Tarca, A. 2012. Ten years of IFRS: practitioners' comments and suggestions for research. Australian accounting review, 22(4):319-330.

Brüggemann, U. 2011. Essays on the economic consequences of mandatory IFRS reporting around the world. Cologne, Germany: Universität zu Köln. (Dissertation - PhD).

Brüggemann, U., Hitz, J.M. \& Sellhorn, T. 2013. Intended and unintended consequences of mandatory IFRS adoption: a review of extant evidence and suggestions for future research. European accounting review, 22(1):1-37.

Bryman, A. \& Bell, E. 2015. Business research methods. 5th ed. New York, USA: Oxford University Press. 
Buckley, P.J., Forsans, N. \& Munjal, S. 2014. The multinational enterprise and the emergence of the global factory. England, UK: Palgrave Macmillan.

Bughin, J. \& Chui, M. 2013. Evolution of the networked enterprise: McKinsey global survey results. McKinsey Quarterly, 29(Spring).

https://www.nextlearning.nl/wp-content/uploads/sites/11/2015/02/McKinsey-on-Impact-socialtechnologies.pdf Date of access: 25 May 2017.

Buys, P., Deichmann, U. \& Wheeler, D. 2010. Road network upgrading and overland trade expansion in sub-Saharan Africa. Journal of African economies, 19(3):399-432.

Cairns, D. 2001. The conceptual framework - the international experience. https://ssrn.com/abstract=2379002 Date of access: 28 Sep. 2018.

Cairns, D., Massoudi, D., Taplin, R. \& Tarca, A. 2011. IFRS fair value measurement and accounting policy choice in the United Kingdom and Australia. The British accounting review, 43(1):1-21.

Calvo, G.A., Leiderman, L. \& Reinhart, C.M. 1996. Inflows of capital to developing countries in the 1990s. The journal of economic perspectives, 10(2):123-139.

Callao, S., Jarne, J.I. \& Laínez, J.A. 2007. Adoption of IFRS in Spain: effect on the comparability and relevance of financial reporting. Journal of international accounting, auditing and taxation, 16(2):148-178.

Cameron, A.C. \& Trivedi, P.K. 2010. Micro-econometrics using Stata revised ed. StataCorp LP: Stata Press books.

Carstensen, K. \& Toubal, F. 2004. Foreign direct investment in Central and Eastern European countries: a dynamic panel analysis. Journal of comparative economics, 32(1):3-22.

Cascino, S. \& Gassen, J. 2010. Mandatory IFRS adoption and accounting comparability. SFB 649 Discussion Paper, Economic Risk. Berlin.

Chakrabarti, A. 2001. The determinants of foreign direct investments: sensitivity analyses of cross-country regressions. Kyklos, 54(1):89-114.

Chambers, R.J. 1955. Blueprint for a theory of accounting. Accounting research, 6(1):17-25.

Chamisa, E.E. 2000. The relevance and observance of the IASC standards in developing countries and the particular case of Zimbabwe. The international journal of accounting, 35(2):267-286.

Chand, P. \& White, M. 2007. A critique of the influence of globalization and convergence of accounting standards in Fiji. Critical perspectives on accounting, 18(5):605-622.

Chand, P., Patel, C. \& Patel, A. 2010. Interpretation and application of "new" and "complex" international financial reporting standards in Fiji: implications for convergence of accounting standards. Advances in accounting, 26(2):280-289. 
Chasteen, L.G., Richard, E.F, \& Melvin C. O'Connor. 1992. Intermediate accounting. 4th ed. New York: McGraw-Hill.

Chen, C.J., Ding, Y. \& Xu, B. 2014. Convergence of accounting standards and foreign direct investment. The international journal of accounting, 49(1):53-86.

Chen, F., Hope, O.K., Li, Q. \& Wang, X. 2011. Financial reporting quality and investment efficiency of private firms in emerging markets. The accounting review, 86(4):1255-1288.

Choudhary, K. \& Bajaj, S. 2013. Price discovery process in nifty spot and futures markets. Global business review, 14(1):55-88.

Christensen, H.B., Hail, L. \& Leuz, C. 2013. Mandatory IFRS reporting and changes in enforcement. Journal of accounting and economics, 56(2-3):147-177.

Christensen, H.B., Maffett, M.G. \& Rauter, T. 2019. Policeman for the world: US enforcement of foreign corruption regulation and corporate investment policies.

http://dx.doi.org/10.2139/ssrn.3349272 Date of access: 20 July 2019.

Christensen, J. 2010. Conceptual frameworks of accounting from an information perspective. Accounting and business research, 40(3):287-299.

Chua, C.L., Lim, Y.Y., Ling, C.Y., Low, X.P. \& Tham, S.J. 2018. Economic growth: does corruption matters?

Evidence from 5 Southeast Asia countries.

http://eprints.utar.edu.my/3096/1/fyp_FN_2018_CCL.pdf Date of access: 11 Jan. 2019.

Chuhan, P., Claessens, S. \& Mamingi, N. 1998. Equity and bond flows to Latin America and Asia: the role of global and country factors. Journal of development economics, 55(2):439-463.

Cieslewicz, J.K. 2014. Relationships between national economic culture, institutions, and accounting: implications for IFRS. Critical perspectives on accounting, 25(6):511-528.

Clarke, F., Dean, G. \& Persson, M. 2019. Antecedents of the international association for accounting education and research (1966-1983): a review of early initiatives to develop an international academic accounting association. Journal of international financial management and accounting, 30(2):163-178.

Clarkson, M.E. 1995. A stakeholder framework for analysing and evaluating corporate social performance. Academy of management review, 20(1):92-117.

Cohen, J. 1992. Statistical power analysis. Current directions in psychological science, 1(3):98101.

Collis, J. \& Hussey, R. 2014. Business research: a practical guide for undergraduate and postgraduate students. 4th ed. New York, USA: Palgrave Macmillan International Higher Education.

Coolican, H. 2014. Research methods and statistics in psychology. 6th ed. London and New York: Psychology Press. 
Cooper, D.R., Schindler, P.S. \& Sun, J. 2014. Business research methods. $12^{\text {th }}$ ed. New York, USA: McGraw-Hill Irwin.

Cooper, D.R., Schindler, P.S. \& Couto, M.F., Peternelli, L.A. \& Barbosa, M.H.P. 2013. Classification of the coefficients of variation for sugarcane crops. Ciência rural, 43(6):957-961.

Covaleski, M.A. \& Dirsmith, M.W. 1988. An institutional perspective on the rise, social transformation, and fall of a university budget category. Administrative science quarterly: 562587.

Cremona, M. 2003. Bridges for development: policies and institutions for trade and integration. Washington, DC: The Inter-American Development Bank.

Creswell, J.W. 2014. Educational research: planning, conducting, and evaluating quantitative and qualitative research. 4th ed. London: Pearson.

Creswell, J.W. \& Poth, C.N. 2017. Qualitative inquiry and research design: choosing among five approaches. 4th ed. California, USA: Sage.

Crotty, M. 1998. The foundations of social research: meaning and perspective in the research process. London, Thousand Oaks, CA: Sage.

Crowther, D. \& Lancaster, G. 2012. Research methods. 2nd ed. London: Routledge.

Çulha, A. 2006. A structural VAR analysis of the determinants of capital flows into Turkey. Central Bank review, 2(2):11-35.

CPI (Corruption Perceptions Index). 2015. Transparency International Corruption Perception Index. http://www.transparency.org/news/feature/corruption_perceptions_index_2016 Date of access 20 Jan. 2018.

Daly, K. \& Vo, X.V. 2013. The determinants of home bias puzzle in equity portfolio investment in Australia. International review of financial analysis, 27:34-42.

Dănescu, T. \& Botoş, A. 2016. Research on the international accounting harmonization process. Annals of the University of Craiova, economic sciences series, 1(44):66-75.

Daske, H., Hail, L., Leuz, C. \& Verdi, R. 2008. Mandatory IFRS reporting around the world: early evidence on the economic consequences. Journal of accounting research, 46(5):1085-1142.

Daude, C. \& Stein, E. 2007. The quality of institutions and foreign direct investment. Economics and politics, 19(3):317-344.

Davies, M. \& Prince, M. 2010. Advertising agency compensation, client evaluation and switching costs: an extension of agency theory. Journal of current issues and research in advertising, 32(1):13-31.

Deb, R. 2019. Accounting theory coherence revisited. Management and labour studies, 44(1):3657. 
Deegan, C. 2013. Financial accounting theory. 3rd ed. North Ryde, Australia: McGraw-Hill.

DeFond, M., Hu, X., Hung, M. \& Li, S. 2011. The impact of mandatory IFRS adoption on foreign mutual fund ownership: the role of comparability. Journal of accounting and economics, 51(3):240-258.

Deloitte IAS Plus. 2017. Use of IFRS jurisdiction.

https://www.iasplus.com/en/resources/ifrs-topics/use-of-ifrs Date of access: 24 Dec. 2017.

Deloitte IAS Plus. 2018. Conceptual framework on financial reporting.

https://www.iasplus.com/en/standards/other/framework Date of access: 20 May 2018.

Denzin, N.K. \& Lincoln, Y.S. 2011. The Sage handbook of qualitative research. California, USA: Sage.

Desai, M.A. \& Dharmapala, D. 2007. Taxes and portfolio choice: evidence from JGTRRA's treatment of international dividends. NBER Working Paper, No. 13281. Cambridge, Massachusetts: National Bureau of Economic Research.

Dillard, J.F., Rigsby, J.T. \& Goodman, C. 2004. The making and remaking of organization context: duality and the institutionalization process. Accounting, auditing and accountability journal, 17(4):506-542.

DiMaggio, P. \& Powell, W.W. 1983. The iron cage revisited: collective rationality and institutional isomorphism in organizational fields. American sociological review, 48(2):147-160.

DiMaggio, P.J. \& Powell, W.W. 2000. The iron cage revisited: institutional isomorphism and collective rationality in organizational fields. (In Baum, J. \& Dobbin, F., ed. Economics meets sociology in strategic management. Bingley, England: Emerald. P. 143-166).

DiMaggio, P.J. \& Powell, W.W. 2004. The iron cage revisited: institutional isomorphism and collective rationality in organizational fields. The new economic sociology:111-134.

Ding, Y., Hope, O.K., Jeanjean, T. \& Stolowy, H. 2007. Differences between domestic accounting standards and IAS: measurement, determinants and implications. Journal of accounting and public policy, 26(1):1-38.

Dobson, P., Myles, J. \& Jackson, P. 2007. Making the case for critical realism: examining the implementation of automated performance management systems. Information resources management journal, 20(2):138-152.

Dondashe, N. \& Phiri, A. 2018. Determinants of FDI in South Africa: do macroeconomic variables matter? https://mpra.ub.uni-muenchen.de/83636/ Date of access: 20 May 2019.

Doupnik, T. S., \& Salter, S. B. 1995. External environment, culture and accounting practices: a preliminary test of a general model of international accounting development. International journal of accounting, Fall:189-207.

Draz, M.U. \& Ahmad, F. 2017. Accounting reforms and foreign portfolio investment in China: an empirical investigation. Asian journal of finance and accounting, 9(2):60-70. 
Dua, P. \& Garg, R. 2013. Foreign portfolio investment flows to India: determinant and analysis. Centre for Development Economics, working paper (225).

http://www.cdedse.org/pdf/work225.pdf Date of access: 22 June 2019.

Dunning, J. H. 2006. Towards a new paradigm of development: implications for the determinants of international business. Transnational corporation, 15(1):173-227.

Dupasquier, C. \& Osakwe, P.N. 2006. Foreign direct investment in Africa: performance, challenges, and responsibilities. Journal of Asian economics, 17(2):241-260.

Easley, D. \& O'hara, M. 2004. Information and the cost of capital. The journal of finance, 59(4):1553-1583.

Easterly, W., Islam, R. \& Stiglitz, J.E. 2001. Shaken and stirred: explaining growth volatility. (In. Boris, P. \& Nicholas, S. 2000. Annual World Bank conference on development economics organised by: World Bank. htttps://doi.org/10.1596/0-8213-4981-3. p. 191-211.).

EC (Commission of the European Communities). 2002. Regulation (EC) no. 1606/2002 of the European Parliament and of the Council of 19 July 2002 on the application of international accounting standards. Official journal of the European Communities, 50:1-4.

Edwards, E.O. \& Bell, P.W. 1965. The theory and measurement of business income. Berkeley and Los Angeles, CA: University of California Press.

Efobi, U. 2017. International financial reporting standard, trade and foreign direct investment in Sub-Sahara African countries. Ota, Nigeria: Covenant University. (Thesis - PhD).

Efobi, U., Iyoha, F.O. \& Mukoro, D. 2014. IFRS adoption and foreign investment in Africa: institutions also matter. http://dx.doi.org/10.2139/ssrn.2492235 Date of access: 15 June 2017.

Efobi, U., Nnadi, M., Odebiyi, J. \& Beecroft, I. 2014. Do the rules attract the money? Implication of IFRS adoption on foreign direct investment. www.ssrn.com/abstract=2460967 Date of access: 20 Jan. 2018.

Ekeocha, P.C., Ekeocha, C.S., Malaolu, V. \& Oduh, M.O. 2012. Modelling the long run determinants of foreign portfolio investment in Nigeria. Journal of economics and sustainable development, 3(8):194-205.

Elkhashen, E. \& Ntim, C.G. 2018. Accounting and philosophy: the construction of social reality framework. Journal of accounting and taxation, 10(3):29-36.

Emeni, F.K. 2014. Foreign direct investments and international financial reporting standards adoption in Africa. Ushus journal business management:27-44.

Erin, O., Oduwole, F., Olojede, P. \& Arumona, J. 2018. Does international financial reporting standards (IFRS) impact profitability ratios of listed banks in Nigeria. Journal of accounting, business and finance research, 2(2):79-90. 
Etikan, I., Musa, S.A. \& Alkassim, R.S. 2016. Comparison of convenience sampling and purposive sampling. American journal of theoretical and applied statistics, 5(1):1-4.

Ezeaku, H.C., Anyalechi, K.C., Onwumere, J.U. \& Okereke, E.J. 2018. The drivers of international financial integration and their implications on the Nigerian economy: an error correction model approach. International journal of economics and financial issues, 8(6):30-34.

Fakile, A.S., Faboyede, O.S. \& Obiamaka, N. 2013. The impact of international financial reporting standards on taxation. International journal of business and social science, 4(10):169174.

FASB/IASB (Financial Accounting Standards Board/International Accounting Standards Board). 2013. Comparability in International Accounting Standards: a brief history. https://www.fasb.org/jsp/FASB/Page/SectionPage\&cid=1176156304264 Date of access: 20 Oct. 2017.

Fernandez-Arias, E. 1996. The new wave of private capital inflows: push or pull? Journal of development economics, 48(2):389-418.

Fernando, S. \& Lawrence, S. 2014. A theoretical framework for CSR practices: integrating legitimacy theory, stakeholder theory and institutional theory. Journal of theoretical accounting research, 10(1):149-178.

Florou, A. \& Pope, P.F. 2012. Mandatory IFRS adoption and institutional investment decisions. The accounting review, 87(6):1993-2025.

Fogarty, T.J. 1996. The imagery and reality of peer review in the US: insights from institutional theory. Accounting, organizations and society, 21(2-3):243-267.

Fontaine, C., Haarman, A. \& Schmid, S. 2006. The stakeholder theory. Edlays education, 1:133.

Forbes, K.J. \& Warnock, F.E. 2012a. Capital flow waves: surges, stops, flight, and retrenchment. Journal of international economics, 88(2):235-251.

Forbes, K.J. \& Warnock, F.E. 2012b. Debt-and equity-led capital flow episodes. NBER Working Paper No. 18329. Cambridge, Massachusetts: National Bureau of Economic Research.

Fratzscher, M. 2012. Capital flows, push versus pull factors and the global financial crisis. Journal of international economics, 88(2):341-356.

Fredona, R. \& Reinert, S.A. 2017. The Harvard research center in entrepreneurial history and the daimonic entrepreneur. History of political economy, 49(2):267-314.

Freeman, R.E. 1984. Strategic management: a stakeholder approach. Advances in strategic management, 1(1):31-60.

Freeman, R.E., Wicks, A.C. \& Parmar, B. 2004. Stakeholder theory and the corporate objective revisited. Organization science, 15(3):364-369. 
Friedland, R., Alford, R.R., Powell, W.W. \& DiMaggio, P.J. 1991. The new institutionalism in organizational analysis. The new institutionalism in organizational analysis:232-263.

Friedman, A.L. \& Miles, S. 2006. Stakeholders: theory and practice. New York, USA: Oxford University Press.

Friedman, E., Johnson, S., Kaufmann, D. \& Zoido-Lobaton, P. 2000. Dodging the grabbing hand: the determinants of unofficial activity in 69 countries. Journal of public economics, 76(3):459493.

Frost, C.A., Henry, E., Lin, S.W. \& Research Committee of the American Accounting Association's International Accounting Section. 2009. Response to the US securities and exchange's proposed rule: roadmap for the potential use of financial statements prepared in accordance with International Financial Reporting Standards by US Issuers. Journal of international accounting research, 8(2):61-85.

Fuertes, A.M., Phylaktis, K. \& Yan, C. 2016. Hot money in bank credit flows to emerging markets during the banking globalization era. Journal of international money and finance, 60:29-52.

Funke, N., Ahmed, F. \& Arezki, R., 2005. The composition of capital flows: is South Africa different? IMF Working Paper No. 05/40. Washington, DC: International Monetary Fund.

Gambrell, K.M. 2019. Culturally sensitive: using grounded theory in a native American study. Thousand Oaks, CA: Sage.

Garg, R. \& Dua, P. 2014. Foreign portfolio investment flows to India: determinants and analysis. World development, 59:16-28.

Gerber, T.C. 2015. The conceptual framework for financial reporting represented in a formal language. Pretoria: UP. (Dissertation $-\mathrm{PhD}$ ).

Ghosh, M.A.R., Ostry, M.J.D. \& Qureshi, M.S. 2017. Managing the tide: How do emerging markets respond to capital flows? IMF Working Paper No. 17/69. Washington, DC: International Monetary Fund.

Gibson, C.H. 2012. Financial reporting and analysis: using financial accounting information. 11th ed. Mason, OH, USA: South-Western Cengage Learning.

Gillis, P.L. 2011. The big four in China: hegemony and counter-hegemony in the development of the accounting profession in China. Sydney, Australia: Macquarie University. (Thesis - PhD).

Glautier, M.W.E., Morris, D. \& Underdown, B. 2011. Accounting theory and practice. 8th ed. Harlow, England/New York: Financial Times Prentice Hall.

Glover, S.M., Taylor, M.H. \& Wu, Y. J. 2016. Current practices and challenges in auditing fair value measurements and complex estimates: implications for auditing standards and the academy. Auditing: a journal of practice and theory, 36(1):63-84. 
Golafshani, N. 2003. Understanding reliability and validity in qualitative research. The qualitative report, 8(4):597-606.

Gomoi, B.C. \& Pantea, M.F. 2016. The impact of signaling theory and agency theory on the financial reporting. Lucrări stiințifice management agricol, 18(2):199-202.

Gordon, L.A., Loeb, M.P. \& Zhu, W. 2012. The impact of IFRS adoption on foreign direct investment. Journal of accounting and public policy, 31(4):374-398.

Gossel, S.J. \& Biekpe, N. 2017. Push-pull effects on South Africa's capital inflows. Journal of international development, 29(6):751-767.

Guba, E.G. \& Lincoln, Y.S. 1994. Competing paradigms in qualitative research. Handbook of qualitative research, 2(163-194):105-117.

Gujarati, D.N. 2007. Basic econometrics. 4th ed. New Delhi, India: Tata McGraw-Hill.

Gumus, G.K., Duru, A. \& Gungor, B. 2013. The relationship between foreign portfolio investment and macroeconomic variables. European scientific journal, 9(34):209-226.

Gupta, M.P. \& Gordon, M.J.P. 2003. Portfolio flows into India: do domestic fundamentals matter? IMF Working Paper No. 03/20. Washington, DC: International Monetary Fund.

Guthrie, G. 2010. Basic research methods: an entry to social science research. New Delhi, India: Sage.

Haider, M.A., Khan, M.A. \& Abdulahi, E. 2016. Determinants of foreign portfolio investment and its effects on China. International journal of economics and finance, 8(12):143.

Hallward-Driemeier, M. \& Pritchett, L. 2015. How business is done in the developing world: deals versus rules. Journal of economic perspectives, 29(3):121-140.

Hamberg, M., Mavruk, T. \& Sjögren, S. 2013. Investment allocation decisions, home bias and the mandatory IFRS adoption. Journal of international money and finance, 36:107-130.

Hasan, Z. 2004. Foreign investment in developing countries. (In Kehal, H.S., ed. Foreign investment in developing countries. London: Palgrave Macmillan. p. 154-170).

HassabElnaby, H.R., Epps, R.W. \& Said, A.A. 2003. The impact of environmental factors on accounting development: An Egyptian longitudinal study. Critical perspectives on accounting, 14(3):273-292.

Hausman, J.A. 1978. Specification tests in econometrics. Journal of the econometric society: $1251-1271$.

Hawley, A. 1981. Urban society: an ecological approach. 2nd ed. New York: Wiley.

Healy, M. \& Perry, C. 2000. Comprehensive criteria to judge validity and reliability of qualitative research within the realism paradigm. Qualitative market research: an international journal, 3(3):118-126. 
Herrmann, S. \& Mihaljek, D. 2013. The determinants of cross-border bank flows to emerging markets. Economics of transition 21(3): 479-508.

Hines, R.D. 1989. The socio-political paradigm in financial accounting research. Accounting, auditing and accountability journal, 2(1):52-76.

Hirsch, P. \& Friedman, R. 1986. Collaboration or paradigm shift? Economic vs. behavioral thinking about policy? (In Guclu, A., ed. 1986. Academy of management proceedings, Briarcliff Manor, NY: Academy of management. p. 31-35).

Hofstede, G. 2011. Dimensionalizing cultures: The Hofstede model in context. Online readings in psychology and culture, 2(1):1-26.

Hong, H.A., Hung, M. \& Lobo, G.J. 2014. The impact of mandatory IFRS adoption on IPOs in global capital markets. The accounting review, 89(4):1365-1397.

Hope, O.K., Jin, J. \& Kang, T. 2006. Empirical evidence on jurisdictions that adopt IFRS. Journal of international accounting research, 5(2):1-20.

Houqe, M.N., Van Zijl, T., Dunstan, K. \& Karim, A.W. 2012. The effect of IFRS adoption and investor protection on earnings quality around the world. The international journal of accounting, 47(3):333-355.

Hsiao, C. 2003. Analysis of panel data. 2nd ed. Ingiltere: Cambridge University.

Humanicki, M., Kelm, R. \& Olszewski, K. 2013. Foreign direct investment and foreign portfolio investment in the contemporary globalized world: should they be still treated separately? NBP Working Paper, No. 167. National Bank of Poland.

Hymer, S.H. 1976. The international operations of national firms: a study of foreign direct investment. Cambridge, MA: Mit Press.

IASB (International Accounting Standards Board). 2010. The conceptual framework for financial reporting. London, UK: IASB. www.ifrs.org Date of access: 21 Oct. 2018.

Ibrahim, T.R., Akinbobola, T.O. \& Ademola, I.J. 2017. Exchange rate reform policies and trade balances in Nigeria. KCA journal of business management, 8(1):14-38.

IFRS (International Financial Reporting Standards) Foundation. 2017. A guide through IFRS. London, UK: IFRS Foundation.

IFRS (International Financial Reporting Standards). 2018. Who uses IFRS standards? www.ifrs.org/use-around-the-world/use-of-ifrs-standards-jurisdiction/development Date of access: 12 Aug. 2017.

Ihuah, P.W. \& Eaton, D. 2013. The pragmatic research approach: a framework for sustainable management of public housing estates in Nigeria. Journal of US-China public administration, 10(10):933-944. 
IMF (International Monetary Fund). 1993. Balance of payments manual. $5^{\text {th }}$ ed. Washington DC: International Monetary Fund.

IMF (International Monetary Fund). 2015. International Financial Statistics. https://data.imf.org/?sk=4C514D48-b6ba-49ed-8ab9 52b0c1a0179b\&sid=1393552803658 Date of access: 23 May 2018.

IMF (International Monetary Fund). 2015. International investment position by indicator: liabilities, portfolio investment. https://data.imf.org/regular.aspx?key=62805745 Date of access: 20 Dec. 2017.

IMF (International Monetary Fund). 2017. Coordinated Portfolio Investment Survey Guide. Washington, DC: International Monetary Fund.

Iyoha, F.O. \& Owolabi, A. 2012. Adopting international financial reporting standards (IFRS) in Africa: benefits, prospects and challenges. African journal accounting, auditing and finance, 1(1):77-86.

Jaccard, J. \& Becker, M.A. 2010. Statistics for the behavioral sciences. 5th ed. Wadsworth, Cengage Learning.

Jaggi, B. \& Low, P.Y. 2000. Impact of culture, market forces, and legal system on financial disclosures. The international journal of accounting, 35(4):495-519.

Jaiblai, P. \& Shenai, V. 2019. The determinants of FDI in Sub-Saharan economies: a study of data from 1990-2017. International journal of financial studies, 7(3):1-31.

Jain, P.K., Kuvvet, E. \& Pagano, M.S. 2017. Corruption's impact on foreign portfolio investment. International business review, 26(1):23-35.

James, E., McLoughlin, K. \& Rankin, E. 2014. Cross-border capital flows since the global financial crisis. RBA Bulletin, June:65-72.

Jankowicz, A.D. 2005. Business research projects. 4th ed. London: Thomson Learning.

Jelilov, G. 2016. The impact of interest rate on economic growth example of Nigeria. African journal of social sciences:51-64.

Jensen, M.C. \& Meckling, W.H. 1976. Theory of the firm: managerial behaviour, agency costs and ownership structure. Journal of financial economics, 3(4):305-360.

Jensen, M.C. \& Smith, C.W. 2000. Stockholder, manager, and creditor interests: applications of agency theory. Theory of the firm, 1(1):1982-1985.

Jeon, B.N. \& Rhee, S.S. 2008. The determinants of Korea's foreign direct investment from the United States, 1980-2001: an empirical investigation of firm-level data. Contemporary economic policy, 26(1):118-131. 
Jermakowicz, E.K. \& Gornik-Tomaszewski, S. 2006. Implementing IFRS from the perspective of EU publicly traded companies. Journal of international accounting, auditing and taxation, 15(2):170-196.

Jermakowicz, E.K., Prather-Kinsey, J. \& Wulf, I. 2007. The value relevance of accounting income reported by DAX-30 German companies. Journal of international financial management \& accounting, 18(3):151-191.

Jhingan, M.L. 1992. Advanced economic theory. 8th ed. New Delhi, India: Konark.

Jinadu, O., Ojeka, S.A. \& Ogundana, O.M. 2016. IFRS adoption and foreign direct investment: evidence from Nigerian quoted firms. Mediterranean journal of social sciences, 7(2):99-105.

Jindrichovska, I. \& Kubickova, D. 2016. Economics and political implications of international financial reporting standards. IGI Global:105-133.

Joshi, P.L., Deshmukh, A. \& Deshmukh, H. 2013. Company characteristics and compliance with IFRS's practice statement (management commentary) by listed companies in Bahrain. International journal of managerial and financial accounting, 5(4):350-366.

Judge, W., Li, S. \& Pinsker, R. 2010. National adoption of international accounting standards: an institutional perspective. Corporate governance: an international review, 18(3):161-174.

Kahai, S. 2004. Foreign investment in developing countries. (In Kehal, H.S., ed. Foreign investment in developing countries. London: Palgrave Macmillan. p. 33-48).

Kahn, R.B., Bennett, A. \& Schadler, S.M. 1993. Recent experiences with surges in capital inflows. IMF Occasional Papers, No. 108. Washington DC: International Monetary Fund.

Kant, C. 2018. Financial openness and institutions in developing countries. Research in international business and finance, 46:240-250.

Kennedy, P. 2003. A guide to econometrics. 5th ed. Cambridge: The MIT Press.

Khayat, S. 2016. Developing countries' foreign direct investment and portfolio investment. Leicester, UK: University of Leicester. (Thesis - PhD).

Khurana, I.K. \& Michas, P.N. 2011. Mandatory IFRS adoption and the US home bias. Accounting horizons, 25(4):729-753.

Kimeli, E. K. 2017. IFRS adoption and capital markets. Journal of finance and accounting, 5(1):19-30.

Kinda, T. 2012. On the drivers of FDI and portfolio investment: a simultaneous equations approach. International economic journal, 26(1):1-22.

Kivunja, C. \& Kuyini, A.B. 2017. Understanding and applying research paradigms in educational contexts. International journal of higher education, 6(5):26-41. 
Klemm, A. \& Van Parys, S. 2012. Empirical evidence on the effects of tax incentives. International tax and public finance, 19(3):393-423.

Koepke, R. 2019. What drives capital flows to emerging markets? A survey of the empirical literature. Journal of economic surveys, 33(2): 516-540.

Kolsi, M. \& Zehri, F. 2013. The determinants of IAS/IFRS adoption by emergent countries. https://cbe.uaeu.ac.ae/en/csafc/pdf/ad_38.pdf Date of access: 21 Oct. 2017.

Kohler, E.L. 1965. Professional accounting in 25 countries. The Accounting review, 40(4): 922

Kothari, S., Ramanna, K. \& Skinner, D.J. 2010. Implications for GAAP from an analysis of positive research in accounting. Journal of accounting and economics, 50(2-3):246-286.

Kribat, M.M. 2009. Financial disclosure practices in developing countries: evidence from the Libyan banking sector. Scotland, UK: University of Dundee. (Dissertation - PhD).

Kutu, A.A. \& Ngalawa, H. 2016. Monetary policy shocks and industrial output in BRICS countries. SPOUDAI-Journal of economics and business, 66(3):3-24.

Kwarbai, J., Ajibade, A.T., Olajumoke, J., Olayinka, I.M., Ogundajo, G.O. \& Kwarbai, J.D. 2016. Accounting standards and foreign direct investment inflows in selected African Countries (19802015). International journal of advanced academic research, social \& management sciences, 2(10):17-28.

Kyereboah-Coleman, A. \& Agyire-Tettey, K.F. 2008. Effect of exchange-rate volatility on foreign direct investment in Sub-Saharan Africa: the case of Ghana. The journal of risk finance, 9(1):52-70.

Lambert, R.A. 2006. Agency theory and management accounting. Handbooks of management accounting research, 1:247-268.

Land, J. \& Lang, M.H. 2002. Empirical evidence on the evolution of international earnings. The accounting review, 77(s-1):115-133.

Landsman, W.R., Maydew, E.L. \& Thornock, J.R. 2012. The information content of annual earnings announcements and mandatory adoption of IFRS. Journal of accounting and economics, 53(1-2):34-54.

Lang, M., Maffett, M.G. \& Owens, E. 2010. Earnings co-movement and accounting comparability: the effects of mandatory IFRS adoption. Simon School Working Paper, No. FR 11-03. https://ssrn.com/abstract=1676937 Date of access: 20 Apr. 2018.

Langenderfer, H.Q. 1973. A conceptual framework for financial reporting. Journal of accountancy (pre-1986), 136(000001):46-55.

Langli, J.C. \& Willekens, M. 2017. Tax avoidance, horizontal agency conflicts and high-quality auditing in private firms. KU Leuven and BI Norwegian business school. https://www.nhh.no/globalassets/departments/accounting-auditing-and-law/seminar-papers/taxavoidance-6.10.2017.pdf Date of access: 10 Feb. 2018. 
Lasmin, R. 2012. The unwanted effects of international financial reporting standards (IFRS) adoption on international trade and investments in developing countries. Journal of economics and economic education research, 13(1):1-14.

Lau, A. \& Ma, R. 1997. Financial reporting in the Pacific Asia Region. World scientific:55-92.

Lee, G. \& Fargher, N.L. 2010. Did the adoption of IFRS encourage cross-border investment? http://dx.doi.org/10.2139/ssrn.1686571 Date of access: 2 Nov. 2017.

Leedy, P.D. \& Ormrod, J.E. 2012. Practical research planning and design. 10th ed. New Jersey: Pearson.

Leeper, T.J. 2017. Interpreting regression results using average marginal effects with R's margins. Comprehensive R Archive Network (CRAN):1-32.

https://rdrr.io/cran/margins/f/inst/doc/TechnicalDetails.pdf Date of access: 31 March 2020.

Lennard, A. 2007. Stewardship and the objectives of financial statements: a comment on IASB's preliminary views on an improved conceptual framework for financial reporting: the objective of financial reporting and qualitative characteristics of decision-useful financial reporting information. Accounting in Europe, 4(1):51-66.

Li, F. \& Shroff, N. 2010. Financial reporting quality and economic growth. http://dx.doi.org/10.2139/ssrn.1265331 Date of access: 11 Mar. 2018.

Li, S. \& Yan, I.K. 2004. The determinants of international portfolio holdings and home bias. IMF Working Paper No. 04/34. Washington, DC: International Monetary Fund.

Lin, S., Riccardi, W.N., Wang, C., Hopkins, P.E. \& Kabureck, G. 2019. Relative effects of IFRS adoption and IFRS convergence on financial statement comparability. Contemporary accounting research, 36(2):588-628.

Lo-Duca, M. 2012. Modelling the time varying determinants of portfolio flows to emerging markets. ECB Working Paper, No. 1468. Frankfurt: European Central Bank (ECB).

Louis, H. \& Urcan, O. 2014. The effect of IFRS on cross-border acquisitions. http://dx.doi.org/10.2139/ssrn.2164995 Date of access: 22 Aug. 2017.

Macve, R. 2010. Conceptual frameworks of accounting: some brief reflections on theory and practice. Accounting and business research, 40(3):303-308.

Madawaki, A. 2012. Adoption of international financial reporting standards in developing countries: the case of Nigeria. International journal of business and management, 7(3):152-161.

Mafuwane, B.M. 2012. The contribution of instructional leadership to learner performance. Pretoria: University of Pretoria. (Thesis - PhD).

Makoni, P.L. \& Marozva, G. 2018. The nexus between foreign portfolio investment and financial market development: evidence from Mauritius. Academy of strategic management journal, 17(5):1-14. 
Manyara, S.M. 2013. Access to capital: examining the effect of adopting international financial reporting standards. San Diego, CA: Northcentral University. (Dissertation - PhD).

Mardini, G.H., Crawford, L. \& Power, D.M. 2012. The impact of IFRS 8 on disclosure practices of Jordanian listed companies. Journal of accounting in emerging economies, 2(1):67-90.

Márquez-Ramos, L. 2011. European accounting harmonization: consequences of IFRS adoption on trade in goods and foreign direct investments. Emerging markets finance and trade, 47(sup4):42-57.

Martins, F.S., da Cunha, J.A.C. \& Serra, F.A.R. 2018. Secondary data in research: uses and opportunities. PODIUM sport, leisure and tourism review, 7(3):1-4.

Matadeen, J., Matadeen, S. \& Seetanah, B. 2011. Trade openness and economic growth: evidence from Mauritius. Paper presented at the ICITI, Hong Kong, 26 March. http://sites.uom.ac.mu/wtochair/Conference\%Proceedings/2.pdf Date of access: 12 May 2019.

Mattessich, R. 2003. Accounting representation and the onion model of reality: a comparison with Baudrillard's orders of simulacra and his hyperreality. Accounting, organizations and society, 28(5):443-470.

Matthew, G.L. 2009. G-20: achieve single set of global accounting standards. www.journalofaccountancy.com/web/20092188.htm Date of access: 20 Feb. 2019.

McCreevy, C. 2005. IFRS: No pain, no gain? European Commissioner for Internal Market and Services speech 05-621. Brussels, 18 October. http://europa.eu/rapid/press-release_SPEECH-05621_en.htm Date of access: 12 May 2018.

McGuire, S.T., Newton, N.J., Omer, T.C. \& Sharp, N.Y. 2012. Does local religiosity impact corporate social responsibility? https://ssrn.com/abstract=1926387 Date of access: 21 June 2018.

McKernan, J.F. 2001. Truth, objectivity and subjectivity in accounting. Glasgow, UK: University of Glasgow. (Dissertation - PhD).

Meyer, M.W. \& Brown, M.C. 1977. The process of bureaucratization. American journal of sociology, 83(2):364-385.

Mijiyawa A. 2015. What drives foreign direct investment in Africa? An empirical investigation with panel data. African development review, 27(4):392-402.

Milner, A.J. 2019. The determinants of inward foreign direct investment: evidence from SubSaharan Africa. Pretoria: University of Pretoria. (Dissertation - PhD).

Molín, J. \& Jirásková, S. 2014. Legal consequences of the determination of corporate income tax base referring to IFRS. European financial and accounting journal, 9(4):25-44.

Moonitz, M. 1961. Accounting research study: American Institute of CPAs. No. 01. guides, handbooks and manuals, 141. https://egrove.olemiss.edu/aicpa_guides/141 Date of access: 15 Dec. 2017. 
Morricone, S., Oriani, R. \& Sobrero, M. 2009. The value relevance of intangible assets and the mandatory adoption of IFRS.

https://eprints.luiss.it/812/1/SSRN-id1600725_oriani_2009.pdf Date of access: 23 May 2019.

Mrša, J., Mance, D. \& Vašiček, D. 2008. Concepts of capital maintenance in fair value accounting. International scientific conference micro CAD 2008.

https://bib.irb.hr/datoteka/326289.Mikolc_2008_Concepts_of_Capital_Maintenance_in_Fair_Va lue_Accounting.pdf Date of access: 10 July 2018.

Muhibudeen, L. 2015. International financial reporting standard and value relevance of accounting information in quoted Cement Firms in Nigeria. International journal of sciences: basic and applied research (IJSBAR), 22(1):81-95.

Mwangi, L.W., Makau, M.S. \& Kosimbei, G. 2014. Relationship between capital structure and performance of non-financial companies listed in the Nairobi Securities Exchange, Kenya. Global journal of contemporary research in accounting, auditing and business ethics, 1(2):72-90.

Naude, W. 2009. Geography, transport and Africa's proximity gap. Journal of transport geography, 17(1):1-9.

Ncube, M., Ndou, E. \& Gumata, N. 2012. How are the US financial shocks transmitted into South Africa? Structural VAR evidence. ADBG Working Paper No. 157. Tunisia: African Development Bank.

Ndikumana, L. \& Boyce, J.K. 2011. Capital flight from sub-Saharan Africa: linkages with external borrowing and policy options. International review of applied economics, 25(2):149-170.

Neuman, W.L. 2013. Social research methods: qualitative and quantitative approaches. London: Pearson.

Ng, C. 2015. Assessing the association between International Financial Reporting Standards (IFRS) and foreign direct investment (FDI): a replication and extension study utilizing econometric analysis. Wilmington, USA: Wilmington University. (Dissertation - PhD).

Nielsen, N, S. \& Bjørnskov, C. 2012. Foreign portfolio investments in Sub-Saharan Africa: why foreign investors might not seek the optimal opportunity? Aarhus school of business and social sciences, Aarhus University (unpublished).

Nnadi, M. \& Soobaroyen, T. 2015. International financial reporting standards and foreign direct investment: the case of Africa. Advances in accounting, 31(2):228-238.

Nobes, C. 1998. Towards a general model of the reasons for international differences in financial reporting. Abacus, 34(2):162-187.

Nobes, C. 2011. International variations in IFRS adoption and practice. The Association of Chartered Certified Accountants (ACCA) research report 124. London: The Association of Chartered Certified Accountants.

Nobes, C., Parker, R.B. \& Parker, R.H. 2008. Comparative international accounting. London: Pearson. 
Nobes, C.W. \& Stadler, C. 2015. The qualitative characteristics of financial information, and managers' accounting decisions: evidence from IFRS policy changes. Accounting and business research, 45(5):572-601.

Nyor, T. 2012. Expected benefits of implementing global accounting standards by Nigerian business entities. International journal of business and management, 7(15):98.

Obansa, S.J., Okoroafor, O.D., Aluko, O. \& Eze, M. 2013. Perceived relationship between exchange rate, interest rate and economic growth in Nigeria: 1970-2010. American journal of humanities and social sciences, 1(3):116-124.

Obstfeld, M. 2009. International finance and growth in developing countries: What have we learned? International Monetary Fund staff papers, 56(1):63-111.

Ocansey, E.O. \& Enahoro, J.A. 2014. Comparative study of the international financial reporting standard implementation in Ghana and Nigeria. European scientific journal, (ESJ). 10(13):529546.

OECD (Organisation for Economic Co-operation and Development). 2013. Foreign direct investment (FDI) statistics). 2013. OECD data, analysis and forecasts.

http://www.oecd.org/corporate/mne/statistics.html Date of access: 26 May 2017.

Okafor, H. O. 2012. Do domestic macroeconomic variables matter for foreign direct investment inflow in Nigeria. Journal of finance and accounting, 39(9):55-67.

Okoye, P.V., Okoye, J.F. \& Ezejiofor, R.A. 2014. Impact of IFRS adoption on stock market movement in Nigerian corporate organization. International journal of academic research in business and social sciences, 4(9):202-218.

Olamide, J.O. \& Ajibade, A.T. 2016. Evolution of accounting standards in Nigeria: a historical perspective. Evolution, 2(8):9-24.

Olokoyo, F.O. 2013. Capital structure and corporate performance of Nigerian quoted firms: a panel data approach. African development review, 25(3):358-369.

Olugbenga, J., Ojeka, S. \& Ogundana, O.M. 2016. IFRS adoption and foreign direct investment: evidence from Nigerian quoted firms. Mediterranean journal of social sciences, 7(2):98-105.

Omolade, A. \& Ngalawa, H. 2014. Oil revenue and manufacturing sector growth in Africa's oilexporting countries. Journal of economic and financial sciences, 7(3):925-944.

Onuorah, A.C.C. \& Nnenna, O.M. 2013. Long run relationship between macroeconomic variables and FDI in Nigeria. Developing country studies, 3(1):162-169.

Onyeiwu, S. \& Shrestha, H. 2004. Determinants of foreign direct investment in Africa. Journal of developing societies, 20(1-2):89-106.

Opare, S., Houqe, N. \& van Zijl, T. 2019. Meta-analysis of the impact of adoption of IFRS on financial reporting comparability, market liquidity, and cost of capital. Paper presented at the Financial markets and corporate governance conference. Organised by Macquarie University, 
Monash University, La Trobe University, and Victoria University of Wellington in 2019. https://ssrn.com/abstract=3319067 Date of access: 19 June 2019.

Ortega, X. 2017. A review of IFRS and US GAAP convergence history and relevant studies. International business research, 10(9):31-38.

Orts, E.W. \& Strudler, A. 2002. The ethical and environmental limits of stakeholder theory. Business ethics quarterly:215-233.

Osemene, O.F. \& Arotiba, K. 2018. Exchange rate volatility and foreign portfolio investment in Nigeria. Global journal of management and business research, 18(2):12-19.

Owolabi, A. \& Iyoha, F.O. 2012. Adopting international financial reporting standards (IFRS) in Africa: benefits, prospects and challenges. African journal of accounting, auditing and finance, 1(1):77-86.

Pacter, P. 2014. IFRS as global standards: a pocket guide. London: IFRS Foundation.

Pala, A. \& Orgun, B.O. 2015. The effect of macroeconomic variables on foreign portfolio investments: an implication for Turkey. Journal of business economics and finance, 4(1)108-126.

Palea, V. 2013. IAS/IFRS and financial reporting quality: lessons from the European experience. China journal of accounting research, 6(4):247-263.

Paşcan, I.D. 2014. Measuring the effects of IFRS adoption in Romania on the value relevance of accounting data. Annales universitatis apulensis series oeconomica, 16(2):263-273.

Pelger, C. 2016. Practices of standard-setting: an analysis of the IASB's and FASB's process of identifying the objective of financial reporting. Accounting, organizations and society, 50:51-73.

Pesaran, M.H. 2007. A simple panel unit root test in the presence of cross-section dependence. Journal of applied econometrics, 22(2):265-312.

Phan, D. 2014. What factors are perceived to influence consideration of IFRS adoption by Vietnamese policy makers? Journal of contemporary issues in business and government, 20(1):2740 .

PwC (PricewaterhouseCoopers'). 2015. World tax summaries online: corporate and individual taxes in 151 territories worldwide.

http://taxsummaries.pwc.com/uk/taxsummaries/wwts.nsf/ID/PPAA-85RDKF\# Date of access: 20 July. 2018.

PwC (PricewaterhouseCoopers). 2016. Financing options: debt versus equity a country overview. https://www.pwc.nl/nl/assets/documents/pwc-financing-options-debt-versus-equity.pdf Date of access: 14 Mar. 2018.

Pricope, C.F. 2016. The role of institutional pressures in developing countries: implications for IFRS. Theoretical and applied economics, 23(2):27-40.

Prockazka, D. 2012. IFRS adoption index: a tool for the measurement of accounting harmonization. http://www.wseas.us/e-library/conferences/pdf Date of access: 17 Aug. 2017. 
Ramanna, K. \& Sletten, E., 2010. Why do countries adopt international financial reporting standards? Harvard Business School Accounting and Management Unit Working Paper No. 09102. https://www.hbs.edu/faculty/Publication\%20Files/09-102_1bc06d7-7340-4f0a-b638e23211a40c41.pdf Date of access: 1 Oct. 2018.

Ramanna, K. \& Sletten, E. 2014. Network effects in countries' adoption of IFRS. The accounting review, 89(4):1517-1543.

Ramasamy, B. \& Yeung, M. 2010. The determinants of foreign direct investment in services. World economy, 33(4):573-596.

Ramírez, C. and González, M., 2017. Have QE programs affected capital flows to emerging markets? A regional analysis. Investigación conjunta-joint research: 155-188.

Riahi-Belkaoui, A. 2012. Accounting theory. 5th ed. Hampshire: Cengage Learning.

Roberts, C.B., Weetman, P. \& Gordon, P. 2005. International financial reporting: a comparative approach. Upper Saddle River, NJ: Financial Times Prentice Hill.

Rocco, T.S., Bliss, L.A., Gallagher, S. \& Pérez-Prado, A. 2003. Taking the next step: mixed methods research in organizational systems. Information technology, learning, and performance journal, 21(1):19.

Rodrigues, L.L. \& Craig, R. 2007. Assessing international accounting harmonization using Hegelian dialectic, isomorphism and Foucault. Critical perspectives on accounting, 18(6):739757.

Rodríguez-Pose, A. \& Cols, G. 2017. The determinants of foreign direct investment in subSaharan Africa: what role for governance? Regional science policy and practice, 9(2):63-81.

Rollins, T.P. \& Bremser, W.G. 1997. The SEC's enforcement actions against auditors: an auditor reputation and institutional theory perspective. Critical perspectives on accounting, 8(3):191-206.

Ruiz, J.L. 2018. Financial development, institutional investors, and economic growth. International review of economics and finance, 54:218-224.

Saidi, F. 2013. Accounting developments in Algeria: the road to IFRS. International research journal of applied finance, 4:124-142.

Salawu, R.O. \& Ile-Ife, N. 2007. An empirical analysis of the capital structure of selected quoted companies in Nigeria. The international journal of applied economics and finance, 1(1):16-28.

Salem, R.B., Damak-Ayadi, S. \& Saïhi, M. 2017. Determinants of full IFRS adoption. International journal of managerial and financial accounting, 9(2):105-123.

Sanders, T.H., Hatfield, H.R. \& Moore, U. 1938. A statement of accounting principles. New York: American Institute of Certified Public Accountants. https://3197d6d14b5f19f2f4405e13d29c4c016cf96cbbfd197c579b45.ssl.cf1.rackcdn.com/collect ion/papers/1930/1938_0101_PrinciplesSanders.pdf Date of access: 12 Jan. 2019. 
Sarantakos, S. 2013. Social research. 4th ed. London: Red Globe Press.

Sarno, L., Tsiakas, I. \& Ulloa, B. 2016. What drives international portfolio flows? Journal of international money and finance, 60:53-72.

Saunders, M.N., Lewis, P. \& Thornhill, A. 2012. Research methods for business students. 6th ed. London: Pearson.

Schellhase, J. \& Woodsome, J. 2017. SMEs and public equity financing: a new dataset of SME boards in emerging-market and developing economies.

https://www.milkeninstitute.org/sites/default/files/reports-pdf/080217-SMEs-and-Public-EquityFinancing.pdf Date of access: 22 Feb. 2018.

Schneidman, W \& Signé, L. 2019 The Trump administration's Africa strategy: primacy or partnership? Brookings https://www.brookings.edu/ Date of access: 22 July 2019.

Schutte, D. \& Buys, P. 2011. A critical analysis of the contents of IFRS for SMEs: a South African perspective. South African journal of economic and management sciences, 14(2): 188209.

Searle, J.R. 2015. Seeing things as they are: a theory of perception. New York, USA: Oxford University Press.

Shandu, P., Boako, G. \& Alagidede, P. 2018. Price leadership in the South African foreignexchange market: an empirical analysis. International journal of emerging markets, 13(1):87-117.

Sherman, T. \& De Klerk, M. 2015. International financial reporting standards and foreign ownership in South African companies. Southern African business review, 19(1):72-88.

Shima, K.M. \& Gordon, E.A. 2011. IFRS and the regulatory environment: the case of US investor allocation choice. Journal of accounting and public policy, 30(5):481-500.

Shima, K.M. \& Yang, D.C. 2012. Factors affecting the adoption of IFRS. International journal of business, 17(3):276-298.

Sichei M. \& Kinyondo G. 2012. Determinants of foreign direct investment in Africa: a panel data analysis. Global journal of management and business research, 12(18):1-14.

Simon, M. \& Goes, J. 2013. Ex-post-facto research: using existing data for your dissertation research.

http://www.dissertationrecipes.com/ex-post-facto-research-existing-data-dissertation-research/ Date of access: 12 June 2018.

Singleton-Green, B. 2015. The effects of mandatory IFRS adoption in the EU: a review of empirical research information for better markets. https://ssrn.com/abstract=2515391 Date of access: 24 Nov. 2017.

Singhania, M. \& Saini, N. 2018. Determinants of FPI in developed and developing countries. Global business review, 19(1):187-213. 
Smimou, K. 2014. International portfolio choice and political instability risk: a multi-objective approach. European journal of operational research, 234(2):546-560.

Smith, M. 2003. Research methods in accounting. London. Sage Publications.

Soderstrom, N.S. \& Sun, K.J. 2007. IFRS adoption and accounting quality: a review. European accounting review, 16(4):675-702.

Spiceland, J.D., Sepe, J.F., Nelson, M.W. \& Thomas, W. 2007. Intermediate accounting. 5th ed. New York, NY: McGraw-Hill/Irwin.

Stainbank, L. 2014. Factors influencing the adoption of international financial reporting standards by African countries. South African journal of accounting research, 28(1):79-95.

Staubus, G.J. 2013. The decision usefulness theory of accounting: a limited history. New York: Routledge.

Stenzel, A. \& Wagner, W. 2015. Opacity and liquidity. CEPR Discussion Paper No. DP10665. https://ssrn.com/abstract=2621569 Date of access: 21 Apr. 2018.

Suliman, O. 2005. Interest rate volatility, exchange rates, and external contagion. Applied financial economics, 15(12):883-894.

Sur, A., Ray, P. \& Nandy, A. 2019. India's external commercial borrowing: pulled by domestic fundamentals or pushed by global conditions? Journal of Asian economics, 61:65-77.

Tabachnick, B.G. \& Fidell, L.S. 2013. Using multivariate statistics. 6th ed. Boston: Pearson Education.

Taiwo, F.H. \& Adejare, A.T. 2014. Empirical analysis of the effect of international financial reporting standards (IFRS) adoption on accounting practices in Nigeria. Archives of business research, 2(2):01-14.

Tarca, A. 2012. The case for global accounting standards: arguments and evidence. https://papers.ssrn.com/abstract=2204889 Date of access: 8 Sep. 2018.

Taşdemir, F. \& Özmen, E. 2018. Exchange rate regimes as thresholds: the main determinants of capital inflows in emerging market economies (No. 1810). Middle East Technical University: ERC-Economic Research Center. http://erc.metu.edu.tr/en/system/files/menu/series18/1810.pdf Date of access: 11 Feb. 2018.

Taylor, M.P. \& Sarno, L. 1997. Capital flows to developing countries: long-and short-term determinants. The World Bank economic review, 11(3):451-470.Taylor, S. 2007. Business statistics: for non-mathematicians. 2nd ed. New York, USA: Palgrave Macmillan.

Teddlie, C. \& Tashakkori, A. 2009. Foundations of mixed methods research: integrating quantitative and qualitative approaches in the social and behavioral sciences. Thousand Oaks, CA: Sage.

Thankgod, O. 2014. Foreign portfolio investment and economic growth in Nigeria (1986-2011). International journal of business and social science, 5(11):108-115. 
TI (Transparency International). 2015. Global corruption barometer. https://www.transparency.org/country Date of access: 15 Oct. 2018.

Tsalavoutas, I., André, P. \& Evans, L. 2012. The transition to IFRS and the value relevance of financial statements in Greece. The British accounting review, 44(4):262-277.

FFP (Fund for Peace). 2017. Fragile state index.

https://fundforpeace.org/fsi/methodology/ Date of access: 12 June 2018.

Thomsen, S. \& House, C. 2005. Foreign direct investment in Africa: the private-sector response to improved governance. Briefing paper, IEP BP, 5(06). London: Royal Institute of International Affairs.

Tuli, F. 2011. The basis of distinction between qualitative and quantitative research in social science: reflection on ontological, epistemological and methodological perspectives. Ethiopian journal of education and sciences, 6(1):97-108.

Tweedie, D. 2006. Prepared statement of Sir David Tweedie, Chairman of the International Accounting Standards Board before the Economic and Monetary Affairs Committee of the European Parliament.

http://www.iasplus.com/resource/0601tweedieeusp.Pdf Date of access: 18 May 2019.

Udah, E. B. \& Ayara, N. 2014. Institutions, governance structure and economic performa nexus in Nigeria. Institutions, 5(3):8-20.

UNCTAD (United Nations Conference on Trade and Development). 1999. Comprehensive thesis of the interrelationship between foreign direct investment and foreign portfolio investment. UNCTAD/GDS/DFSB.

https://unctad.org/en/Docs/pogdsdfsbd5.pdf Date of access: 11 Sep. 2017.

UNCTAD (United Nations Conference on Trade and Development) Report. 2013. Global value chains: investment and trade for development.

https://unctad.org/en/PublicationsLibrary/wir2013_en.pdf Date of access: 15 June 2018.

UNCTAD (United Nations Conference on Trade and Development). 2014. Putting sustainable development first, delivering results. New York and Geneva.

http://unctad.org/en/PublicationsLibrary 15 June 2018.

UNCTAD (United Nations Conference on Trade and Development). 2015. Making the financial architecture work for international development New York and Geneva.

http://unctad.org/en/PublicationsLibrary Date of access: 25 Aug. 2018.

UNCTAD (United Nations Conference on Trade and Development) Report. 2016. Investors nationality: policy challenges.

https://unctad.org/en/PublicationsLibrary/wir2016_en.pdf Date of access: 25 Aug. 2018.

Van Greuning, H., Scott, D. \& Terblanche, S. 2011. International financial reporting standards: a practical guide. 6th ed. Washington, DC, USA: World Bank. 
Vidal-García, J., Vidal, M., Boubaker, S. \& Uddin, G.S. 2016. The short-term persistence of international mutual fund performance. Economic modelling, 52:926-938.

Vo, X.V., Nguyen, D.P., Ho, V.T. \& Nguyen, T.T. 2017. Where do the advanced countries invest? An investigation of capital flows from advanced countries to emerging economies. Journal of international financial markets, institutions and money, 51:142-154.

Vogt, W.P. \& Johnson, B. 2011. Dictionary of statistics and methodology: a nontechnical guide for the social sciences. Thousand Oaks, CA: Sage.

Wall, R., Grafakos, S., Gianoli, A. \& Stavropoulos, S. 2019. Which policy instruments attract foreign direct investments in renewable energy? Climate policy, 19(1):59-72.

Walliman, N. 2011. Your research project: designing and planning your work. 3rd ed. London: Sage.

Walliman, N. 2017. Research methods: the basics. 2nd ed. London: Routledge.

Walton, P. \& Aerts, W.T. 2007. Global financial accounting and reporting: principles and analysis. London: Thomson Learning.

Waqas, Y., Hashmi, S.H. \& Nazir, M.I. 2015. Macroeconomic factors and foreign portfolio investment volatility: a case of South Asian countries. Future business journal, 1(1):65-74.

Warsame, M. 2006. An empirical analysis of the impact of adopting International Financial Reporting Standards: evidence from emerging African capital markets. Baltimore, Maryland: Morgan State University. (Thesis - PhD).

Watts, R.L. \& Zimmerman, J.L. 1978. Towards a positive theory of the determination of accounting standards. Accounting review:112-134.

Weetman, P. 2006. Financial and management accounting: an introduction. London: Pearson.

Wilson, J. 2014. Essentials of business research: a guide to doing your research project. 2nd ed. London: Sage.

World Bank Report. 2014. Foreign direct investment net inflows. http/www./data.worldbank.org/indicator,BX.KLT.DINV.WD.GD.ZS

Date access: 10 April 2017.

World Bank. 2015. World Development Indicators.

https://databank.worldbank.org/data/source/world-development-indicators Date of access: 11 Aug. 2018.

World Bank. 2015. Worldwide Governance Indicators.

https://databank.worldbank.org/data/source/worldwide-governance-indicators Date of access: 11 Aug. 2018.

Yasas, T. \& Perera, H. 2019. The impact of IFRS adoption on quality of accounting information: evidence from Sri Lanka. Kelaniya journal of management, 8(1):21-36. 
Yip, R.W. \& Young, D. 2012. Does mandatory IFRS adoption improve information comparability? The accounting review, 87(5):1767-1789.

Yousaf, T. \& Akhtar, Y. 2018. The effect of economic institutions on foreign direct investment. Asia proceedings of social sciences, 2(2):16-20.

Yu, G. \& Wahid, A.S. 2014. Accounting standards and international portfolio holdings. The accounting review, 89(5):1895-1930.

Yu, H. \& Guernsey, A. 2009. What is the Rule of Law? Center for International Finance and Development. (Iowa City, Iowa: University of Iowa, 2005).

www. uiowa.edu/ifdebook/faq/rule_of_law Date of access: 2 Feb. 2018.

Zalaghi, H. \& Khazaei, M. 2016. The role of deductive and inductive reasoning in accounting research and standard setting. Asian journal of finance and accounting, 8(1):23-37.

Zeff, S.A. 1999. The evolution of the conceptual framework for business enterprises in the United States. Accounting historians' journal, 26(2):89-131.

Zeghal, D. \& Mhedhbi, K. 2006. An analysis of the factors affecting the adoption of international accounting standards by developing countries. The international journal of accounting, 41(4):373-386.

Zehri, F. \& Chouaibi, J. 2013. Adoption determinants of the International Accounting Standards IAS/IFRS by the developing countries. Journal of economics, finance and administrative science, 18(35):56-62.

Zhuang, J., Gunatilake, H.M., Niimi, Y., Khan, M.E., Jiang, Y., Hasan, R., Khor, N., Martin, A.L., Bracey, P. \& Huang, B. 2009. Financial sector development, economic growth, and poverty reduction: a literature review. ADB Economics Working paper Series, No. 173. Manila: Asian Development Bank (ADB). http://hdl.handle.net/11540/1829 Date of access: 8 July 2018.

Zikmund, W.G., Babin, B.J., Carr, J.C. \& Griffin, M. 2013. Business research methods. 9th ed. Stamford, UK: Cengage Learning 
APPENDIX A: TREND ANALYSIS OF FPI INFLOW BEFORE AND AFTER THE ADOPTION OF IFRS

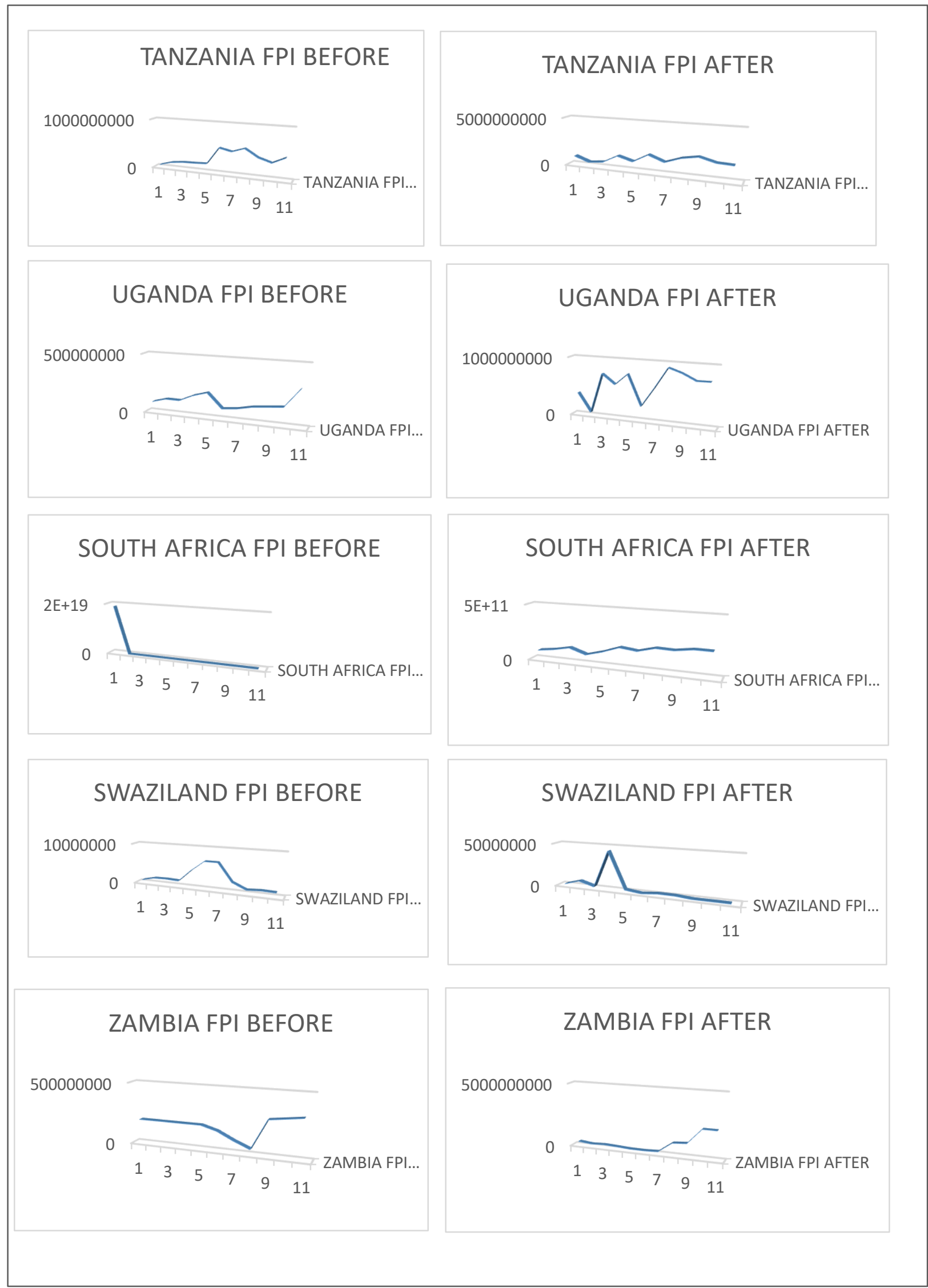




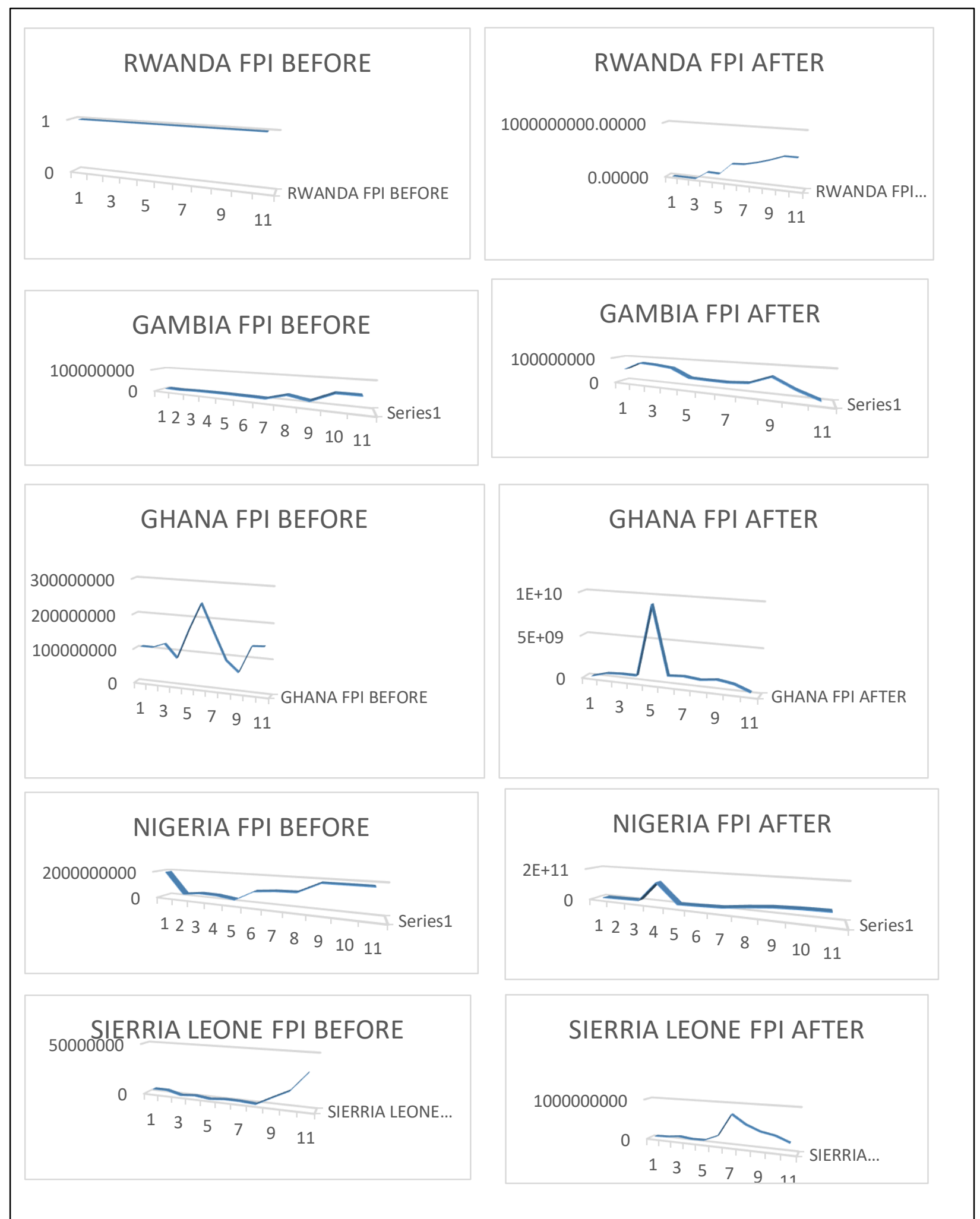

Trends of FPI's of selected African countries that have adopted IFRS

Source: Results obtained from data analysis using E-views 10 


\section{APPENDIX B: $\quad$ POOLED OLS REGRESSION RESULTS BEFORE IFRS ADOPTION}

Dependent Variable: LNFPI

Method: Panel Least Squares

Date: 06/15/19 Time:23:56

Sample: 19942004

Periods included: 11

Cross-sections included: 15

Total panel (balanced) observations: 165

\begin{tabular}{crrrr}
\hline \hline Variable & Coefficient & Std. Error & t-Statistic & Prob. \\
\hline C & 4.648926 & 1.981780 & 2.345834 & 0.0203 \\
INF & 1.606477 & 1.324801 & 1.212617 & 0.2271 \\
INT & 0.585109 & 1.726674 & 0.338865 & 0.7352 \\
LNEXR & -0.100001 & 0.065058 & -1.537109 & 0.1263 \\
EG & 0.841979 & 2.632824 & 0.319801 & 0.7496 \\
TOP & -1.251790 & 0.790702 & -1.583138 & 0.1154 \\
TAX & 7.875816 & 4.295128 & 1.833663 & 0.0686 \\
LNMCAP & 0.167591 & 0.060908 & 2.751553 & 0.0066 \\
REG & 121.7133 & 34.56804 & 3.520978 & 0.0006 \\
COR & 3.282068 & 18.03888 & 0.181944 & 0.8559 \\
\hline \hline & & & & \\
R-squared & 0.206182 & Mean dependent var & 7.472191 \\
Adjusted R-squared & 0.160089 & S.D. dependent var & 2.417595 \\
S.E. of regression & 2.215644 & Akaike info criterion & 4.487655 \\
Sum squared resid & 760.9074 & Schwarz criterion & 4.675895 \\
Log likelihood & -360.2316 & Hannan-Quinn criter. & 4.564068 \\
F-statistic & 4.473208 & Durbin-Watson stat & 0.157025 \\
Prob(F-statistic) & 0.000031 & & & \\
\hline \hline
\end{tabular}

APPENDIX C: CROSS SECTIONAL DEPENDENCE TEST BEFORE IFRS ADOPTION

Residual Cross-Section Dependence Test

Null hypothesis: No cross-section dependence (correlation) in residuals

Equation: Untitled

Periods included: 11

Cross-sections included: 15

Total panel observations: 165

Note: non-zero cross-section means detected in data

Cross-section means were removed during computation of correlations

\begin{tabular}{lccc}
\hline \multicolumn{1}{c}{ Test } & Statistic & d.f. & Prob. \\
\hline \hline Breusch-Pagan LM & 347.8906 & 105 & 0.0000 \\
Pesaran Scaled LM & 16.76104 & & 0.0000 \\
Pesaran CD & 0.817990 & & 0.4134 \\
\hline \hline
\end{tabular}




\section{APPENDIX D: $\quad$ FIXED-EFFECTS REGRESSION RESULTS BEFORE IFRS ADOPTION}

Dependent Variable: LNFPI

Method: Panel Least Squares

Date: 06/16/19 Time:00:00

Sample: 19942004

Periods included: 11

Cross-sections included: 15

Total panel (balanced) observations: 165

\begin{tabular}{crrrr}
\hline \hline Variable & Coefficient & Std. Error & t-Statistic & Prob. \\
\hline C & 4.236513 & 2.906785 & 1.457457 & 0.1472 \\
INF & -0.739319 & 0.696148 & -1.062013 & 0.2900 \\
INT & -0.003713 & 0.696335 & -0.005333 & 0.9958 \\
LNEXR & 0.076715 & 0.162793 & 0.471245 & 0.6382 \\
EG & -0.035639 & 0.998331 & -0.035699 & 0.9716 \\
TOP & -0.435891 & 0.541844 & -0.804460 & 0.4225 \\
TAX & 8.597511 & 3.183524 & 2.700627 & 0.0078 \\
LNMCAP & -0.096613 & 0.323736 & -0.298431 & 0.7658 \\
REG & -9.907640 & 22.17011 & -0.446892 & 0.6556 \\
COR & 45.45256 & 19.38033 & 2.345294 & 0.0204 \\
\hline \hline & & & & \\
\hline \hline & Effects Specification & & \\
\hline Cross-section fixed (dum & \multicolumn{5}{l}{} \\
\hline \hline
\end{tabular}




\section{APPENDIX E: $\quad$ THE HAUSMAN TEST BEFORE IFRS ADOPTION}

Correlated Random Effects - Hausman Test

Equation: Untitled

Test cross-section random effects

\begin{tabular}{lrrr}
\hline \hline Test Summary & Chi-Sq. Statistic & Chi-Sq. d.f. & Prob. \\
\hline \hline Cross-section random & 2.445475 & 9 & 0.9823 \\
\hline \hline
\end{tabular}

\section{APPENDIX F: $\quad$ RANDOM-EFFECTS REGRESSION RESULTS BEFORE IFRS}

\section{ADOPTION}

Dependent Variable: LNFPI

Method: Panel EGLS (Cross-section random effects)

Date: 06/16/19 Time: 00:02

Sample: 19942004

Periods included: 11

Cross-sections included: 15

Total panel (balanced) observations: 165

Swamy and Arora estimator of component variances

\begin{tabular}{|c|c|c|c|c|}
\hline Variable & Coefficient & Std. Error & t-Statistic & Prob. \\
\hline C & 3.260373 & 2.230094 & 1.461989 & 0.1458 \\
\hline INF & -0.833467 & 0.665394 & -1.252591 & 0.2122 \\
\hline INT & -0.047728 & 0.693461 & -0.068826 & 0.9452 \\
\hline LNEXR & 0.036969 & 0.132578 & 0.278851 & 0.7807 \\
\hline EG & 0.042040 & 0.975500 & 0.043096 & 0.9657 \\
\hline TOP & -0.351430 & 0.524792 & -0.669655 & 0.5041 \\
\hline TAX & 8.806705 & 3.139682 & 2.804967 & 0.0057 \\
\hline LNMCAP & 0.045170 & 0.206224 & 0.219035 & 0.8269 \\
\hline REG & -5.915256 & 21.79415 & -0.271415 & 0.7864 \\
\hline COR & 43.73872 & 18.81299 & 2.324921 & 0.0214 \\
\hline \multicolumn{5}{|c|}{ Effects Specification } \\
\hline & & & S.D. & Rho \\
\hline Cross-section random & & & 3.228057 & 0.9478 \\
\hline Idiosyncratic random & & & 0.757429 & 0.0522 \\
\hline \multicolumn{5}{|c|}{ Weighted Statistics } \\
\hline R-squared & 0.092133 & \multirow{5}{*}{\multicolumn{2}{|c|}{$\begin{array}{l}\text { Mean dependent var } \\
\text { S.D. dependent var } \\
\text { Sum squared resid } \\
\text { Durbin-Watson stat }\end{array}$}} & 0.527313 \\
\hline Adjusted R-squared & 0.039418 & & & 0.756297 \\
\hline S.E. of regression & 0.741242 & & & 85.16306 \\
\hline F-statistic & 1.747766 & & & 1.208459 \\
\hline Prob(F-statistic) & 0.082625 & & & \\
\hline \multicolumn{5}{|c|}{ Unweighted Statistics } \\
\hline R-squared & 0.062016 & \multirow{2}{*}{\multicolumn{2}{|c|}{$\begin{array}{l}\text { Mean dependent var } \\
\text { Durbin-Watson stat }\end{array}$}} & 7.472191 \\
\hline Sum squared resid & 899.0961 & & & 0.114466 \\
\hline
\end{tabular}




\section{APPENDIX G: $\quad$ SGMM REGRESSION RESULTS BEFORE IFRS ADOPTION}

Dependent Variable: LNFPI

Method: Panel Generalized Method of Moments

Transformation: First Differences

Date: 06/17/19 Time: 11:11

Sample (adjusted): 19972004

Periods included: 8

Cross-sections included: 15

Total panel (balanced) observations: 120

Difference specification instrument weighting matrix

White period standard errors \& covariance (d.f. corrected)

Instrument specification: @DYN(LNFPI,-2) INF INT LNEXR EG TOP TAX LNMCAP REG COR

\begin{tabular}{crcrr}
\hline \hline Variable & Coefficient & Std. Error & t-Statistic & Prob. \\
\hline LNFPI(-1) & 0.489764 & 0.108050 & 4.532770 & 0.0000 \\
LNFPI(-2) & 0.003399 & 0.025364 & 0.133993 & 0.8937 \\
INF & 0.162348 & 0.448216 & 0.362209 & 0.7179 \\
INT & 0.225012 & 0.612021 & 0.367653 & 0.7138 \\
LNEXR & 0.109477 & 0.089373 & 1.224949 & 0.2232 \\
EG & 1.105300 & 0.551719 & 2.003374 & 0.0476 \\
TOP & -0.263112 & 0.203765 & -1.291254 & 0.1993 \\
TAX & 1.488651 & 1.091570 & 1.363770 & 0.1754 \\
LNMCAP & -0.253978 & 0.203451 & -1.248349 & 0.2146 \\
REG & 16.25996 & 7.635165 & 2.129614 & 0.0355 \\
COR & -3.970236 & 9.877593 & -0.401944 & 0.6885 \\
\hline \hline & Effects Specification & & \\
\hline \hline Cross-section fixed (first differences) & & & \\
Root MSE & 0.428619 & Mean dependent var & & 0.027122 \\
S.D. dependent var & 0.359590 & S.E. of regression & & 0.449726 \\
Sum squared resid & 22.04568 & J-statistic & & 0.256000 \\
Instrument rank & Prob(J-statistic) \\
\hline \hline
\end{tabular}




\section{APPENDIX H: SERIAL CORRELATION TEST BEFORE IFRS ADOPTION}

Arellano-Bond Serial Correlation Test

Equation: Untitled

Date: 06/17/19 Time: 11:12

Sample: 19942004

Included observations: 120

\begin{tabular}{ccccc}
\hline \hline Test order & m-Statistic & rho & SE(rho) & Prob. \\
\hline \hline AR(1) & -4.388948 & -9.564072 & 2.179126 & 0.0000 \\
AR(2) & 0.089377 & 0.193291 & 2.162655 & 0.9288 \\
\hline \hline
\end{tabular}

\section{APPENDIX I: $\quad$ POLS REGRESSION RESULTS AFTER IFRS ADOPTION}

Dependent Variable: LNFPI

Method: Panel Least Squares

Date: 03/12/20 Time: 10:06

Sample: 19942015

Periods included: 22

Cross-sections included: 15

Total panel (balanced) observations: 330

\begin{tabular}{crlrr}
\hline \hline Variable & Coefficient & Std. Error & t-Statistic & Prob. \\
\hline C & 5.051504 & 1.197649 & 4.217851 & 0.0000 \\
IFRSFA & 1.370923 & 0.236229 & 5.803363 & 0.0000 \\
INF & 1.357581 & 0.984206 & 1.379367 & 0.1687 \\
INT & 0.450200 & 1.203661 & 0.374025 & 0.7086 \\
LNEXR & -0.068453 & 0.037672 & -1.817067 & 0.0701 \\
EG & 0.018138 & 2.013899 & 0.009006 & 0.9928 \\
TOP & -1.181648 & 0.485021 & -2.436283 & 0.0154 \\
TAX & 6.932207 & 2.634384 & 2.631434 & 0.0089 \\
LNMCAP & 0.153122 & 0.036342 & 4.213316 & 0.0000 \\
REG & 108.5361 & 23.91520 & 4.538372 & 0.0000 \\
COR & 3.336300 & 12.25175 & 0.272312 & 0.7856 \\
\hline \hline Root MSE & 1.905025 & R-squared & & 0.222083 \\
Mean dependent var & 7.965009 & Adjusted R-squared & 0.197697 \\
S.D. dependent var & 2.163182 & S.E. of regression & 1.937592 \\
Akaike info criterion & 4.193534 & Sum squared resid & 1197.609 \\
Schwarz criterion & 4.320170 & Log likelihood & -680.9331 \\
Hannan-Quinn criter. & 4.244047 & F-statistic & 9.106960 \\
Durbin-Watson stat & 0.217196 & Prob(F-statistic) & 0.000000 \\
\hline \hline
\end{tabular}




\section{APPENDIX J: $\quad$ CROSS SECTIONAL DEPENDENCE TEST AFTER IFRS ADOPTION}

Residual Cross-Section Dependence Test

Null hypothesis: No cross-section dependence (correlation) in residuals

Equation: Untitled

Periods included: 22

Cross-sections included: 15

Total panel observations: 330

Note: non-zero cross-section means detected in data

Cross-section means were removed during computation of correlations

\begin{tabular}{lccc}
\hline \multicolumn{1}{c}{ Test } & Statistic & d.f. & Prob. \\
\hline \hline Breusch-Pagan LM & 275.9770 & 105 & 0.0000 \\
Pesaran scaled LM & 11.79853 & & 0.0000 \\
Pesaran CD & -0.122988 & & 0.9021 \\
\hline \hline
\end{tabular}

\section{APPENDIX K: $\quad$ FIXED-EFFECTS REGRESSION RESULTS AFTER IFRS ADOPTION}

Dependent Variable: LNFPI

Method: Panel Least Squares

Date: 03/12/20 Time: 10:11

Sample: 19942015

Periods included: 22

Cross-sections included: 15

Total panel (balanced) observations: 330

\begin{tabular}{crrrr}
\hline \hline Variable & Coefficient & Std. Error & t-Statistic & Prob. \\
\hline C & 3.984752 & 1.377946 & 2.891805 & 0.0041 \\
IFRSFA & 0.914104 & 0.175101 & 5.220431 & 0.0000 \\
INF & -0.010029 & 0.720738 & -0.013915 & 0.9889 \\
INT & 0.682319 & 0.768609 & 0.887732 & 0.3754 \\
LNEXR & -0.042935 & 0.148628 & -0.288877 & 0.7729 \\
EG & 0.496598 & 1.153148 & 0.430645 & 0.6670 \\
TOP & -0.208989 & 0.449025 & -0.465428 & 0.6420 \\
TAX & 0.956088 & 2.373487 & 0.402820 & 0.6874 \\
LNMCAP & 0.023712 & 0.141709 & 0.167326 & 0.8672 \\
REG & 93.72041 & 17.17065 & 5.458175 & 0.0000 \\
COR & 98.24259 & 13.29204 & 7.391084 & 0.0000 \\
\hline \hline & Effects Specification & & \\
\hline \hline Cross-section fixed (dummy & variables) & & & \\
\hline \hline Root MSE & 1.024357 & R-squared & & 0.775076 \\
Mean dependent var & 7.965009 & Adjusted R-squared & 0.757378 \\
S.D. dependent var & 2.163182 & S.E. of regression & 1.065513 \\
Akaike info criterion & 3.037523 & Sum squared resid & 346.2717 \\
Schwarz criterion & 3.325333 & Log likelihood & -476.1914 \\
Hannan-Quinn criter. & 3.152327 & F-statistic & 43.79235 \\
Durbin-Watson stat & 0.808750 & Prob(F-statistic) & 0.000000 \\
\hline \hline
\end{tabular}




\section{APPENDIX L: $\quad$ RANDOM-EFFECTS REGRESSION RESULTS AFTERIFRS ADOPTION}

Dependent Variable: LNFPI

Method: Panel EGLS (Cross-section random effects)

Date: $03 / 12 / 20$ Time: 10:14

Sample: 19942015

Periods included: 22

Cross-sections included: 15

Total panel (balanced) observations: 330

Swamy and Arora estimator of component variances

\begin{tabular}{|c|c|c|c|c|}
\hline Variable & Coefficient & Std. Error & t-Statistic & Prob. \\
\hline $\mathrm{C}$ & 3.809189 & 1.455990 & 2.616219 & 0.0093 \\
\hline IFRSFA & 0.894955 & 0.165670 & 5.402023 & 0.0000 \\
\hline INF & 0.129934 & 0.693703 & 0.187304 & 0.8515 \\
\hline INT & 0.683157 & 0.767135 & 0.890530 & 0.3739 \\
\hline LNEXR & 0.013379 & 0.118793 & 0.112620 & 0.9104 \\
\hline$E G$ & 0.408824 & 1.146446 & 0.356601 & 0.7216 \\
\hline TOP & -0.289010 & 0.441186 & -0.655075 & 0.5129 \\
\hline TAX & 1.317922 & 2.351680 & 0.560417 & 0.5756 \\
\hline LNMCAP & 0.035774 & 0.121265 & 0.295010 & 0.7682 \\
\hline REG & 93.81979 & 17.12138 & 5.479685 & 0.0000 \\
\hline COR & 94.14060 & 13.00351 & 7.239630 & 0.0000 \\
\hline \multicolumn{5}{|c|}{ Effects Specification } \\
\hline & & & S.D. & Rho \\
\hline Cross-section random & & & 2.821558 & 0.8752 \\
\hline Idiosyncratic random & & & 1.065513 & 0.1248 \\
\hline \multicolumn{5}{|c|}{ Weighted Statistics } \\
\hline Root MSE & 1.037398 & R-squared & & 0.382295 \\
\hline Mean dependent var & 0.639207 & Adjusted R-squ & ared & 0.362931 \\
\hline S.D. dependent var & 1.321947 & S.E. of regressi & & 1.055133 \\
\hline Sum squared resid & 355.1443 & F-statistic & & 19.74279 \\
\hline Durbin-Watson stat & 0.778548 & Prob(F-statistic & & 0.000000 \\
\hline \multicolumn{5}{|c|}{ Unweighted Statistics } \\
\hline R-squared & -0.088637 & Mean depende & t var & 7.965009 \\
\hline Sum squared resid & 1675.966 & Durbin-Watson & stat & 0.164978 \\
\hline
\end{tabular}

\section{APPENDIX M: THE HAUSMAN TEST RESULTS AFTER IFRS ADOPTION}

Correlated Random Effects - Hausman Test

Equation: Untitled

Test cross-section random effects

\begin{tabular}{lrrr}
\hline \hline Test Summary & $\begin{array}{l}\text { Chi-Sq. } \\
\text { Statistic }\end{array}$ & Chi-Sq. d.f. & Prob. \\
\hline \hline Cross-section random & 3.815051 & 10 & 0.9553 \\
\hline \hline
\end{tabular}




\section{APPENDIX N: $\quad$ SGMM REGRESSION RESULTS AFTER IFRS ADOPTION}

Dependent Variable: LNFPI

Method: Panel Generalized Method of Moments

Transformation: First Differences

Date: 03/12/20 Time: 16:39

Sample (adjusted): 19962015

Periods included: 20

Cross-sections included: 15

Total panel (balanced) observations: 300

Difference specification instrument weighting matrix

White period standard errors \& covariance (d.f. corrected)

Instrument specification: @DYN(LNFPI,-2) IFRSFA INF INT LNEXR EG TOP TAX LNMCAP REG COR

\begin{tabular}{crrrr}
\hline \hline Variable & Coefficient & Std. Error & t-Statistic & Prob. \\
\hline \hline LNFPI(-1) & 0.403569 & 0.112308 & 3.593397 & 0.0000 \\
IFRSFA & 0.246350 & 0.116098 & 2.121905 & 0.0347 \\
INF & -0.078993 & 0.519561 & -0.152038 & 0.8793 \\
INT & 0.122269 & 0.430600 & 0.283949 & 0.7767 \\
LNEXR & 0.225412 & 0.141990 & 1.587519 & 0.1135 \\
EG & 0.185570 & 0.490025 & 0.378696 & 0.7052 \\
TOP & 0.334987 & 0.361895 & 0.925647 & 0.3554 \\
TAX & -3.053620 & 2.101427 & -1.453117 & 0.1473 \\
LNMCAP & 0.075470 & 0.140079 & 0.538768 & 0.5905 \\
REG & 31.70798 & 16.62166 & 1.907631 & 0.0574 \\
COR & -0.327894 & 8.323069 & -0.039396 & 0.9686 \\
\hline \hline
\end{tabular}

Cross-section fixed (first differences)

\begin{tabular}{lrll}
\hline \hline Root MSE & 0.782590 & Mean dependent var & 0.070896 \\
S.D. dependent var & 0.667301 & S.E. of regression & 0.797344 \\
Sum squared resid & 183.7340 & J-statistic & 201.7682 \\
Instrument rank & 205 & Prob(J-statistic) & 0.336159 \\
\hline \hline
\end{tabular}




\section{APPENDIX O: $\quad$ SERIAL CORRELATION TEST AFTER IFRS ADOPTION}

Arellano-Bond Serial Correlation Test

Equation: Untitled

Date: 03/12/20 Time: 16:36

Sample: 19942015

Included observations: 300

\begin{tabular}{ccccc}
\hline \hline Test order & m-Statistic & rho & SE(rho) & Prob. \\
\hline \hline AR(1) & -6.065459 & -69.890840 & 11.522761 & 0.0000 \\
AR(2) & -0.981536 & -12.116145 & 12.344063 & 0.3263 \\
\hline \hline
\end{tabular}

\section{APPENDIX P: $\quad$ SGMM REGRESSION RESULTS, IFRS ADOPTING AND NON- ADOPTING COUNTRIES}

Dependent Variable: LNFPI

Method: Panel Generalized Method of Moments

Transformation: First Differences

Date: 03/12/20 Time: 20:47

Sample (adjusted): 20072015

Periods included: 9

Cross-sections included: 35

Total panel (balanced) observations: 315

White period instrument weighting matrix

White period standard errors \& covariance (d.f. corrected)

Instrument specification: @DYN(LNFPI,-2) IFRSFA INF INT LNEXR EG TOP

TAX LNMCAP REG COR

\begin{tabular}{crrrr}
\hline \hline Variable & Coefficient & Std. Error & t-Statistic & Prob. \\
\hline \hline LNFPI(-1) & 0.350575 & 0.028425 & 12.33353 & 0.0000 \\
IFRSFA & 0.728535 & 0.098032 & 7.431643 & 0.0000 \\
INF & -0.318835 & 0.300048 & -1.062612 & 0.2888 \\
INT & 0.359075 & 0.422587 & 0.849707 & 0.3962 \\
LNEXR & -0.090657 & 0.220870 & -0.410452 & 0.6818 \\
EG & -1.818095 & 1.533887 & -1.185286 & 0.2368 \\
TOP & 0.425951 & 0.044490 & 9.574112 & 0.0000 \\
TAX & 3.362260 & 1.030473 & 3.262830 & 0.0012 \\
LNMCAP & 0.040987 & 0.043959 & 0.932394 & 0.3519 \\
REG & -37.68399 & 10.18820 & -3.698788 & 0.0003 \\
COR & 23.32891 & 6.093084 & 3.828752 & 0.0002 \\
\hline Eross-section fixed (first differences) & & \\
\hline \hline Root MSE & 1.395441 & Mean dependent var & 0.258992 \\
S.D. dependent var & 1.320654 & S.E. of regression & 1.420463 \\
Sum squared resid & 613.3852 & J-statistic & 26.35485 \\
Instrument rank & 35 & Prob(J-statistic) & 0.335409 \\
\hline \hline
\end{tabular}




\section{APPENDIX Q: $\quad$ SERIAL CORRELATION TEST ADOPTING AND NON- ADOPTING COUNTRIES}

Arellano-Bond Serial Correlation Test

Equation: Untitled

Date: 03/12/20 Time: $20: 54$

Sample: 20052015

Included observations: 315

\begin{tabular}{crrrr}
\hline \hline Test order & m-Statistic & rho & SE(rho) & Prob. \\
\hline \hline AR(1) & -2.178997 & -200.623021 & 92.071286 & 0.0293 \\
AR(2) & 0.027827 & 1.016794 & 36.540076 & 0.9778 \\
\hline \hline
\end{tabular}

APPENDIX R: $\quad$ DIFFERENCE-IN-DIFFERENCE (DID) TEST, ADOPTED AND NON-ADOPTED COUNTRIES RESULTS,

\begin{tabular}{|l|c|c|c|c|c|}
\hline \multicolumn{7}{|c|}{ WSRT Descriptive Statistics } \\
\hline & $\mathrm{N}$ & Mean & $\begin{array}{c}\text { Std. } \\
\text { Deviation }\end{array}$ & Minimum & Maximum \\
\hline $\begin{array}{l}\text { Pre-FPI non- } \\
\text { adopted }\end{array}$ & 220 & 2.1668 & 3.1835 & 1.1549 & 19.2787 \\
\hline Pre-FPI adopted & 165 & 7.4721 & 2.4175 & .0000 & 19.2787 \\
\hline $\begin{array}{l}\text { Post-FPI non- } \\
\text { adopted }\end{array}$ & 220 & 6.5894 & 3.5337 & .0000 & 10.3502 \\
\hline Post-FPI adopted & 164 & 8.4409 & 1.7393 & .0000 & 11.3471 \\
\hline
\end{tabular}

\begin{tabular}{|l|c|c|}
\hline \multicolumn{2}{|c|}{ WSRT Statistics } \\
\hline & $\begin{array}{c}\text { Post-FPI non-adopted - } \\
\text { Pre-FPI non-adopted }\end{array}$ & $\begin{array}{c}\text { Post-FPI adopted - Pre- } \\
\text { FPI adopted }\end{array}$ \\
\hline$Z$ & $-10.054^{\mathrm{b}}$ & $-7.947^{\mathrm{b}}$ \\
\hline Asymp. Sig. (2-tailed) & .000 & .000 \\
\hline Exact Sig. (2-tailed) & .000 & .000 \\
\hline Exact Sig. (1-tailed) & .000 & .000 \\
\hline Point Probability & .000 & .000 \\
\hline a. Wilcoxon Signed Ranks Test & & \\
\hline
\end{tabular}




\section{APPENDIX S: $\quad$ LOGIT REGRESSION RESULTS FOR IFRS DETERMINANTS (LOGARITHMIC ODDS OF IFRS ADOPTION)}

\begin{tabular}{|c|c|c|c|}
\hline \multirow[t]{3}{*}{ Logistic regression } & Number of obs & $=$ & 385 \\
\hline & Wald chi2(10) & $=$ & 98.09 \\
\hline & Prob > chi2 & $=$ & 0.0000 \\
\hline Log pseudo likelihood $=-110.61408$ & Pseudo R2 & $=$ & 0.5626 \\
\hline
\end{tabular}

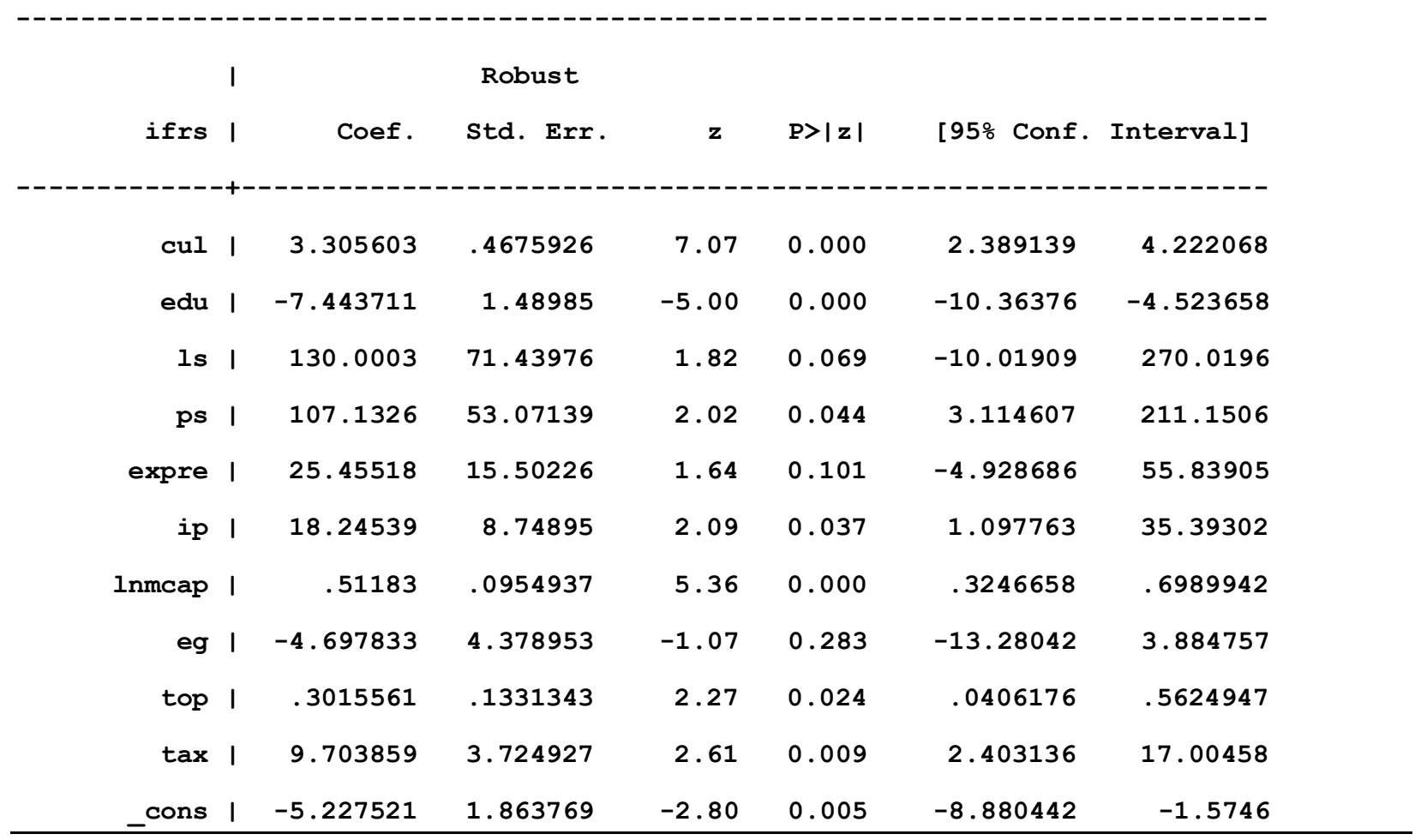

Note: Cons = constant $; C U L=$ culture, EDU=education, LS=legal system, EXPRE=external pressure, IP=investor protection, $M C A P=$ market capitalisation, $E G=$ economic growth, TOP=trade openness, TAX=tax rate, ***, ** and, $*=$ level of significance at 1\%, 5\%, and 10\% respectively. (see Chapter 4 for the description and measurement of the variables). 


\section{APPENDIX T: $\quad$ LOGIT REGRESSION RESULTS (ODDS RATIOS)}

$\begin{array}{lllr}\text { Logistic regression } & \text { Number of obs } & 385 \\ & \text { Wald chi2 }(10) & = & 98.09 \\ & \text { Prob > chi2 } & 0.0000 \\ \text { Log pseudo likelihood }=-110.61408 & \text { Pseudo R2 } & = & 0.5626\end{array}$

\begin{tabular}{|c|c|c|c|c|c|c|c|}
\hline & 1 & & Robust & & & & \\
\hline ifrs & 1 & Odds Ratio & Std. Err. & $\mathbf{z}$ & $P>|z|$ & {$[95 \%$ Conf. } & Interval] \\
\hline cul & 1 & 27.26499 & 12.74891 & 7.07 & 0.000 & 10.9041 & 68.17433 \\
\hline edu & 1 & .0005851 & .0008717 & -5.00 & 0.000 & .0000316 & .0108493 \\
\hline is & 1 & $2.87 e+56$ & $2.05 e+58$ & 1.82 & 0.069 & .0000445 & $1.9 e+117$ \\
\hline ps & 1 & $3.37 e+46$ & $1.79 e+48$ & 2.02 & 0.044 & 22.52457 & $5.03 e+91$ \\
\hline expre & 1 & $1.14 \mathrm{e}+11$ & $1.76 e+12$ & 1.64 & 0.101 & .007236 & $1.78 e+24$ \\
\hline ip & 1 & $8.39 e+07$ & $7.34 e+08$ & 2.09 & 0.037 & 2.997454 & $2.35 e+15$ \\
\hline Inmcap & 1 & 1.668341 & .1593161 & 5.36 & 0.000 & 1.383568 & 2.011728 \\
\hline eg & 1 & .009115 & .0399142 & -1.07 & 0.283 & $1.71 e-06$ & 48.65512 \\
\hline top & 1 & 1. 351961 & .1799924 & 2.27 & 0.024 & 1.041454 & 1.755045 \\
\hline $\operatorname{tax}$ & 1 & 16380.7 & 61016.9 & 2.61 & 0.009 & 11.0578 & $2.43 e+07$ \\
\hline cons & 1 & .0053668 & .0100025 & -2.80 & 0.005 & .0001391 & .2070904 \\
\hline
\end{tabular}

Note: _cons estimate baseline odds.

Note: $C U L=$ culture, EDU=education, LS=legal system, EXPRE=external pressure, IP=investor protection, $M C A P=$ market capitalisation, $E G=$ economic growth, $T O P=$ trade openness, $T A X=$ tax rate, ***, ** and, * =level of significance at 1\%, 5\%, and 10\% respectively. (see Chapter 4 for the description and measurement of the variables). 


\section{APPENDIX U: $\quad$ LOGIT REGRESSION RESULTS (AVERAGE MARGINAL EFFECTS)}

margins, dydx(_all) noatlegend

Average marginal effects

Number of obs =

385

Model VCE: Robust

Expression: Pr(ifrs), predict ()

$d y / d x$ w.r.t.: cul edu ls ps expre ip lnmcap eg top tax

\begin{tabular}{|c|c|c|c|c|c|c|c|}
\hline & \multirow{2}{*}{$\begin{array}{l}1 \\
1\end{array}$} & \multicolumn{3}{|c|}{ Delta-method } & \multirow[b]{2}{*}{$\mathrm{P}>|\mathbf{z}|$} & \multirow[b]{2}{*}{$95 \%$ Conf. } & \multirow[b]{2}{*}{ Interval] } \\
\hline & & $d y / d x$ & Std. Err. & $\mathbf{z}$ & & & \\
\hline cul & 1 & .2905208 & .0257274 & 11.29 & 0.000 & .240096 & .3409456 \\
\hline edu & 1 & -.6542081 & .0953302 & -6.86 & 0.000 & -.8410518 & -.4673644 \\
\hline ls & 1 & 11.42538 & 6.266467 & 1.82 & 0.068 & -.8566694 & 23.70743 \\
\hline ps & 1 & 9.415603 & 4.263246 & 2.21 & 0.027 & 1.059794 & 17.77141 \\
\hline expre & 1 & 2.237189 & 1.261751 & 1.77 & 0.076 & -.2357974 & 4.710175 \\
\hline ip & 1 & 1.603539 & .7182947 & 2.23 & 0.026 & .1957075 & 3.011371 \\
\hline Inmcap & 1 & .0449834 & .0056038 & 8.03 & 0.000 & .0340001 & .0559666 \\
\hline eg & 1 & -.4128801 & .3807293 & -1.08 & 0.278 & -1.159096 & .3333356 \\
\hline top & 1 & .026503 & .011853 & 2.24 & 0.025 & .0032715 & .0497344 \\
\hline $\operatorname{tax}$ & 1 & .8528466 & .3015056 & 2.83 & 0.005 & .2619065 & 1.443787 \\
\hline
\end{tabular}

Note: CUL=culture, EDU=education, LS=legal system, EXPRE=external pressure, IP=investor protection, $M C A P=$ market capitalisation, $E G=$ economic growth, $T O P=$ trade openness, $T A X=$ tax rate, ***, ** and, *=level of significance at 1\%, 5\%, and 10\% respectively. (see Chapter 4 for the description and measurement of the variables). 


\section{APPENDIX V: $\quad$ REGISTRATION OF TITLE}

Dear Mr. Omotoso

\section{REGISTRATION OF TITLE}

At the recent meeting of a relevant committee meeting of the Faculty of Economic and Management Sciences your title was approved as follows:

The effect of the adoption of International Financial Reporting Standards on foreign portfolio investment in Africa

The above-mentioned title may under no circumstances be changed without consulting your supervisor and obtaining the approval from the relevant committee in the mentioned faculty, in regard of which this office must be furnished with the latest approved title.

In the instance that you wish to submit for examination, please inform your supervisor/promoter accordingly. Also ensure absolute adherence to the prescripts of A Rule 4.10 for the submission of a Master's study and of A rule 5.10 for the submission of Doctoral thesis.

Upon approval of your supervisor/promoter, please ensure that the Notice of Submission form is submitted THREE months in advance to this office.

Note that the Notice of Submission-form is available at the Higher Degree Administration Officer or the Faculty Administrator of the faculty.

For ease of reference, herewith a reference to the following useful resources:

- General Academic Rules (A-Rules):

- Manual for Master's and Doctoral Studies :

We wish you a pleasant and successful period of study.

Yours sincerely

Ms Margaret Kruger

for REGISTRAR

Original details: (10812187) M:IHDA Toolbox \Phase $2 \backslash 1$ Title Registration $\backslash$ Title registration letter.docm

13 February 2019

File reference: 7.1.11.1 


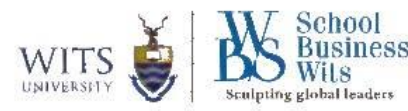

African Review of Economics and Finance Conference

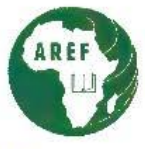

This certificate is awarded to:

\section{Matthew Olubayo Omotoso}

North-West University

For attending and presenting a research paper at the African Review of Economics and

Finance Conference held at the Wits Business School from 29th to 30 h Augusi 2019.
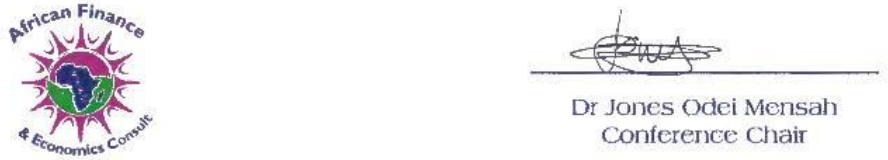

NiLEE 


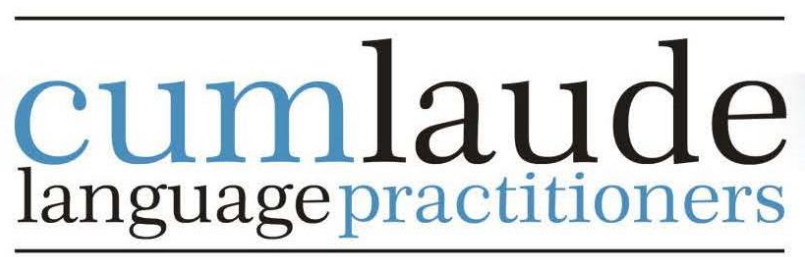

Director: CME Terblanche - BA (Pol Sc), BA Hons (Eng), MA (Eng), TEFL

22 Strydom Street

Baillie Park, 2531

Tel 0828213083

cumlaudelanguage@gmail.com

\section{DECLARATION OF LANGUAGE EDITING}

I, Christina Maria Etrecia Terblanche, hereby declare that I edited the research study titled:

The effect of the adoption of International Financial Reporting

Standards on foreign portfolio investment in Africa

for Matthew Olubayo Omotoso for the purpose of submission as a postgraduate research study. Changes were indicated in track changes and implementation was left to the author.

Regards,

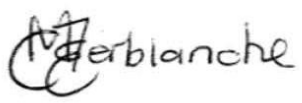

CME Terblanche

Cum Laude Language Practitioners (CC)

South African Translators Institute accr nr: 1001066

Full member of the Professional Editors Guild 


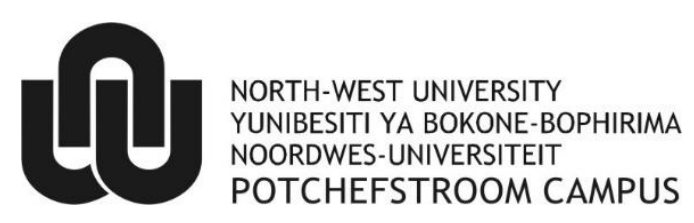

\author{
Private Bag X6001, Potchefstroom \\ South Africa 2520 \\ Tel: $\quad$ (018) 299-1111/2222 \\ Web: http://www.nwu.ac.za \\ Statistical Consultation Services \\ Tel: (018) 2992180 \\ Fax (018) 2992557 \\ E-Mail: faans.steyn@nwu.ac.za
}

12 November 2019

Re: Mr Matthew Olubayo Omotoso

I hereby confirm that I have assisted Mr Matthew Olubayo Omotoso, student number 29332583, with the statistical aspects of his $\mathrm{PhD}$ thesis in Accounting Sciences at the North-West University, with the title: THE EFFECT OF THE ADOPTION OF INTERNATIONAL FINANCIAL REPORTING STANDARDS ON FOREIGN PORTFOLIO INVESTMENT IN AFRICA.

Kind regards,

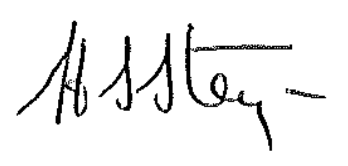

Prof Faans Steyn (PhD, Pr. Sci. Nat)

Statistical consultant 